ANL-79-35

th. 1100

ANL-79-35

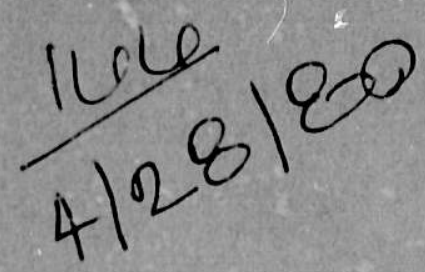

\title{
MASTER
}

\section{REACTOR PHYSICS STUDIES IN THE GCFR PHASE III CRITICAL ASSEMBLY}

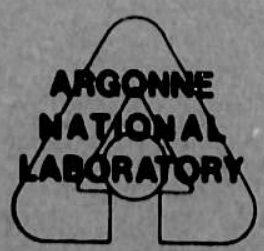

ARGONNE NATIONAL LABORATORY, ARGONNE, ILLINOIS

Proparod for the U. S. DEPARTMENT OF ENERGY

under Contract W-31-109-Eng-38 

Distribution Category:

Gas Cooled Reactor Technology (UC-77)

ANL-79-35

ARGONNE NATIONAL LABORATORY

9700 South Cass Avenue

Argonne, Illinois 60439

REACTOR PHYSICS STUDIES IN THE GCFR PHASE III CRITICAL ASSEMBLY

Edited by

J. A. Morman

Applied Physics Division

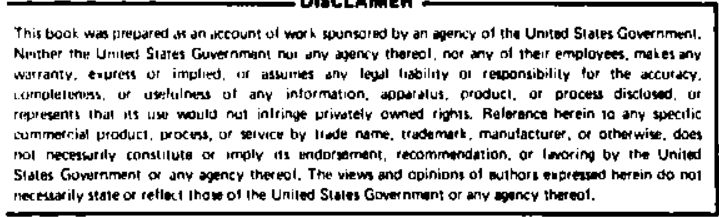

March 1980 

The GCFR Program described herein was planned jointly by ANL and the General Atomic Company. R. Moore and A. Hess of General Atomic were instrumental in planning the GCFR/ZPR program and in the exchange of information and suggestions during the course of the program. The results reported here are compiled from a series of internal memoranda based on the efforts of the following persons during the program: R. G. Bucher, M. M. Bretscher, R. D. McKnight, J. A. Morman, I. K. Olson, R. B. Pond, W. R. Robinson, D. M. Smith and D. C. Wade.

Design and implementation of the special equipment needed during the program, especially steam simulation materials and the special voided/steamfilled calandria, was provided by E. F. Groh and his staff of machinists.

Operational support for the ZPR-9 facility was provided by G. K. Rusch, F. H. Martens, and the supervisors and operators of ZPR-9. 

†. THE GCFR PHASE III ASSEMRLY . . . . . . . . . . . . . 1

A. Introduction. . . . . . . . . . . . . . . 1

B. Description of the Reference Assembly . . . . . . . . I

C. Description of the Pin Zone Assembly. . . . . . . 3

D. Approach to Critical. . . . . . . . . . 4

E. Corrections to the Reference Assembly Critical Mass . . . 6

1. Excess Reactivity and Temperature Correction. . . . . 6

2. Source Subcriticality Correction. . . . . . 6

3. Edge Smoothing Corrertions. . . . . . . . . 7

F. Operational Measurements. . . . . . . . . . 7

1. Measurement of the Reactivity Excess of the

Reference Assembly. . . . . . . . . . . 8

2. Measurement of Temperature Coefficient. . . . . . 9

3. Measurement of ${ }^{10}$ B and DP Rod Worths. . . . . . 9

4. Measurement of Edge Drawer Worth. . . . . . . 10

5. Determination of $241 \mathrm{Pu}$ Decay Coefficient. . . . . 11

II. Calculational Methods . . . . . . . . . . . . . 11

A. Introduction. . . . . . . . . . . . . . . 11

B. Generation of Atom Densities. . . . . . . . . . 11

C. Broad-group Crcss Sections. . . . . . . . . . . 12

D. Benoist Antsotropic Diffusion Coefficlents. . . . . . 14

E. The RZ Mode1 and the Eigenvalue of the Reference Configuration ................... 15

F. KInet1cs Parameters and the ${ }^{241} \mathrm{Pu}$ Decay Coefficient.... 17

G. The RZ Mode1 and Eigenvalue of the P1n-loaded Reference Configuration ............... 
H. The XY Model of the Plate-loaded Reference

Configuration. ................. 18

I. Comparison of Plate and Pin Geometry Eigenvalues and

Streaming Corrections. .............. 19

J. Summary. . . . . . . . . . . . . . . . . 21

III. SMALL SAMPLE WORTHS. . . . . . . . . . . . . . 22

A. Introduction . . . . . . . . . . . . . . 22

B. Assembly Configuration . . . . . . . . . . . . 22

C. Experimental Methods . . . . . . . . . . . . 23

D. Calculational Methods. . . . . . . . . . . 23

E. Central Reactivity Worth Results . . . . . . . . . 24

F. Radial Reactivity Worth Traverse Results . . . . . . . 25

G. Comparison of Results to GCFR Phase I. . . . . . . . . 27

IV. REACTION RATE MEASUREMENTS. . . . . . . . . . . . . 27

A. Central Fission Rate Measurements. . . . . . . . . 28

B. Foil Data Analysis . . . . . . . . . . . 28

C. Ce11-Averaged Reaction Rates . . . . . . . . . . 30

1. Plate-loaded Assembly. . . . . . . . . . . 30

2. Pin Zone Assembly............... 33

D. Reaction Rate Distributions. . . . . . . . . . 34

1. Plate-loaded Assembly. . . . . . . . . . . 34

2. Pin Zone Assembly. ............. 35

E. Calculational Techniques . . . . . . . . . . 35

F. Results and Discussion . . . . . . . . . . . 36 
Page

V. MEASUREMENT OF ABSORPTION-TO-FISSION RATIOS

AND THE CENTRAL CORE CONVERSION RATIO. . . . . . . . . 37

A. Introduction . . . . . . . . . . . . . . 37

B. The Reactivity-Reaction Rate Method. . . . . . . . . 37

C. Measured Quantities. . . . . . . . . . . . . 39

D. Calculated Quantities. . . . . . . . . . 40

E. Perturbation Denominator Measurements. . . . . . . 40

F. Absorption-to-Fission Ratios ............. 41

G. The Central Core Conversion Ratio. . . . . . . . . 43

H. Summary. . . . . . . . . . . . . . 44

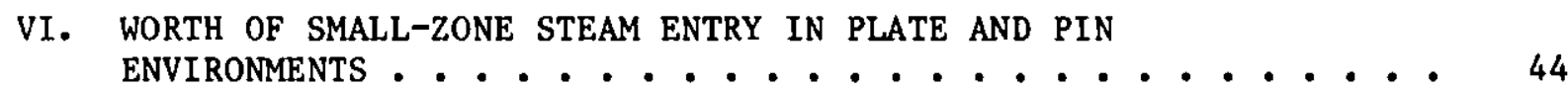

A. Introduction . . . . . . . . . . . . . 44

B. Measurement Techniques . . . . . . . . . . . 44

VII. REFERENCES. . . . . . . . . . . . . . . . 46 
I- 1. Matrix Loading for the GCFR Phase III Reference

Configuration. . . . . . . . . . . . . . . . .

I- 2. RZ Geometry for the GCFR Phase III Reference Configuration. . . . . . . . . . . . . . . . .

I- 3. Drawer Loading Patterns for Zone I Core (Upper) and Axial Blanket (Lower), GCFR Phase III.............

I- 4. Drawer Loading Patterrs for Zone II Core (Upper) and Axial Blanket (Lower), GCFR Phase III. . . . . . . . 48

I- 5. Drawer Loading Pacterns for Zone III Core (Upper) and Axlal Blanket (Lower), GCFR Phase III.............

I- 6. Drawer Loading Pattern for the Radial Blanket Region, GCFR Phase III . . . . . . . . . . . . . . . . .

I- 7. Drawer Loading Pattern for the Reflector Region, GCFR Phase III . . . . . . . . . . . . . . . . .

I- 8. Drawer Loading Patterns Illustrating the Disruption of Vertical Streaming Paths at Zone and Region Interfaces. . . 50

I- 9. GCFR Phase III Stationary Half Drawer Master for Zone I Core Plus Axial Blanket. . . . . . . . . . . 50

I-10. GCFR Phase III Stationary Half Drawer Master for Zone II, Type 1 Core Plus Axial Blanket . . . . . . . . . . 51

I-11. GCFR Phase III Stat lonary Half Drawer Master for Zone II, Type 2 Core Plus Axial Blanket . . . . . . . . . . . 51

I-12. GCFR Phase III Stationary Half Drawer Master for Zone II, Type 3 Core Plus Axial Blanket . . . . . . . . . . .

I-13. GCFR Phase III Stationary Half Drawer Master for Zone III, Type 1 Core Plus Axial Blanket . . . . . . . . . . .

I-14. GCFR Phase III Stationary Half Drawer Master for the Radlal Blanket........................

I-15. GCFR Phase III Stationary Half Drawer Master for the Radial Reflector .......................

I-16. Matrix Loading for the GCFR Phase III PIn Zone Keference Configuration. . . . . . . . . . . . . . 54

I-17. Drawer Loading Pattern in the GCFR Phase III Approach- 
I-18. Approach-to-Critical Plots for U-235 Fission Counter in S-23/23 Axial Blanket. . . . . . . . . . . . 55

I-19. Approach-to-Critical Plots for Experimental Channe1 SP-11. . . 55

I-20. Approach-to-Critical Plots for Reactor Channel No. 2 . . . 56

I-21. Approach-to-Critical Plots for Reactor Channe1 No. 4 . . . . 56

I-22. Core Zone III/Radial Blanket Boundary. . . . . . . . . 57

I-23. Determination of GCFR Phase III Temperature Coefficient. . . . 57

I-24. Differences ( $S P-11$ minus SP-10 in Inhours) of $10 \mathrm{~B}$ Rod Worth as Measured on Experimental Flux Channels. . . . . . 57

II- 1. RL Calculational Model of the GCFR Phase III Plate Reference Configuration. . . . . . . . . . . . 58

II- 2. RZ Calculational Model of the GCFR Phase III Pin Zone Assembly ........................ 58

II- 3. XY Calculational Model of the GCFR Phase III Plate Reference Configuration. . . . . . . . . . . . . 59

II- 4. Modifled RZ Calculational Model of the GCFR Phase III Plate Reference Configuration. . . . . . . . . . . 59

III- 1. Matrix Configuration for the GCFR Phase III Small Sample Reactivity Worth Experiment. . . . . . . . . . . 60

III- 2. MB-10 (239Pu) Reactivity Worth Traverse. .......... 60

III- 3. MB-21 (235U) Reactivity Worth Traverse ............6 61

III- 4. MB-25 (238U) Reactivity Worth Traverse . . . . . . . . 61

III- 5. MB-19 (SST-304) Reactivity Worth Traverse. . . . . . . 62

III- 6. B-7 (10B) Reactivity Worth Traverse. . . . . . . . . 62

III- 7. LI-5 (6Li) React1vity Worth Traverse . . . . . . . . 63

III- 8. CH2(F)-6 Reactivity Worth Traverse . . . . . . . . . 63

IV- 1. Position of Fission Chamber Within Stationary half

Zone I Core Drawer . . . . . . . . . . . . . . 64

IV- 2. Energy Spectrum of Gamma Rays Emitted Following Irradiation of Depleted Uranfum Folls. . . . . . . . . . . . 65 
IV- 3. Aluminum Foll Holders (1-mil thick) Used for Irradiations with Enriched and Depleted Uranium and Plutonium Folls . . . . . . . . . . . . .

IV- 4. Intra-cel1 ${ }^{239} \mathrm{Pu}$ Fissio: Rates in Core Zone I: $\mathrm{S}-23 / 23, \mathrm{Z}=1.6 \mathrm{~cm} ; \mathrm{s}-15 / 23, \mathrm{Z}=1.6 \mathrm{~cm} ; \mathrm{s}-23 / 23$, $z=57.5 \mathrm{~cm}$. . . . . . . . . . . . . .

IV- 5. Intra-cel1 ${ }^{239} \mathrm{Pu}$ Fission Rates in Core Zone II: $\mathrm{S}-13 / 22-24, \mathrm{z}=1.6 \mathrm{~cm}$.................

IV- 6. Intra-cell ${ }^{239} \mathrm{Pu}$ Fission Rates in Core Zone II: $\mathrm{S}-23 / 32-34, \mathrm{z}=1.6 \mathrm{~cm}$. ................

IV- 7. Intra-cel1 ${ }^{239} \mathrm{Pu}$ Fission Rates in Core Zone III: $\mathrm{s}-11 / 23, \mathrm{z}=1.6 \mathrm{~cm}$. . . . . . . . . . . . .

IV- 8. Intra-cel1 $235 \mathrm{U}$ Fission Rates in Core Zone I: $\mathrm{S}-23 / 23, \mathrm{Z}=1.6 \mathrm{~cm} ; \mathrm{s}-15 / 23, \mathrm{Z}=1.6 \mathrm{~cm} ; \mathrm{s}-23 / 23$,

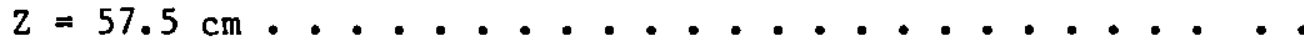

IV- 9. Intra-ce11 ${ }^{235} \mathrm{U}$ Fission Rates in Core Zone II: $\mathrm{S}-13 / 22-24, \mathrm{z}=1.6 \mathrm{~cm}$. . . . . . . . . . . .

IV-10. Intra-cell ${ }^{235} \mathrm{U}$ Fission Rates in Core Zone II: $\mathrm{S}-23 / 32-34, \mathrm{z}=1.6 \mathrm{~cm}$. . . . . . . . . . . . . .

IV-11. Intra-ce11 ${ }^{235} \mathrm{U}$ Fission Rates in Core Zone III: $\mathrm{S}-11 / 23, \mathrm{z}=1.6 \mathrm{~cm}$..................

IV-12. Intra-cel1 235U Fission Rates in the Axial Blanket Region: $S-23 / 23, Z=62.5 \mathrm{~cm} ; \mathrm{S}-23 / 23, \mathrm{Z}=87.9 \mathrm{~cm} . . .$.

IV-13. Intra-cel1 235U Fission Rates in the Radirl Blanket Region: $S-6 / 23, Z=1.6 \mathrm{~cm} ; \mathrm{s}-10 / 23, \mathrm{Z}=1.6 \mathrm{~cm} . . . .$.

IV-14. Intra-ce11 ${ }^{238} \mathrm{U}$ Fission Rates in Core Zone I:

$\mathrm{S}-23 / 23, \mathrm{Z}=1.6 \mathrm{~cm} ; \mathrm{s}-15 / 23, \mathrm{Z}=1.6 \mathrm{~cm} ; \mathrm{s}-23 / 23$,

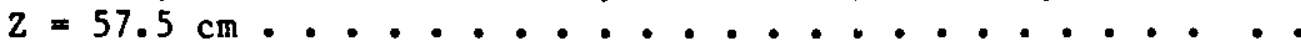

IV-15. Intra-cell ${ }^{238_{U}}$ Fission Rates in Core Zone II:

$\mathrm{S}-13 / 22-24, \mathrm{z}=1.6 \mathrm{~cm}$. . . . . . . . . . . .

IV-16. Intra-ce11 ${ }^{238} \mathrm{U}$ Fission Rates In Core Zone II:

$\mathrm{S}-23 / 32-34, \mathrm{z}=1.6 \mathrm{~cm}$. . . . . . . . . . . . .

IV-17. Intra-ce11 ${ }^{238} \mathrm{U}$ Fission Rates in the Core Zone III:

$\mathrm{s}-11 / 23, \mathrm{z}=1.6 \mathrm{~cm}$. .................. 
IV-18. Intra-cell 238U Fission Rates in the Axial Blanket

Region: $\mathrm{S}-23 / 23, \mathrm{Z}=62.5 \mathrm{~cm} ; \mathrm{S}-23 / 23, \mathrm{Z}=87.9 \mathrm{~cm} . . .$.

IV-19. Intra-ce11 ${ }^{238} \mathrm{U}$ Fission Rates in the Radial Blanket Region: $\mathrm{S}-6 / 23, \mathrm{Z}=1.6 \mathrm{~cm} ; \mathrm{s}-10 / 23, \mathrm{Z}=1.6 \mathrm{~cm}$. .....

IV-20. Intra-cel1 $238^{\mathrm{U}}$ Capture Rates in Core Zone I: $\mathrm{S}-23 / 23, \mathrm{Z}=1.6 \mathrm{~cm} ; \mathrm{S}-15 / 23, \mathrm{Z}=1.6 \mathrm{~cm} ; \mathrm{S}-23 / 23$,

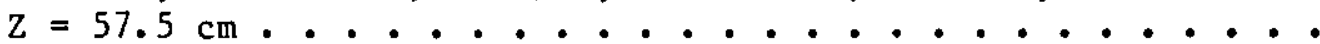

IV-21. Intra-ce11 $238 \mathrm{U}$ Capture Rates in Core Zone II: $\mathrm{S}-13 / 22-24, \mathrm{z}=1.6 \mathrm{~cm}$. . . . . . . . . . . . 74

IV-22. Intra-cel1 $238_{\mathrm{U}}$ Capture Rates in Core Zone II: $\mathrm{s}-23 / 32-34, \mathrm{z}=1.6 \mathrm{~cm}$. . . . . . . . . . 75

IV-23. Intra-cel1 $238_{\mathrm{U}}$ Capture Rates in Core Zone III: $\mathrm{S}-11 / 23, \mathrm{z}=1.6 \mathrm{~cm}$. . . . . . . . . . . 75

IV-24. Intra-cell 238U Capture Rates in the Axial Blanket Region: $\mathrm{S}-23 / 23, \mathrm{Z}=62.5 \mathrm{~cm} ; \mathrm{S}-23 / 23, \mathrm{Z}=87.9 \mathrm{~cm} . . . . .76$

IV-25. Intra-cell $238_{\mathrm{U}}$ Capture Rates in the Radial Blanket Region: $\mathrm{S}-6 / 23, \mathrm{z}=1.6 \mathrm{~cm} ; \mathrm{S}-10 / 23, \mathrm{z}=1.6 \mathrm{~cm} . . . . . .76$

IV-26. Sixteen Pin Array Within Each Calandria Included in the Pin Zone of the GCFR Phase III Assembly . . . . . . . 76

IV-27. Aluminum Foil Holder (1-mil thick) Showing Positions of Plutonium (X), Enriched Uranium (o), and Depleted Uranium Foils for Axial Reaction Rate Distributions . . . . . . 77

IV-28. Radial ${ }^{239} \mathrm{Pu}$ Fission Rate Distribution, Column $23 . \ldots 78$

IV-29. Radial 235 U Fission Rate Distribution, Column 23. . . . . 78

IV-30. Radial ${ }^{238_{U}}$ Fission Rate Distribution, Column 23. . . . . 79

IV-31. Radial 238U Capture Rate Distribution, Column 23. . . . . . 79

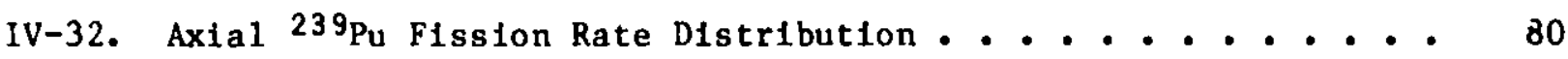

IV-33. Axial $235_{U}$ Fission Rate Distribution. . . . . . . . . 80

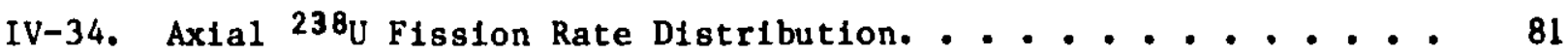

IV-35. Axial ${ }^{238}$ U Capture Rate Distribut1on. . . . . . . . . 81

IV-36. Axial ${ }^{239} \mathrm{Pu}$ Fission Rate Distribution in the Pin Zone..... 81 


\section{LIST OF TABLES}

No.

$\underline{\text { Title }}$

Page

I- I. Unit Cell Averaged Atom Densities for GCFR Phase III

Plate Compositions $\left(10^{21}\right.$ atoms $\left./ \mathrm{cm}^{3}\right)$. . . . . . . . . . .

I- 2. Number of Drawers Per Half, Fuel Plate Loading and Unit Cell Averaged Atom Densities for Each Type of Zone III Core Drawer . . . . . . . . . . . . . . . . . . . . .

I- 3. Number of Drawers Per Half, Corresponding Equivalent Radii and Fissile-Plut onium Mass for Each Zone or Region . . . . . . . . . . . . . . . . . . . . . . . .

I- 4. Atom Densities for the Pin Zone and Zone I Plate Unit Cells. . . 84

I- 5. Fuel Loadings for the GCFR Phase III Approach-to-Critical. . . . 84

I- 6. Est imated Critical Mass of Fissile Plıtonium, $M_{c}$ (kg), Using $1 / \mathrm{c}$ vs. $\mathrm{M}_{\mathrm{f}}$ Technique . . . . . . . . . . . . . . . . . .

1- 7. Est imated Crit ical Mass of Fissile Plutonium, $M_{c}$ (kg), Using $\mathrm{M}_{\mathrm{f}} / \mathrm{C}$ vs. $\mathrm{M}_{\mathrm{f}}$ Technique. . . . . . . . . . . . . . .

I-8. Summary of the Reactivity Corrections and the Corresponding Adjustments to the GCFR Phase III Reference Assembly Critical Mass. . . . . . . . . . . . . . . . . . . . . . 86

I- 9. Summary of ZPR-9 GCFR Phase III Operat ional Measurements . . . . 86

I-10. Locations and Measured Worths of the 2PR-9 Control Rods

for the GCFR Phase III Assembly. . . . . . . . . . . . . . . . . 86

II- 1. Energy/Lethargy Group St ructure for the 29-Group

Calculations . . . . . . . . . . . . . . . . . . . . . 87

II- 2. Benoist Anisotropic Diffusion Coefficient Mult ipliers, MI,

for the GCFR-III Plate Unit Cells. . . . . . . . . . . . . . . .

II- 3. Benoist Anisotropic Diffusion Coefficient Multipliers, $M_{\perp}$, for the GCFR-III Plate Unit Cells. . . . . . . . . . . . . . .

II- 4. Comparison of Benoist Anisot ropic Diffusion Coefficient Modifiers for the GCFR-III Central Pin and Plate Zones . . . . .

II- 5. Kinetics Parameters for the GCFR Phase III Assembly. . . . . .

II- 6. Delayed Neutron Fract ions and Effective Decay Constants for the GCFR Phase III Assembly. . . . . . . . . . . . . . . . . 90

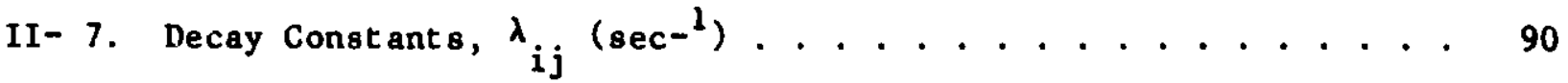


II- 8. Summary of Calculated E1genvaiues and Kinetics Parameters for Plate and Pin Zone Reference Configurations. . . . . .

II- 9. Worth of Pin Zone Replacing Plate Zone:

Experimentai Determination................

II-10. Worth of Pin Zone Replacing Plate Zone:

Calculational Determination of Components and

Total Worth. ....................

II-11. Calculated Components of the Pin-for-Plate Replacement

Worth. . . . . . . . . . . . . . . . . .

III- 1. Reactivity Worth Sample Description. . . . . . . . . . 94

II I- 2. Reactivity Worth Sample Composition. . . . . . . . . 95

III- 3. Experimental Small Sample Central Reactivity

Worths in GCFR Phise III . . . . . . . . . . . .

III- 4. Experimental Snall Sample Radial Reactivity Worth

Traverses in GCFR Phase III. . . . . . . . . . . .

III- 5. LI-5 ( $\left.{ }^{6} \mathrm{Li}\right)$ Experimental Small Sample Radial

Reactivity Worth Traverse in GCFR Phase III. . . . . . .

III- 6. ORNL-NSD-56 ( ${ }^{252}$ Cf $)$ Experimental Sma11 Sample

Radial Reactivity Worth Traverse in GCFR Phase III . . . .

III- 7. Calculated and Experimental Central Small Sample

Reactivity Worths for GCFR Phase III . . . . . . . . .

III- 8. Calculated Central Isotopic Reactivity Worths. . . . . .

III- 9. Calculated and Experimertal Radial Reactivity Rurth

Traverse Results for $\mathrm{MB}-10\left({ }^{239} \mathrm{Pu}\right)$ and $\mathrm{MB}-21\left({ }^{235_{\mathrm{U}}}\right), \ldots$

III-10. Calculated and Experimental Radial Reactivity Worth

Traverse Results for MB-25 ( $\left.{ }^{238} \mathrm{U}\right)$ and MB-19 (SST-304). ...

III-11. Calculated and Experimental Radial Reactivity Worth

Traverse Results for $\mathrm{B}-7\left({ }^{10} \mathrm{~B}\right)$ and $\mathrm{LI}-5\left({ }^{6} \mathrm{~L} 1\right) . . . . .$.

III-12. Calculated and Experimental Radial Reactivity Worth

Traverse Results for $\mathrm{CH}_{2}(\mathrm{~F})-6\left(\mathrm{CH}_{2}\right.$-Foam) .........

III-13. Comparison of GCFR Phase I and Phase III Central

Worth C/E's. . . . . . . . . . . . . . . . . 


\section{LIST OF TABLES}

No.

$\underline{\text { Title }}$

$\underline{\text { Page }}$

IV- 1. Mass and Composition of Fission Counter Sources. . . . . . 106

IV- 2. Measured and Calculaced Central Cavity Spectral Indices

in the GCFR Phase III Assembly ............... 106

IV- 3. Gamma-ray Peaks Analyzed to Determine Fission and

Capture Rates in Folls . . . . . . . . . . . . 107

IV- 4. Description of Activation Folls Used for Plate

Measurements ............... 107

IV- 5. In-Ce11 Reaction Rates, Core Zone I. . . . . . . . . 108

IV- 6. In-Cell Reaction Rates, Core Zone II, Row 13......... 109

IV- 7. In-Cell Reaction Rates, Core Zone II, Row 23 with

Radial Corrections . . . . . . . . . . . . 109

IV- 8. In-Cell Reaction Rates, Core Zone III. . . . . . . . . . 110

IV- 9. In-Ce11 Reaction Rates, Axial Blanket Region . . . . . . 110

IV-10. In-Ce11 Reaction Rates, Radial Blanket Region. . . . . . . 111

IV-11. Ce11-Average-to-Mapping-Fo11 Ratios. . . . . . . . . . 111

IV-12. Measured and Calculated Ce11-Averaged Per-Atom Reaction

Rate Ratios in the GCFR Phase III Assembly . . . . . . . . 112

IV-13. Description of Activation Folls for Pin Zone Measurements. . . 112

IV-14. GCER Phase III Pin Zone Intra-Cell Reaction Rates. . . . . 113

IV-15. Ce11-Averaged Reaction Rate Ratios in the GCFR Phase III

Plate- and Pin-Loaded Assemblies . . . . . . . . . 113

IV-16. Normalized Experimental Radial Reaction Rate Distributions

Ir. the GCFR Phase III Plate-Loaded Assembly. . . . . . . . . . 114

IV-17. Normalized Experimental Axial Reaction Rate Distributions

in the GCFR Phase III Plate-Loaded Assembly. . . . . . . . . 114

IV-18. Normalized Calculated Radial Reaction Rate Distributions

In the GCFR Phase III Plate-Loaded Assembly. . . . . . . . 115

IV-19. Normalized Calculated Axlal Reaction Rate Distributions

In the GCFR Phase III Plate-Loaded Assembly. . . . . . . . . 115 


\section{LIST OF TABLES}

No.

$\underline{\text { Title }}$

$\underline{\text { Page }}$

IV-20. Experimental ${ }^{239} \mathrm{Pu}$ Axial Fission Rate Distributions

in the GCFR Phase III Plate and Pin Loadings. . . . . . .

116

IV-21. Calculated 239Pu Axial Fission Rate Distribution

in the GCFR Phase III Pin Zone. . . . . . . . . . . . •

V- 1. Central Cavity Fission Rate Ratios in the GCFR

Phase III Assembly. . . . . . . . . . . . . . . .

V- 2. Absolute Reaction Rate Measurements in the GCFR

Phase III Assembly . . . . . . . . . . . . . . . •

V- 3. Description of the GCFR Phase III Reactivity Samples. . . . 118

v- 4. Composition (w/o) of Reactivity Samples ......... 119

V- 5. Small Sample Reactivity Measurements in the GCFR

Phase III Assembly. . . . . . . . . . . . . . . .

V- 6. Apparent Worth of $252 \mathrm{Cf}$ Spontaneous Fission Neutrons in the GCFR Phase III Assembly . . . . . . . . . . . .

V- 7. Calculated Quantities (ENDF/B-IV) for the GCFR Phase III Assembly. . . . . . . . . . . . . . . . . .

V- 8. Un-normalized Perturbation Denominator for the GCFR

Phase III Assembly. . . . . . . . . . . . . . . .

V- 9. Normalized Perturbation Denominator in the GCFR

Phase III Assembly. . . . . . . . . . . . . . .

V-10. Thin Sample $(1+\bar{\alpha})$ Values in the GCFR Phase III Assembly . .

V-11. Errors in $(1+\bar{\alpha})$ from Uncertainties in the Measured Quantities at the Central Location of the GCFR Fhase III Assembly. . . . . . . . . . . . . . . . . .

V-12. Error Sensitivities in $(1+\vec{a})$ Measurements at the Central Location of the GCFR Phase III Assembly . . . . . . .

V-13. Some C/E Ratios for the GCFR Phase III Assembly . . . . •

V-14. Central Point Conversion Rat1o Measurement in the GCFR Phase III Assembly . . . . . . . . . . . . .

VI- 1. Worth of Steam Zone Relative to Steam-free Reference. . .

VI- 2. Steam Worth for Each 12-1n. Axial Increment of the Steam Zone. . . . . . . . . . . . . . . . . . 
REACTOR PHYSICS STUDIES I.J THE

GCFR PHASE IIJ CRITICAL ASSEMBLY

edited

by

J. A. Morman

ABSTRACT

The third phase of the gas cooled fast reactor (GCFR) program, 2PR-9 Assembly 30, is based on a multi-zoned core of $\mathrm{PuO}_{2}-$ $\mathrm{UO}_{2}$ with radial and axial blankets of $\mathrm{UO}_{2}$. Studies performed in this assembly will be compared to the previous phases of the GCFR program and will help to define parameters in this powerflattened demonstration plant-type core.

Measurements in the Phase III program included small sample reactivity worths of varfous materfals, central reaction rates and reaction rate distributions, absorption-to-fission ratios and the central point conversion ratio and the worth of steam entry into a small central zone. The reactivity change associated with the construction of a central pin zone in the core and axial blanket was measured. Reaction rate and steam entry measurements were repeated in the pin environment.

Standard analysis methods using ENDF/B-IV data are described and the results are compared to measurements performed during the program. 


\section{THE GCFR PHASE III ASSEMBLY}

A. Introduction

The GCFR Phase III assembly is the third in the series of critical assemblies in support of the gas cooled fast reactor design. The assembly was constructed in the ZPR-9 facility at Argonne, I11inols and was designated as Assembly 30. The objective of this final phase of the program was to characterize a multi-zoned GCFR core of varying enrichments in preparation for a possible future Engineering Mock up Critical of the 300 MWe GCFR Demonstration Plant. Also, the effects of the loading environment we re studied by measuring central reaction rates, foll reaction rate traverses, and steam zone reactivity worths in both a normal plate and a central pin zone loading.

This report contalns the detalled description of the Phase III reference assembly and the pin zone loading, along with the results of the measurements performad in both the plate-loaded configuration and pin-loaded zone. Calculational techniques are described and analytical results are compared to the measurements. The results reported here include $\mathrm{ZPR}-9$ operational measurements, the approach-to-critical, small sample reactivity worths, central reaction rates and reaction rate distributions in plate and pin environments, absorption-to-fission ratios and the central point conversion ratio and the worth of steam entry into a small central zone for both plate and pin environments. Some comparisons with results from Phases I and II of the GCFR program ${ }^{1}, 2,3$ are also included.

\section{B. Description of the Reference Assembly}

The GCFR Phase III assembly contalns a mult1-zoned core more characteristic of the 300 MWe Gas Cooled Fast Reactor Demonstration Plant than previous GCFR assemblies in the ZPR series. The piutonfum enrichment in the outer zones is increased in order to provide a flatter power distribution in the core. Figure I-1 shows the conflguration of the radially zoned core. The enrichments* in Zones I, II, and III were $13.1 \%, 17.3 \%$, and $25.5 \%$, respective1y. Figure I-2 shows the radial and axlal dimensions of the assembly. The core helght is $122.08 \mathrm{~cm}$ (48.06 inches); the height-to-diameter ratio is 0.86 . The axial and radial blanket thicknesses are $30.48 \mathrm{~cm}$ (12 inches) and $28.99 \mathrm{~cm}$ (11.4 inches), respectively. The reactor is surrounded by a stainless stee1 reflector, $6-1$. thick.

Al1 unit cell structures, drawer masters, and matrix loading configurations introduced below are the stationary-half diagrams; the corresponding movable-half diagrams are the mirror tmages.

The unft cell loadings for the zone I core and axial blanket are given In Fig. I-3. Core zone II consists of a three-drawer untt cell identical to the Phase II core loading. The axial blanket loading 18, however, 8lightly modifled from the Phase II blanket in order to make the average composition of all Phase III axial blanket zones nominally the same. The unit cell structures for zone II are shown 1n F1g. I-4. The core and axtal blanket

Enrichment denotes the ratio of the fissile plutonium $\left({ }^{239} \mathrm{Pu}+{ }^{241} \mathrm{Pu}\right)$ atom density to the heavy metal (all Pu and U) atom density. 
loadings for zone III, presented in Fig. I-5, are symmetric, single-drawer unit cells. All three core and axlal blanket zones have a void fraction of approximately $43 \mathrm{v} / \mathrm{o}$. The Phase III radial blanke:, shown in Fig. I-6, is Identical to the Phase II loading with a void fraction of $37 \mathrm{v} / \mathrm{o}$. The radial and axial reflectors consist of stainless steei blocks as shown in Fig. I-7.

The void columns in the core and axial blanket loadings for each zone are aligned so as to maintain the axial streaming paths throughout the assembly. However, void columns in adjacent zones are not, in general, aligned. Vertical streaming paths are therefore disrupted at zone and region interfaces as shown in Fig. I-8.

The stationary-half drawer masters for the core and axial blanket of each zone and for the radial blanket and reflector are shown in Figs. I-9 through I-15. The homogeneous atom densities for each region are presented in Table I-1. Due to limited availability of specific fuel-plate sizes, core zone III is composed of 3 drawer types. The type 1 drawer master is represented in Fig. I-13, and types 2 and 3 differ only in the lengths of the individual fuel plates. The zone III atom densities in Table I-1 are the weighted averages for the zone. The atom densities, the fuel plate loading, and the number per half for each zone III drawer type are given in Tatle I- 2 .

Each radial blanket matrix tube has two drawers -- a front drawer containing a 24-in. loading of blanket material, and a back drawer containing the last 12 inches. An approximate 3/8-in. gap between the two sections of radial blanket loading contains the drawer ends and a leaf spring to prevent the front 24-in. of the loading from shifting. The back $12 \mathrm{in}$. is held in position by a 1/4-in. high by 2-in. wire stainless steel column positioned against the plate ends and lyirg along the bottom of the back drawer.

The radial reflector is composed of stainless steel blocks loaded to an axial half-height of $36 \mathrm{in.}$. In the standard 36.25-in. long stainless steel. drawer. The axial reflector stalnless steel blocks are loaded directly in the matrix tubes bifilind the core-plus-axial-blanket drawers. A gap of approximately $1 / 4 \mathrm{in}$. between the blanket and reflector contains the drawer end and leaf spring. No axial reflector is loaded behind the radial blanket.

The stationary-half matrix loading established for the GCFR Phase III reference configuration is given in Fig. I- 1 . The drawer types for zones II and III are specifled for the lower portion of the assembly half. Zone II drawers in the same vertical column are of the same type and the zone III drawer pattern in the upper half is a reflection of that for the lower half. Each zone or region boundary is symmetric about both the horizontal and vertical axes and also about a set of axes rotated $45^{\circ}$ with respect to these. However, the asymmetric zone II drawer loading destroys the quarter-core symmetry of the assembly.

Also indicated in Fig. I-1 are the locations of the experimental thermocouple drawers $(T)$ and the operational fuel rods and $10_{B}$ blades. Fue 1 rod positions that are not symmetric about the assembly midplane are marked with an $S$ (for stationary half only) or an $M$ (for movable half only). 
Table I-3 contains a summary of the number of drawers per half, the corresponding equivalent radius calculated by preserving cross-sectional area, and the fissile plutonium mass for each zone or region. Figure I-2 illustrates the $\mathrm{RZ}$ geometry of the reference configuration. The $61.04 \mathrm{~cm}$ core half-height includes the 32-mil thick stalnless steel drawer front.

\section{Description of the Pin Zone Assembly}

The final configuration in the GCFR program consisted of a central pin zone loaded within zone I of the multi-zoned GCFR Phase III assembly. The pin zone provided a close compositional match with the zone I plate loading but afforded markedly different heterogeneity and streaming characteristics. The limited experimental program in the Phase III pin zone assembly included the following measurements:

1. eigenvalue of the reference assembly,

2. central cavity measurements of fission rates for ${ }^{239} \mathrm{Pu},{ }^{235} \mathrm{U}$, and $238_{U}$ and of ${ }^{238} \mathrm{U}$ capture,

3. unit cell reaction rates for ${ }^{239} \mathrm{Pu},{ }^{235} \mathrm{U}$, and ${ }^{238} \mathrm{U}$ fission and ${ }^{238_{\mathrm{U}}}$ capture,

4. axial fission rate distribution for ${ }^{239} \mathrm{Pu}$, and

5. worths of central $5 \times 5$ drawer (simulated) steam-filled pin zones of Incremental axial half-heights.

The pin zone, loaded within zone I of the GCFR Phase III assembly, was composed of 85 matrix locations per half, corresponding to an equivalent radius of $28.74 \mathrm{~cm}$. The central $5 \times 5$ locations contained special calandria into which $\mathrm{CH}_{2}$ foam could be loaded, and the remaining 60 locations contained the normal sodium-voided calandria. The matrix configuration for the pin zone reference assembly is shown in Fig. I-16. The zone and region boundaries are identical to those of the plate geometry Phase III reference configuration (Fig. I-1) except for the zone III/radial blanket boundary. Locations $S / M-12 / 17$ and $S / M-34 / 17$ were zone III, type 3 core-plus-axial-blanket drawers in the plate reference but were radial blanket drawers in the pin zone reference **

The central $5 \times 5$ locations in the pin zone were loaded with calandria specifically designed for the pin zone steam entry experiment. Eaci calandria was composed of a $4 \times 4$ array of stainless steel tubes, 12 inches in length, supported by two drilled end assemblies and two interior-positioned rectangular grids. Three such special calandria, two loaded with mixed oxide fuel rods ( $15 \% \mathrm{PuO}_{2}$ and $85 \% \mathrm{UO}_{2}$, core region) and one with depleted uranium oxide rods (axial blanket region) were placed end-to-end axially in standard 36.25-in. long stainless steel drawers and inserted into the central

*Matrix locations denoted by $I / J$ refers to row I, column J; S refers to stationary half, and $M$ refers to movable half. 
$5 \times 5$ matrix positions. The resulting stainless steel density in the special calandria region was only slightly greater than that in the surrounding normal calandria region.

The masses of the individual special calandria were recorded and accumulated to produce a distribution of calandria masses. An apparently significant varlation in the 3/8-in. ID stock stainless steel tubing produced a pronounced double-lobed distribution with approximately 50 calandria peaked about 348.5 grams and approximately 85 calandrla peaked about 340 grams. Fifteen additional. calandria had masses scattered in the 356 gram to 362 gram region. The calandria were sorted according to mass -- the minor lobe in the distribution being used in the axial blanket region and the major lobe plus the large mass "stragglers" being used in the core region.* The mean special calandria mass in the axial blanket was $348.28 \pm 0.10$ grams and that for the core was $343.07 \pm 0.63$ grams.

Table I-4 11sts the atom densities for the normal and spectal calandria in the core and axial blanket regions.

\section{Approach to Critical}

The experimental procedure for the GCFR Phase III approach to the delayedcritical configuration was basically the source multiplication technique. In this technique the inverse neutron count rate, $1 / \mathrm{C}$, or equivalently the inverse multiplication, is plotted as a $i$ unction of some measure of the reactivity, such as the fissile plutonium mass, $M_{f}$. Extrapolation of the inverse neution count rate to zero (corresponding to infinite multiplication) gives an estimate of the critical mass for the assembly. To account for neutrons emitted by the spontaneous fission of ${ }^{240} \mathrm{Pu}$, an examination of $M_{f} / C$ vs. $M_{f}$ has been demonstrated in the earlier GCFR assemblies to be a more rellable, yet conservative, indicator of criticality, as detailed in Ref. 1.

The as-planied GCFR Phase III assembly configuration is outlined in Fig. I-17. The numbers at each location summarize the drawer loading steps in the approach-to-critical. All the inner zone and the dual purpose (DP) rods we re included in the first loading step. The approach-to-critical was completed in six loading steps, with a seventh step required to establish the reference configuration shown in Fig. I-1. All fuel loading steps were symmetric about the assembly midplane and, with the single exception of $S / M-15 / 29$, were symmetric also about both the horizontal and vertical axes. The correlation between the assembly loading numbers and the approach-tocritical loading step number is given in Table I-5. Also tabulated is the f1ssile plutontum mass after each loading step. The $241 \mathrm{Pu}$ mass is decaycorrected to the date that the reactivity excess of the reference assembly** was measured, 7/1/76. Detalls of the loading steps are given below.

\footnotetext{
*The large mass "stragglers" were placed in the 16 coruer positions of the $5 \times 5$ array and 84 calandria from the major lobe filled the remalnder of the central zone. Th1s symmetric loading of the special calandria in the core region was not accounted for in the calculational modeling.

**The reference assembly is characterized by specifying the reference configuration (the assembly geonetry) and the operational parameters (excess at reference temperature, power level, etc.).
} 
The Phase III approach-to-critical began with the final subcritical reference configuration of the Phase II steam entry program. ${ }^{3}$ The Phase II drawers in the region designated as zone I were converted to Phase III, zone I drawers. The ring of Phase II core-plus-axial-blanket drawers that remalned became the initial loading of the Phase III, zone II drawers. The axial blanket of the Phase II, type 1 drawers were modified by replacing one $1 / 8-1 \mathrm{n}$. depleted uranium column with uranium oxide. Fuel rod loadings were modified to match the composition of the zone in which they were located and 1nstalled in the assembly. Twelve single-bladed $10^{0} \mathrm{~B}$ rods were also installed. To

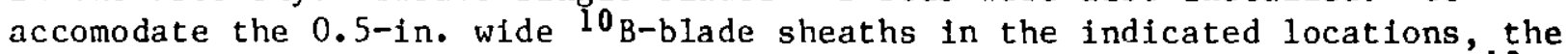
normal zone I drawer contents, except the $0.5-i n$ void column nearest the $10_{B}$ blade, were loaded into a special three-quarter width drawer. Finally, the radial reflector was moved outward to 1 ts anticipated final location, leaving voided tubes in the outer areas of the radial blanket region. All the above modifications constituted the first step in the approach-to-critical.

For all subsequent steps in the approach-to-critical, the added core drawers replaced radial blanket drawers. These blanket drawers were moved to the volded tubes in the outer radial blanket region. The Phase III, zone II loading was completed in the second loading step. For the additional steps toward criticality, the radial blanket inner-edge drawers indicated in Fig. I-17 we re replaced with zone III core-plus-axial-blanket drawers. Pre-analysis calculations for the assembly over-estimated the critical mass, requiring that four radial blanket drawers per half remain within the as-planned zone III region. The final loading step was required to complete the outer radial blanket region, to load additional radial reflector, and to symmetrize the drawer types in core zone III. Fission counters used to accumulate approach-to-critical data were also removed at this time. The resulting reference configuration has been piesented in Fig. I-1.

The subcriticality of the assembly during approach-to-critical vas monitored by the six reactor operational channels and the two experfmentil channels, SP-10 ard SP-11. Count rate data were also accumulated $\mathrm{rrm}$ $235 \mathrm{U}$ fission counters loaded into the axial blanket portion of $\mathrm{S} / \mathrm{M}-23 / 2$ ? Data we:e colleciced at each loading step with all $10 \mathrm{~B}$ and $\mathrm{nP}$ rods in their most reactive and also in their least reactive positions.

The estimated critical masses using the $1 / C$ and $M_{f} / C$ techniques are reported in Tables I-6 and I-7, respectively. These numbers were calculated using the most-reactive configuration data. Estimates for the total rod worth were obtained by subtracting the most-reactive from the least-reactive critical mass estimates.

Plots of $1 / C$ vs. $M_{f}$ and $M_{f} / C$ vs. $M_{f}$ for representative detection systems are shown in FIgs. I-18 through I-21. Both fission counters (e.g., as shown in Fig. I-18), historically considered to be reliable early indicators of the critical mass, provided extremely low initial estimates while successive steps did yield more consistent results. The data from the experimental and reactor operational channels were quite good. The $1 / \mathrm{C}$ technique produced the expected conservative critical mass estimates and the $M_{f} / C$ technique gave more accurate, though generally conservative estimates. 
E. Corrections to the Reference Assembly Critical Mass

The reference assembly as shown in Fig. I-1 has a critical mass of $888.1 \pm 0.2$ fisstle $\mathrm{kg}$ and an excess reactivity of $214.5 \pm 1.7 \mathrm{Ih}$. A series of corrections was made to the fissile plutonfum mass of the reference assembly to obtain the critical mass of a hypothetical zero-excess, delayed-critical, cylindrical assembly. The more significant of these reactivity adjustments corrected for the built-in excess reactivity of the reference configuration, the adjustment of the measured excess to a reference temperature, the source subcriticality at the reference power level due to $240 \mathrm{Pu}$ spontaneous fission neutrons, and the reactivity effects due to the stepwise region/zone boundaries. Each of these corrections is discussed in detail in the following paragraphs. The measurements of the experimental quantities used for these analyses are described in Section I.F.

The quoted value of the critical mass of the reference assembly (shown in Fig. I-1), $888.1 \pm 0.2 \mathrm{~kg}$, includes only the fisstle plutonium isotopes $239 \mathrm{Pu}$ and $24 \mathrm{lPu}$. Since $24 \mathrm{lPu} \beta^{-}$decays with a half-life of 14.5 years to $24 \mathrm{lAm}$, it was necessary to re-evaluate the critical mass $i$ the assembly to reflect this decrease. Consequently, all fuel loading figures quoted in this report are adjusted to the date that the reactivity excess of the reference configuration was measured, $7 / 1 / 76$.

\section{Excess Reactivity and Temperature Correction}

The reference Phase III assembly had a built-in apparent excess reactivity of $217.2 \pm 1.7 \mathrm{Ih}$ * This measured excess has been ad justed to correspond to the reference temperature, $25.0^{\circ} \mathrm{C}$, through the use of a measured temperature coefficient of $-3.00 \pm 0.03 \mathrm{Ih} /{ }^{\circ} \mathrm{C}$. Based upon the experimental value of the worth of a cor 2 edge drawer relative to a radial blanket drawer, the excess reactivity is equivalent to $7.78 \pm 0.08 \mathrm{~kg}$ of "edge fie 1 ". This reduction in the critical mass would be required for a zero-excess configuration of the Phase III assembly.

\section{Source Subcriticality Sossetton}

The spontaneous fission of $240 \mathrm{Pu}$ constitutes a bu1t-1n neutron source in all plutonium-fueled assemblies. The effect of this source is to make an apparently critical assembly actually subcritical. The magnitude of this effect is given by

$$
\Delta k=-\frac{S \ell}{n}
$$

where $S$ is the effective neutron source per unit volume, $\ell$ is the neutron lifetime and $\mathrm{n}$ is the neutron density. For $240 \mathrm{Pu}$ spontaneous fission, $\mathrm{S}$ Is equal to $4.30 \times 1012$ neutrons/sec per gm of $240 \mathrm{Pu}$. The experimental value of the source subcriticality at the reference power level, $\Delta \mathrm{k}=-2.7 \pm 0.2 \mathrm{Ih}$, translates into an increase in the critical mass of $0.10 \pm 0.01 \mathrm{~kg}$. Normaliy, both the temperature coefficlent and source subcriticality are combined with the measured excess and reported as the assembly excess. Thus, the excess of the GCFR Phase III reference assembly is $214.5 \pm 1.7 \mathrm{Ih}$.

\footnotetext{
*This value does not include the source subcriticality discussed below.
} 


\section{Edge Smoothing Corrections}

The actual zone and region interfaces of the reference assembly are not cylindrical boundaries as represented in RZ eigenvalue calculations, but rather step-wise boundaries produced by the drawer-loading geometry.

Consider, for example, the core/radial blanket boundary of the Phase III reference configuration. The radius of a cylindrical core region with an equal-area cross sect on is readily computed from the expression

$$
R_{c}(\mathrm{~cm})=\left[(\text { number of core drawers per half }) \times(5.5245 \mathrm{~cm})^{2 / \pi}\right]^{1 / 2} \text {. }
$$

Both the step-wise and the equal-area circular boundaries are shown in Fig. I-22 for one quadrant of the assembly. Since the reactivity worth of fuel at this interface has a negative radial gradient, the worth of the fuel located outside the circular boundary is less than the worth of the equal quantity of fuel displaced from inside the circular boundary. Consequently, a calculated smoothing of the core/radial blanket boundary would increase the excess of the as-built assembly and thus reduce the zero-excess critical mass.

A numerical algorithm was coded to calculate the reactivit worth of the edge-smoothing correction. The radial dependence of the edge core drawer worth was assumed to be that given by the preanalysis value for the axiallyaveraged worth distribution of $\mathrm{Pu}$ fuel at the core/radial blanket interface. This radial dependence was then normalized to the experimental value of the core edge-drawer worth of $36.9 \pm 0.3 \mathrm{Ih} / \mathrm{drawer}$, at the mean radial position of $69.22 \mathrm{~cm}$. The resulting radial gradient was $0.74 \mathrm{Ih} / \mathrm{drawe}$ per $\mathrm{cm}$. The numerical routine divides the regions between the step-wise and circular boundaries into a grid of approximately square elements. The worth of each element is calculated relative to the equal-area circular boundary and summed over all elements. Since the clrcular boundary is an equi-reactivity line, this sum is the net worth of the edge-smoothing effect. The numerical calculation for one quadrant of the reference assembly (full core height) computed that 2.47 drawers displaced a mean distance of $1.94 \mathrm{~cm}$ produced a reactivity change of 7.12 Ih. Assuming a $\pm 10 \%$ uncertainty in the value for the radial. gradient of the core edge drawer worth, the total edge-smoothing correction for the Phase III reference assembly is $28.5 \pm 2.9$ Ih with a corresponding reduction in the critical mass of $1.02 \pm 0.10 \mathrm{~kg}$.

These reactivity corrections and the corresponding adjustments $t$ the as-built critical mass are summarized in Table I- 8. Applying these corrections yielded a zero-excess delayed-critical fissile plutonjum mass for the Phase III reference assembly operating at $25^{\circ} \mathrm{C}$ of $879.4 \pm 0.2 \mathrm{~kg}$.

\section{F. Operational Measurements}

After establishing the reference configuration of the GCFR Phase III assembly, a series of measurements was made to determine operational characteristics of the assembly such as excess reactivity, control rod worths and the temperature coefficient of reactivity. Tables I-9 and I-10 summarize the operational measurements and include some ralculated parameters such as the conversion from $\Delta k / k$ to Inhours (calculations are discussed in Section II). 
1. Measurement of the Reactivity Excess of Reference Assembly

The measured reactivity excess for the GCFR Phase III reference assembly was $214.5 \pm 1.7$ Ih. This figure includes the reactivity adjustments for the assembly temperat ure and source subcriticality that are discussed below. The quoted excess was determined from two consecutive startups from the complete shutdown configuration. For each startup, the excess was measured ly positioning the $10 B$ rod at $M-19 / 30 \mathrm{full} 1 \mathrm{n}$, the $D P$ rod at $S-15 / 20$ full out, and cortrolling on the DP rod at $s-27 / 26$.

The uncertainty associated with a single measurement of the reactivity excess for a given configuration is taken to be the sum, added in quadrature, of three components: (1) configuration reproducibility uncertainty, (2) rod calibration uncertainties, and (3) statistical uncertainties of the measurement. Other sources of uncertainty, such as the temperature correction, the $240 \mathrm{Pu}$ source correction, and the $241 \mathrm{Pu}$ decay correction are less significant and contribute negligibly to the uncertainty of the measured txicss. If several independent determinations of the reactivity excess are made, the final uncertalnty in the excess is obtained by adding in quadrature the uncertainties from each measurement.

The first of these uncertainties in keff reflects the difficulties in precisely reproducing the assembly configuration. The major source of this uncertainty is attributed to table closure reproductbility, although errors in positioning the $10 \mathrm{~B}$ and $\mathrm{DP}$ rods $1 \mathrm{n}$ their most or least reactive configurations also contribute. Configuration reproducibility, determined for the Phase IiI reference assenbly from the two excess reactivity measurements results in a value of one standard deviation in the measured excess of 0.7 Ih. Consequent$l y$, an uncertainty of \pm 1 Ih was assigned to $k_{\text {eff }}$.

The accuracy of the control rod calibrations (reactivity worth as a function of position) and the control rod worths (reactivity worth at most reactive versus ieast reactive positions) used to measure the configuration excess represent a second source of possible uncertainty. The mechanical linkages, limit switches, and electro-mechanical position readouts introduce uncertainties during both the rod-worth and configuration-excess measurements. Furthermore, use of high-worth poison (or $f$ uel) control rods may contribute to appreciable distortions in the space- and energy-dependent spectrum, resulting in systematic errors associated with changing detector efficiency. To consider an extreme example, the reactivity excess of the reference configuration, measured with the $10 \mathrm{~B}$ rod at $5-19 / 30$ full-in and controlling on the DP rod at S-16/29, was $220.3 \pm 2.6$ Ih. Thus the effect of using over two hundred inhours of control located in a small $\varepsilon$ : $t$ ion of the assembly was to increase the apparent excess by $5.8 \pm 3.1 \mathrm{Ih}$, a ignificant systematic deviation. Since the rod-worth component of the uncertainty in the measured excess is dependent on the amount of reactivity control that is introduced, it is represented by a percentage of the apparent excess. Experience ind 1cates that a value of $1 \%$ is a reasonable first approximation. Obviously, the systematic deviations caused by flux distortions are not included.

The third component of the uncertainty in the measurement of the configuration excess is the statistical uncertainty associated with the measuring process. The repeated measurement of the control ind position and the assembly temperature provides a spread about the mean which reflects this coniribution to the uncertainty. 


\section{Measurement of Temperature Coefficient}

In order to compare reactivity excesses measured at different operating temperatures, it is necessary to adjust the measured values to the same reference temperature. A measured temperature coeffictent of reactivity is used for this correction, and is equivalent to measuring the excess at the reference temperature. The teinperature coefficlent was determined for the Phase III reference configuration by measuring the reactivity excess as a $f$ unction of the assembly temperature. The experimental technique was as follows. After start-up, the assembly was operated at standard power until thermal equilibrium had been reached; at that point the reactor cooling system was shut down and the assembly temperature allowed to rise from $27.5^{\circ} \mathrm{C}$ to $32^{\circ} \mathrm{C}$. The rate of rise, approximately $3.5^{\circ} \mathrm{C} / \mathrm{hr}$, was sufficiently low so as to roughly maintain thermal equilibrium. No data were accumulated as the assembly temperature was decreasing, since previous GCFR measurements had shown the cooling-down data to be inconsistent with the heating-up data. This inconsistency is attrtbuted to the large void channels in a GCFR assembly allowing the cooling process to proceed too rapidly.

For experimental purposes the assembly temperature was monitored by a network of 16 Copper-Constantan (type T) thermocouples. The thermocouples were positioned at axial heights of approximutely $0,6,12$, and 18 inches from the assembly midplane in each of the matrix locations S/M-29/19 and $\mathrm{S} / \mathrm{M}-17 / 27$. The TC reference junction was maintained at $150^{\circ} \mathrm{F}$. A leastsquares fit to tabulated millivolt-to ${ }^{\circ} \mathrm{C}$ conversion valies over the range $15 \leq T\left({ }^{\circ} \mathrm{C}\right) \leq 40$ produced the calibration equation,

$$
T\left({ }^{\circ} \mathrm{C}\right)=2.2411584 \times 10^{-2}+2.5785378 \times 10^{1} \times R-6.0465744 \times 10^{-1} \times R^{2}
$$

where $R$ is the thermincouple reading in millivolts plus the reference constant $2.711 \mathrm{mV}$. The as jenliny temperature was taken to be the arithmetic mean of the 16 thermocoupie temperatures. The reactivity excess of the asrembly was determined by recording the position of a calibrated dual purpose cod, and the position data we converted to reactivity excesses using a fourth order fit to the inverse-kinetics calibration data for the rod.

A linear least-squares $f i t$ of the measured excess as a function of the assembly temperature established a temperature coefficient of $-3.00 \pm 0.03 \mathrm{ih} /{ }^{\circ} \mathrm{C}$. The experimental data and the resulting least-squares linear fit are shown in Fig. I-23. The quoted uncertainty is the quantity calculated from the error matrix of the least-squares fitting procedure. The effects of systematic errors in the determination of the temperature and the excess are reduced since only the slope of the linear fit is of interest.

\section{Measurement of $10_{B}$ and DP Kod Worths}

The worths of the ZPR-9 $10 \mathrm{~B}$ and DP control and safety rods are needed in order to satisfy administrative reactivity requirements for each startup. These rod worths were obtained whlle operating in a critical configuration by scramming each rod individually from its most reactive position. Flux data we re accumulated on the SP-10 and SP-11 channels as a function of time and analyzed using inverse kinetics. The worths of the rods as determined from 
the data of each detection system are reported in Table I-10. The worths of the DP rocis at $S-16 / 29$ and $S-27 / 26$ were determined from the rod calibration data using SP-11 only.

The ${ }^{10} \mathrm{~B}$ rods at $M-30 / 23, M-16 / 23$, and $S-16 / 23$ we re dual-bladed rods installed during the Phase III approach-to-critical. A dual-bladed $10 \mathrm{~B}$ rod is composed of two standard $10_{B}$ blades separated by a normal 2-in. drawer and a special 3/4-width drawer, a total distance of $11.05 \mathrm{~cm}$ center-to-center. The actual positions of the $10_{\mathrm{B}}$ blades are shown in Fig. I-1 and $\mathrm{I}-17$. Additional rods of this design replaced several of the remaining single-bladed $10_{B}$ rods as the experimental program progressed.

The agreement between the SP-10 and SP-11 results for the DP rod worths is quite good, less than $0.5 \%$ discrepancy. The agreement for the ${ }^{10} \mathrm{~B}$ rods, though good, shows evidence of systematic errors. These deviations are best illustrated by the sketch in Fig. I-24. The boxes indicate the relative positions of the $10 \mathrm{~B}$ rods in the stationary and movable halves, and the numbers are the differences (in inhours) between the worths as measured hy the two detectors, that is, SP-11 minus SP-10. The boxes labeled SP-11 and SP-10 indicate which detector is above each half of the assembly. The agreement for the three ${ }^{10} \mathrm{~B}$ rods in the lower portion of either half of the assembly is very good and does not indicate any systematic trends. However, the worths as determined by SP-11 fir the $10_{\mathrm{B}}$ zods in the upper portion of the stationary half are more than the corresponding worths as determined by SP-10, and the converse applies to the movable half. The worths of the $10_{\mathrm{B}}$ rods nearest the detectors (that is, in row 16 ) differ by $2-1 / 2 \%$. The worths of the $10_{B}$ rods in row 19 , though only disagreeing by $1 / 2 \%$, definitely reflect systematic errors. These results ind isate that a $1{ }^{10} \mathrm{~B}$ od inserted in the upper portion of one half of the assembly tends to shield the detector above that half. Though these discreparw: ies are minor and insignificant in regards to operationa 1 measurements, the systeitatic effect is of consequence to experimental measuremeats.

The inverse-kinatics analysis of the rod drops aiso yieldel valnes of the degree of subcriticality prior to the rod drop. This initial subiriticality is caused by the presence of $240 \mathrm{Pu}$ spontaneous fission noutrons and is commonly referred to as the source subcriticality. The luagnitude of this effect as determined from the $10_{\mathrm{B}}$ rod drops using SP-11 data is $2.7 \pm 0.2$ Ih at a powe $r$ level designated as standard for the assembly.

\section{Measurement of Edge Drawer Worth}

The reactivity worth of a core edge drawer relative to a radial bianket drawer is needed to evaluate the reactivity change associated with a change in the core/radial blanket boundary. This vilue is not only useful 1 ir est:mating reactivity effects of loading changes, but also necessary for the experimental steam zone worth measurements. To determine the edge drawer worth, eight symmetrically-positioned type 3, zoise III core-plus-axial-blanket drawers were removed from the Phase III reference assembly and replaced with radial blanket drawers. The eight drawers $\mathrm{S} / \mathrm{M}-12 / 17,-34 / 17,-12 / 29$, and $-34 / 29$ contained $10.61 \pm 0.02 \mathrm{~kg}$ of fissile plutonium $\left({ }^{239} \mathrm{Pu}+241 \mathrm{Pu}\right)$, and each drawer was located $69.22 \mathrm{~cm}$ radially from the assembly center. The subcriticality of the assembly was determined from the SP-10 and SP-11 data 
for three rod drops to be $-81.0 \pm 1.4 \mathrm{Ih}$. Each rod drop consisted of a singlebladed $10_{B}$ rod scrammed from its most reactive configuration. The worth of a core edge drawe $r$ relative to a radial blanket drawer is thus $36.9 \pm 0.3$ Ih/drawer, or $27.9 \pm 0.2 \mathrm{Ih} / \mathrm{kg}$ of fuel at the edge of the core.

\section{Determination of $241_{\mathrm{Pu}}$ Decay Coefficient}

The ${ }^{24} \mathrm{l} \mathrm{Pu}$ in the core, representing approximately $1-1 / 4 \%$ of the fissile plutonium mass, decays by $\beta^{-}$emission with a half-life of 14.5 years to $241 \mathrm{Am}$. Consequently, there is a decrease in the excess reactivity of the reference configuration as the experimental program progresses. Because of the rather large uncertalnty associated wtth a single measurement of the reactivity excess and of the short Phase III experimental program, it would have been difficult to measure the decay coefflcient with any confidence.* Consequently, a calculated value of 0.12 Ih/day was established as the ${ }^{241} \mathrm{Pu}$ decay coefficient. The details of the calculation are presented in the discussion of the RZ analysis model.

\section{CAILCULATIONAL METHODS}

\section{A. Introduction}

The calculational methods used for the analysis of the GCFR Phase III assembly are presented below. The half-height RZ and quarter-core XY two dimensional calculations of the reference configuration are based on 29-group diffusion theory with Benoist anisotropic diffusion coefficients. The spaceand energy-independent transverse buckling of the $X Y$ model was chosen so that the XY and RZ models produced the same elgenvalue. The cross sections were generated using the ENDF/B-IV data base and the ETOE-II/MC $2-2 / S D X$ cross section processing codes, ${ }^{4-6}$ accounting for spatial and energy self-shielding.

\section{B. Generation of Atom Densities}

Atom densities for the analysis of the Phase III assembly wice generated from the standard ZPR materials inventory data. Heterogeneous or "plate" number densities represent the physical density of the plate materials and are used in the cross section shielding calculations. The homogeneous or "cell-averaged" atom densitles 1 isted in Table $I-1$ are used in the diffusion theory calculations. A set of "stretched plate" number densities were generated by assuming that all plates were stretched to the full height of the unit cel1, 2.175 in., for the calculation of directional diffusion coefficients. The stainless steel from the matrix tube top and bottom, drawer bottom, fuel plate cladding ends, etc., was distributed into the plates in the

*The attempt to experimentally determine the ${ }^{241} \mathrm{Pu}$ decay coefficient was abandoned when the digltal voltmeter that reads the experimental thermocouples falled. The replacement DVM, though compatible, was not intercalibrated with the initial unit, producing a discrete shift in the measured assembly temperature. 
one dimensional representation of the unit cell.7 In each set of atom densities, the trace elements $\mathrm{Cu}, \mathrm{P}, \mathrm{S}$ and $\mathrm{Co}$ were added to $\mathrm{Fe}$ while $\mathrm{C}, \mathrm{S} 1$ and $\mathrm{Al}$ were added to 0 .

Atom densities for the normal calandria core and axial blanket unit cells as well as the special calandria unit cells were also calculated using standard ZPR materials inventory data. The mean spectal calandria mass for the specific region was usei, and calculational techniques wore consistent with those used to generate plate atom densities. The resulting pin zone atom densities are listed in Table I-4 wh.ere it can be seen that only the atom densities for the components of stainless steel differ for the special versus normal calandria. For comparison, the atom densities for the Phase III zone I plate-geometry unit cell are also included in Table $\mathrm{I}-4$.

The composition match for the fissile and fertile isotopes in the plateloaded and pin-loaded core unit cells is quite good. The atom densities for the components of stainless steel show greater deviations but are, on the whole, well matched. The plutonium oxide/depleted uranium oxide rods do not contain molybdenum. The atom densities for the axial blanket region contain significant deviations for both the fertile and structural isotopes.

\section{Broad-group Cross Sections}

The 29 broad-group, flux-welghted cross section set for the Phase III analysis was generated from ENDF/B Version IV data using the ETOE-2/MC $2-2 / S D X$ cross-section processing codes. 4-6 The 226 fine-group base library input to the SDX calculations was intially generated by $M^{2}-2$ for the criticallybuckled, homogenized GCFR Phase I unit cell. An additional $\mathrm{MC}^{2}-2$ calculation for the stainless steel reflector was made to add energy self-shielded reflect.or cross sections to this base library. The thermal group cross sections represented ENDF/B version III rather than version IV data and were $2200 \mathrm{~m} / \mathrm{sec}$ values. The SDX calculations were set up to generate three types of broad-group cross sections -- "self-shielde1", "detector", and "plate."

1. "Self-shielded" cross sections include the effects of plate spatial self-shielding and resonance energy self-shielding in such a way that cellaveraged reaction rates are correctly predicted using a diffusion theory model in which the unit cell composition is homogenized.

2. "Detector" cross sections, which do not include the plate spatial" self-shielding effects, correctly predict infinitely-dilute, spatially-homogeneous detector reaction rates in the diffusion theory model.

3. "Plate" cross sections are used in the generation of Benoist anisotropic diffusion coefficients.

Radial and axial (one dimensional) SDX calculations produced broadgroup cross sections for each unit cell composition collapsed over appropriate asymptotic and/or transition fine-group spectra. The twelve unit cell compositions and assoctated alphanumeric labels are: 


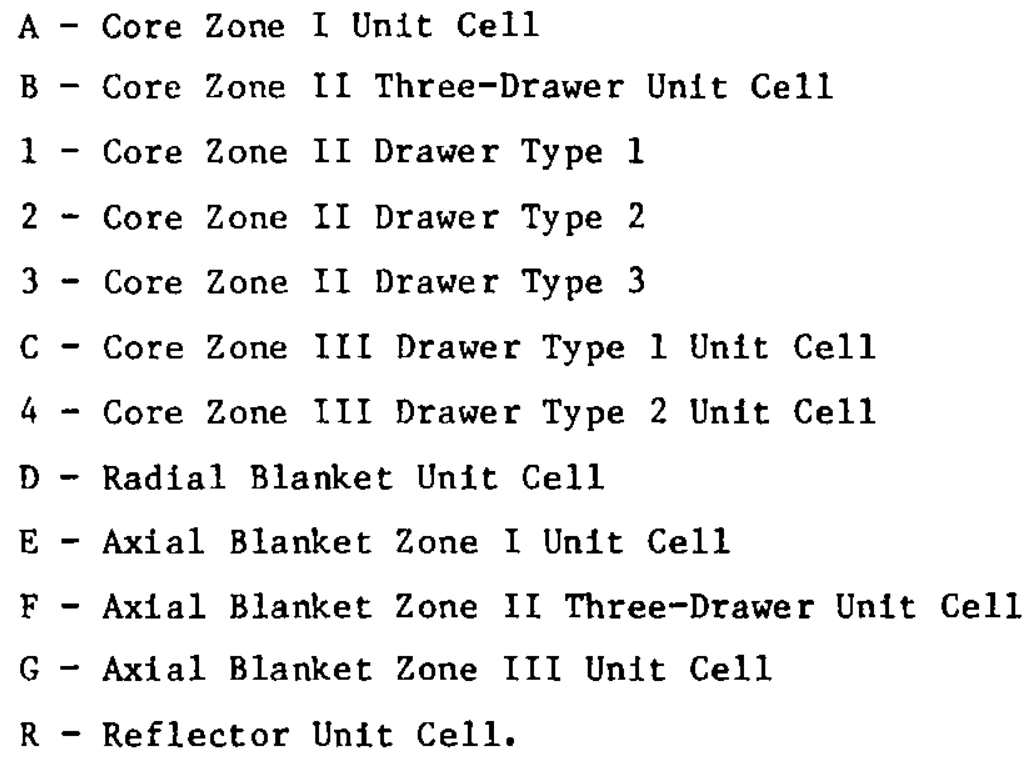

The core and axial blanket zone II three-drawer unit cells were the models developed for the Phase II analysis. The eleven spectrum-collapse regions and associated alphanumeric labels are:

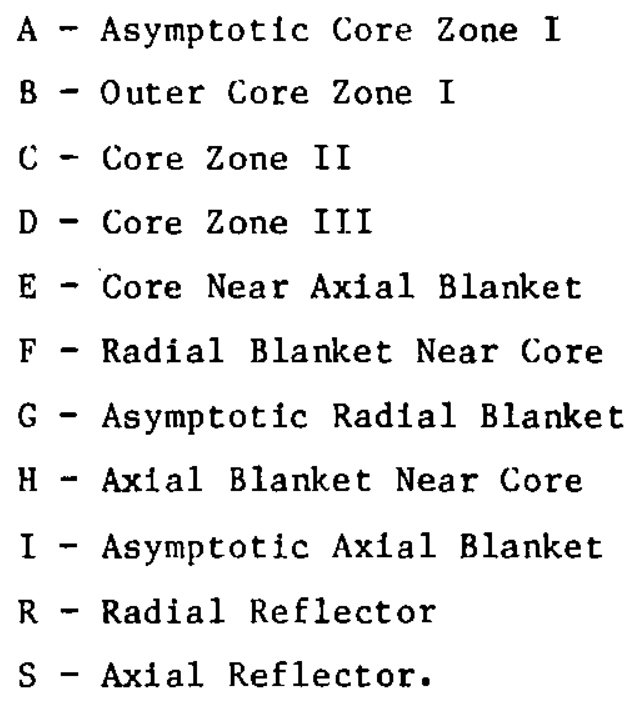

The broad-group energy/lethargy structure, the same as used in both the Phase I and Phase II analyses, is tabulated in Table II-1.

"Self-shielded" and "detector" cross sections were generated for each 1sotope in the unlt cell composition in each appropriate spectrum-collapse region. "Detector" cross sections were also generated for Infinftely-dilute, spatially-uniform "trace" 1sotopes in each core and blanket unit cell composition and associated spectrum-collapse region. The trace 1sotopes were:

$\begin{array}{lcrl}\mathrm{H} & { }^{9} \mathrm{Be} & 23 \mathrm{Na} & 181_{\mathrm{Ta}} \\ { }^{3} \mathrm{He} & 10 \mathrm{~B} & \mathrm{S1} & 232 \mathrm{Th} \\ { }^{4} \mathrm{He} & 11_{\mathrm{B}} & 27 \mathrm{Al} & 233_{\mathrm{U}} \\ { }^{6} \mathrm{LI} & 12 \mathrm{C} & 151_{\mathrm{Eu}} & 234_{\mathrm{U}} \\ { }^{7} \mathrm{LI} & 14 \mathrm{~N} & 153_{\mathrm{Eu}} & 236 \mathrm{U} .\end{array}$


The five principle plutonium 1sotopes plus ${ }^{241} \mathrm{Am}$ and Mo were 1ncluded as trace elements in the radial and axial blanket regions. "Plate" cross sections were calculated only for the heavy metal plates in each unit cell of the assembly and for the isotopes $239 \mathrm{Pu}, 240 \mathrm{Pu}, 241 \mathrm{Pu}, 241 \mathrm{Am}, 235 \mathrm{U}$, and ${ }^{238} \mathrm{U}$.

Cross sections for the pin zone were generated with ENDF/B-IV data using the standard processing codes described above. An axial SDX calculation produced broad-group cross sections for the core and axial blanket spectal calandria unit cells collapsed over asymptotic and transition spectra. The four unit cel1, spectrum-collapse regtons are:

PA - Special Calandria Asymptotic Core

PE - Special Calandria Core Near Axial Blanket

QH - Special Calandria Axial Blanket Near Core

QI - Special Calandria Asymptotic Axial Blanket,

where the unt cell composition labels are defined as

$$
\begin{aligned}
& \text { P - Special Calandria Core Unit Cell } \\
& \text { Q - Special Calandria Axial Blanket Unit Ce11. }
\end{aligned}
$$

\section{Benolst Antsotropic Diffusion Coefficients}

In $Z P R$ assemblies of a gas cooled fast reactor design, the coolant channels are simulated with air-filled "void cans." Within a given untt cell these "vold cans" align to form essentially-voided vertical planes that pass axially through the unit cell (see Figs. I-9 to I-15). The existence of these streaming paths required the use of anisotropic diffusion coefficients. Energy-dependent Benolst modifiers ${ }^{8}$ were generated for directions parallel, $M_{\mid}$, and perpendicular, $i_{j}$, to the streaming channels. Using the normal isotroplc diffusion coefficient, $1 / 3 \Sigma_{t r}$, and the Benoist modifiers, the anisotropic diffusion coefficients for directions parallel to the void slots are

$$
D_{\| l}=M_{\|} / 3 \Sigma_{t r}
$$

and for the direction perpendicular to the slots are

$$
D_{\perp}=M_{\perp} / 3 \Sigma_{t r}
$$

In $\mathrm{RZ}$ geometry diffusion theory models, the radial direction coefficlents are taken to be the average of the two directions,

$$
D_{R}=\left(M_{\perp}+M_{1}\right) / 6 \Sigma_{t r}
$$


The broad-group Benoist modiflers were generated for seven plate-loaded unit cel1, spectrum-collapse region combinations:

\author{
AA - Asymptotic Core Zone I Unit Cel1 \\ BC - Core Zone II Three-Drawer Unft Cel1 \\ CD - Core Zone III Drawer Type I Unit Ce11 \\ DG - Asymptotic Radial Blanket Unit Cell \\ EI - Asymptotic Axial Blanket Zone I Unit Cell \\ FI - Asymptotic Axial Blanket Zone II Unit Cell \\ GI - Asymptotic Axial Blanket Zone III Unit Cell.
}

The two-character alphanumeric label indicates, respectively, the unit cell composition and the spectrum-collapse region. Although generated for a specific collapse region within the unit cell, the resulting anisotropic diffusion coefficlents were applied to the entire zone or region. The 29-group Benolst modifiers, $M_{\uparrow}$ and $M_{\perp}$, are listed for each plate zone or region in Tables II-2 and II-3.

Broad-group Benoist diffusion coefficient modifiers were generated for the special calandria asymptotic core (PA) and axial blanket (QI) regions. The $z$ one I plate- and pin-geonttry Benolst modifiers, $M_{Z}$ and $M_{R}$ are tabulated in Table II-4. A much smaller degree of anisotropy in the diffusion coefficients is evidenced for the pin case.

E. The RZ Model and the Elgenvalue of the Reference Configuration

The cylindrical version of the Phase III plate-loaded reference configuration given in Fig. I-2 was represented for calculational purposes by the RZ model shown in FIg. II-1. The solid lines, other than the $R$ and $Z$ axes, indicate composition boundaries. The dashed lines distinguish the spectrumcollapse regions within a given composition. A two-character label identifies each area. The first character indicates the unit cell composition, r.nd the second, the spectrum-collapse region -- both according to the labeling convention defined above. A mesh spacing of approximately $2 \mathrm{~cm}$ was maintained in the core and blanket regions in both the $R$ and $Z$ directions. A homogenized matrix tube composition, MT, filled the remalnder of the cylindrical assembly except for the region behind the radial blanket. In this region the drawer and additional stainless steel that are required to position the back 12 in. of the radial blanket is included in the composition labeled $\mathrm{MT}^{-\infty}$. Logarithmic boundary conditions, with an extrapolation distance of $0.71^{\star} \lambda_{t r}$ were applied to the $R$ and $Z$ exterfor boundaries, and symmetry required that zero-current boundary conditions be used at the $R$ and $Z$ axes.

The three-drawer unit cell cross sections were used in the zone II core and axial blanket regions. Core zone III used the broad-group cross sections for the type 1 drawer, but the composition was the drawer-weighted average for the zone as reported in Table I-1. Reflector cross sections were used in the matrix tube regions. 
The anisotropic diffusion coefficlents in the $Z$ direction were the products of the 1sotropic D's and the Benolst mult1pliers, $M_{\|}$, for the appropriate region and broad group. The anisotropic diffusion coefficients in the $R$ direction were the products of the 1sotropic $D^{\prime} s$ and the average of the appropriate Benolst multipliers in the parallel and perpendicular directions, that is, $\left(M_{\|}+M_{\perp}\right) / 2$. Isotropic diffusion coefficients were used in both the reflector and matrix tube regions.

The Phase III efgenvalue calculated using the RZ model with Benotst anisotropic diffusion coefficients is 0.9856 . Using isotropic diffusion coefficients in the RZ model produced an elgenvalue of 0.9990 , corresponding to a $\delta k$ due to streaming of $-1.34 \%$. The RZ calculations of the GCFR Phase II reflected assembly ${ }^{2}$ produced a with-streaming elgenvalue of 0.9994 and a $\delta \mathrm{k}$ due to streaming of $-1.53 \%$. Although the $\delta \mathrm{k}^{\prime} \mathrm{s}$ due to streaming are in reasonable agreement for the two assemblies, the Phase III elgenvalue has a rather large negative blas relative to that for Phase II. The following possible sources of the bias were investigated:

a) disruption of the vertical streaming paths at zone and region boundaries,

b) selection of reflector cross sections,

c) reflection from ZPR structural material, and

d) arrangement of transition regions in the RZ model.

The results are discussed below.

As pointed out in the description of the Phase III reference assembly and as illustrated in Fig. I-8, the vertical streaming paths are disrupted at zone interfaces, requiring a decrease in the radicil anisotropic diffusion coefficients. Although the decrease in the radial Benoist multipliers cannot be calculated, the upper limit on the magnitude of this effect can be established by assuming isotropic diffusion coefficients in the radial direction for all regions in the assembly. The eigenvalue calculated using the RZ model with axial streaming only is 0.9916 , corresponding to a $\delta \mathrm{k}$ due to axial streaming of $-0.74 \%$; the $\delta k$ due to radial streaming 1 s therefore $-0.60 \%$. Consequently, the increase in $k_{e f f}$ due to the disruption of the vertical streaming paths at all zone or region boundaries in the assembly must be less than $0.60 \%$. Since the physical decrease in radial streaming is greater in the narrower zones, the impact on $k_{e f f}$ was computed for zones II and III Individually. Using an $\mathrm{RZ}$ model with 1sotropic radial diffusion coefficients in the zone II core and axial blanket produced a $\delta k$ due to radial streaming in zone II of $0.17 \%$. Simflarly, a $\delta k$ due to radial streaming in zone III was calculated as $0.15 \%$.

The use of asymptotic blankel cross sections in the reflector regions, rather than the specifically-generated reflector cross sections, increased $k_{\text {eff }}$ by $0.09 \%$. Blanket cross sections have normally been used in the reflector regions for previous GCFR analyses. 
Reflection from the radial and axial ZPR structural components, most notably the bed and knees, was scoped by filling the unoccupled regions of the assembly with reflector composition. This corresponded to a $160 \% 1 \mathrm{n}$ crease in the thickness of the radial reflector and a $100 \%$ increase in that of the axial reflector. The change in the eigenvalue was $0.14 \%$, with the radial portion of this increased reflector accounting for $0.09 \%$.

The arrangement of the core zone I transition regions were altered such that the outer core zone I (regton AB In Fig. II-1) extended the full $61 \mathrm{~cm}$ half-height of the co:e rather than only $40 \mathrm{~cm}$. Consequently, the zone I core-near-axial-blanket (AE) region was located only behind the asymptotic core zone $I$ (AA). No change $(0.00 \%)$ in $k_{\text {eff }}$ was calculated. In summary, none of these model variations produced a significant change in keff

F. K1net1cs Parameters and the $241 \mathrm{Pu}$ Decay Coefficient

The GCFR Phase III kinetics parameters were generated using the RZ model for the three streaming cases introduced above -- with streaming, with axial streaning, and without streaming. The values are summarized in Table II-5. The delayed neutron fractions, expressed as a function of family and isotope, and the effective decay constants are reported for the with-streaming case in Table II-6. The decay constants are given in Table II-7 as a function of family and isotope.

The ${ }^{241} \mathrm{Pu}$ decay coefficient for Phase III was calculated using the withstreaming $\mathrm{RZ}$ model of the reference assembly. For each zone the $241 \mathrm{Pu}$ atom densities were decreased by $1 \%$, this decrease being added to the ${ }^{241}$ Am atom densities. Using the 14.5 year half-life for $241 \mathrm{Pu}$, a $1 \%$ decay corresponds to 76.8 days. The decrease in the eigenvalue associated with these changes in compositions was $0.0099 \%$, with a $k_{\text {eff }}$ convergence criterion for each $\mathrm{RZ}$ calculation of $0.0001 \%$. The resulting calculated $241 \mathrm{Pu}$ decay coefficient was $0.12 \mathrm{Ih} /$ day. Since the data avallable on the materials library inventory as given in Table $I-1$ reflect the plutonium isotoplc concentrations on $7 / 1 / 75$, the $241 \mathrm{Pu}$ number densities in the physical reference assembly $(7 / 1 / 76)$ a re approximately $5 \%$ less than the values used in the analysis. The calculated $241 \mathrm{Pu}$ decay coefficient can be used to adjust the value of $k_{\mathrm{eff}}$ computed for the $\mathrm{RZ}$ model to more accurately reflect the composition on the day the reference assembly was defined. This adjustment to the calculated $\mathrm{k}_{\mathrm{eff}}$ was $0.05 \%$ - on the order of the $\delta \mathrm{k}$ 's associated with the model variations discussed above.

\section{G. The RZ Mode1 and E1genvalue of the PIn-Loaded Reference Configuration}

The RZ calculational model of the GCFR Phase III pin zone reference configuration is given in Fig. II-2. The two-character alphanumeric label Identifies each area according to the notation defined above. The solid 11nes, other than the $R$ and $Z$ axes, Indicate composition boundaries. The dashed 11 nes distinguish the spectrum collapse regions within a given composition. The pin $z$ one, as indicated by the dotted/dashed 1 ine, is composed of the central $5 \times 5$ special calandria zone and the outer 60-drawer-per-half normal calandria zone. The pin zone cross sections, though collapsed speciflcally for the special calandria composition, were also used in the normal calanc'ria zone. However, the number densities in the two zones represent the actual special or normal 
calandria values. In addition, the Benolst diffusion coeffictent modifiers generated for the special calandria asymptotic core and axial blanket untt cells were also applied to the special calandria transition regions and to the normal calandria asymptotic and transition regions.

Other zones of the RZ calculational model are identical to those of the plate-geometry reference configuration model, except for the zone III/radial blanket boundary which has been reduced to reflect the removal of two edge core drawers per half. A mesh spacing of approximately $2 \mathrm{~cm}$ was malntained In the core and blanket regions in both the $R$ and $Z$ directions. Logarithmic boundary conditions, with an extrapolation distance of $0.71 * \lambda_{t r}$, were ap.)lied to the $R$ and $Z$ exterior boundaries. Symmetry required that zero current boundary conditions be used at the $R$ and $Z$ axes.

The eigenvalue for the $\mathrm{RZ}$ model of the pin zone reference configuration, calculated using 29-group diffusion theory with Benoist diffusion coefficients, was 0.98455 . The use of Isotropic diffusion coefficients in the pin zone only produced an eigenvalue of 0.98511 , or a $\delta k$ due to streaming in the pin zone of $-0.056 \%$.

H. The XY Model of the P1ate-Loaded Reference Configuration

The matrix loading configuration for the Phase III reference assembly given in Fig. I-1 was represented for calculational purposes by the quartercore XY model shown in Fig. II-3. As with the RZ model, a two-character alphanumeric label identifles each area. The first identifies the unft cell composition, and the second the spectrum-collapse region, both according to the labeling convention given above. A cross-sectional area equivalent drawer loading pattern was defined for the asymptotic core zone I and asymptotic radial blanket region. A homogeneous matrix tube composition filled the unoccupied assembly perimeter. The mesh spacings in both the $X$ and $Y$ directions are precisely two mesh points per drawer. Logarithmic boundary conditions, with an extrapolation distance of $0.71 * \lambda_{t r}$, were applied to the $\mathrm{X}$ and $\mathrm{Y}$ exterior boundaries. Symmetry required that zero-current boundary conditions be used at the $\mathrm{X}$ and $\mathrm{Y}$ axes.

The asymmetric three-drawer loading pattern in zone II does not destroy the quarter-core symmetry of the XY model since the three-drawer unlt cell cross sections are used for each drawer type in the zone and since an equal number of each drawer type is present. The three core drawer types in zone III are represented by two cross section sets -- one each for types 1 and 2 . The set generated for drawer type 1 is also applied to drawer type 3 (see Section I.B). However, the number densities assigned to each drawer type are the values computed for the specific composition. Reflector cross sections were used in the matrix tube region.

The anisotropic diffusion coefficlents in the $X$ direction were the products of the lsotropic $D^{\prime} s$ and the Benoist multipliers $M_{\perp}$; those in the $Y$ direction were the products of the isotropic $D^{\prime}$ 's and $M_{1}$. Isotropic diffusion coefficients were used in both the reflector and matrix tube regions. 
The space- and energy-independent $t$ ? $\mathrm{cm}^{-2}$, corresponding to an extrapolated $h$. so that the elgenvalue for the XY model would agree with that for the RZ model.

The $X Y$ model calculations were used in analyses of the foil reaction rate and small sample reactivity worth traverses to be described in subsequent sections.

I. Comparison of Plate and Pin Geometry Eigenvalues and Streaming Corrections

As reported above, the eigenvalue for the pin zone reference configuration, computed using Benoist diffusion coefficients in all core and blanket regions, was 0.98455 . The $\delta k$ due to streaming in the pin zone, computed using isotropic diffusion coefficients in the central pin zone, was $-0.056 \%$.

The $R Z$ calculational model of the Phase III plate reference configuration was modified in order to compute the corresponding $\delta^{k}$ due to streaming in plate geometry; the modified $\mathrm{RZ}$ model is shown in Fig. II-4. The radius of the asymptotic core zone $\mathrm{I}$, region $\mathrm{AA}$, was increased to equal that of the pin zone. The two areas labeled $A E$ are identical in both cross sections and number densities, but can be assigned different sets of diffusion coefficients. This also applies to the areas labeled EH and EI. The plate reference eigenvalue with Benolst diffusion coefficients in all core and blanket regions was 0.98564 . Inserting isotropic diffusion coefficients in the central zone yielded an eigenvalue of 0.98753 , corresponding to a $\delta k$ due to streaming in the plate-geometry central zone of $-0.189 \%$.

The calculated streaming in the pin zone 1 s $30 \%$ of the value calculated for an equivalent plate-geometry zone. The results of the calculations on the plate and pin zone reference configurations are summarized in Table II-8.

In order to compare the calculated and experimental $\delta \mathrm{k}$ for the plateto-pin conversion of the central zone, all differences between the two reference configurations must be accounted for. The two differences between the plate reference configuration and pin zone reference configuration, other than the central zone itself, were:

1. the absence of the zone III drawers $S / M-12 / 17$ and $-34 / 17$ in the pin zone reference configuration and

2. the change in $241 \mathrm{Pu}$ and $241 \mathrm{Am}$ atom densities due to $241 \mathrm{Pu} \mathrm{B}^{-}$ decay.

Consider the experimental determination of the $\delta \mathrm{k}$ for the plate-to-pin conversion outlined in Table II-9. The excess reactivity of the plate reference configuration, ZPR-9 Loading $45 / 1$, was measured on $8 / 18 / 76$ to be $193.1 \pm 2.2 \mathrm{Ih} *$ at $25^{\circ} \mathrm{C}$. Th1s is step 1 of Table II-9. The excess reactivity of the pin zone reference configuration, $L 48 / 1$, was measured on $8 / 28 / 76$ to be $12.6 \pm 1.2$ Ih at $25^{\circ} \mathrm{C}$. This is step 5 of Table II-9.

*The matrix conf Iguration for the plate reference, loading 45/1, is Identical to that established for the GCFR Phase III reference configuration of Section I. The difference in the measured excess is attributed to $241 \mathrm{Pu} \beta^{-}$decay, no intercalibration of the replacement thermocouple DVM, and possible minor variations in the individual plate loadings. 
The operationally-motivated differences between the two reference configurations (edge dxawer configuration and ${ }^{241} \mathrm{Pu}$ decay) can be corrected through the use of the Phase III operational measurements. The reactivity associated with the two zone III core-plus-axial-blanket drawers per half is four times the operational value of the edge drawer worth, $36.94 \pm 0.28 \mathrm{Ih} / \mathrm{drawer}$ (Step 2 of Table II-9). The four drawers in question constituted half of the drawers removed for the edge drawer worth measurement (the other half were the symmetrically located zone III drawers) and as such remove possible syscematics in the measured value.

The reactivity change due to ${ }^{24} \mathrm{l} \mathrm{Pu}$ decay during the nine-day interval between the reference configurations is nine times the calculated ${ }^{24}{ }^{1} \mathrm{Pu}$ decay coefficient, $-0.12 \pm 0.01$ Ih/day (Step 3 of Table II-9).

The results of the adjustments yield a hypothetical reactor existing on $8 / 27 / 76$ which is the pin zone reference configuration just before the replacement of plates by pins (Step 4 of Table II-9). Its excess at $25^{\circ} \mathrm{C}$ is $4 \frac{4}{4} \pm 2.5 \mathrm{Ih}$. The difference between this and the excess $(+12.6 \pm 1.2 \mathrm{Ih})$ of the pin zone is the reactivity change caused by the pin-for-plate replacement in the zone (Step 6 of Table II-9), $-31.7 \pm 2.8 \mathrm{Ih}$.

This pin-for-plate replacement worth consisted of three components:

a. the worth due to different zone-averaged compositions between the plate and pin zones,

b. the worth due to the different heterogeneity effects of the plate and relatively more homogeneous pin unfi -ells, and

c. the worth due to the different streaming effects in the plate and pin unit cells.

While these individual components could not be measured, they can be calculated along with the net result of the pin-for-plate replacement. The calculational sequence is outlined in Table II-10 and makes use of the computed eigenvalues displayed in Table II-1l.

Starting with the plate reference core whose $k_{\text {eff }}=0.98564$, the components of a pin-for-plate replacement in the plate reference core are:

$$
\begin{array}{ll}
\text { composition change } & +157.80 \mathrm{Ih} \\
\text { he terogeneity change } & -250.96 \mathrm{Ih} \\
\text { streaming change } & +122.63 \mathrm{Ih} \\
\hline \multicolumn{1}{c}{\text { net change }} & +29.47 \mathrm{Ih} .
\end{array}
$$

These components were computed for the plate reference core outer boundary, but are expected to apply as well to the pin reference core outer boundary. Both the plate and pin zone models had $241 \mathrm{Pu}$ atom densities adjusted to the same date, $7 / 1 / 75$, so that no correction was required for ${ }^{24}{ }^{\mathrm{Pu}} \mathrm{B}^{-}$decay in this comparison of calculations. 
Thus, comparing the calculated and measured pin-for-plate replacement worth, it is seen that the calculation slightly overpredicts the net result.

$$
\begin{array}{lll}
\text { calculated (C) }+29.47 & \text { Ih } \\
\text { measured } & (\mathrm{E}) \frac{-31.7 \pm 2.8 \mathrm{Ih}}{\mathrm{C}-\mathrm{E}} & \frac{61.2 \pm 2.8 \mathrm{Ih}}{(0.0006 \Delta \mathrm{k}) .}
\end{array}
$$

In view of the fact that the individual components are two to three times this value, the calculational prediction is taken to be quite good. At present, it is not possible to further determine which of the components is in error.

The data in Table II-11 permit a calculational determination of the edge drawer worth for the pin zone reference core. This computation is shown (Step 6) in Table II-10. The $\mathrm{C} / \mathrm{E}$ value for edge drawer worth is found to be 0.90 , and the $\mathrm{C}-\mathrm{E}$ is $-15.13 \mathrm{Ih}$.

\section{J. Summary}

In summary, the critical mass of the GCFR Phase III plate-loaded reference assembly is $888.1 \pm 0.2 \mathrm{~kg}$ with an excess reactivity of $214.5 \pm 1.7 \mathrm{Ih}$. This reactivity value includes corrections for the assembly temperature and the source subcriticality, but does not include edge-smoothing effects of the zone/region interfaces. The eigenvalue of the reference assembly calculated using 29-group diffusion theory with Benoist anisotropic diffusion coefficients is 0.9856 with a $\delta k$ due to streaming of $-1.34 \%$.

The calculated eigenvalue of the pin zone reference configuration is 0.98455 , with a $\delta k$ due to streaming in the pin zone of $-0.056 \%$.

The change in eigenvalue for the plate-to-pin conversion of the central zone is the sum of the following competing processes:

1) the $\delta k$ due to the compositional changes in the zone,

2) the $\delta k_{\infty}$ due to the conversion from plate-to-pin, and the resulting change in spatial plate/pin and energy resonance self shielding, and

3) the change in leakage probability due to the different streaming characteristics of plate versus pin geometry.

The magnitudes of each of these effects are several tenths of a percent in $\Delta k / k$, and the algebraic sum of these positive and negative contributions has been shown to agree with experiment to within $0.06 \% \Delta \mathrm{k} / \mathrm{k}$. 


\section{I. SMALL SAMPLE WORTHS}

\section{A. Introduction}

Central reactivity worths and radial reactivity worth traverses were measured in the Phase III plate-loaded assembly. The measurements of the worths were made using the sample-oscillation, reactivity difference technique. In order to examine in detail the worths of materials in a spectrum characteristic of the zone I composition, central reactivity worths were measured for a variety of fissile and fertile isotopes, for scattering, structural and control materials, and simulated steam. Reactivity worth traverse data were accumulated in each of the three core zones and in the radial blanket region. In addition, radial reactivity worth traverses were conducted for ${ }^{6} \mathrm{~L} 1$ and ${ }^{252} \mathrm{Cf}$ in order to determine the central core conversion ratio ( see Section $\mathrm{V}$ ).

\section{B. Assembly Configuration}

The basic matrix loading configuration for these measurements was the GCFR Phase III plate-loaded reference assembly described in Section I. This reference loading was modified to include the following: (1) the radial insertion hole for the sample changer traverse tube, (2) the fine autorod (FAR), and (3) adjustments to the core zone III/radial blanket interface.

To accommodate the sample changer traverse tube, spectally-drilled drawers and materlals were loaded into the stationary half of the assembly along row 23, from columns 21 through 43. Although drilled iron oxide plates, depleted urani um oxide plates and stainless steel void cans were loaded into the drawers in these matrix locations, drilled fuel plates were not available. Consequently, no fuel material was loaded into the fuel columns adjacent to the sample changer traverse tube from the axial distances of 1 inch to 3 inches from the assembly midplane. Stainless steel void frames were placed in the fuel columns at 1 to 3 inches to position the remaining fuel plates. The resulting radial insertion hole was $1-1 / 4$ inches in diameter and was vertically centered in row $23,1-3 / 4$ inches axially from the assembly midplane. The zone II, type 2 drawe rs in $\mathrm{S} / \mathrm{M}-23 / 14$ we re removed and the fine autorod (FAR) Installed in this 10cation. To compensate for the reactivity losses accompanying these modifications to the reference assembly, two radial blanket drawers at the core zone III/radial blanket interface $(S / M-14 / 32)$ were replaced with zone III, type 1 fuel drawers.

The resulting small sample reactivity worth experimental matrix configuration, shown in Fig. III-1, had an excess of approximately 120 Ih at $25^{\circ} \mathrm{C}$. The control rod configuration during the measurement was as follows: the dual-bladed boron rod at $\mathrm{M}-30 / 22-24$ was parked at approximately $60 \%$ out and the DP rod at $s-16 / 29$, being used for control, was positioned near 50 to $55 \mathrm{~cm}$ ( $60 \mathrm{~cm}$ is the nominal full-out position.) 
C. Experimental Methods

The worths of the sample capsules and the associated dumy (empty) capsules and capsule holders (rabbtts) were measured using the sampleoscillation, reactivity difference technique. With this technique the reactivity difference (worth) is obtained by noting the change in the mean equilibrium position of a calibrated autorod as an encapsulated sample is pneumatically oscillated radially in and out of the assembly. The detailed experimental procedure for measuring sample worths has been documented previous $1 y \cdot 1-3$

The samples used in the GCFR Phase III series of worth measurements are described in Tables III-1 and III-2.

The FAR was calibrated using both the oscillation and single-pass techniques, as discussed in Ref. 1. From the oscillation technique, the mean total linear worth of the FAR was measured to be $4.966 \pm 0.010$ Ih. The total linear worth is twice the coeffictent of the first order Legendre polynomial resulting from a least squares fit of the FAR worth vs. position data.

The experimental data and reduced data are presented in Tables III-3 through III-6.

\section{Calculationa 1 Methods}

The central reactivity worths and radial reactivity worth traverses were calculated using the RZ and XY models, respectively, of the GCFR Phase III reference assembly. The fluxes and adjoints were generated as described in Section II, and the worths were then calculated using first order perturbation theory with the detector cross sections which simulate an infinitely dilute sample spanning the unit cell. Details of these models and of the cross section preparation are given in Section II. Note that the standard ARC processing codes use $f l u x$-weighting rather than billnear-weighting for cross section collapse. No sample size correction factors were applied.

Sample and isotopic central worths were calculated using first order perturbation theory and a 29-group RZ diffusion theory model of the reference assembly. The sample compositions used in the calculations are reported in Table III-2. The calculated sample central worths are listed in Table III-7. These calculated central worths correspond to the worths at the central mesh point which extends radially from 0.00 to $2.12 \mathrm{~cm}$ and axially from 0.00 to $2.00 \mathrm{~cm}$. Sample reactivity worths were also calculated at the radiallycentered mesh point extending axially from 4.00 to $6.00 \mathrm{~cm}$ since sample worths are actually measured $4.45 \mathrm{~cm}$ axially from the assembly midplane. The percentage deviations of the worths at this mesh point from that at the central mesh point are given in parentheses beside the calculated value in Table III-7. For all fissile and absorbing materials, whose worth curves behave essentially as cosine squared, these deviations are on the order of -0.8 to $-0.9 \%$. For all scattering materials, the axial worth distribution falls of $f$ more rapidly and the deviations vary from -1.0 to $-1.8 \%$.

The 1sotopic central worths, Issted in Table III-8 by increasing atomic number, were calculated at the central mesh point for every isotope for which 
infinitely dilute detector cross sections were avallable. Because of the lack. of available experimental values for the worths of the minor 1sotopes and elements in the reactivity samples, no determination of the 1sotopic or elemental reactivity worths was attempted by the unfolding of experimental data. Previous experience ${ }^{1-3}$ has shown that, for the samples measured in the GCFR assemblies, the isotopic and elemental C/E's are in precise agreement with the sample $\mathrm{C} / \mathrm{E}$ for the corresponding reactivity sample (oily the ${ }^{240} \mathrm{Pu} \mathrm{C} / \mathrm{E}$ deviates from this behavior*). Consequently, the C/E's in Table III-8 are the $C / E$ 's of the smallest sample for which the specifled isotope or element is the predominant component.

Radial reactivity worth traverses were salculated using first order perturbation theory and a 29-group XY diffusion theory model of the reference assembly. The calculated worth distributions, normalized to the calculated $\mathrm{RZ}$ worth at the central mesh point, are presented in Tables III-9 through III-12. These calculated distributions renormalized to 1.00 at the central mesh point, are plotted in Figs. III-2 through III-8. A cubic spline interpolation routine was used to remove the piece-wise appearance of the calculated curve. For XY model calculations, the axial displacement of the samples from the assembly midplane requires that the worths be integrated over a transverse integration half-height. Assuming that the shape of the axial worth distribution is given by a cosine squared $f$ unction, the transverse integration half-height $(T)$ was selected such that the average of the cosine squared from 0 to $T$ was equal to the value of the cosine squared at the axial position of the sample (S). This condition is approximated by the relation $T=\sqrt{3} \mathrm{~S}$. For GCFR Phase III, this technique reduces the calculated midplane $(Z=0)$ worths by a factor of 0.9921 . All points in the radial traverse were calculated in this manner. For $\mathrm{CH}_{2}, \mathrm{SST}$, and ${ }^{238} \mathrm{U}$, the assumption of a cosine squared axial worth distribution is less applicable, (see Ref, 2 or Table III-7) and consequently, the absolute value of these central worths calculated with an XY model is more uncertain.

Given the adjustments discussed above in both the RZ and XY calculations in order to correct for the axially off-center position of the sampie in the central worth measurement, there remains a discrepancy in the central worths calculated using the $\mathrm{XY}$ and $\mathrm{RZ}$ models. For all samples used in radial traverses, except $\mathrm{CH}_{2}(\mathrm{~F})-6$, the central worths calculated using the XY mode1 are $2-1 / 2$ to $3-1 / 2 \%$ larger than those calculated using the $\mathrm{RZ}$ model. For the fissile isotopes ${ }^{239} \mathrm{Pu}$ and ${ }^{235} \mathrm{U}$, the discrepancy is 3.12 and $3.11 \%$, respectively, and for the absorber isotopes ${ }^{10} \mathrm{~B}$ and ${ }^{6} \mathrm{~L} 1$, the discrepancy is 3.45 and $3.43 \%$, respectively. For all comparisons of calculated and experimental central worths, the RZ model risults are used. For all comparisons of the calculated and experimental reactivity worth traverses, the calculated traverse is normalized to the calculated $R Z$ worth at the central mesh point.

\section{E. Central Reactivity Worth Results}

The calculated and experimental central reactivity worths of the samples and the corresponding C/E's are summarized in Table III-7. To be consistent

*The ${ }^{240} \mathrm{Pu}$ sample is an oxide, $\mathrm{PuO}_{2}$, and the reduction to 1 sotopic $240 \mathrm{Pu}$ worth requires an experimental value of the oxygen worth which was not avaflable. 
with previous GCFR small sample reports ${ }^{1-3}$, the reported calculated central worths are the values obtained at the central RZ mesh point, with the deviations (see Section III.D) in the worths calculated at the approximate sample position given in parentheses. The effects of sample size and local environment are not included in the calculations. The uncertalnties associated with the $C / E^{\prime} s$ reflect only the uncertainties in the experimental values. The central $C / E^{\prime} s$ are typical of the observed central worth discrepancy - C/E's of $\sim 1.15$ to $\sim 1.20$ for fissile material, $\mathrm{C} / \mathrm{E}$ of 1.05 for ${ }^{10} \mathrm{~B}$, and $\mathrm{C} / \mathrm{E}^{\prime} \mathrm{s}$ of $\gtrsim 1.30$ for scatterers.

\section{F. Radial Reactivity Worth Traverse Results}

The calculated and experimental radial reactivity worth traverses and the corresponding C/E's and C-E's are summarized in Tables III-9 through III-12. The calculated spatial distributions of the worths were computed using an XY model and normalized at the central mesh point to the RZ central worth. Plots of the reactivity worth traverses are presented in Figs. III-2 through III-8, where the horizontal axis is the radial position of the sample with zone/region boundaries indicated, and the vertical axis is the normalized reactivity worth. These normalized, calculated and experimental traverses are computed for point $i$ by $C_{i} /\left|C_{o}\right|$ and $E_{i} /\left|E_{o}\right|$, respectively, where $C_{o}$ and $E_{o}$ are the values at the central point. With this normalization, each traverse has a magnitude of 1.0 at the central point. Due to the behavior of the experimental $\mathrm{CH}_{2}(\mathrm{~F})-6$ reactivity worth traverse, the normalization $\mathrm{E}_{i} / 1.20 / \mathrm{E}_{\mathrm{d}}$, corresponding to a magnitude of 0.1 at the center, is more appropriate.

Because of the plot normalization technique, neither the C/E ratio nor C-E difference is preserved. For example, the actual $\mathrm{C} / \mathrm{E}$ equals the apparent $\mathrm{C} / \mathrm{E}$ from the plot times the absolute value of the actual central $\mathrm{C} / \mathrm{E}$,

$$
\frac{C_{i}}{E_{i}}=\frac{\left|c_{o}\right|}{\left|E_{o}\right|} \times \frac{\left[c_{i} /\left|c_{o}\right|\right]}{\left[E_{1} /\left|E_{d}\right|\right]}
$$

where the quantities in brackets [] are the normalized reactivity worths and where the apparent $C / E$ is the ratio of the normalized quantities. In addition, the actul C-E is not directly proportional to the apparent C-E from the plot. One form of the relationship is given by

$$
c_{i}-E_{i}=\left|E_{0}\right|\left\{\left[C_{i} /\left|c_{0}\right|\right]-\left[E_{i}|| E_{0} \mid\right]+\left(\left[\left|c_{0}\right|\left|E_{0}\right|\right]-1\right) \times\left[c_{i}|| c_{0} \mid\right]\right\}
$$

where the apparent $C-E$ is the difference in the normalized quantities. In each case, the additional factor or term is required because the calculated and experimental traverses have distinct normalization factors, that is, because the absolute value of the central $\mathrm{C} / \mathrm{E},\left|\mathrm{C}_{\mathrm{o}}\right| /\left|\mathrm{E}_{\mathrm{o}}\right|$, is not 1.0 . Consequently, caution must be used in interpreting the plotted traverse data.

Table III-9 and Figs. III-2 and III-3 contain the reactivity worth distributions of the fissile samples, $M B-10(239 \mathrm{Pu})$ and $M B-21(235 \mathrm{U})$. For the ${ }^{239} \mathrm{Pu}$ sample, the $\mathrm{C} / \mathrm{E}$ increases approximately $3 \%$ from $1.16 \pm 0.01$ at the center to 1.1: \pm 0.01 midway through the traverse of core zone $I$ and decreases gradually to $1.06 \pm 0.07$ in the radial blanket region. For the $235 \mathrm{U}$ sample, the 
$C / E$ is nearly flat (within statistics) in the central region of core zone I and decreases gradually in the core region. In the radial blanket region, however, the $\mathrm{C} / \mathrm{E}$ drops to $0.93 \pm 0.03$, well below the corresponding $\mathrm{C} / \mathrm{E}$ for the ${ }^{239} \mathrm{Pu}$ sample. This systematic variation in the misprediction is also revealed in the normalized plots.

The calculated and experimental reactivity worth distributions of the fertile sample, MB-25 $(238 \mathrm{U})$, is presented in Table III-10 and Fig. III-4. The tabulated $C-E$ shows only slight spatial varlations, suggesting that the relative magnitude of the negative (positive) component of the worth is approximately uniformly overpredicted (underpredicted). A striking feature of the calculated distribution is that the worth is nearly zero throughout the entire radial blanket region.* In the earlier GCFR assemblies ${ }^{2} 2$ the normalized calculated reactivity worth became slightly positive $(\langle 0 .$.$) near the$ core/blanket boundary, decaying to zero in the radial blankêt region. In the present assembly, the calculated worth vanishes at the boundary and can therefore not decrease toward zero at larger radii.

The reactivity worth distributions of the structural sample, MB-19 (SST-304), are given in Table III-10 and Fig. III-5. In core zone I, the C/E, in general, increases slightly for increasing radius, although, except for the central point, the C-E decreases. These observations are not definitive since the magnitude of the uncertainties are comparable (within a factor of 2) to the magnitude of the variations. The plotted traverses and tabulated values indicate that the experimental central worth may be approximately $5 \%$ too large and that renormalization would improve the agreement in core $z$ one $I$. However, the quoted experimental central value is the mean of two independent measurements which differed by only $1-1 / 2 \%$. The poor $\mathrm{C} / \mathrm{E}$ values in the outer core zones and radial blanket ragion indicate the difficulties in calculating the relative magnitudes of the positive and negative components of the worth and, hence, the position at which the worth changes sign.

For both MB-25 $\left({ }^{238} \mathrm{U}\right)$ and $\mathrm{MB}-19(\mathrm{SST}-304)$, the $\mathrm{C}-\mathrm{E}$ is the largest in core zone II. The fact that the samples were centered in a type 3 drawer of the core zone II three-drawer unit cell is not considered in the analysis.

The calculated and experimental reactivity worth distributions of the absorber samples, B-7 $\left(10_{\mathrm{B}}\right)$ and $\mathrm{LI}-5\left({ }^{6} \mathrm{LI}\right)$, are presented in Table III-11 and Figs. III-6 and III-7. As is characteristic of pure absorbers, the agreement between calculations and experiments on radial shape is very good. The capture component of the central worth of B-7 is approximately $98 \%$ of the total worth, while for LI-5 it is approximately $95 \%$. The minor deviations in the $\mathrm{C} / \mathrm{E}$ comparisons for $\mathrm{B}-7$ in the core region may be related to the fact that the dumny used to measure the reactivity effects of the SST capsule and capsule holder was, for this traverse, not ideally matched to the actual capsule of the sample.

*Possible sources of calculational error have been investigated. The radial blanket detector cross sections (DDF and DDG) for $238 \mathrm{U}$ in the sample were replaced with the shielded cross sections for the blanket (SDF and SDG) and with the detector cross sections for core zone I (DAA) and produced essentially identical results. In addition, the ARC input has been checked and fr und to be correct. 
The results of the $\mathrm{CH}_{2}$ (F)-6 polyethylene foam measurements and analysis are presented in Table III-12 and Fig. III-8. The lack of agreement between the experimental and the calculated values may be attributable to the failure of first order perturbation theory to account for the large spectrum degradation resulting from even a $0.90 \mathrm{gm}\left(24.5 \mathrm{~cm}^{3}\right)$ sample of $\mathrm{CH}_{2}$ foam. From the graph, however, the shape of the calculated curve does qualitatively follow the change in experimental value.

G. Comparison of Results to GCFR Phase I

Comparison of GCFR Phase I and Phase III central worth results reveals a systematic bias in the central C/E discrepancy for these two similar unit cells. The central C/E values of major isotopes are listed in columns 3 and 4 of Table III-13. The tabulated values represent the $\mathrm{C} / \mathrm{E}^{\prime} \mathrm{s}$ for the same samples in each assembly, thus minimizing any problems associated with uncertainties in composition.

The major component of the discrepancy is associated with errors in the calculation of the perturbation denominator. Normalized C/E's, obtained by dividing a given $\mathrm{C} / \mathrm{E}$ by the $\mathrm{C} / \mathrm{E}$ for ${ }^{239} \mathrm{Pu}$, are the $\mathrm{C} / \mathrm{E}^{\prime} \mathrm{s}$ for the ratios of the perturbation numerators, and are not affected by calculational errors in the perturbation denominator. These normalized C/E's are reported in columns 5 and 6 of Table III-13. With the exception of the ${ }^{240} \mathrm{PuO}_{2}$ and SST samples, these normalized $\mathrm{C} / \mathrm{E}^{\prime} \mathrm{s}$ are in good agreement for Phases I and III (the uncertainty in the normalized $\mathrm{C} / \mathrm{E}$ of the ${ }^{238} \mathrm{U}$ sample is on the order of 0.05$)$.

An alternate approach to remove the calculational error in the perturbation denominator is to adjust the sample worth $\mathrm{C} / \mathrm{E}$ with the $\mathrm{C} / \mathrm{E}$ of the normalized perturbation denominator (its measurement is discussed in Section V). The $\mathrm{C} / \mathrm{E}$ for the ${ }^{252} \mathrm{Cf}$ measurement of the perturbation denominator in Phase I is $0.75^{\mathrm{l}}$ and for Phase III is 0.86 . These adjusted C/E's are given in columns 7 and 8 of Table III-13. The normalized and adjusted C/E's for Phase III are identical since a perturbation denominator $\mathrm{C} / \mathrm{E}$ of 0.86 removes the $\mathrm{C} / \mathrm{E}$ bias in the ${ }^{239} \mathrm{Pu}$ sample.

Discrepancies in the normalized $\mathrm{C} / \mathrm{E}$ values may be attributable to varying fissile enrichment in the unit cell -- the Phase III core zone I unit cell contains a 1/4-in. wide $\mathrm{U}_{3} \mathrm{O}_{8}$ column that was a void in the Phase $\mathrm{I}$ core unit cell. This change in the ${ }^{2}{ }^{8} \mathrm{U}$ density may produce a systematic change in the ability to calculate the adjoint flux. The deviations in the normalized $\mathrm{C} / \mathrm{E}$ may be due to errors in the calculated scattering component of the worth as is evidenced by the normalized $\mathrm{C} / \mathrm{E}$ of ${ }^{240} \mathrm{PuO}_{2}$ and SST (the scattering component of the ${ }^{240} \mathrm{PuO}_{2}$ sample is $\sim 20 \%$ of the total worth).

\section{REACTION RATE MEASUREMENTS}

Three fission rates $\left({ }^{239} \mathrm{Pu},{ }^{235} \mathrm{U}\right.$ and $\left.{ }^{238_{\mathrm{U}}}\right)$ were measured in a 2 -inch cubic cavity at the center of the Phase III assembly using Kirn-type fission counters. Cell-averaged reaction rates were determined at several locations in the core and blankets using foil irradiation techniques. Foil irradiations were also used to measure radial and axial reaction rate distributions ( $f^{49}$, 
$\mathrm{f}^{25}, \mathrm{f}^{28}$ and $\mathrm{c}^{28}$ ) through the core and blanket regions. The ZPR-9 configuration for all reaction rate measurements ts the reference assembly shown in Fig. I-1.

\section{A. Centra1 Fission Rate Measurements}

Absolute fission rates were measured for ${ }^{239} \mathrm{Pu},{ }^{235} \mathrm{U}$ and ${ }^{238} \mathrm{U}$ in a 2-inch cubic cavity at the center of the assembly (location $\mathrm{s}-23 / 23$ ) using a $5.1-\mathrm{cm}$ diameter Kirn-type fission counter. A second counter was positioned in drawer S-23/18 to normalize successive reactor runs. Figure IV-1 shows the position of the detector within the drawers. The front two inches of drawer materials are removed to accommodate the detector, with the fission source positioned $1.91 \mathrm{~cm}$ from the front of the drawer.

In the pin zone measurements, the calandria within the two counter drawers were moved back two inches from the midplane to accommodate the detectors.

Scaler count rate data were accumulated for each of the counters along with the energy spectrum of each. The fission counters register counts from fissions, proton-recoll events and alpha-particle emissions. Energy resolution is good enough to allow rejection of nearly all of the low energy nonfission events, but a small data correction is still applied.

To eliminate this small fraction of low-energy counts, the minimum or valley of the spectrum below the flssion events is found using an orthogonal polynomial fitting routine. The fitted data value, CTVL, at the valley channel, CHVL, is then extrapolated at constant value to channel zero, and a correction factor for the scaler data, $\alpha$, is found according to

$$
\alpha=\frac{\text { CHVL } * \text { CTVL }+ \text { TCAVL }}{\text { TOTAL }}
$$

where TCAVL is the sum of the counts in the spectrum above the valley channel and TOTAL is the sum of all counts in the spectrum. The correction $(1-\alpha)$ to the scaler data is normally less than $0.5 \%$.

Using the monitor counter, all fission rates are normalized to the same reactor power level. The compositions listed in Table IV-1 are then used to derive 1sotopic rates from which ratios are calculated. For those isotopes whose fission rates are not measured, a calculated ratio, e.g., $\mathrm{f}^{26 / f^{25}}$, $1 \mathrm{~s}$ used for isotopic corrections.

Table IV-2 11sts the measured and calculated 1sotopic reaction rate ratios for the plate-loaded core at the central detector position. These values are normalized to a monitor count rate of 500 counts/sec., corresponding to a power level of approximately 120 watts. Included in the table are the central measured and calculated ratios for the pin zone.

\section{B. Foll Data Analysis}

Analysis of foll data is the same for intra-cell measurements and reaction rate distributions. A series of computer codes process the data to produce a relative capture or f1ssion rate for each foll. The data are then used to derive the specific information which will be compared to calcilations, 
e.g., cell-averaged reaction rates or reaction rate distributions. The GCFR Phase III foil data was the first to be accumulated solely with new Ge(LI) detector-based sample changers, and was the first data analyzed with the new standard set of computer codes. Comparisons of reaction rate distributions measured in GCFR Phase II showed excellent agreement between the $\mathrm{NaI}$ and $\mathrm{Ge}(\mathrm{L} 1$ ) systems. Because of this change, the analysis methods are presented here in some detail.

After irradiation, the foils are removed from the reactor and placed in an automatic sample changer system. Using this computer-controlled system, each foil is positioned above a $\mathrm{Ge}(\mathrm{Li})$ detector, and a gamma-ray spectrum is collected for a preset time. The typlcal counting electronics (preamplifier, amplifier, pulse-height analyzer, ADC) are set to accumulate a 1024-channel energy spectrum over the energy range of 0 to $1024 \mathrm{keV}$. The spectrum from each foll is accumulated and stored on magnetic tape a minimum of four times, usually six to eight times.

Figure IV-2 shows a typical multichannel analyzer spectrum for a depleted uranium foil. Four fission product gamma-ray peaks and one capture product peak are labelled, and these are used to determine reaction rates. Using a computer code SKEWGAUS ${ }^{10}$, somewhat modified from the original version, each photopeak of interest is fitted to a multi-parameter function. This function takes the form of a skewed Gaussian peak shape, and has the capability to fit unresolved multiplets within a spectrum. The area of each peak is found by numerically integrating the fitted function describing that peak. Thus, the contributions from the interferring peaks are not included in the result, and the background under the peak is subtracted as part of the fit. Four peaks are used for fission rate analysis and one for capture in ${ }^{238} \mathrm{U}$. Table IV-3 lists the photopeaks used and pertinent information about these gamma-ray peaks.

Two methods are used to obtain final results from this peak area integration data, depending on whether the fission or capture rate is being analyzed. For capture rates, the area of the one peak is corrected for decay subsequent to the 1rradiation, deadtime and ccunting cycle length. The corrected counts for each pass of each foll are then examined for anomalous counts, averaged and normalized for the power history of the run. For fission rates, the same corrections are applied to the integrated areas and the results for each foll are averaged as for capture rate data. Then the results from each of the four fission product peaks are averaged together to form one fission rate for each foll.

In order to form reaction rate ratios or to make isotopic corrections, the fission and capture rates must be put on an absolute basis. Absolute capture rates in foils are determined by callbrating the detector system with a standard source of ${ }^{243} \mathrm{Am}$ for ${ }^{238} \mathrm{U}$ capture. Fission foil data are normalized to absolute fission counter results. During the foll irradiation, a KIrn-type counter (the same type used In the central rate measurements) was placed in matrix location S-23/18 with two folls of the appropriate type (plutoni um, enriched or depleted uranium, depending upon the folls being Irradiated) on the face of the counter. The folls are in the same environment as the source on the $\mathrm{KI}$ rn counter, and should measure the same absolute rates as the fission counters. Thus, to get. a normalization factor for each type of foll, the average value of the relative rates of each pair of folls on the 
counter is equated to the absolute fission counter results. Isotopic compositions are accounted for, and the small change in spectral indices between the core center and the moni:or counter location is also factored into the no rmalization.

This normalization technique assumes only that the folls placed on the front of the counter react to the same flux as the counter itself. While the detector cavity does perturb the local flux, no assumption is made that the detector samples a unit cell-averaged reaction rate or any drawer-averaged rate. Measurements of fission rates with and without the folls in place show that the folls do not affect the fission rate in the counter for non-threshold fissioning isotopes. Similarly, measurements of the ${ }^{238_{U}}$ capture rate in the counter cavity with and without the counter in place show that the counter does not affect the capture rate in the foils to any measurable extent.

Isotopic reaction rates are derived from the enriched and depleted uranium foil data using the compositions given in Table IV-4. The isotopic rites $\mathrm{f}^{25}$ and $\mathrm{f}^{28}$ are derived from the equations

$$
\begin{aligned}
& E N R=f_{E}^{25}\left(N_{E}^{25}+\frac{f^{24}}{f^{25}} N_{E}^{24}+\frac{f^{26}}{f^{25}} N_{E}^{26}\right)+f_{E}^{28} N_{E}^{28} \\
& D E P=f_{D}^{25}\left(N_{D}^{25}+\frac{f^{26}}{f^{25}} N_{D}^{26}\right)+f_{D}^{28} N_{D}^{28}
\end{aligned}
$$

where $N_{j}^{i}$ is the mass fraction of isotope 1 in foil type $j$ as given in Table IV-4. The ratios $\mathrm{f}^{24} / \mathrm{f}^{25}$ and $\mathrm{f}^{26} / \mathrm{f}^{25}$ are calculated for each assembly, but their small contribution to the fission rate does not signifisantly change the equations from one core to the next.

No isotopic corrections are made to the ${ }^{239} \mathrm{Pu}$ fission rate data. Any corrections would have to be calculated, and such a technique would bias the experimental results. Instead, the absolute normalization factor derived from the fission counter data for ${ }^{239} \mathrm{Pu}$ assumes that the foils contain only $239 \mathrm{Pu}$ and that the contributions from the other isotopes is a constant factor. This is an excellent approximation for ${ }^{239} \mathrm{Pu}$ fission measurements throughout the core, but may introduce some relative errors when traversing both the core and blanket. Since no plutonium folls were 1rradiated in the blanket, this problem does not arise except very near the edge of the core.

\section{Ce11-Averaged Reaction Rates}

1. Plate-loaded Assembly

Detalled intra-cell reaction rates were measured in the core and both blanke:s of the assembly. These results provide cell-averaged reaction rate ratios and are also used to convert point reaction rate data to cell-averaged results. 
In three of the one-drawer unit cell core locations, the normal $0.25-i n$. thick fuel plates were replaced by pafrs of $0.125-i n$. thick plates, and foil packets placed between them. Wherever possible, the uranium oxide plates were replaced with 0.125-in. thick plates for a more detailed analysis. Table IV-4 describes the foils used for the unit cell measurements.

Intra-cell reaction rates were measured by placing foils between the plates of selected unit cells in the core, axial blanket, and radial blanket. Plutonium folls were used only in the core region, and only next to the fuel plates. Folls were held in 1-mil thick aluminum folders as shown in Fig. IV-3.

Data from the foils were analyzed and normalized as described above. In order to eliminate the effects of gross flux shapes through some of the unit cell regions, results within each unit cell region were corrected for positional differences in the radial direction. Multiparameter polynominal curves were fit to the experimental radial reaction rate distribution data (see Section IV.D). These curves were interpolated to give a value of each reaction rate at each foil location within the unit cells. The experimental reaction rate values at the foll locations within the unit cells were then corrected to a common radius by multiplying by the ratio of the fitted value at a reference location to the fitted value at each foil location.

Figures IV -4 to IV-7 show the distribution of plutonium fission reaction rates in the core region unit cells. Figures IV-8 to IV-13 show the distributions of the ${ }^{235} \mathrm{U}$ fission rate in the core, axial blanket and radial blanket regions. Figures IV-14 to IV-19 show distributions of the ${ }^{238} \mathrm{U}$ fission rate for these unit cells, and Figs. IV-20 to IV-25 show the $238_{U}$ capture rate distributions in the core, axial blanket and radial blanket regions. The intra-cell distributions in Figs. IV-6, IV-10, IV-16 and IV-22 are shown after the radial corrections discussed above we re applied. The other unit cell locations were chosen such as to make the radial position difference corrections negligible. The notation at the tops of the figures define the matrix location and axial distance from the core midplane at which the measurement was made. The error bars on the plots indicate relative statistical uncertainty only.

Tables IV-5 to IV-10 summarize the foil data for each of the unit cell locations. Since individual data point uncertalnties are very consistent, they have not been 11 sted in the tables. For $239 \mathrm{Pu}$ and $235 \mathrm{U}$ fission and $238 \mathrm{U}$ capture statistical uncertainties are approximately $0.75 \%$ in the core region and $1.0 \%$ in the blanket regions. The uncertainties for ${ }^{238} \mathrm{U}$ fission are somewhat higher, ranging from $1.0 \%$ in the core region to $2.0 \%$ in the blanket regions. These uncertainties include only the statistical uncertainties in the foll count-rate data and the uncertainty in the foil position. Positional uncertainties were estimated by calculating the change in the reaction rate results when the foil position was changed $\pm 0.125 \mathrm{in}$. according to the measured radial and axial distributions. The listed uncertainties do not include possible small uncertainties in the half-lives used to correct the counting data, in the dead time corrections to the data or other systematic uncertainties. 
With the exception of the fuel plates, a plate-averaged reaction rate is taken to be the numerical average of the foil reaction rates on either side of the plate. These values for the foils are derived as described above. The cel1-averaged reation rate is an atom-density weighted average, defined by

$$
\mathrm{CA}_{k}=\frac{\sum_{i=1}^{J}(\mathrm{PA})_{i}^{\mathrm{k}} \mathrm{N}_{i}^{\mathrm{k}} \mathrm{w}_{i}}{\sum_{i=1}^{J} \mathrm{~N}_{i}^{k} w_{i}}
$$

In this expression, $C_{A}$ is the cell-averaged reaction rate of type $k$ (where $\mathrm{k}$ is either ${ }^{239} \mathrm{Pu},{ }^{235} \mathrm{U}$ or ${ }^{238} \mathrm{U}$ fission or ${ }^{238} \mathrm{U}$ capture), (PA) ${ }_{1}^{\mathrm{k}}$ is the plate average of the $k^{\prime}$ th reaction rate in plate $i, N_{1}^{k}$ is the atom density of isotope $k$ in $p l$ ate $i$ and $w_{i}$ is the volume of plate $i$. The sum is over all plates with in the unit cell.

Two corrections are normally applied to the plate-averaged rates for the fuel plates. The first accounts for the fact that the stainless steel clad (0.015-in. thick) on the fuel plates affects the values of the reaction rates measured next to the surface of the clad. Previous GCFR measurements have shown that the only reaction rate which is noticeably affected is ${ }^{238} \mathrm{U}$ capture. This stainless steel correction factor is relatively insensit ive to spectral differences, so the values measured in the GCFR Phase II assembly ${ }^{2}$ were used to correct the Phase III data. These factors were measured by placing extra stainless steel between the fuel plate and the foil (both outside the plate and between the half-width plates), then extrapolating the data to zero-thickness clad. The correction factor for foils on the outside of normal fuel plates is $0.999 \pm 0.008$, and for foils between half-width plates is $0.984 \pm 0.008$. These factors have not been applied to the data in Tables IV-5 to IV-11.

The second correction to the fuel plate data accounts for the dip in the capture rate and the peak in the fission rate within the plate. As part of the measurements, the normal ( 0.25 in.) fuel plate in the two central zone I unit cells and the two plates in one zone III unit cell were replaced by pairs of half-width ( 0.125 in.) plates in order to estimate the reaction rate peaking or depression. After applying the stainless steel corrections, the rat io of the plate average to the exterior surface foil average was formed. Only the values for the depleted uranium foils differed from essentially unity, but for consistency the factors were applied to all the reaction rates. The factors used to obtain in-fuel-plate reaction rates from the surface-foil averages are: for ${ }^{238} \mathrm{U}$ fission, $1.0151 \pm 0.0043$ for ${ }^{238} \mathrm{U}$ capture, $0.9640 \pm$ 0.0032 ; for ${ }^{239} \mathrm{Pu}$ fission, $0.9963 \pm 0.0064$; for ${ }^{235} \mathrm{U}$ fission $0.9979 \pm 0.0029$.

Table IV-11 lists the ratios of the cell averaged reaction rate to the "mapping foil" reaction rate. These numbers are used to convert reaction rate distribution data to cell-averaged values as discussed below.

Table IV-12 summarizes the unit cell measurements in the form of reaction rate ratios, which are also compared to calculated values in the table. Calculational methods are described below. 
2. Pin Zone Assembly

Intra-cell reaction rates of $\mathrm{f}^{49}, \mathrm{f}^{25}, \mathrm{f}^{28}$ and $\mathrm{c}^{28}$ were also measured in the core and all except $\mathrm{F}^{49}$ were measured in the axial blanket region of the $p$ in zone in the GCFR Phase IIl assembly.

In the core region (matrix location $5-23 / 23$, approximately three inches away from the stationary half/movable half boundary), special three-inch long stainless steel pins containing $\mathrm{PuO}_{2} / \mathrm{UO}_{2}$ pellets were used. The cladding on one end of these pins was reduced to a thickness of five mils to reduce the effect of stainless steel on the reaction rate measured in the adjacent measurement foil. Table IV-13 describes the foils used for the unit cell measurements.

The 0.20 -inch diameter plutonium foils were centered, with silicon grease, on a five-mil thick, 0.346-inch diameter aluminum disc and then wrapped in one-mil thick aluminum. The package was then positioned between the special thin-end-capped fuel pins at locations Al, B6, and $\mathrm{C}$ (see Fig. IV-26). Enriched and depleted uranium foils, 0.346-inch diameter, were also wrapped in 1-mil aluminum foil and positioned between special pins at the locations A3, $\mathrm{Cl}$ and $\mathrm{A} 2, \mathrm{~B} 8, \mathrm{C} 3$ respect ively.

In the axial blanket region (mat $\mathrm{rix}$ location $\mathrm{S}-23 / 23$ approximately 27 inches away from the stationary half/movable half boundary), enriched and depleted uranium foils, 0.346-inch diameter, were wrapped in 1 -mil thick aluminum and placed between the depleted $\mathrm{UO}_{2}$ pellets within special six-inch lorg stainless steel clad open ended pins.

Enriched uranium foils were placed at locations A2, B8 and C3 and depleted uranium foils at locations A1, B6, and C2 (Fig. IV-26).

Foil data acquisition and analys is methods are described above. Table IV-14 1 ists the measured relative reaction rates at the various intracell positions in the pin zone.

Cell-averaged rates were formed by multiplying each positional rate times the number of pin positions it represents, e.g., $\mathrm{CA}_{\mathrm{DEP}}=4(\mathrm{Al})+8(\mathrm{~B} 6)+4(\mathrm{C} 2)$, referring to Fig. IV-26. No corrections to the data $h$ ave been made for the effect of the stainless steel clad on the pins. Measurements in plate-loaded drawers have shown the effect is not iceable only for ${ }^{238} \mathrm{U}$ capture, and is on the order of one percent for foils placed next to the $15-\mathrm{mil}$ thick clad on the plates. Based on this, no correction is made here for the 5-mil thick end caps. After normalization to the absolute rate measurements, ratios of the cell-averaged rates were calculated. Table IV-15 summarizes the intra-cell measurements in the form of measured and calculated cell-averaged ratios. Also given are the results of similar measurements in the plate-loaded GCFR Phase III assembly. The listed uncertainties are stat istical only, resulting from count ing statistics and normalization factors. No est imate of systemat ic uncertaint ies is included. 


\section{Reaction Rate Distributions}

\section{Plate-1oaded Assembly}

Radial and axial fission and capture rate distributions $\left(f^{49}, f^{25}, f^{28}\right.$ and $c^{28}$ ) were measured in the plate-loaded core and blanket regions of the GCFR Phase III assembly. The foils used are described in Table IV 4 .

The radial traverses were made in the stationary half outward from the core center along column 23. Foils were placed in the front portion of the drawers in 1-mil aluminum folders as shown in Fig. IV-3. Each foil was placed at the mid-height of its drawer. In zone I of the core region, the foils were placed against the left side of the fuel plate in each drawer. In zones II and III of the core, the foils were placed against the left side of the right hand fuel column and in the radial blanket region, the foils were placed between uranium oxide plates 0.25 inch to the right of the drawer center.

The axial distributions of the uranium fission rates and the ${ }^{238} \mathrm{U}$ capture rate were measured in a central stationary half matrix location. Foils were placed at the mid-height of the drawer, held inside a folded length of 1-mil aluminum as shown in Fig. IV-27. The traverse holder was positioned against the right side of the fuel plates in drawer $\mathrm{s}-22 / 23$.

Enriched uranium and plutonium foils were spaced at regular intervals through the core and axial blanket (enriched uranium only in the blanket) in one irradiation and depleted uranium foils were placed at the identical locations as the enriched uranium in a second irradiation.

Reaction rates in the distribution foils are determined using the analysis methods described in Section IV.B. Using the cell-averaged to mappingfoil ratios of Table IV-11, the traverse foil results are converted to cel1averaged reaction rates. In cases where these ratios vary across the core or blanket region (e.g., from $\mathrm{s}-23 / 23,0-2$ in. to $s-23 / 23,22-24$ in. in

Table IV-11) a linear fit was performed to obtain a correction factor for each foil position in the traverse.

The experimental fission rate data from the depleted and enriched uranium traverse foils were isotoplcally corrected to fission rates in $235 \mathrm{U}$ and $238 \mathrm{U}$ by normalizing to the absolute fission counter results, then solving the simultaneous equations for $\mathrm{f}^{28}$ and $\mathrm{f}^{25}$.

Tables IV-16 and IV-17 1 ist the measured radial and axial relative reaction rate distributions (reactions per gram). For each reaction rate in each direction, the experimental data were fit to a multiparameter polynomial function using a least-squares routine. Each traverse was then normalized to 1000. at the peak value given by the fit. The locations of the measured data points are the actual radial positions of the folls in the assembly. Tables IV-18 and IV-19 list the calculated reaction rate distributions (reactions per gram) in the radial and axial directions respectively. The locations of the calculated points are given as the center of the mesh region used in the flux calculation. Calculational techniques are described below. 
Figures IV-28 through IV-35 compare calculated and measured reaction rate distributions in both the radial and axial directions (both normalized to 1000 at the core center).

\section{Pin Zone Assembly}

The axial distribution of the ${ }^{239} \mathrm{Pu}$ fission rate was measured in the central matrix location at pin location C2 (Fig. IV-26). As for the unit ce11 measurements, the 0.20-in. diameter plutonium folls were centered, with silicon grease, on five-mil thick, 0.346-in. diameter aluminum discs and then wrapped in 1-mil aluminum. The packages were then positioned between special three inch stainless steel clad fuel pins over the total core height (stationary and movable halves). The special pins were arranged such that the thinwindow ends of two pins were facing so that alternate foils on the axial traverse over the 48-in. core height were positioned between the thin ends of two special pins. The other foils were between the normal ends of two adjacent fuel pins.

Reaction rates in the plutonium foils were determined using the same techniques as those described above. The experimental data were fit using a least squares code and then normalized to 1000. at the peak value given by the fit.

Table IV-20 lists the measured axial reaction rate distribution in both the pin- and plate-loaded GCFR Phase III assemblies. Table IV-2l lists the calculated distribution for the pin-loaded configuration. Figure IV-36 compares the measured and calculated axial ${ }^{239} \mathrm{Pu}$ fission rate distribution in the pin zone.

\section{E. Calculationa1 Techniques}

The calculated central reaction rate ratios in Table $I V-2$ are computed with the detector cross sections described in Section II. The XY model was used for the plate assembly rates and the pin zone RZ model for the pin assembly rates. While appropriate for the fission sources on the counters, these calculations do not in any way account for the fact that a 2 -in. cubical vold was created in the core, and that extra stainless steel (the counter) was placed around the source. In many cases, e.g., threshold fissioning isotope rates, the effects of these perturbations are non-negligible. Studies done in the GCFR Phase I assembly ${ }^{1}$ indicate that threshold fission might be reduced by approximately $10 \%$ in the cavity environment.

Calculated values of the cell-averaged reaction rate ratios are derived from the shielded cross sections. For the plate-loaded assembly, the XY mode1 flux was used for all unit cells at the reactor midplane and the $R Z$ flux for all others. Pin zone ratios were calculated with the pin cross sections and RZ flux.

The XY model of the plate assembly has four mesh regions per drawer, and the RZ models have a mesh spacing of approximately $2 \mathrm{~cm}$. To calculate unit cell reaction rate ratios, the ratio was formed for the mesh intervals adjacent to the unit cell location and the average value of the ratios was taken to be the cell-averaged ratio. 


\section{F. Results and Discussion}

Both measured fission counter ratios at the core center of the plate assembly agree well with calculated values. The $f^{25 / f^{49}}$ ratio $(1.040)$ is increased over the GCFR Phase II value of 0.992 . The $\mathrm{f}^{28 / \mathrm{f}^{49}}$ ratio $(0.0249)$ is lowered from the Phase II value $(0.0309)$ indicating the softer spectrum in the central core zone of the Phase III assembly.

In the pin zone, for the two central spectral index ratios, $f 25 / f 49$ and $\mathrm{f} 28 / \mathrm{f}^{49}$, excellent agreement was obtained between measurement and calculations, although corrections to account for the cavity in the calculation were not made.

Unit cell measurements of the $\mathrm{f} 25 / \mathrm{f} 49$ ratio are consistent in all core regions and agree well with calculated values. The c $28 / \mathrm{f}^{49}$ and $\mathrm{c} 28 / \mathrm{f} 25 \mathrm{re}-$ sults are consistently higher than past measurements by approximately $3 \%$. The two ratios at the outer 1 imits of the blankets have $\mathrm{C} / \mathrm{E}$ values of $\sim 0.99$. In this region the $\mathrm{c} 28 / \mathrm{f} 49$ ratio is a rapidly changing function of position and these $\mathrm{C} / \mathrm{E}$ values are not unexpected.

Similar results hold for the $f 28 / f 49$ and $f 28 / f 25$ ratios. Near region boundaries $C / E$ values vary because of the rapidly changing $f 28 / f^{49}$ ratio, but the values away from the boundaries are typical of past measurements.

The in-core unit cell-averaged ratios from the pin zone are consistent with those obtained from the plate-loaded assembly. In both assemblies, the $\mathrm{C} / \mathrm{E}$ value for the ratio $\mathrm{c}^{28 / \mathrm{f}} 49$ is $3 \%-5 \%$ higher than the GCFR Phase II results. C/E ratios for the unit cell-averaged reaction rate ratios, $f 28 / f 25$ and $\mathrm{c}^{28 / \mathrm{f}} 25$ in the axial blanket of the $\mathrm{p} 1 \mathrm{n}$ zone are higher than those for the plate loaded assembly. However, both reaction rate ratios undergo rapid changes as the distance into the axial blanket increases.

Calculated radial distributions of the $\mathrm{f}^{49}, \mathrm{f} 25, \mathrm{f} 28$ and $\mathrm{c} 28$ reaction rates in the plate assembly agree very well with measurements except for a slight under-prediction of the capture rate in the radial blanket. There is a noticeable discontinuity in the measured distribution of the $f 25$ rate at approximat, $30 \mathrm{~cm}$. It should be noted that the 449 rate distribution matches $t r$ attern in the $\mathrm{f} 25$ distribution. Its cause has not been identified.

The calculated axial distributions also agree very well with measurement for the plate-loaded assembly except for a slight underprediction of the $238 \mathrm{U}$ capture rate in the blanket. Two features of the $\mathrm{f}_{28}$ distribution are noticeable. The depression of the central data point is due to the drawer front and gap between the reactor halves. This effect has been seen in previous measurements. The data point at $38.1 \mathrm{~cm}$ is low for the $238 \mathrm{U}$ fission traverse, but high for the $238 \mathrm{U}$ capture traverse. It was found that the one foil used to measure the fission and capture rate at this point was centered over the adjoining ends of two fuel plates. The high capture/low fission effect is attributed to a local perturbation caused by the relatively large amount of stainless steel at the junction of the two fuel plate claddings. The plutonium plate loading alongside this axial traverse was composed of lengths of 8-7-5-4 inches. The data point at 15 inches $(38.1 \mathrm{~cm})$ was the only foil position 
point along the traverse that matched the location of the ends of two adjacent plutonium plates and this was the only point that showed the effect.

Normalization of the axial ${ }^{239} \mathrm{Pu}$ fission rate distribution near the core center results in calculated values which are underpredicted farther from the axial midplane (see Fig. IV-36). Previous studies have shown that Benoist diffusion coefficients can underpredict the amount of axial streaming in the pin zone, and it is probably such an effect which appears in Fig. IV-36. It should be noted that no systematic difference is evident among the data for foils placed between special pins and normal pins, indicating that the stainless steel has a negligible effect on the $\mathrm{f}^{49}$ fission rate measured next to the pin ends.

\section{MEASUREMENT OF ABSORPTION-TO-FISSION RATIOS AND THE CENTRAL CORE CONVERSION RATIO}

\section{A. Introduction}

Spectrum-averaged absorption (capture plus fission)-to-fission ratio measurements in fast critical assemblies are of considerable interest because they provide spectral indices which can be compared with calculations based on differential cross section data and because the value of the breeding ratio depends on these $(1+\vec{\alpha})$ values. Because of the low fluxes characteristic of $Z P R$ facilities, the reactivity-reaction rate method ll was used to determine the $(I+\bar{\alpha})$ values reported here. Measurements were made for ${ }^{233} \mathrm{U},{ }^{235} \mathrm{U}$, ${ }^{238} \mathrm{U},{ }^{239} \mathrm{Pu}$ and $240 \mathrm{Pu}$. The central core conversion ratio has been obtained by combining these results with a measurement of the cell-averaged reaction rate ratio, $c^{28} / \mathrm{f}^{49}$.

\section{B. The Reactivity-Reaction Rate Method}

The details of this method have been described previously (for example, see Ref. 2) and the final equation for the spectrum-averaged, position-dependent, absorption-to-fission ratio derived from perturbation theory $f$.s

$$
1+\bar{\alpha}(\underline{r})=\frac{D\left({ }^{6} \mathrm{Li}\right)}{\overline{\phi_{a}^{*}(\underline{r})}}\left[\frac{\bar{v}(\underline{r}) \bar{\phi}_{f}^{*}(\underline{r})}{D\left({ }^{252} \mathrm{Cf}\right)} \frac{\rho(\underline{r}) \mathrm{RCF}}{\mathrm{R}_{\mathrm{nf}}(\underline{r})}\right]-F C F
$$

where

$$
\begin{aligned}
& \bar{\phi}_{\underline{f}}^{*}(\underline{r}) \equiv \sum_{i=1}^{N G} \phi_{1}^{*}(\underline{r}) x_{i} \\
& \bar{\phi}_{a}^{\star}(\underline{r}) \equiv \sum_{i=1}^{N G} \phi_{1}^{*}(\underline{r}) \sigma_{a_{i}} \phi_{i}(\underline{r}) / \sum_{i=1}^{N G} \sigma_{a_{i}} \phi_{i}(\underline{r})
\end{aligned}
$$




$$
\begin{aligned}
& \bar{v}(\underline{r}) \equiv \sum_{i=1}^{N G}\left(v \sigma_{f}\right)_{i} \phi_{i}(\underline{r}) / \sum_{i=1}^{N G} \sigma_{f_{i}} \phi_{i}(\underline{r}) \\
& R C F \equiv\left[1-\left(\rho_{s}+\rho_{\ell}\right) / \rho\right] \\
& F C F \equiv\left(R_{n p}+R_{n \alpha}-R_{n 2 n}\right) / R_{n f} .
\end{aligned}
$$

In these equations, $\phi_{i}$ and $\phi_{1}^{*}$ represent the flux and adjoint distributions, respectively, while $\sigma_{a_{i}}$ and $\sigma_{f_{i}}$ are the absorption and fission cross sections. The spectrum of prompt fission neutrons is given by $x_{i}$ and $\bar{v}$ is the average number of neutrons per fission event. The reactivity correction factor, RCF, adjusts the measured reactivi.ty $\rho$ for scattering and leakage effects in the sample. To account for neutron absorbing events other than capture and fission in the sample, the correction factor FCF is introduced. Two independent determinations of the perturbation denominator $D$ are available from measurements made with samples of ${ }^{6} \mathrm{Li}$ and ${ }^{252} \mathrm{Cf}$ :

$$
\begin{aligned}
& D\left({ }^{6} \mathrm{Li}\right)=-\frac{\bar{\phi}_{\mathrm{a}}^{*}\left({ }^{6} \mathrm{Li}\right) \mathrm{R}_{\mathrm{n} \alpha}\left({ }^{6} \mathrm{Li}\right) \operatorname{ACF}\left({ }^{6} \mathrm{Li}\right)}{\rho\left({ }^{6} \mathrm{Li}\right) \mathrm{RCF}\left({ }^{6} \mathrm{Li}\right)} \\
& \mathrm{D}\left({ }^{252} \mathrm{Cf}\right)=\frac{\bar{\phi}_{\mathrm{f}}^{*}\left({ }^{252} \mathrm{Cf}\right) \mathrm{S}\left({ }^{252} \mathrm{Cf}\right)}{\rho^{-}\left({ }^{252} \mathrm{Cf}\right)} .
\end{aligned}
$$

The absolute specific absorption rate for the ${ }^{6} \mathrm{Li}(\mathrm{n}, \alpha)^{3} \mathrm{H}$ reaction is denoted by $R_{n \alpha^{*}}$ Other types of absorption processes are accounted for by the small correction term ACF, where ACF $\equiv\left[1+\left(R_{n \gamma}+R_{n p}\right) / R_{n \alpha}\right]$. The apparent reactivity, $\rho^{-}(\mathrm{Cf})$, of a calibrated ${ }^{252} \mathrm{Cf}$ spontaneous fission neutron source of strength $S$ is evaluated at the power level used for the measurement of the absolute specific reaction rates $R_{n f}$ and $R_{n \alpha}$. If the value of the perturbation denominator is insensitive to the local perturbation by the sample, $\mathrm{D}\left({ }^{6} \mathrm{Li}\right)=\mathrm{D}\left({ }^{252} \mathrm{Cf}\right)$ and $\mathrm{Eq} \cdot \mathrm{V}-1$ becomes

$$
1+\bar{\alpha}(\underline{r})=\frac{1}{\bar{\phi}_{a}^{*}(\underline{r})}\left[\bar{v}(\underline{r}) \bar{\phi}_{f}^{*}(\underline{r})-\frac{D \rho(\underline{r}) R C F}{R_{n f}(\underline{r})}\right]-F C F .
$$

The measured quantities are the relative specific reactivities $\rho\left({ }^{6} \mathrm{Li}\right)$ and $\rho(\underline{r})$ for the fissile and fertile samples, the apparent reactivity $\rho^{\prime}\left({ }^{252} \mathrm{Cf}\right)$, the absolute specific reaction rates $R_{n f}$ and $R_{n g}\left({ }^{6} \mathrm{Li}\right)$, and the neutron emission rate, $S(C f)$, from the extraneous source. The remaining terms in Eqs. V-1 to $\mathrm{V}-3$ are calculated from fundamental nuclear data. If the measured reactivities and reaction rates are corrected for sample size effects, the flux and adjoint distributions in Eqs. $V-1$ to $V-4$ refer to the unperturbed reactor and so the corresponding $(1+\bar{\alpha})$ results depend on reactivity ratios and are therefore independent of any absolute reactivity calibration. 


\section{Measured Quantities}

Metallic lithium samples $\left(99.2 \mathrm{w} / 0^{6} \mathrm{Li}\right.$ ) having a diameter of 0.309 in. and clad in 20-mil aluminum were used for both absorption rate and reactiv1ty measurements. The neutron absorption rate $1{ }^{6} \mathrm{~L} 1$ is strongly dominated by the ${ }^{6} \mathrm{Li}(n, \alpha){ }^{3} \mathrm{H}$ reaction. In fact, only a few hundredths of one percent of the absorptions result from $(n, \gamma)$ and $(n, p)$ processes. Thus, the ${ }^{6} \mathrm{LI}$ absorption rates were determined by measuring the tritium activity induced in irradiated samples using the methods described in Ref. 12.

Absolute ${ }^{239} \mathrm{Pu}$ fission rates were measured by gamma counting irradiated plutonium foils 0.0004-in. thick using Ge(Li) detectors. The gamma detectors were calibrated by counting folls irradiated on the face of a 5.1-cm diameter Kirn-type fission counter as discussed in Section IV.B. To determine the radial distribution of plutonium fission rates, foils were activated at numerous positions within the thin-walled stainless steel tube of the radial sample changer. A least squares polynominal fit of this distribution data was made, subject to the symmetry requirement $R_{f}(X)=R_{f}(-X)$, to determine the ${ }^{239} \mathrm{Pu}$ fission rates at the locations where small sample reactivities were measured. The fission rates for the other isotopes $\left({ }^{23} \mathrm{U},{ }^{235} \mathrm{U}\right.$, $238 \mathrm{U}$ and $240 \mathrm{Pu}$ ) were obtained by combining measured fission ratios (see Table IV-2) with the ${ }^{239} \mathrm{Pu}$ fission rates. Unfortunately, $\mathrm{f}^{23} / \mathrm{f}^{49}$ and $\mathrm{f}^{40} / \mathrm{f}^{49}$ were not measured in the GCFR Phase III assembly. The values used for these ratios were obtained by dividing the calculated ratio by the corresponding $\mathrm{C} / \mathrm{E}$ value obtained in the GCFR Phase II measurements (see Ref. 2, Table VI-3). Table V-1 summarizes the results of the fission ratio measurements.

Absolute reaction rate measurements for the ${ }^{6} \mathrm{Li}(\mathrm{n}, \alpha)$ and the ${ }^{239} \mathrm{Pu}(\mathrm{n}, \mathrm{f})$ processes, in units of events/sec-g, are shown in Table V-2. The measured rates were multiplied by a calculated sample size correction factor, $R_{0} / R$, which accounts for flux distortions due to the stainless steel tubes and cladding surrounding the sample and flux perturbations within the sample itself. To evaluate $R_{0} / R$, flux distortion factors were calculated using the perturbation integral transport code PIT. 13 The errors shown in Table V-2 do not include uncertainties associated with the evaluation of $R_{0} / R$.

The small sample worth measurements have been described in Section III. A description of the reactivity samples used for these $(1+\bar{a})$ measurements is provided in Tables $V-3$ and $V-4$. The measured reactivities are shown in Table $\mathrm{V}-5$. As with the $R_{0} / R$ calculation, the PIT code was used to ca1culate distortion factors from which the sample size correction factor, $\rho_{0} / \rho$, was evaluated. The term $1_{\rho_{0}} / \rho_{0}$ converts the measured reactivity to that of the principal isotope (i) in the sample. Thus, ${ }^{i} \rho_{0}$ (Table V-5) is the isotopic specific reactivity corrected for local disturbances in the flux and adjoint spectra. Since reactivities appear as ratios in the expression for $(1+\bar{\alpha}$ ) (see Eqs. $v-1$ to $v-3$ ), the errors in Table $v-5$ do not include the approximately $1 \%$ uncertainty in the calibration of the autorod. Also, no error has been assigned to the calculated value of $\rho_{0} / \rho$.

A new californium source was used for the measurements made in the GCFR Phase III assembly. This source, designated as ORNL-NSD-56, was obtained from the Oak Ridge National Laboratory and has been calibrated by the 
National Bureau of Standards and by the University of Michigan. At each radial position the worth of the ${ }^{252}$ Cf source was measured at two power levels, differing by about an order of magnitude, in order to separate the apparent worth of the spontaneous fission neutrons from the reactivity of the source capsule. Table V-6 shows the measured apparent worth, $\rho^{-}(E)$, at each radial position evaluated at the power level corresponding to the absolute reaction rates given in Table $\mathrm{V}-2$. The source strength shown in Table V-6 corresponds to the time when the ${ }^{252} \mathrm{Cf}$ worth measurements were made. Again the PIT code was used to account for the distortion in the adjoint spectrum resulting from the stainless steel tubes surrounding the source and the source container itself. The PIT distortion factors were used to evaluate the correction term $\rho_{0}^{\prime} / \rho^{\prime}$ shown in Table V-6. This correction assumes that the stainless steel surrounding the source absorbs a negligible number of source neutrons and does not significantly alter the spectrum_of ${ }^{252} \mathrm{Cf}$ spontaneous fission neutrons. With these assumptions, $\rho_{0}^{\prime} / \rho^{\prime}=\bar{\phi}_{f_{0}}^{*}(\mathrm{Cf}) / \phi_{f}^{\star}$, where $\bar{\phi}_{\text {f }}^{\star}$ and $\bar{\phi}_{f}^{*}$ are the spontaneous fission neutron importance .erms calculated using undistorted and distorted adjoint distributions, "spectively.

D. Calculated Quantities

Multigroup cross sections and appropriate flux and adjoint distributions are needed to calculate spectrum-averaged values of $\bar{v}$, the importance terms $\bar{\phi}^{*}$ and $\bar{\phi}^{*}$, and the correction factors RCF, FCF and ACF which appear in $E_{\mathrm{q}}^{\mathrm{a}} \mathrm{V} . \mathrm{V}-1$ to $\mathrm{V}-4$. Section II describes the methods used to generate the 29 broad-group cross sections for the GCFR Phase III assembly beginning with ENDF/B Version IV data. Self-shielded cross sections, which include the effects of plate spatial self-shielding and resonance energy self-shielding, were used in a quarter-core XY model diffusion theory calculation (one mesh point per drawer - this model is identical to that described in Section II with the exception of the mesh interval) with Benoist anisotropic diffusion coefficients to determine the required flux and adjoint distributions (see Section II). These flux and adjoint distributions were used with 29 broadgroup "detector" cross sections to calculate the required quantities in Eqs. $\mathrm{V}-1$ to V-4. The "detector" cross sections do not include the effects of plate spatial self-shielding, but correctly predict infinitely-dilute and spatially homogeneous detector reaction rates within the framework of the diffusion theory model. Table V-7 summarizes the calculated quantities for infinitely-dilute samples.

The ${ }^{252} \mathrm{Cf}$ reactivity measurements were made with the point source displaced $1.95 \mathrm{~cm}$ from the center of the drawer toward the center of the assembly. However, the calculated values of $\phi_{f}^{*}(\mathrm{Cf})$ refer to the center of the drawer. Therefore, a least squares polynomial fit of $\Phi$ t $(C f)$, subject to condition that $\phi_{f}^{*}(X)=\phi_{f}^{*}(-X)$, was made for the purpose of interpolating the $\phi_{f}^{*}$ values to correspond to the locations where the ${ }^{252} \mathrm{Cf}$ reactivity measurements were made. These interpolated values are shown in Table V-6.

\section{E. Perturbation Denominator Measurements}

The ${ }^{252} \mathrm{Cf}$ data and the ${ }^{6} \mathrm{Li}$ data provide independent measurements of the perturbation denominator. $D\left({ }^{252} \mathrm{Cf}\right)$ and $D\left({ }^{6} \mathrm{~L} 1\right)$ were evaluated from Eqs. V-3 and $V-2$, respectively, using the data given in Tables $V-2, V-5, V-6$ and $V-7$. 
The results are presented in Table $\mathrm{V}-8$. It is seen that the mean value of the ${ }^{252} \mathrm{Cf}$ perturbation denominator, $\overline{\mathrm{D}}\left({ }^{252} \mathrm{CF}\right)$, is about $2.4 \%$ larger than $\overline{\mathrm{D}}\left({ }^{6} \mathrm{Li}\right)$. For the GCFR Phase II measurements (see Ref. 2 ), $\bar{D}\left({ }^{25 \mathbf{2}_{\mathrm{Cf}} \text { ) was }}\right.$ $.2 \%$ larger than $\overline{\mathrm{D}}\left({ }^{6} \mathrm{~L} i\right)$.

Since the magnitude of the perturbation denominator depends on the reactor power level, a normalization is required if the measured results are to be compared with calculation. A convenient normalization factor (NF) is

$$
\mathrm{NF}=\frac{\mathrm{S}^{*}(0) \mathrm{S}(0)}{\mathrm{Ih} /\left(\delta_{\mathrm{k}} / \mathrm{k}\right)}
$$

where

$$
S^{*}(0) \equiv \sum_{i=1}^{N G} x_{i}{ }^{\operatorname{core}} \phi_{i}^{*}(0)
$$

and

$$
S(0) \equiv \sum_{j=1}^{N I} \sum_{i=1}^{N G}\left(\nu \Sigma_{f}\right)_{i j} \phi_{i}(0)=\frac{{ }^{49} R_{f}}{N_{0} / 49_{A}} \sum_{i=1}^{N I} i_{\bar{v}} i_{N}\left(i_{f} / 49_{f}\right) .
$$

NG and NI are the number of groups and the number of $f$ issionable isotopes, respectively, $\mathrm{N}_{0}$ is Avogadro's number, $A$ is the atomic weight, ${ }^{\mathrm{N}}$ is the at om density of isotope $i$, and ${ }^{49} \mathrm{R}_{\mathrm{f}}$ is the ${ }^{239} \mathrm{Pu}$ fission rate in fissions/sec-g, and ${ }^{49} \mathrm{f}$ is the calculated per-atom $\mathrm{f}$ ission rate. $S^{*}(0)$ and $S(0)$ are $S^{*}(\underline{r})$ and $S(\underline{r})$ evaluated at the center of the reactor. The Ih/ $\delta \mathrm{k} / \mathrm{k}$ term in Eq. $\mathrm{V}-5$ is needed because the reactivities used in the expression for $D\left({ }^{6} \mathrm{Li}\right)$ and $\mathrm{D}\left({ }^{252} \mathrm{Cf}\right.$ ) (Eqs. $\mathrm{V}-2$ and $\mathrm{V}-3$ ) are measured in inhours. To obtain the experimental values for the normalized perturbation denominator, $\bar{D}\left({ }^{252} \mathrm{Cf}\right)$ and $\bar{D}\left({ }^{6} \mathrm{Li}\right)$ are divided by the value of $\mathrm{NF}$.

The normalized calculated perturbation denominator, $D_{n}(C)$, is

$D_{n}(C)=\int_{\text {react or }} S *(\underline{r}) S(\underline{r}) d V / S *(0) S(0)$.

An RZ model calculation was used to evaluate $D_{n}(C)$. Table V-9 compares the measured and calculated perturbation denominators. The $\mathrm{C} / \mathrm{E}$ rat io for the results based on the ${ }^{252} \mathrm{Cf}$ data is $0.857 \pm 0.014$ which is consistent with the value $0.850 \pm 0.014$ obtained in the GCFR Phase II measurement (Ref. 2).

\section{F. Absorption-to-Fission Ratios}

From Eq. V-1, the absorption-to-f ission ratios, $(1+\bar{\alpha})$, for ${ }^{23}{ }^{3} \mathrm{U},{ }^{235} \mathrm{U}$, ${ }^{238} \mathrm{U},{ }^{239} \mathrm{Pu}$ and $240 \mathrm{Pu}$ were evaluated using the mean values of the perturbation denominator, $\overline{\mathrm{D}}\left({ }^{252} \mathrm{Cf}\right)$ and $\overline{\mathrm{D}}\left({ }^{6} \mathrm{Li}\right)$, given in Table $\mathrm{V}-8$. The other data needed for these evaluations are given in Tables $\mathrm{V}-1, \mathrm{~V}-2, \mathrm{~V}-5$ and $\mathrm{V}-7$. Table $\mathrm{V}-10$ shows the experimental (E) values of $(1+\bar{\alpha})$ and the corresponding calculated $(C)$ ones. These values refer to a very dilute detector spanning the width of the matrix drawer. 
The errors (10) shown in Table V-10 include uncertainties in $\bar{v}$, the relative reactivity measurements, the absolute reaction rate determinations, and the calibration of the Cf neutron source strength. However, no error has been assigned to the calculation of the sample size effects, $\rho_{0} / \rho$ and $R_{0} / R$, the importance terms, $\vec{\phi}_{\mathrm{f}}^{\star}$ and $\vec{\phi}_{\mathrm{a}}^{\star}$, nor to the correction factors, RCF and FCF. For the Li measurements, samples of identical size were used for both reactivity and absorption rate determinations. Therefore, the value of $D\left({ }^{6} \mathrm{~L} 1\right)$ depends on the ratio $\left(R_{0} / R\right) /\left(\rho_{0} / \rho\right)$ which 1 very insensitive to the sample size corrections. In the expression for $(1+\alpha), \mathrm{Eq} \cdot \mathrm{V}-1,1$, the importance terms enter as ratios of the form $\phi_{\mathrm{a}}^{*}\left({ }^{6} \mathrm{Li}\right) / \phi_{\mathrm{a}}^{*}\left({ }^{23}{ }^{9} \mathrm{Pu}\right)$ and $\phi_{\mathrm{f}}^{*}\left({ }^{240} \mathrm{Pu}\right) / \phi_{\mathrm{f}}^{*}\left({ }^{252} \mathrm{Cf}\right)$. These ratios are thought to be quite insensitive to the details of the calculation. This argument is espectally true for the $\bar{\phi}_{\mathrm{f}}^{\star}$ terms which are calculated using a Maxwellian description of the spectrum of prompt fission neutrons. Table V-7 shows that the correction factors RCF and FCF are very small for all the isotopes except ${ }^{238} \mathrm{U}$. Therefore, errors in the calculations of RCF and FCF contribute negligible uncertainties to the measured values of $(1+\vec{\alpha})$, except for the case of $23{ }^{8} \mathrm{U}$.

Errors and error sensitivities are summarized in Tables V-11 and V-12. Table V-11 shows that the uncertainty in the fission rate contributes the largest uncertainty to $\left(1+233_{\alpha}\right)$ whereas_almost all the uncertainty in $(1+240 \bar{\alpha})$ comes from the uncertainty in $\bar{v}$. From Table $V-12$ it can be seen that a $1.0 \%$ increase in $\bar{v}$, or a $1.0 \%$ decrease in $\mathrm{S}(\mathrm{CF})$, will increase the $\left(1+\frac{\alpha}{\alpha}\right)$ values by $2.8 \%, 2.3 \%, 0.50 \%, 2.8 \%$ and $1.7 \%$ for ${ }^{23}{ }^{3} \mathrm{U},{ }^{23}{ }^{5} \mathrm{U},{ }^{23}{ }^{8} \mathrm{U},{ }^{23}{ }^{9} \mathrm{Pu}$ and $240 \mathrm{Pu}$, respectively. Similarly, a $1.0 \%$ increase in $\mathrm{R}_{\mathrm{f}}$, or a $1.0 \%$ decrease in $\rho$, w 111 increase $(1+\bar{\alpha})$ by $1.8 \%, 1.3 \%,-0.50 \%, 1.8 \%$ and $0.69 \%$ for $233_{U}$, ${ }^{235} \mathrm{U},{ }^{238} \mathrm{U},{ }^{239} \mathrm{Pu}$ and ${ }^{240} \mathrm{Pu}$, respectively.

Generally speaking, the measured $(1+\bar{\alpha})$ values are in reasonably good agreement with the calculated ones. However, the $\mathrm{C} / \mathrm{E}$ values are smaller at positions away from the center of the reactor than at the central location. After sample size corrections have been applied, the $U-3$ and $M B-21$ reactivity samples (see Tables V-3 and V-4) yield essentially the same values for $(1+235 \bar{\alpha})$, as Table $\mathrm{V}-10$ indicates. The same is true for the ${ }^{239} \mathrm{Pu}$ reactivity samples, $\mathrm{Pu}-25$ and $\mathrm{MB}-10$. However, the reactivity measurement for the $\mathrm{Pu}-27$ sample leads to an unusually large value of $(1+239 \alpha)$. Because of selfmultiplication effects, one would expect the measured specific reactivity of the $\mathrm{Pu}-27$ sample to be larger than that for the $\mathrm{Pu}-25$ sample. This was indeed the case for the GCFR Phase II measurement (see Ref. 2), but was not observed in the present measurement, as Table V-5 shows. The unexpectedly low $\rho$-value for the $\mathrm{Pu}-27$ sample is the reason for the correspondingly large value of $(1+239 \alpha)$. Because of the somewhat softer spectrum, the GCFR Phase III experimental $(1+239 \alpha)$ values are somewhat larger than the Phase II measurements (see Ref. 2).

Table V-13 lists $\mathrm{C} / \mathrm{E}$ values for the position-dependent ratios $\mathrm{R}_{\alpha_{0}}\left({ }^{6} \mathrm{LL}\right) / \mathrm{R}_{\mathrm{f}_{0}}(239 \mathrm{Pu}), \rho_{0}\left({ }^{6} \mathrm{LI}\right) / \rho_{0}(239 \mathrm{Pu})$ and $\left[\rho_{0}^{-}(\mathrm{Cf}) / \rho_{0}(239 \mathrm{Pu})\right] \times\left[\mathrm{R}_{\mathrm{f}_{0}}(239 \mathrm{Pu}) / \mathrm{S}(\mathrm{Cf})\right]$. The mean values of the $\mathrm{C} / \mathrm{E}$ ratios are shown at the bottom of the lable where they are compared with the corresponding quantities for the GCFR Phase II measurements (Ref. 2). The low $\mathrm{C} / \mathrm{E}$ values for the $\mathrm{Pu}-27$ sample and the $\mathrm{MB}-10$ sample at the matrix location $S-23 / 28$ are consistent with the abnormally low $\rho(E)$ values (Table $V-5)$ and the large $(1+\vec{\alpha})$ values (Table V-10) for these samples and positions. Th1s suggests the presence of a systematic error associated with these measurements and therefore these $C / E$ values were not 
included in the evaluation of $\overline{C / E}$. Table $V-13$ shows that the measured reaction rate ratio, $R_{\alpha_{0}}\left({ }^{6} \mathrm{Li}\right) / \mathrm{R}_{\mathrm{f}_{0}}\left({ }^{239} \mathrm{Pu}\right)$, agrees remarkably well with calculation and this observation is in agreement with the GCFR Phase II data. Also, the $\mathrm{C} / \mathrm{E}$ value for the ratio $\left[\rho_{0}^{-}(\mathrm{Cf}) / \rho_{0}\left({ }^{339} \mathrm{Pu}\right)\right] \times\left[\mathrm{R}_{\mathrm{f}_{0}}\left({ }^{239} \mathrm{Pu}\right) / \mathrm{S}(\mathrm{Cf})\right]$ is in reasonable agreement with the Phase II results. For the ${ }^{6} \mathrm{Li} /{ }^{239} \mathrm{Pu}$ reactivity ratio, however, the Phase III $\overline{\mathrm{C} / \mathrm{E}}$ value is nearly $4 \%$ larger than the Phase II result. This may be the primary reason why the perturbation denominator ratio, $\overline{\mathrm{D}}\left({ }^{252} \mathrm{Cf}\right) / \overline{\mathrm{D}}\left({ }^{6} \mathrm{Li}\right)$, was significantly greater in the Phase II measurement than in the Phase III experiment (see Section V.E).

\section{G. The Central Core Conversion Ratio}

The instantaneous central core conversion ratio, $\mathrm{CR}_{\mathrm{p}}$, may be defined as the rate of production of fissile material divided by its rate of loss evaluated at the center of the reactor. In terms of the central, cell-averaged reaction rates, $\mathrm{CR}_{\mathrm{P}}$ may be written as

$$
\begin{aligned}
& \mathrm{CR}_{\mathrm{P}}=\frac{28 \mathrm{~N}^{28} \mathrm{c}+{ }^{40} \mathrm{~N}^{40} \mathrm{c}}{{ }^{49} \mathrm{~N}^{49} \mathrm{f}\left(1+{ }^{49} \bar{\alpha}\right)+41 \mathrm{~N}^{41} \mathrm{f}(1+41 \bar{\alpha})+25 \mathrm{~N}^{25} \mathrm{f}(1+25 \bar{\alpha})}
\end{aligned}
$$

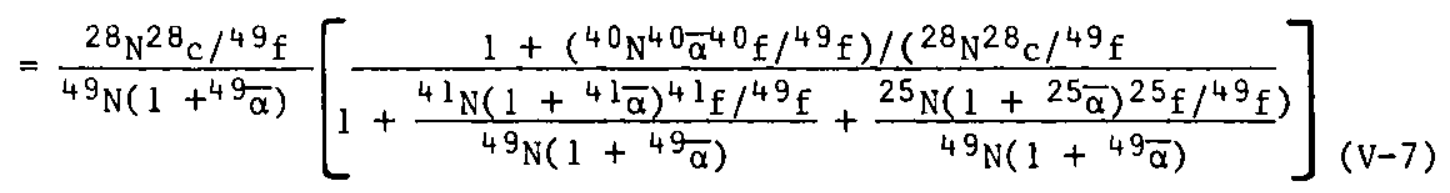

where ${ }^{i} \mathrm{~N}$ is the atom density of 1sotope $i$ and where ${ }^{i} \mathrm{c}$ and ${ }^{i_{f}}$ are the cel1averaged, per-atom capture and fission rates. The $(1+\bar{\alpha})$ values in Eq. V-7 are the cell-averaged absorption-to-fission ratios. These were obtained by dividing the calculated cell-averaged absorption-to-fission ratios by the corresponding thin sample $\mathrm{C} / \mathrm{E}$ values given in Table $\mathrm{V}-10$. The measurement of the cell-averaged $c^{28} / f^{49}$ ratio has been reported in section IV. Since the $\mathrm{f}^{40} / \mathrm{f}^{49}$ and $\mathrm{f}^{41} / \mathrm{f}^{49}$ ratios were not measured in the GCFR Phase III assembly, these C/E values were taken from the GCFR Phase II data (see Ref. 2). Table V-14 summarizes the evaluation of $\mathrm{CR}_{\mathrm{P}}$ at the center of the GCFR Phase III assembly. It is seen that the central conversion ratio is over-calculated by nearly $15 \%$, mostly because of the over-calculation of the $c^{28 / f^{49}}$ ratio.

Instead of using foil data, the $c^{28} / \mathrm{f}^{49}$ ratio may be written in terms of the measured $238 \mathrm{U}$ capture-to-fission ratio,

$$
c^{28} / f^{49}=28 \bar{\alpha} f^{28} / f^{49} \text {. }
$$

Table $\mathrm{V}-14$ shows that when this evaluation is used there is excellent agreement between the measured and calculated central core conversion ratins. The $\mathrm{C} / \mathrm{E}$ value now becomes $1.004 \pm 0.039$. Th1s same conclusion applies to the GCFR Phase II measurement for which the $\mathrm{C} / \mathrm{E}$ value for the central core conversion ratio changes from $1.097 \pm 0.032$ to $0.993 \pm 0.034$ if $\mathrm{Eq}$. V-8 is used. It should be remembered, however, that for ${ }^{238} \mathrm{U}$, neutron scattering effects contribute a significant fraction to the total reactivity signal. Therefore, the ${ }^{238} \mathrm{U}(1+\bar{a})$ values depend rather strongly on the calculated value of the 
reactivity correction factor RCF (see Table V-7). For the GCFR Phase III measurements, $28_{\rho} / 28 \rho=1-R C F$ would have to be increased by about $64 \%$ in order to make $28 \bar{\alpha}^{28} \mathrm{f} / /^{49} \mathrm{f}$ agree with the foil measurement of ${ }^{28} \mathrm{c} /{ }^{48} \mathrm{f}$.

\section{H. Summary}

Absorption-to-fission ratios $(1+\bar{\alpha})$ have been measured in the core region of the GCFR Phase III assembly by the reactivity-reaction rate technique for ${ }^{233} \mathrm{U}, 235 \mathrm{U}, 238 \mathrm{U}, 23{ }^{23} \mathrm{Pu}$ and $240 \mathrm{Pu}$. Generally speaking, the central values of $(1+\bar{\alpha})$ are in favorable agreement with calculations based on the ENDF/B Version IV data.

The core conversion ratio wis evaluated at the center of the GCFR Phase III assembly by combining the absorption-to-fission-ratio measurements with an independent determination of the cell-averaged ${ }^{28} \mathrm{c} /{ }^{49} \mathrm{f}$ reaction rate ratio. The central core conversion ratio is over calculated by nearly $15 \%$ mostly because of the $13 \%$ overprediction of the ${ }^{28} \mathrm{c} / 49_{\mathrm{f}} \mathrm{ratio}$. If the ${ }^{28} \mathrm{c} /{ }^{49} \mathrm{f}$ ratio is replaced by the measured value of $28 \alpha^{28} \mathrm{f} /{ }^{49} \mathrm{f}$, however, excellent. agreement is obtained between the measured and calculated central core conversion ratios.

\section{WORTH OF SMALL-ZONE STEAM ENTRY IN PLATE AND PIN ENVIRONMENTS}

\section{A. Introduction}

The reactivity effects of steam entry into the coolant channels of a Gas Cooled Fast Reactor has been examined in each of the three GCFR assemblies built in ZPR-9. In Phase $I$, the worth of a small central steam zone was measured as a function of the steam density.' An extensive program in Phase II studied the effects of a full-core and blanket flooding with steam. ${ }^{3}$ The objective of the Phase III steam-entry program was to compare the reactivity worth of steam in a plate environment as used in the Phase I and II programs to that in the pin environment of Phase III that is more characteristic of a GCFR design. In each phase, steam entry was simulated by inserting polyethylene foam $\left(\mathrm{CH}_{2}\right)$ into the void regions (the simulated helium-coolant channels) of the assembly.

\section{B. Measurement Techniques}

In the Phase III program, polyethylene foam was loaded into the central $5 \times 5$ drawer array in three steps: 1) to an axial half-height of \pm 12 in. relative to the axial midplane; 2) to an axial half-height of $\pm 24 \mathrm{in}$. (that is, to the core/axial blanket interface); 3 ) to an axial half-height of \pm 36 in. (that is, to the axial blanket/reflector interface). For the plate loading, full-density polyethylene foam strips were inserted into the two $0.5-1 \mathrm{n}$. vold cans of the zone $I$ unit cell. This resulted in an average $\mathrm{CH}_{2}$ density of $0.0136 \mathrm{~g} / \mathrm{cm}^{3}$. Multiplying this density by the ratio of the mclecular weights of $\mathrm{H}_{2} \mathrm{O}$ and $\mathrm{CH}_{2}$ conserves the hydrogen atom-number density and yields an equivalent steam density of $0.0174 \mathrm{~g} / \mathrm{cm}^{3}$. For the pin loading, pre-drilled polyethylene foam blocks were inserted over the $4 \times 4$ pin array of the special calandria so that $\mathrm{CH}_{2}$ completely filled the volds between the calandria pins. 
The average $\mathrm{CH}_{2}$ density in each calandria was $0.0149 \mathrm{~g} / \mathrm{cm}^{3}$, corresponding to an equivalent steam density of $0.0191 \mathrm{~g} / \mathrm{cm}^{3}$. Note that the average foam density is $9 \%$ greater in the pin environment than in the plate environment.

The steam-zone worths, relative to a steam-free reference configuration, are presented in Table VI-1 for both the plate and pin environments. The total worth of the steam zone at each loading step is $50-75 \%$ greater in the pin environment than in the plate environment, and the difference in the total worth increases as the axial half-height of the steam zone increases. The uncertainties reflect only the uncertainty in the measured excess of each loading step and of the steam-free reference. The uncertainty in the measured excess is estimated by adding in quadrature an uncertainty of 1 Ih due to table closure and a $1 \%$ uncertainty in the excess reactivity as measured on the control rods. The worth $(\mathrm{Ih} / \mathrm{kg}$ ) of the foam added at each of the three successive 12-in. loading steps and the total foam worth are given in Table VI-2, which also lists the ratio of the worth in the pin environment to that in the plate environment. This ratio of the worths is 1.42 for the first 12 in. of the steam zone, 1.60 for the second $12 \mathrm{in.,}$ and 1.11 in the axial blanket. For the full steam zone, the ratio is 1.59 .

No calculations were made of the steam entry experiments in Phase III. 


\section{REFERENCES}

1. S. K. Bhattacharyya, "An Experimental Study of the Neutronics of the First Gas Cooled Fast Reactor Benchmark Assembly (GCFR Phase I Assembly)," Argonne National Laboratory Report ANL-76-36, (December, 1976).

2. R. B. Pond, ed., "Reactor Physics Studies in the GCFR Phase-II Critical Assembly," Argonne National Laboratory Report ANL-76-108 (September, 1976).

3. S. K. Bhattacharyya, "Reactor Physics Studies in the Steam Flooded GCFRPhase II Critical Assembly," Argonne National Laboratory Report ANL-78-83 (August, 1978).

4. W. M. Stacey, et a1., "A New Space-Dependent Fast Neutron MuZtigroup Cross-Section Preparation Capability," Trans. Am. Nuc1. Soc. 15, 292 (1972).

5. H. Henryson, B. J. Toppel and C. G. Stenberg, "ETOE-2/MC ${ }^{2}-2 / S D X M u Z t i-$ group Neutron Cross-Section Processing," Seminar on Nuclear Data Processing Codes, Ispra, Italy, Decomber 5-7, 1973, EACRP-U-52.

6. H. Henryson, B. J. Toppel and C. G. Stenberg, "MC ${ }^{2}-2$ : A Code to Calculate Fast Neutron Spectra and Multigroup Crose Sections," Argonne National Laboratory Report ANL-8144 (June, 1976).

7. D. C. Wade and E. M. Gelbard, "Neutron Streaming in Plate Criticals," Paper presented at the ANS Topical Meeting on Advanced Reactors: Physics, Design and Economics, Atlanta, Georgia, September, 1974, CONF-740903.

8. P. Benoist, "Streaming Effects and Collision Probabilities in Lattices," Nuc1. Sc1. Eng. 34, 285-307 (1968).

9. D. C. Wade and R. G. Bucher, "Conservc on of the Adjoint Neutron Spectrum by Use of Bilinear-Weighted Cross Sections and Its Effect on Fast Reactor Calculations," Nuc1. Sci. Eng. 64, 517-538 (1977).

10. W. C. Schick, Jr., "SKEWGAUS: A Fortran Program for Fitting Peaks in Semiconductor Detector Spectra," IS-3460, Ames Laboratory, Iowa State University (1974).

11. M. $\mathrm{M}_{33}$ Bretscher and W. C. Redman, "Low Flux Measurements of ${ }^{239} \mathrm{Pu}$ and ${ }^{33}$ Capture-to-Fission Ratios in a Fast Reactor Spectrum," Nuc1. Sci. Eng. 39, 368 (1970).

12. M. M. Bretscher, "Li as a Reference Absorber for Capture-to-Fission Ratio Measurements in Zero Power Fast Critical Assemblies," Reactor Physics Division Annual Report, July 1, 1967 to June 30, 1968, ANL-7410, pp. 178-182, Argonne Nationa1 Laboratory (1969).

13. P. H. Kier and M. Salvatores, "The Effect of Local Flux Distortions on the Doppler Effect of Small Fissile Samples," Nucl. Sc1. Eng. 53, 479-482 (1974). 

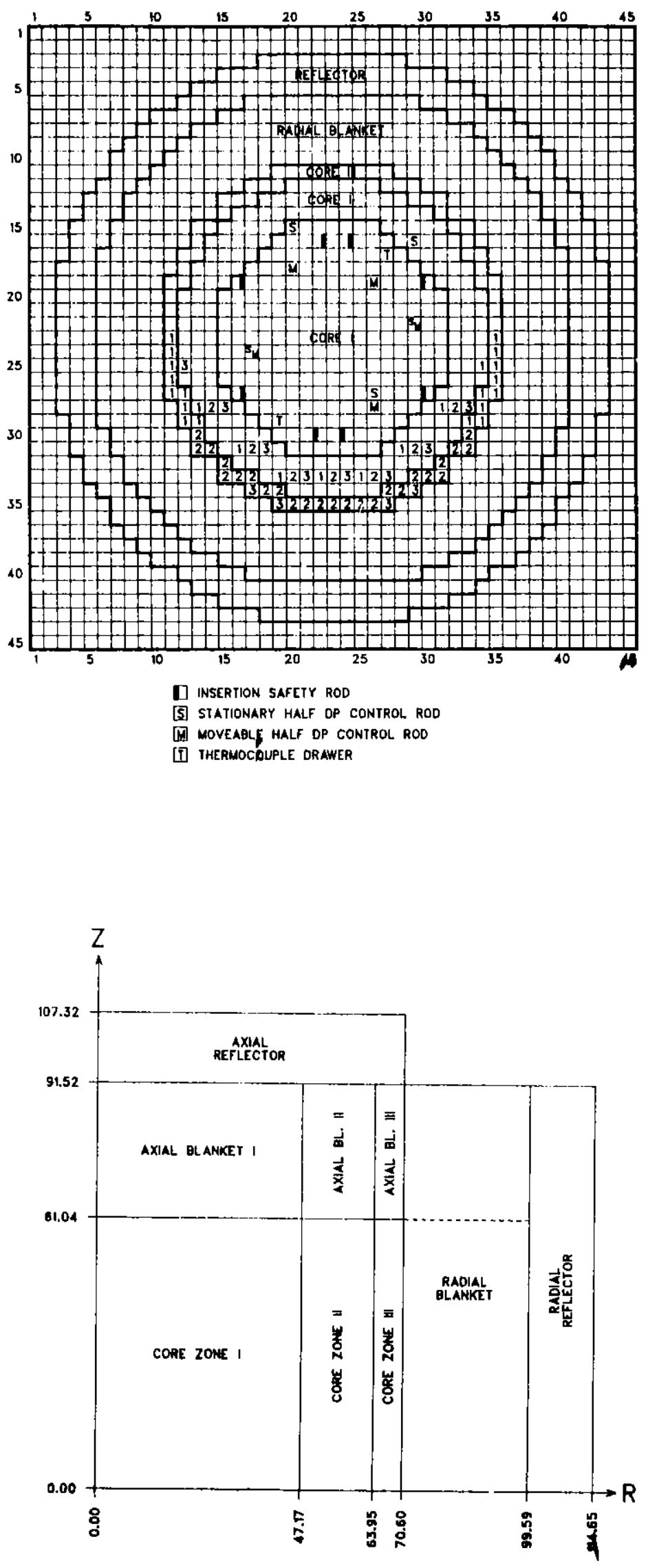

Fig. I-1.

Matrix Loading for the GCFR Phase III Reference Configuration.

ANL Neg. No. 116-80-43
Fig. I-2.

RZ Geometry for the GCFR Phase III Reference Configuration.

ANL Neg. No. 116-80-35 

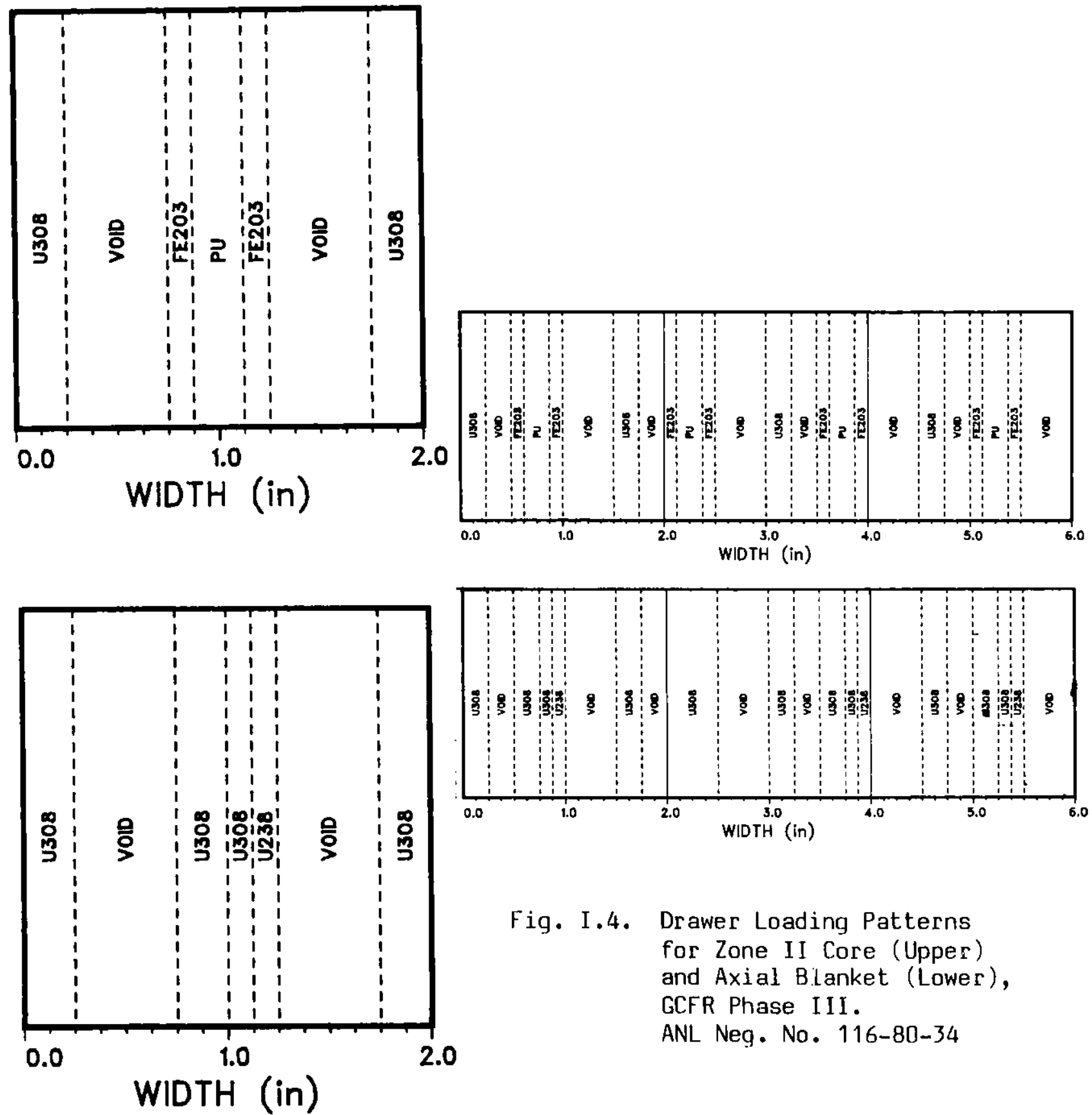

Fig. I.4. Drawer Loading Patterns for Zone II Core (Upper) and Axial Blanket (Lower), GCFR Phase III.

ANL Neg. No. 116-80-34

Fig. I-3. Drawer Loading Patterns for Zone I Core (Upper) and Axial Blanket (Lower), GCFR Phase II I.

ANL Neg. No. 116-80-30 

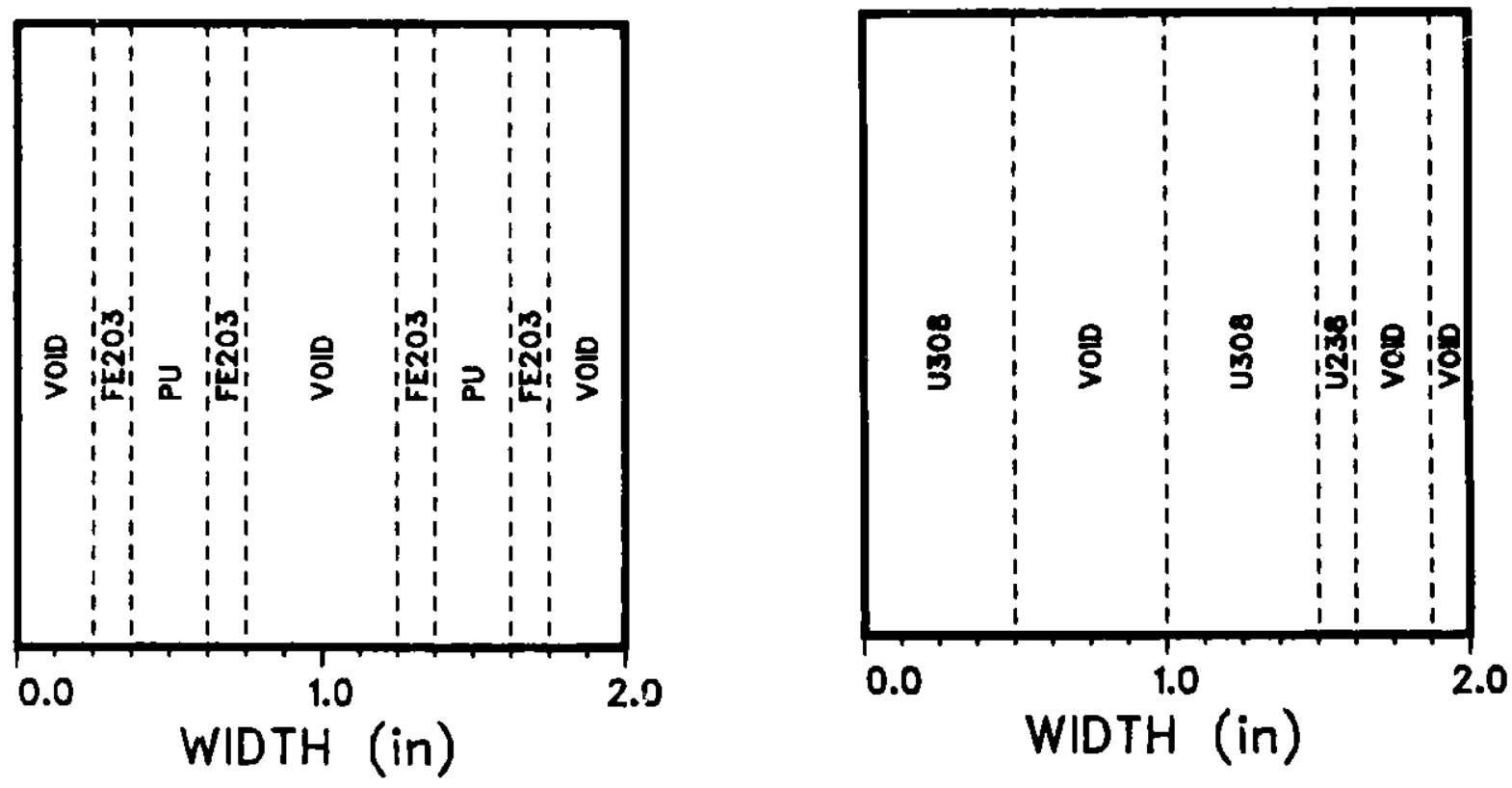

Fig. I-6. Drawer Loading Pattern for the Radial Blanket Region, GCFR Phase III. ANL. Neq. No. 116-80-54

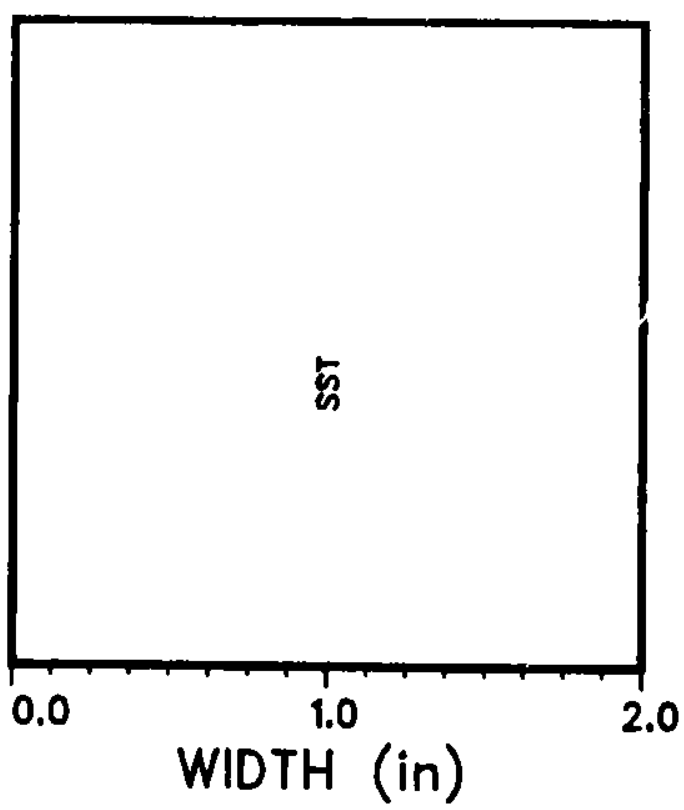

Fig. I-7. Drawer Loading Pattern for the Reflector Region, GCFR Phase III. ANL Neg. No. 116-80-53. 


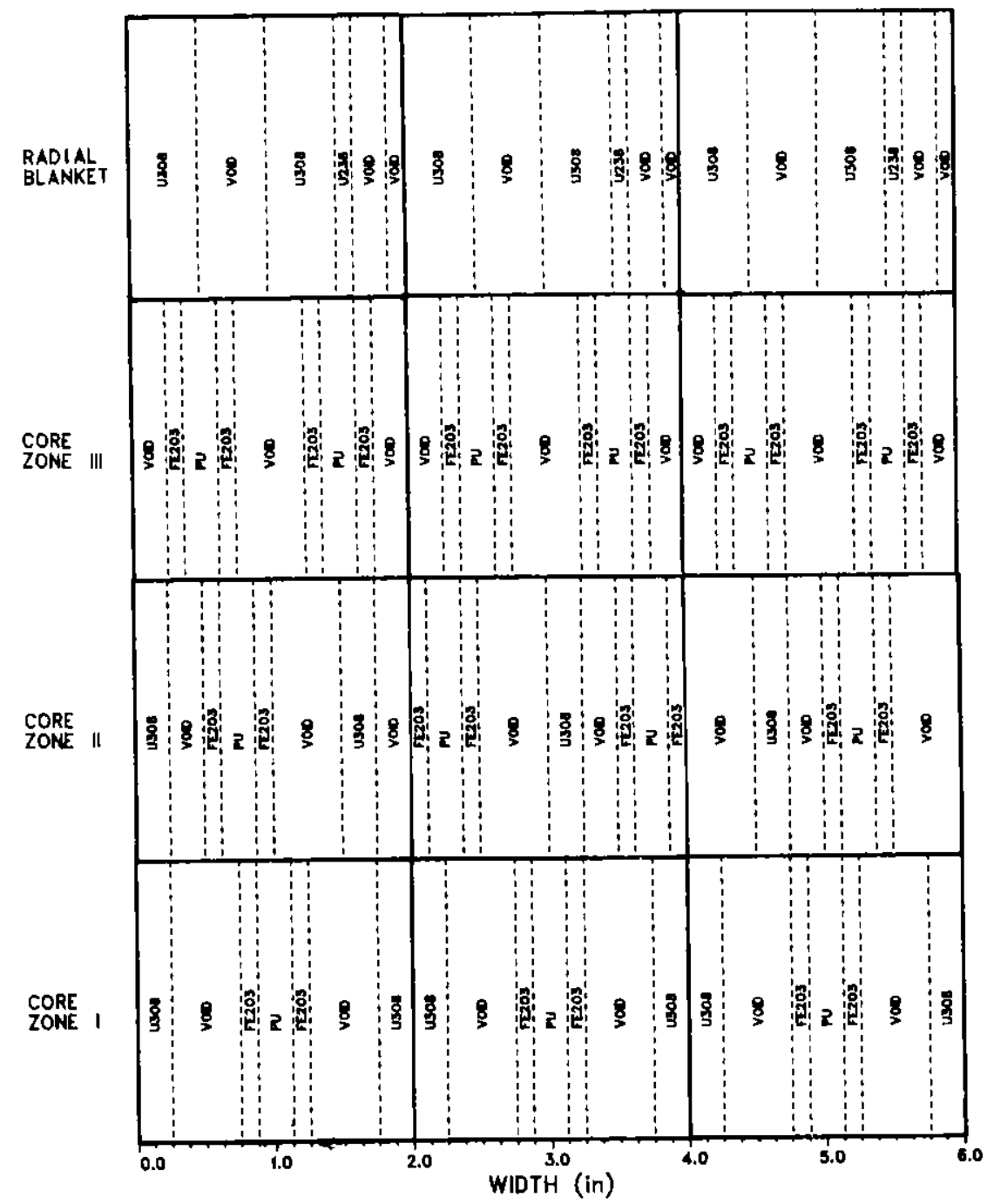

GCFR Phase IIt Core Zone I

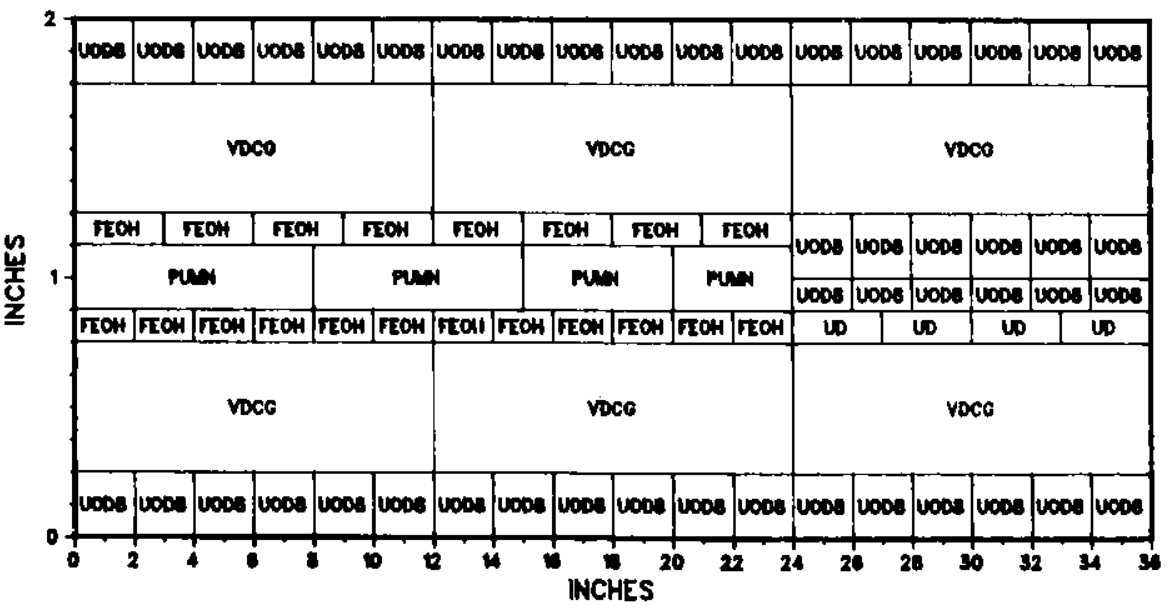

Fig. I-8.

Drawer Loading Patterns Illustrating the Disruption of Vertical Streaming Paths at Zone and Region Interfaces. ANL. Neg. No. 116-80-11
Fig. I-9.

GCFR Phase III Stationary Half Drawer Master for Zone I Core Plus Axial Blanket. ANL Neg. No. 116-80-10 
GCFR Phase III Core Zone II Type 1

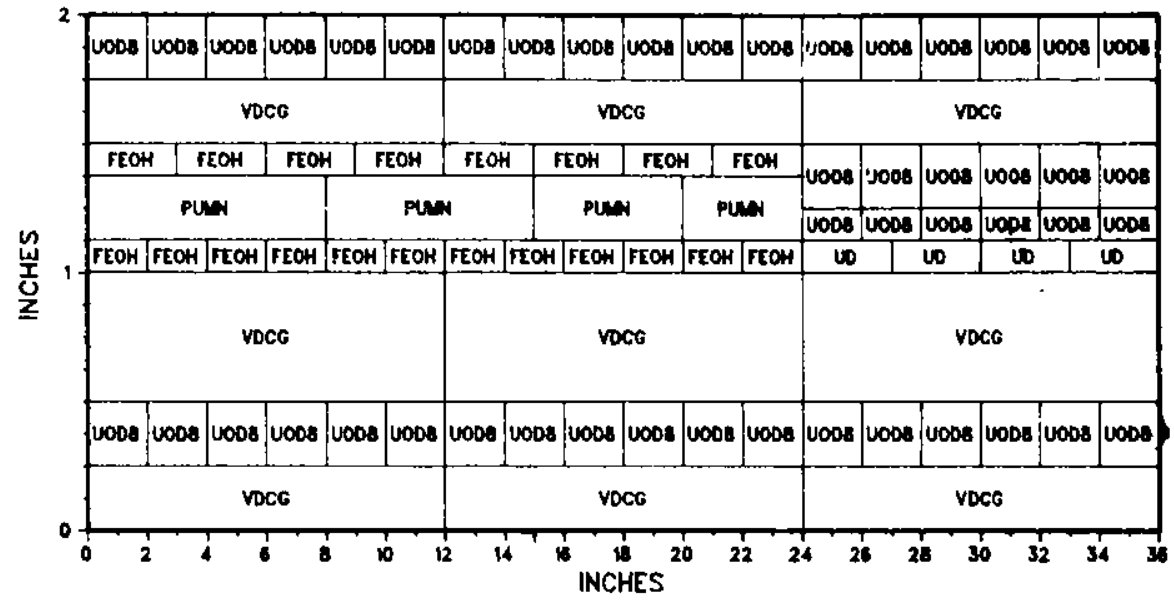

Fig. i.10. GCFR Phase III Stationary Half Drawer Master for Zone II, Type 1 Core Plus Axial Blanket. ANL Neg. No. 116-80-33

GCFR Phase III Core Zone II Type 2

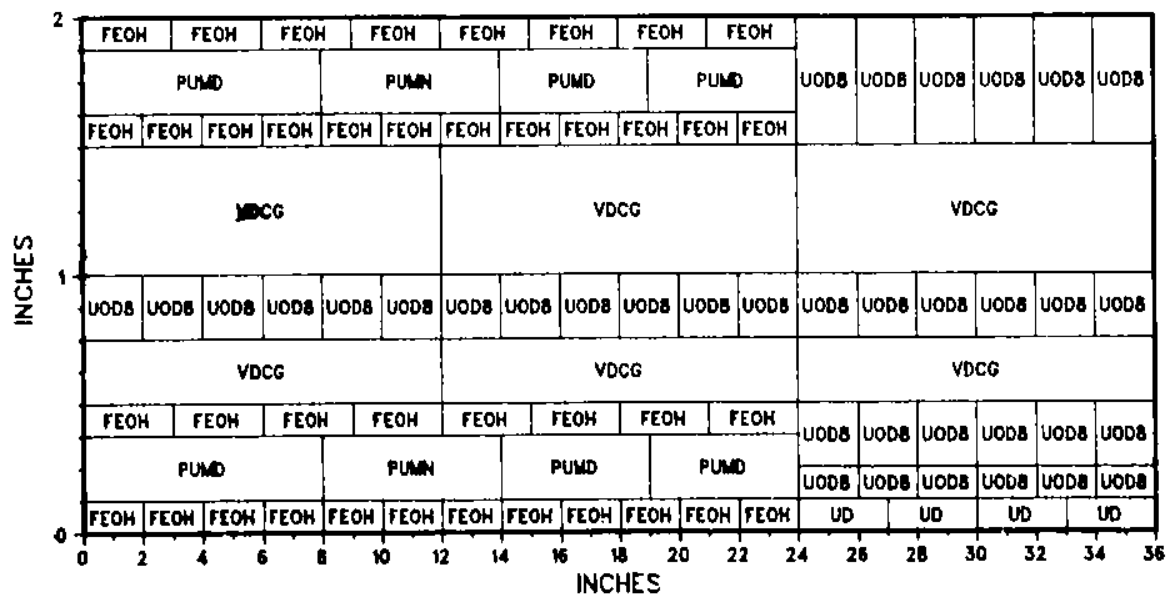

Fig. I-11. GCFR Phase III Stationary Half Drawer Master for Zone II, Type 2 Core Plus Axial Blanket. ANL Neg. No. 116-80-32 
GCFR Phose III Core Zone II Typo 3

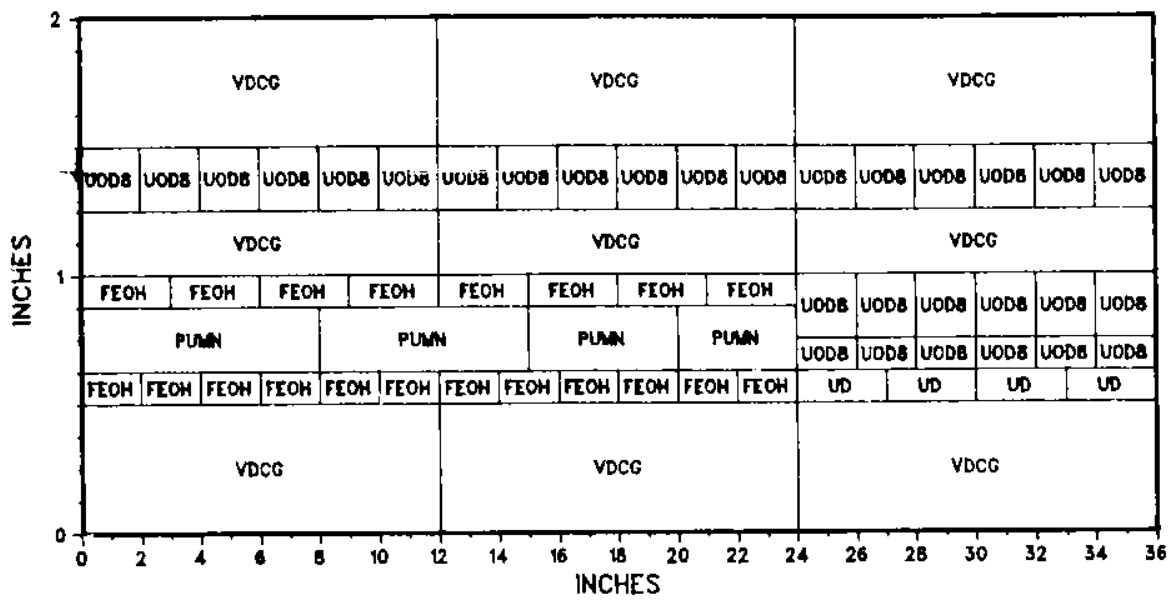

Fig. I-12. GCFR Phase III Stationary Half Drawer Master for Zone II, Type 3 Core Plus Axial Blanket. ANL Neg. No. 116-80-31.

GCFR Phase III Core Zone III

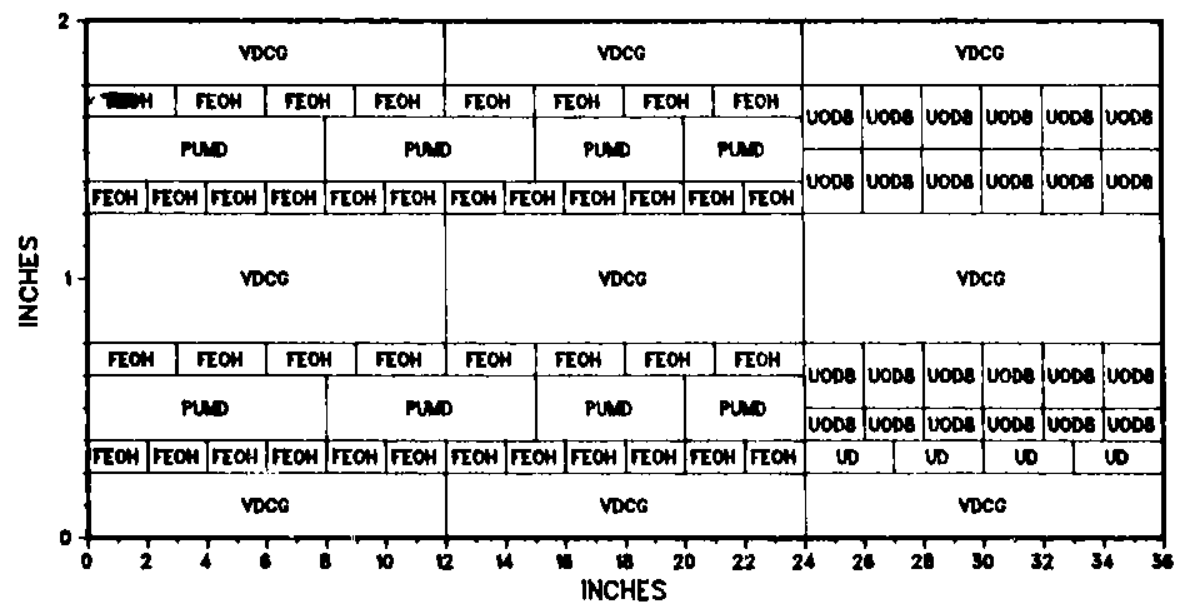

Fig. I-13. GCFR Phase III Stationary Half Drawer Master for Zone III, Type 1 Core Plus Axial Blanket. ANL Neg. No. 116-80-42. 
GCFR Phose III Radial Blanket

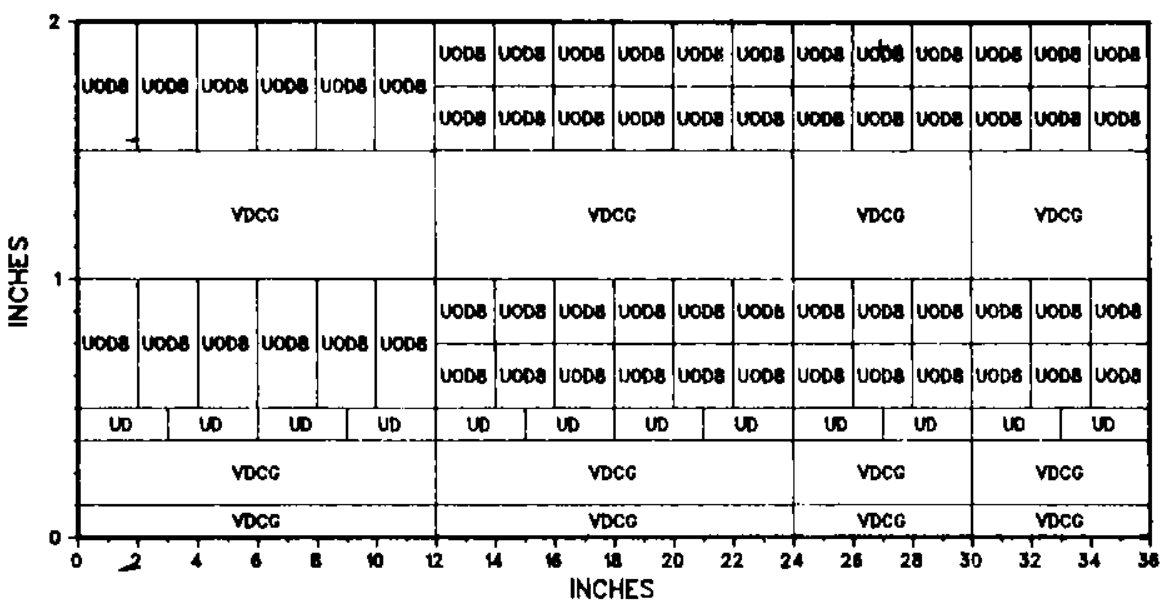

Fig. I-14. GCFR Phase III Stationary Half Drawer Master for the Radial Blanket.

ANL Neg. No. 116-80-41

GCFR Phase III Radial Reflector

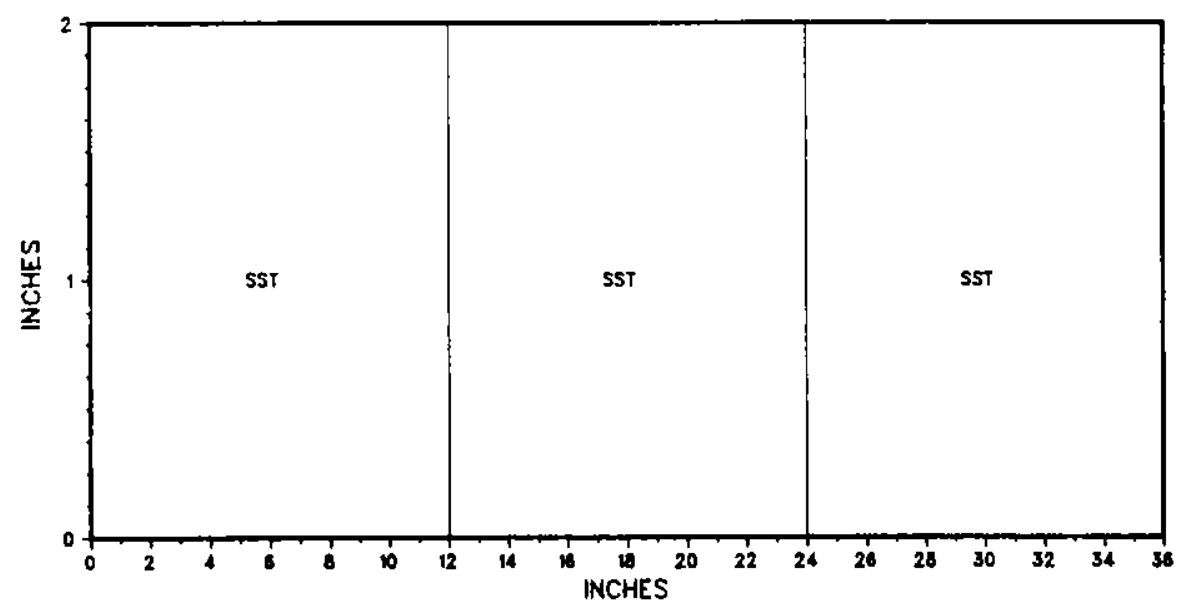

Fig. I-15. GCFR Phase III Stationary Half Drawer Master for the Radial Reflector. ANL Neg. No. 116-80-57. 

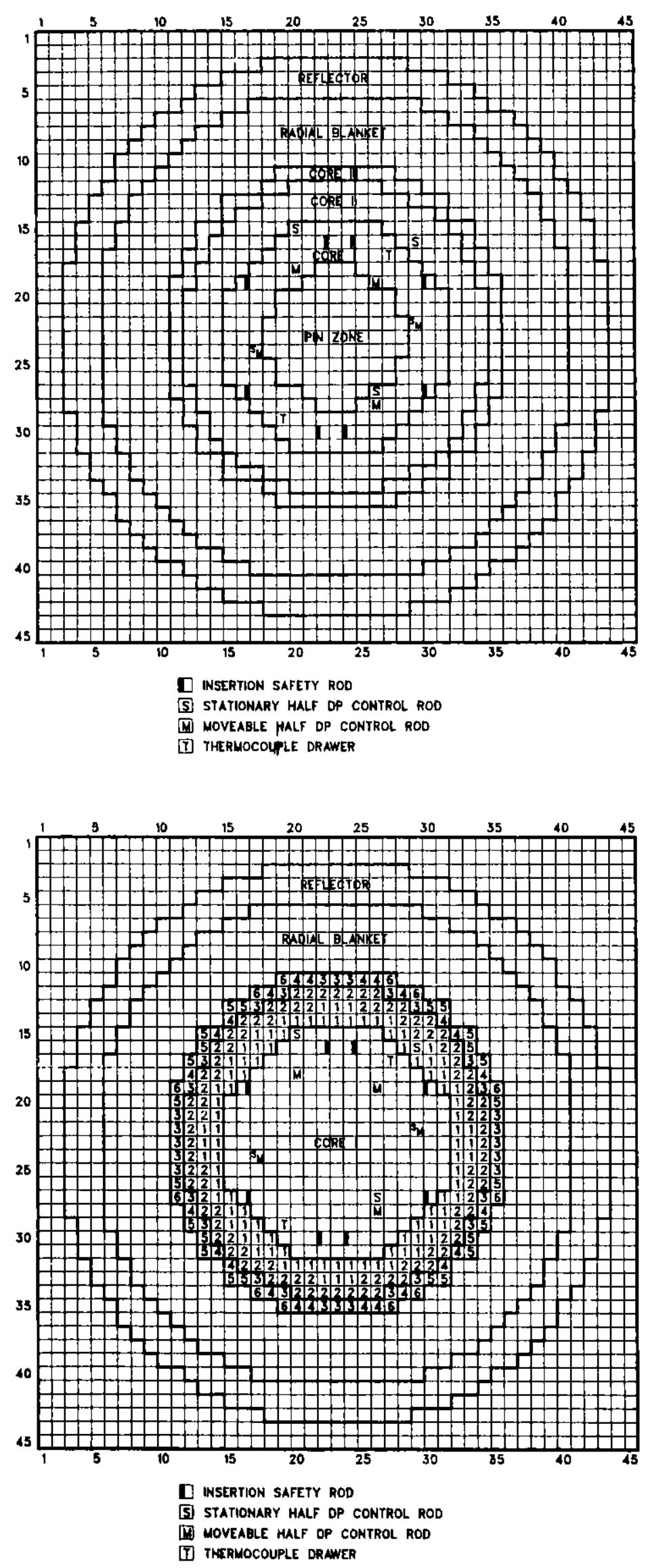

Fig. I-16.

Matrix Loading for the GCFR Phase III Pin Zone Reference Configuration.

ANL Neq. No. 116-80-51
Fig. I-17.

Drawer Loading Pattern in the GCFR Phase III Approach-toCritical.

ANL Neg. No. 116-80-52 


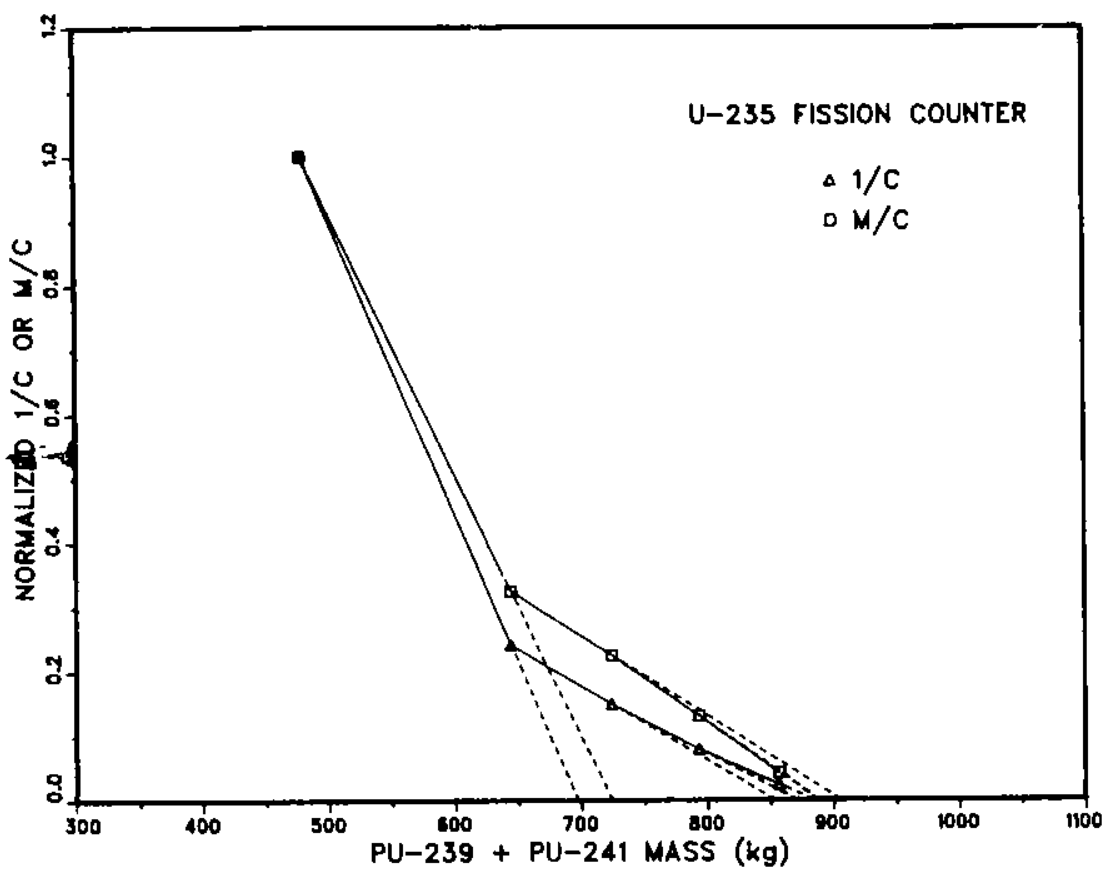

Fig. I-18. Approach-to-Critical Plots for U-235

Fission Counter in S-23/23 Axial

Blanket.

ANL Neg. No. 116-80-18

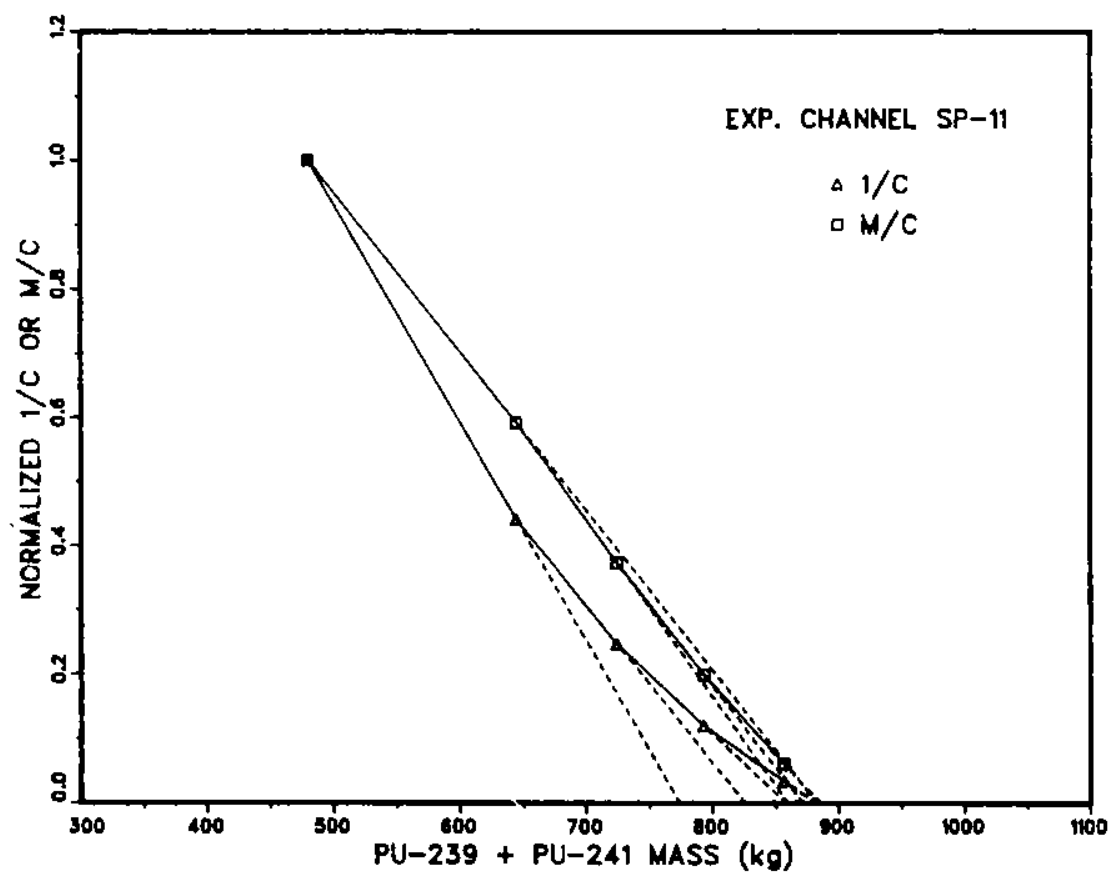

Fig. I-19. Approach-to-Critical Plots for Experimental Channel SP-11.

ANL Neg. No. 116-80-36 


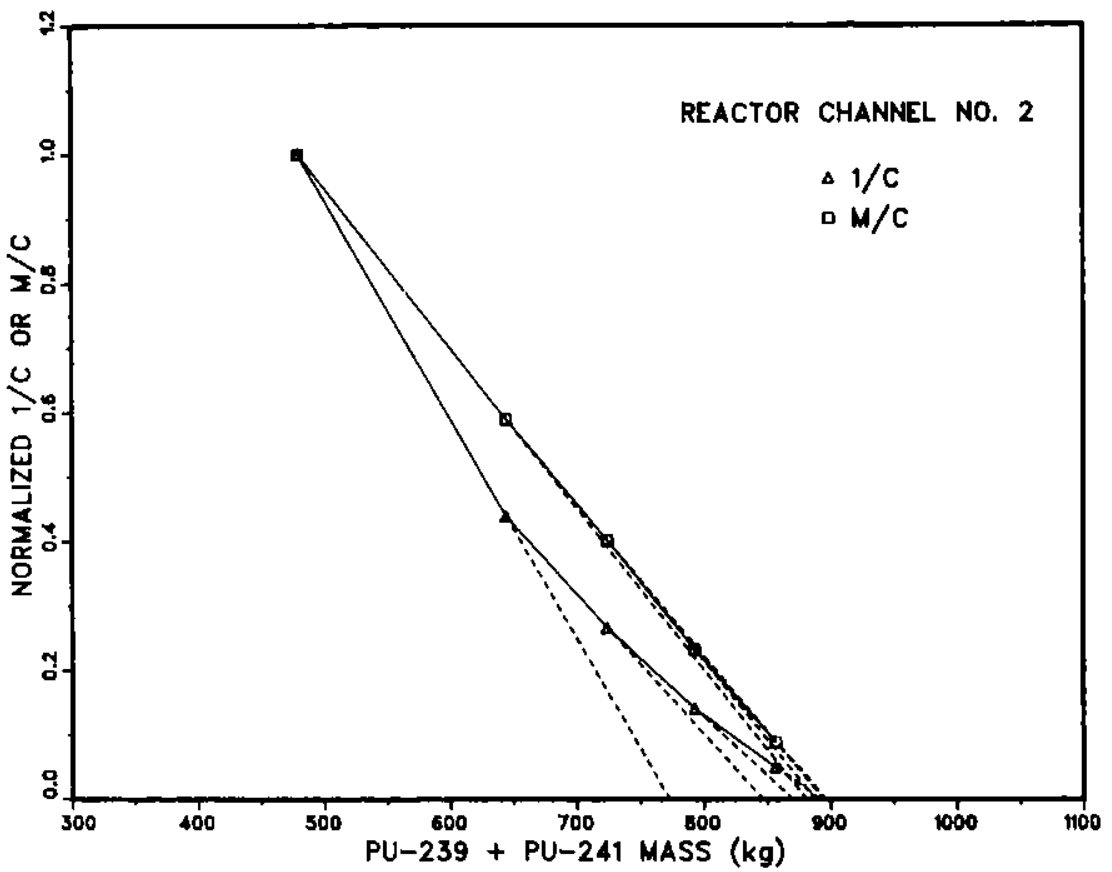

Fig. I-20. Approach-to-Critical Plots for Reactor Channel No. 2.

ANL Neg. No. 116-80-55

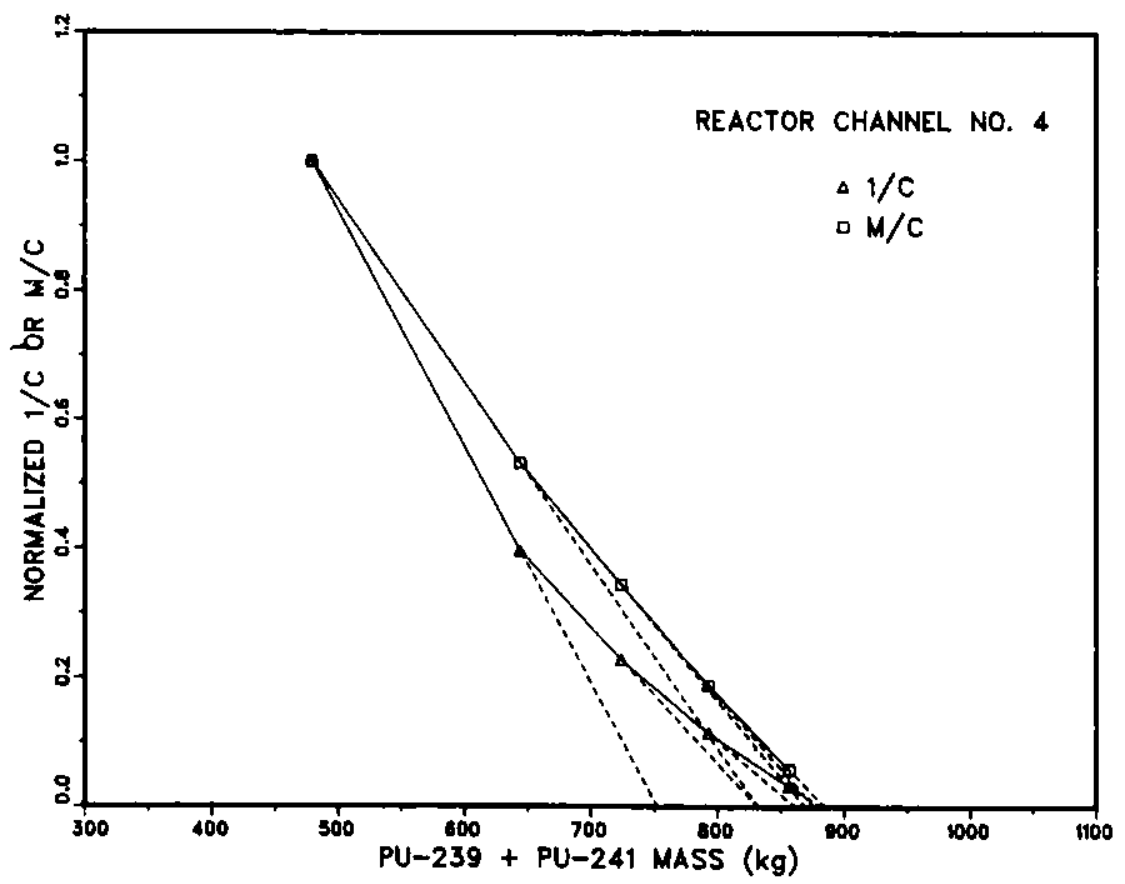

Fig. I-21. Approach-to-Critical Plots for Reactor Channel No. 4.

ANL Neg. No. 116-80-21 

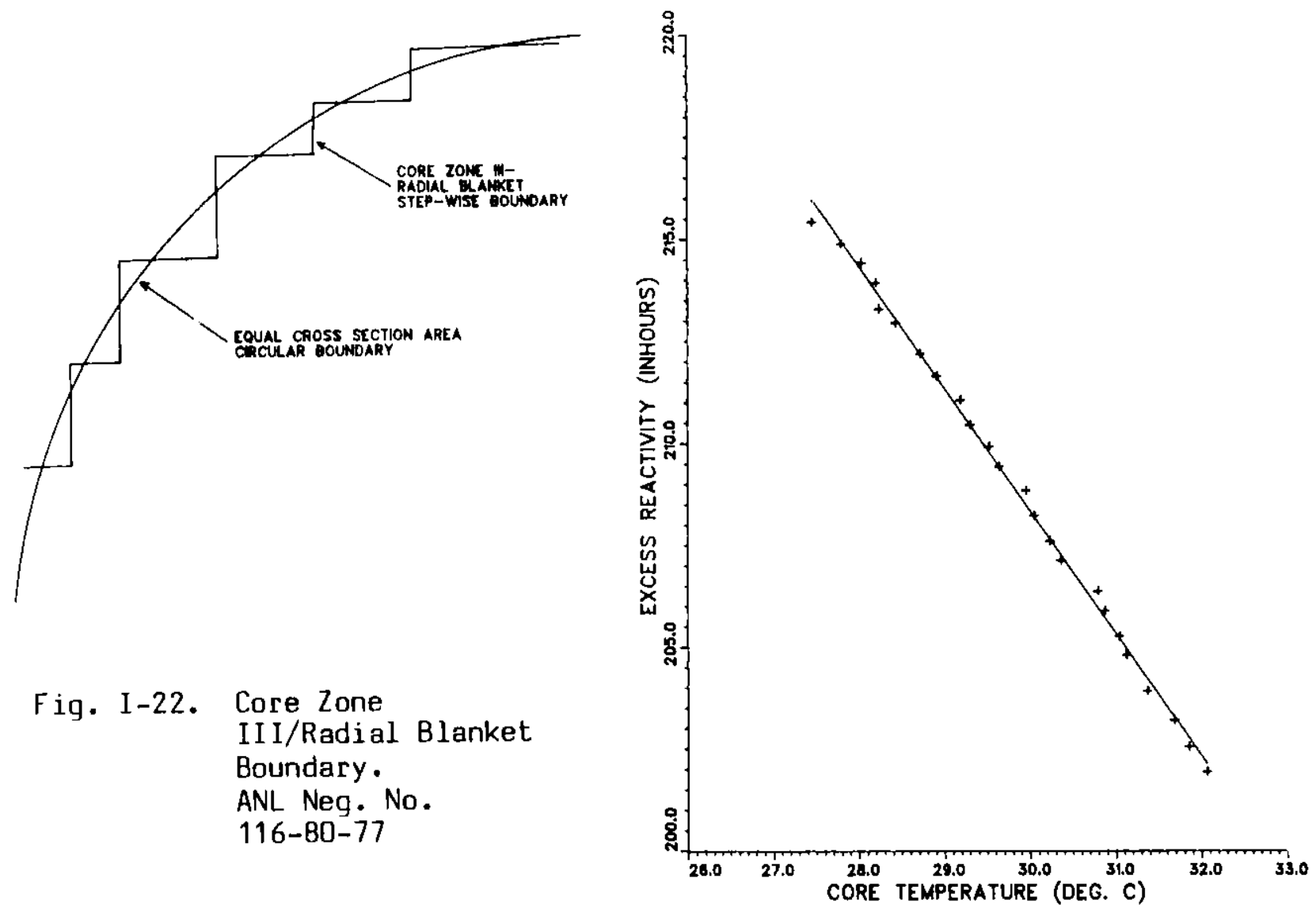

Fig. I-22. Core Zone

II I/Radial Blanket

Boundary.

ANL Neg. No.

116-80-77

Fig. I-23. Determination of GCFR

Phase III Temperature Coefficient.

ANL Neg. No. 116-80-75

$\mathrm{SP}-11$

SP-10

Fig. I-24.

Differences (SP-11

minus SP-10 in Inhours)

of $10_{B}$ Rod Worth as

Measured on Experimental Flux Channels.

ANL Neg. No. 116-80-76
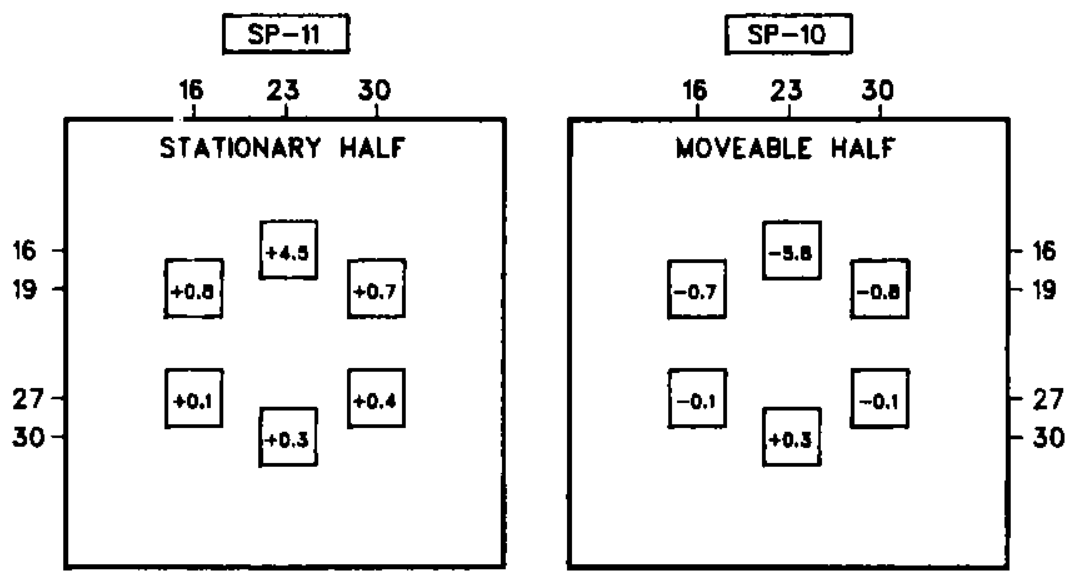


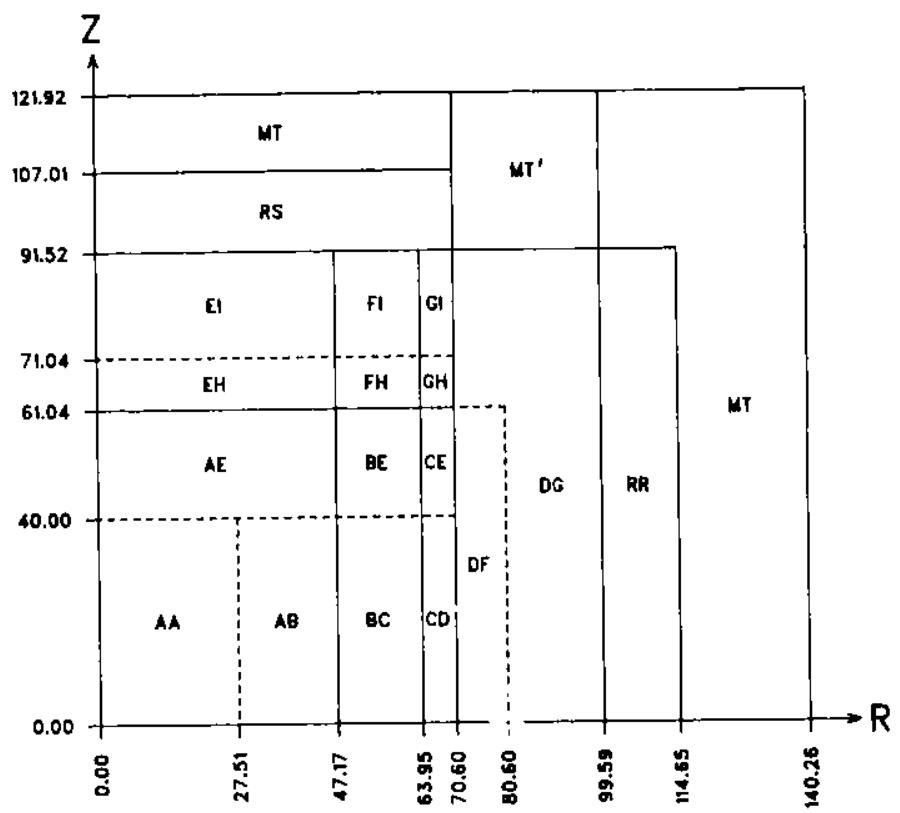

Fig. II-1. RZ Calculational Model of the GCFR Phase III Plate Reference Configuration.

ANL Neg. No. 116-80-60

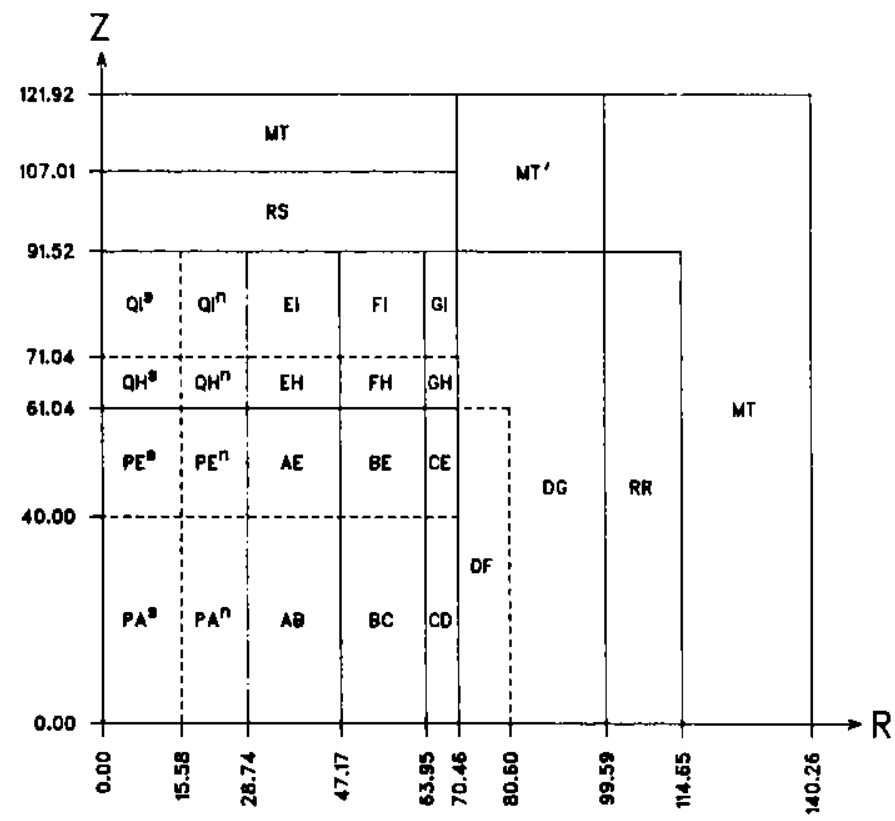

Fig. II-2. RZ Calculational Model of the GCFR Phase III Pin Zone Assembly.

ANL Neg. No. 116-80-62 


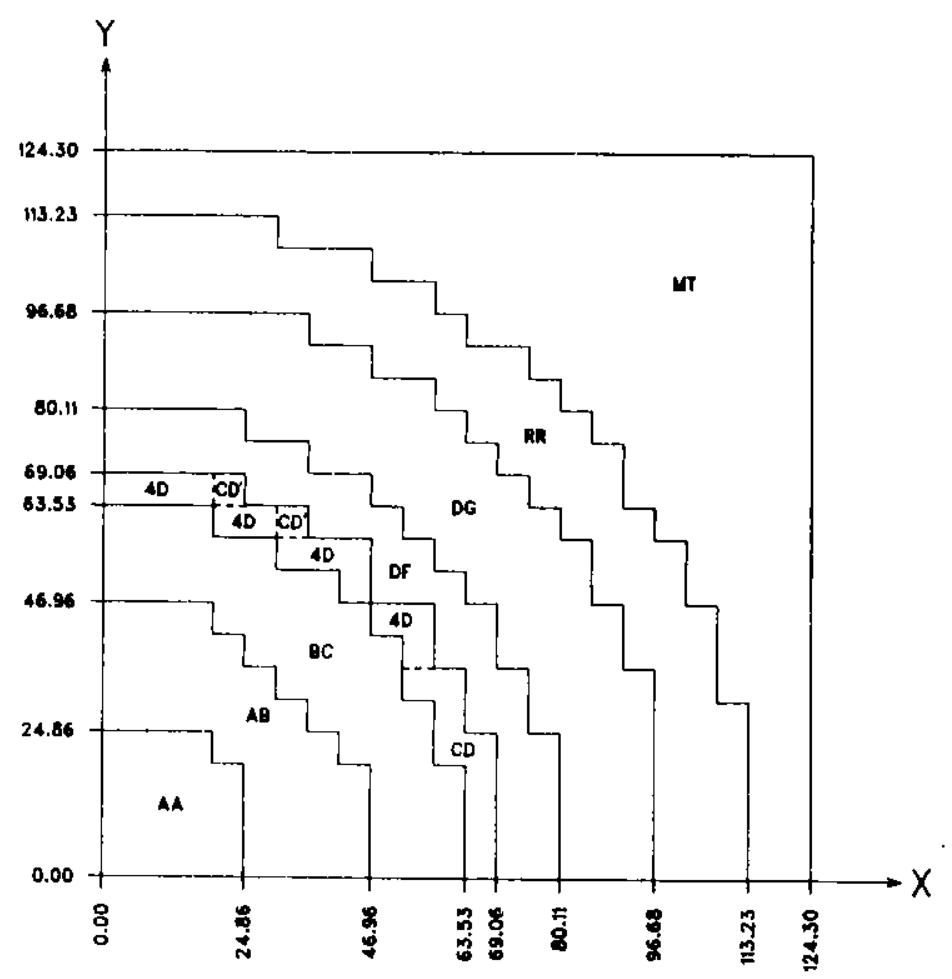

Fig. II-3.

$X Y$ Calculational Model of the GCFR Phase III Plate Reference Configuration. ANL Neg. No. 116-80-61

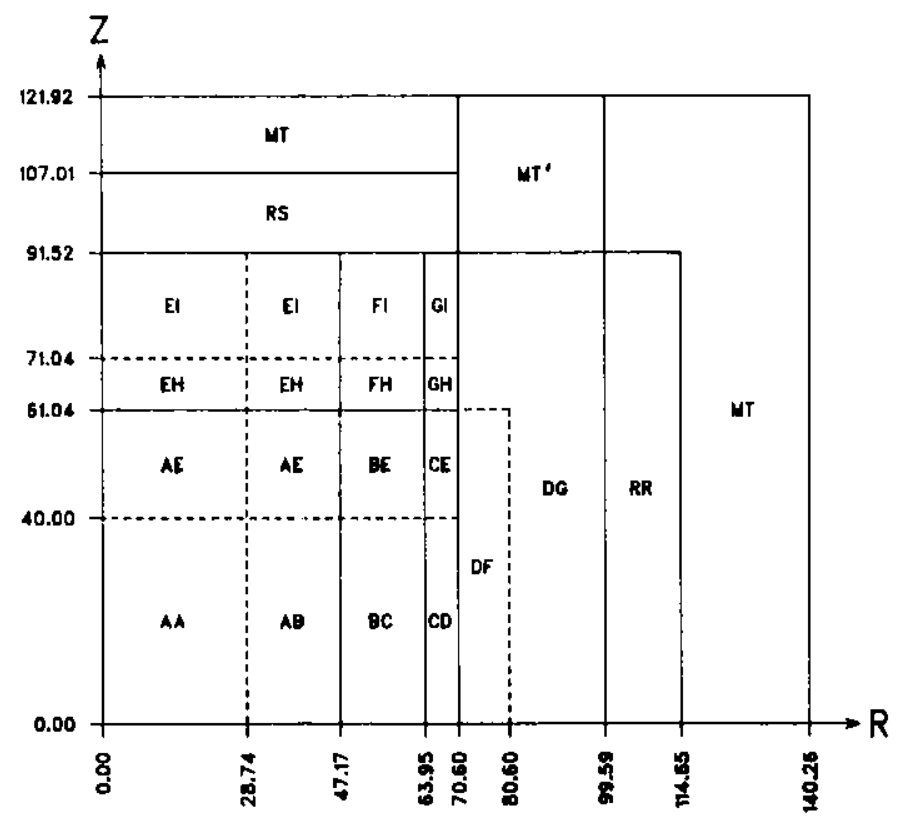

Fig. II-4.

Modified RZ Calculational Model of the GCFR Phase III Plate Reference Configuration. ANL Neg. No. 116-80-71 


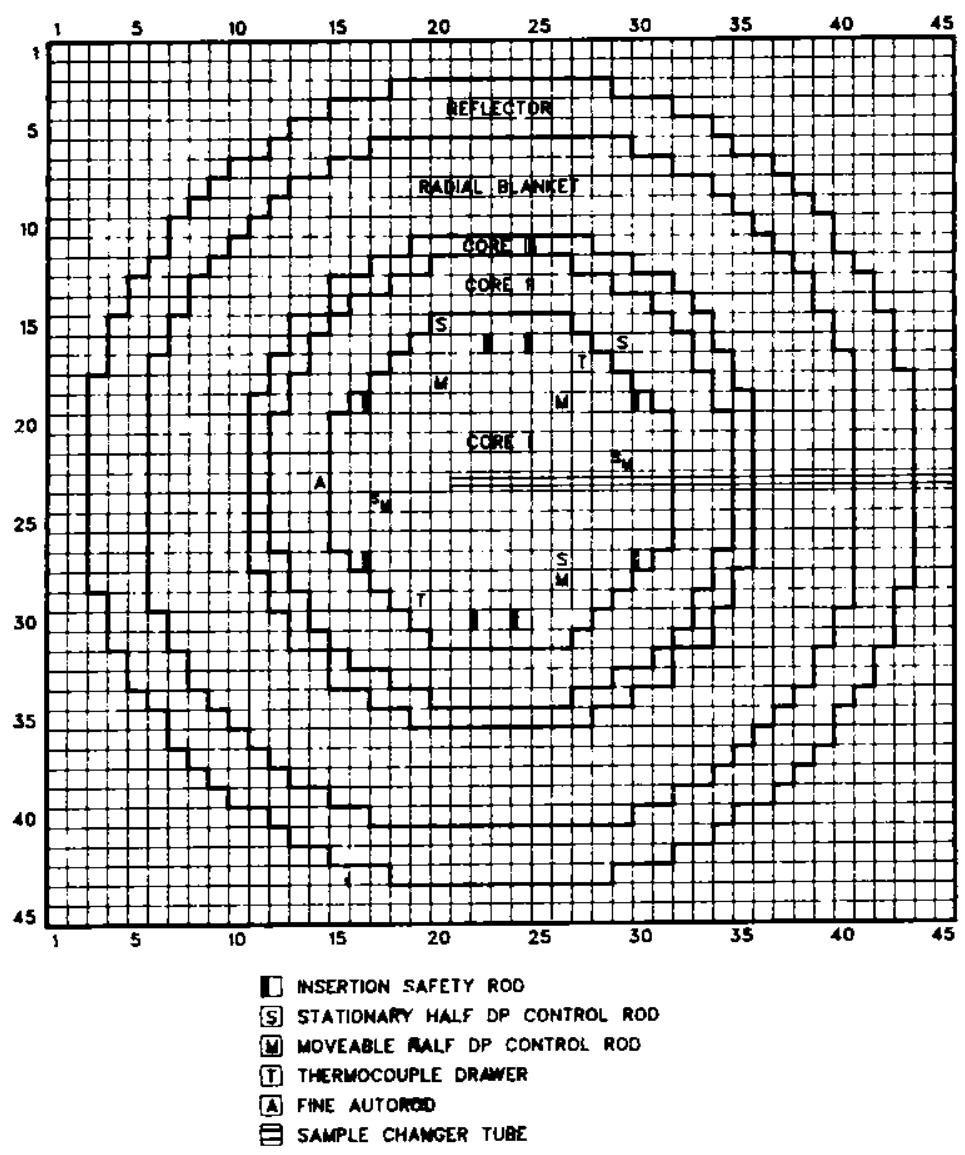

Fig. III-1. Matrix Configuration for the GCFR Phase III Small Sample Reactivity Worth Experiment.

ANL Neg. No. 116-80-22
MB-10 ( $\left.{ }^{239} \mathrm{Pu}\right)$ REACTIVITY-WORTH TRAVERSE

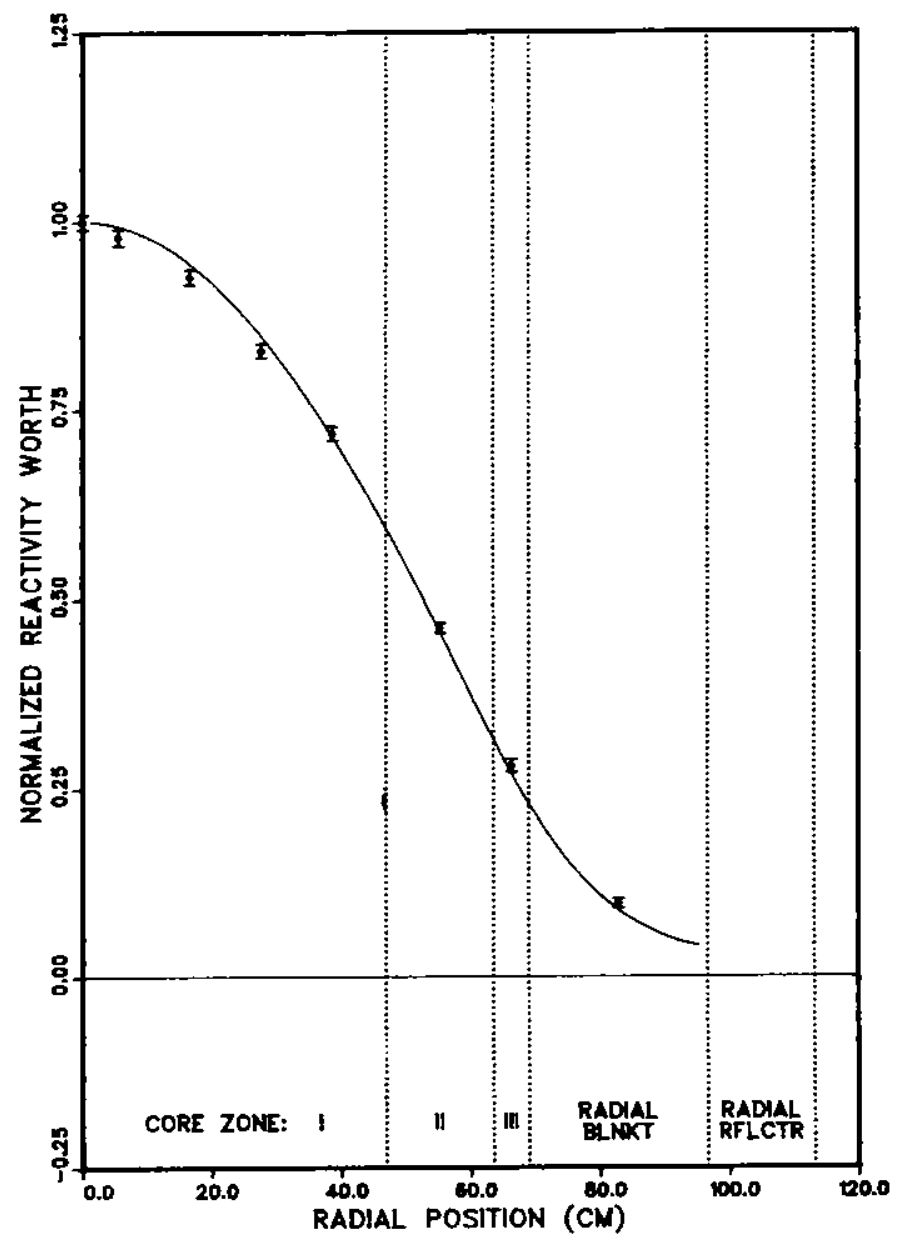

Fig. III-2. MB-10 (239Pu) Reactivity Worth Traverse.

ANL Neq. No. 116-80-13 
MB-21 $\left({ }^{235} U\right)$ REACTIVITY-WORTH TRAVERSE

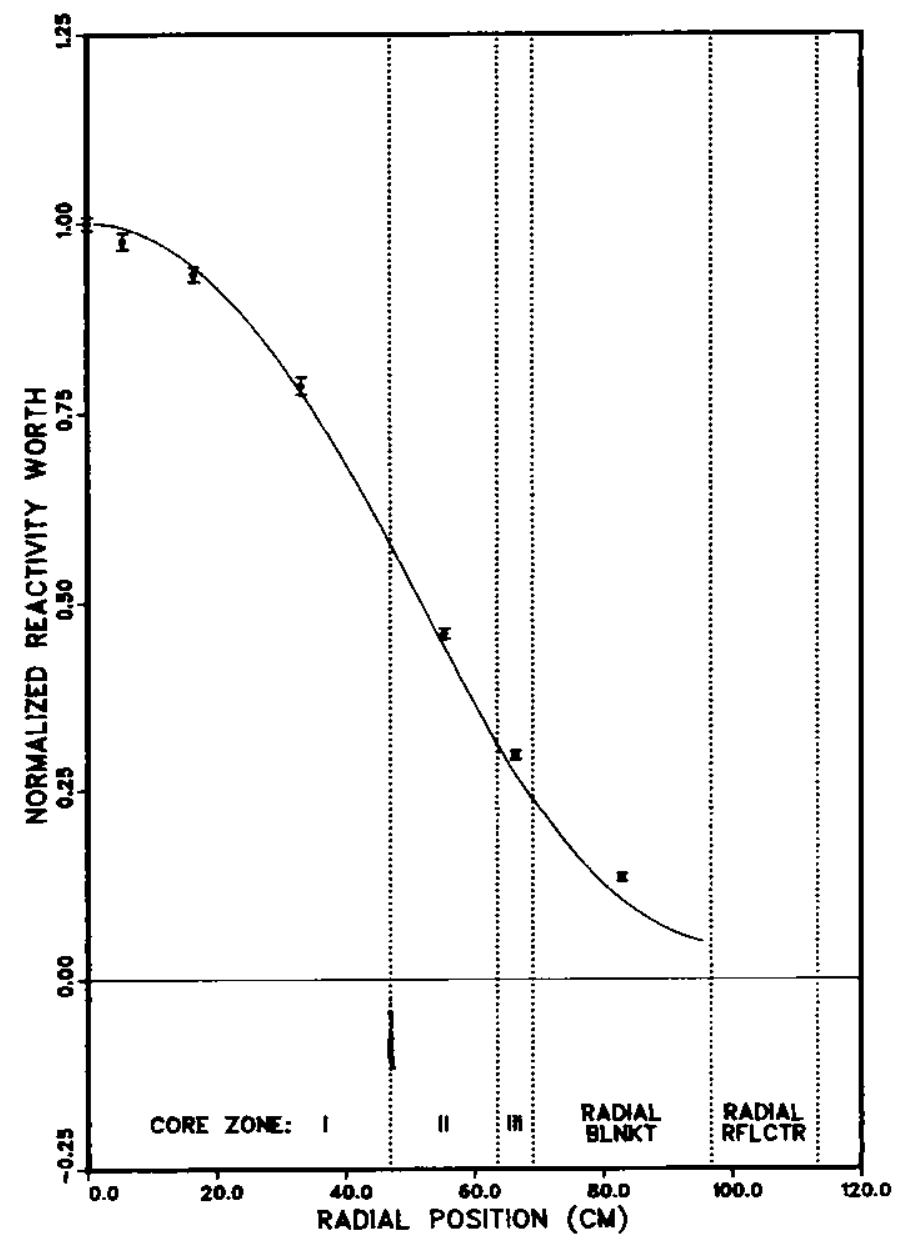

Fig. III-3. MB-21 (235U) Reactivity Worth Traverse. ANL N'eg. No. 116-80-12
MB-25 ( ${ }^{238_{U}}$ ) REACTIVITY-WORTH TRAVERSE

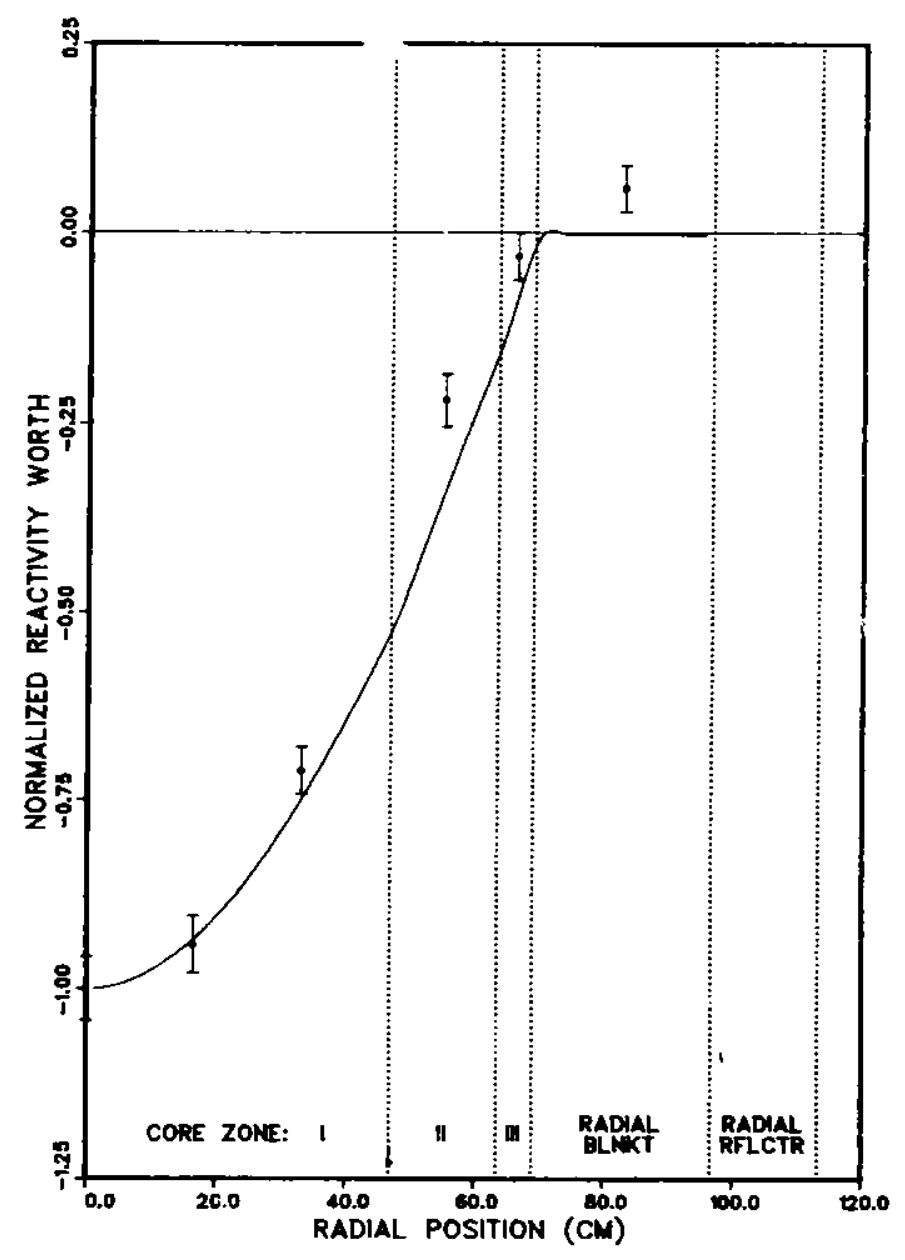

Fig. III-4. MB-25 (238U) Reactivity Worth Traverse.

ANL Neg. No. 116-80-23 
MB-19 (SST-304) REACTIVITY-WORTH TRAVERSE

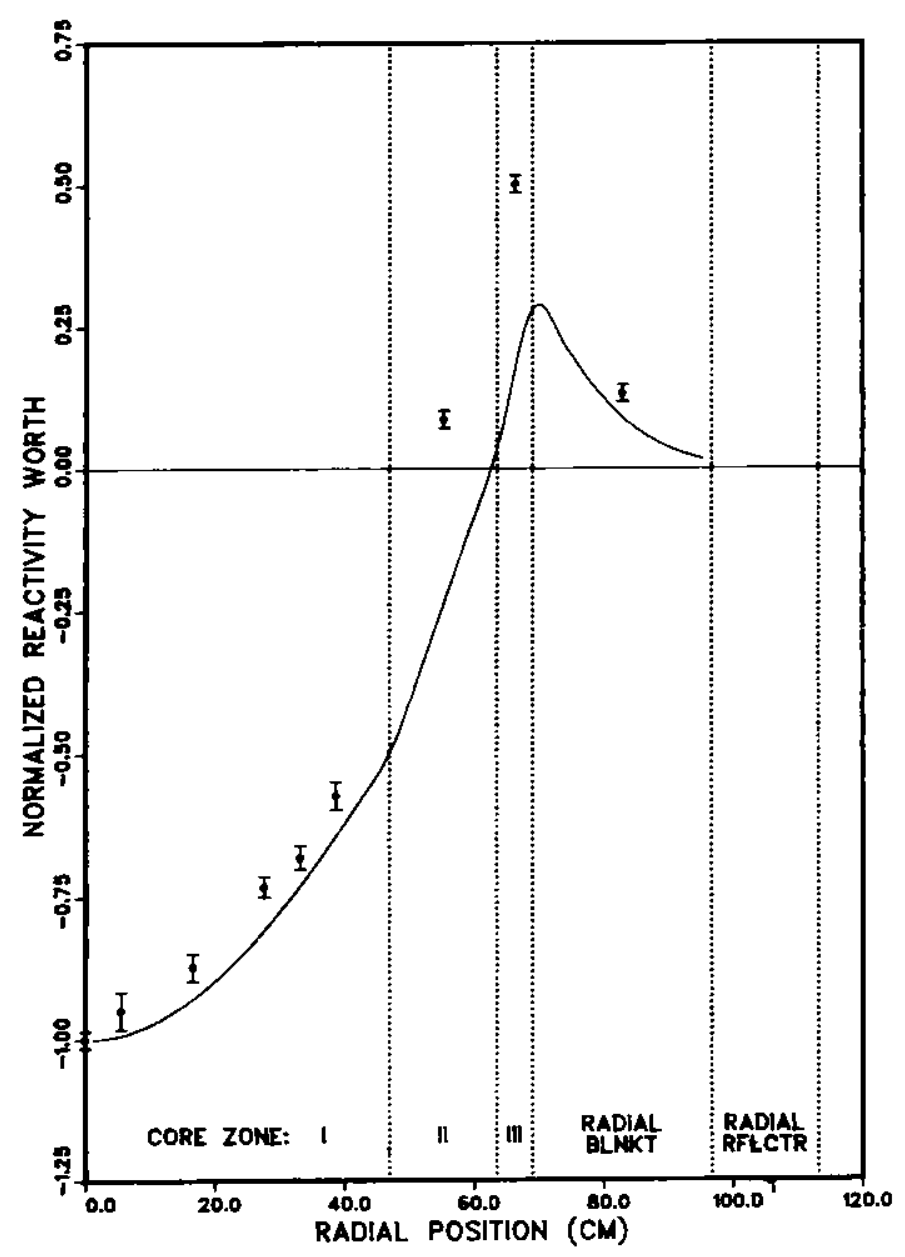

Fig. III-5. MB-19 (SST-304) Reactivity Worth Traverse.

ANL Neg. No. 116-80-24
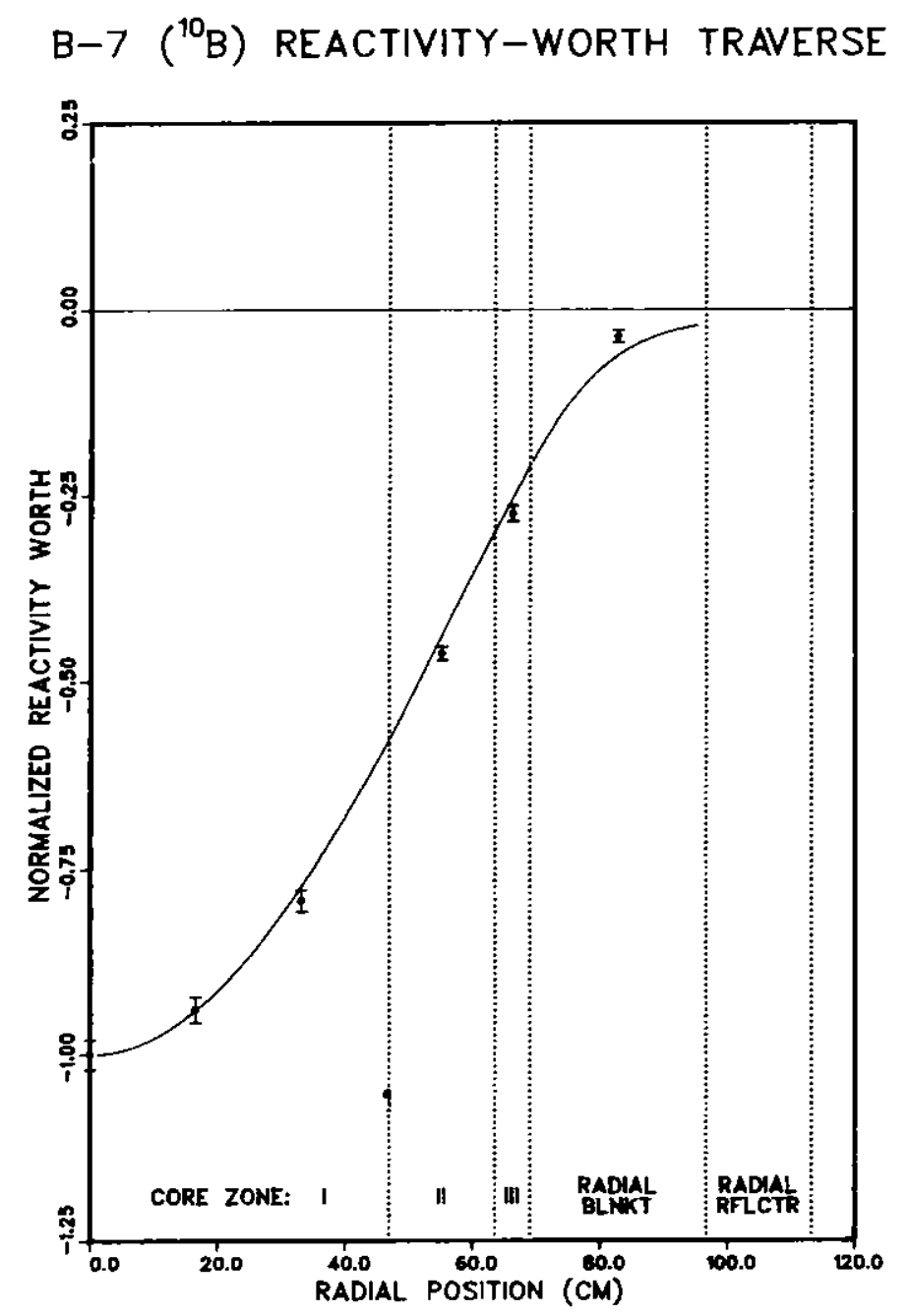

i

Fig. III-6. B-7 (10B) Reactivity Worth Traverse.

ANL Neg. No. 116-80-19 


\section{LI-5 ( $\left.{ }^{6} L i\right)$ REACTIVITY-WORTH TRAVERSE}

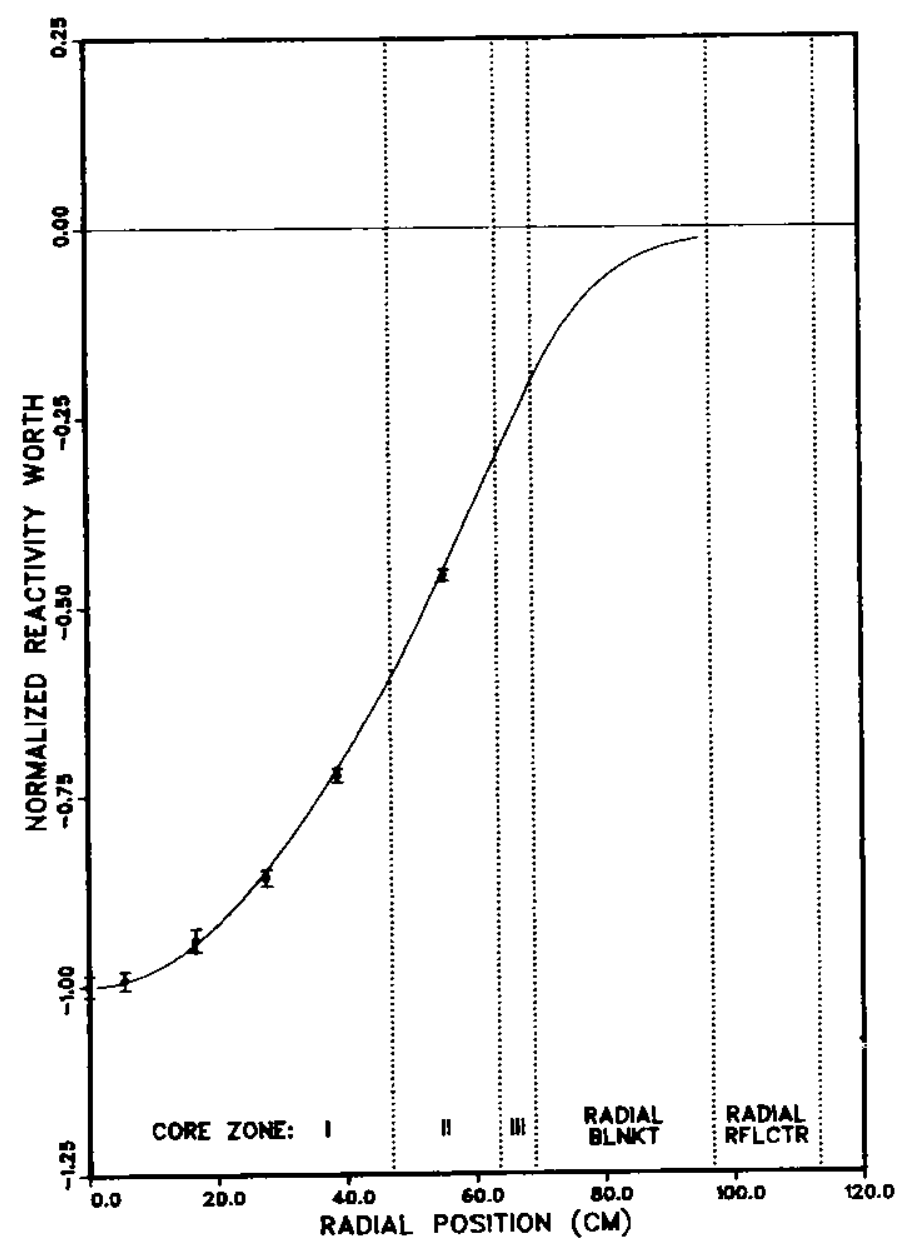

Fig. III-7. LI-5 ( $\left.{ }^{6} \mathrm{Li}\right)$ Reactivity Worth Traverse.

ANL Neg. No. 116-80-20
$\mathrm{CH}_{2}(\mathrm{~F})-6$ (CH ) REACTIVITY-WORTH TRAVERSE

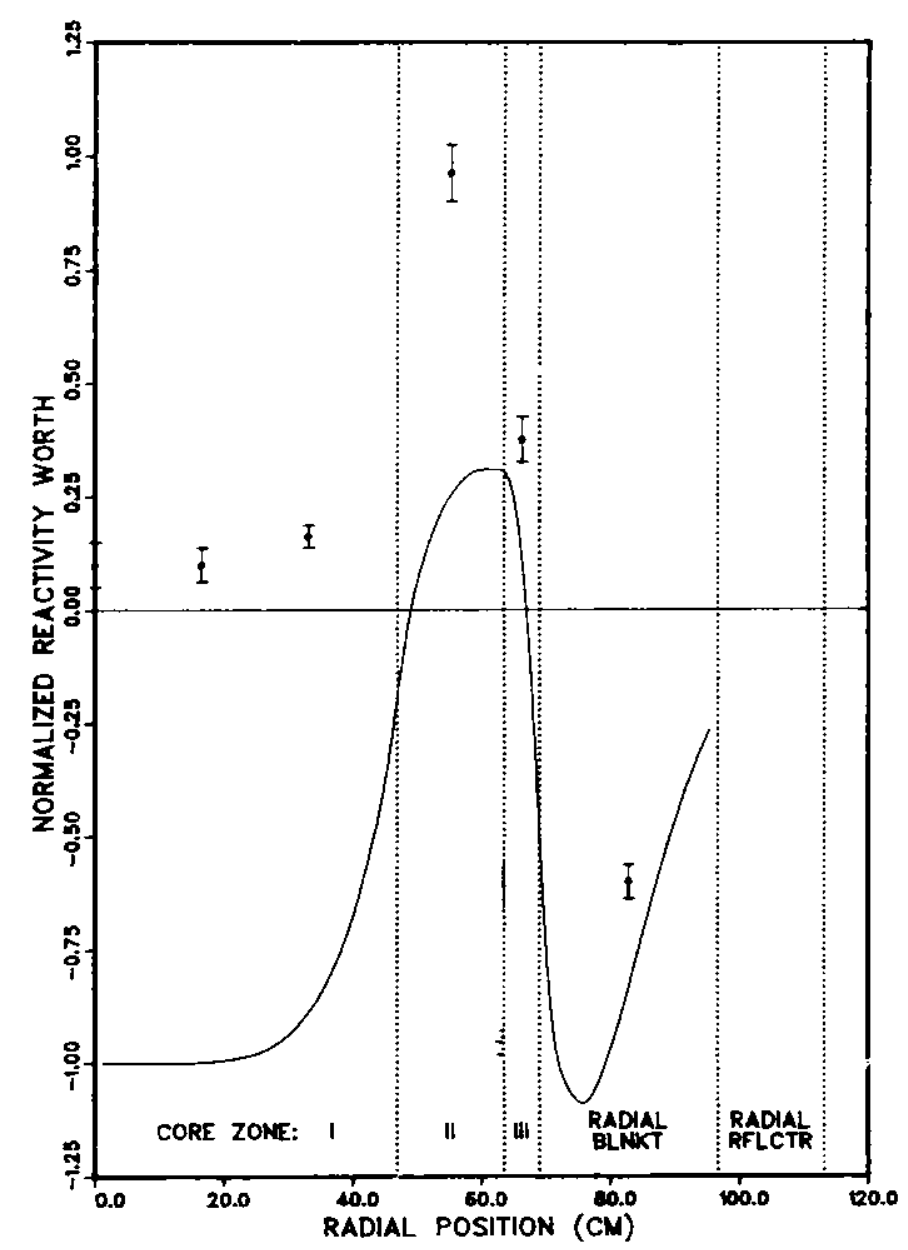

Fig. III-8. CH2(F) -6 Reactivity Worth Traverse.

ANL Neg. No. 116-80-56 

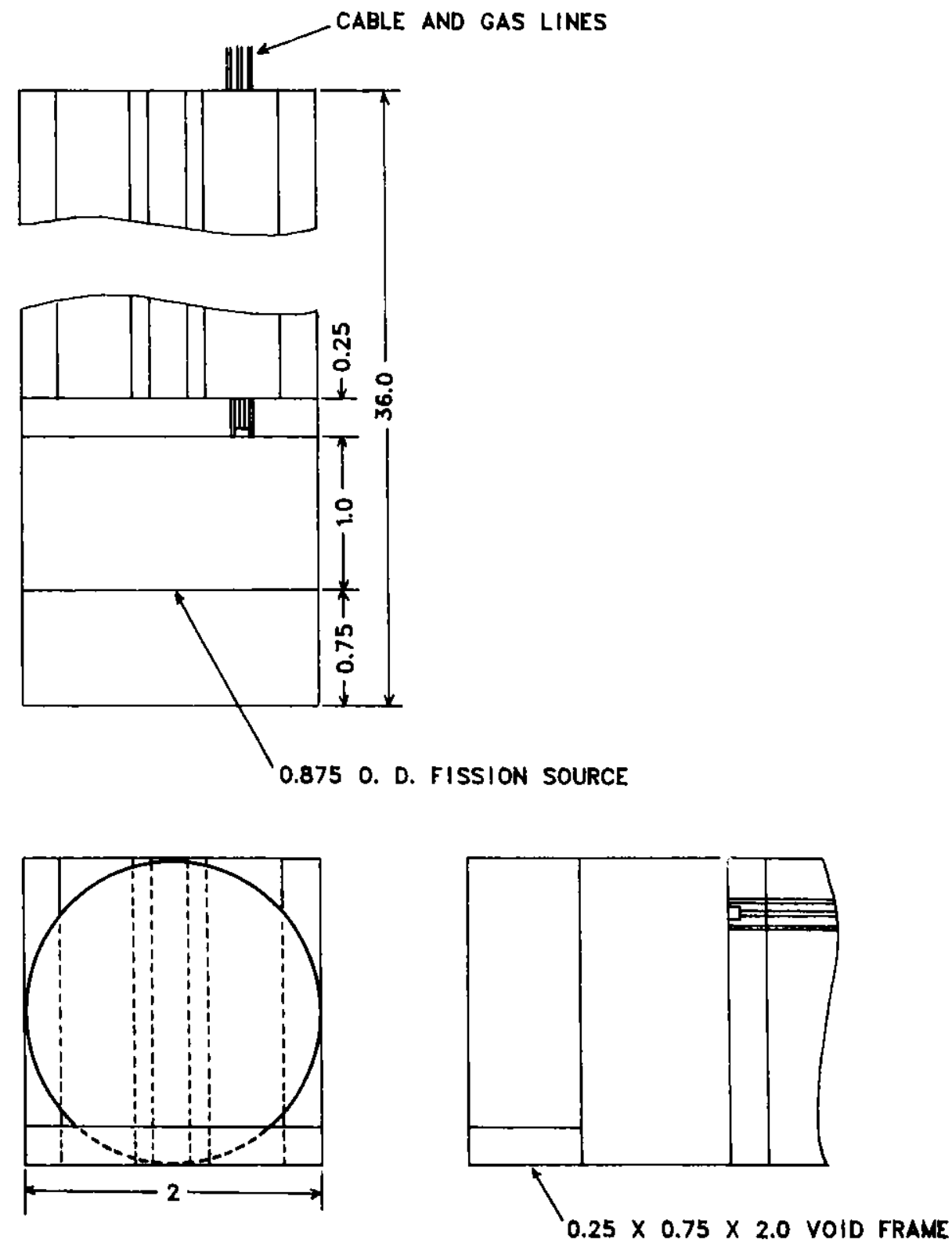

Fig. IV-1. Position of Fission Chamber Within Stationary Half Zone I Core Drawer.

ANL Neg. No. 116-80-48 


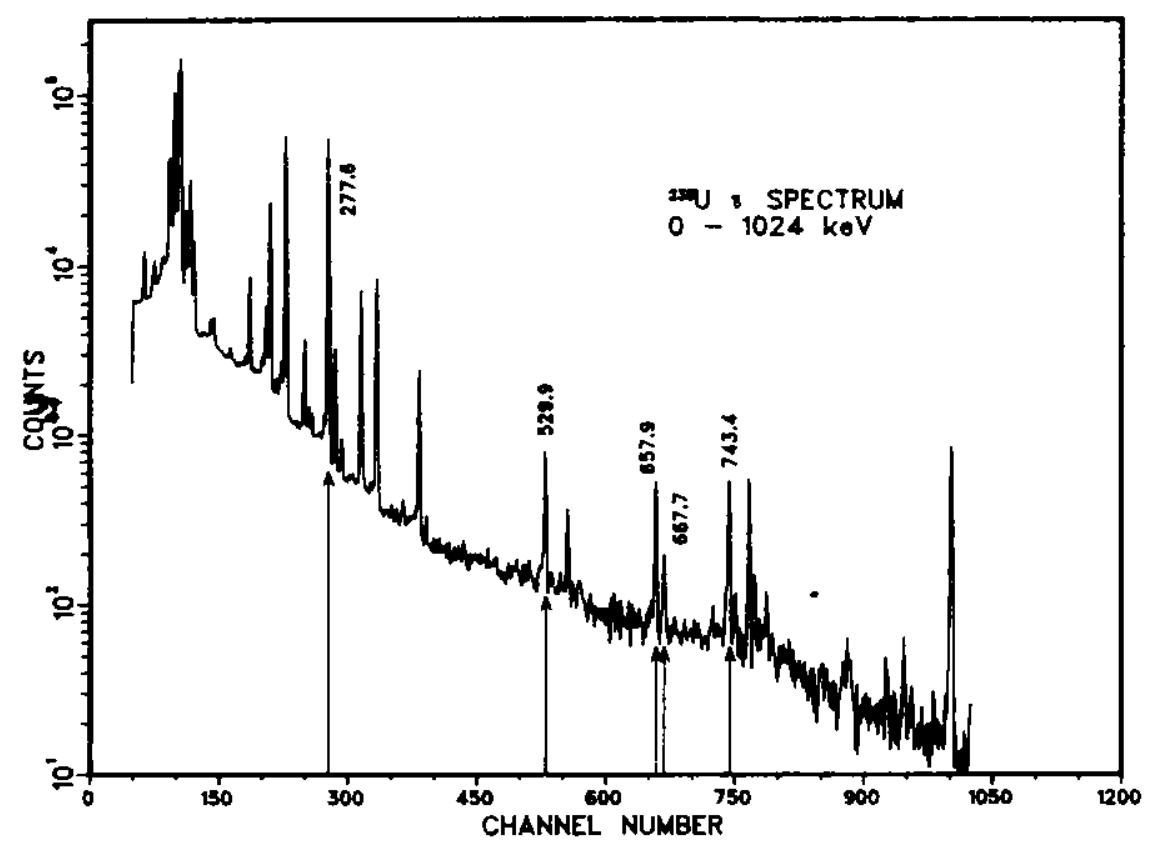

Fig. IV-2. Energy Spectrum of Gamma Rays Emitted Following Irradiation of Depleted Uranium Foils.

ANL Neg. No. 116-80-47

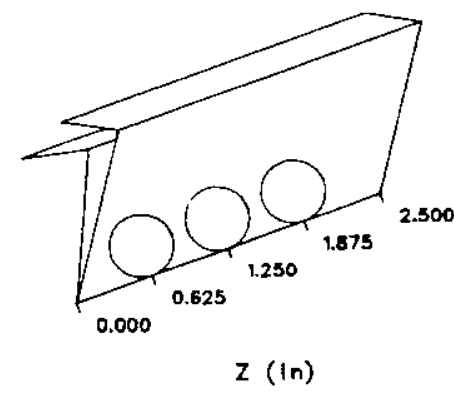

\begin{tabular}{|c|c|c|c|c|}
\hline $\begin{array}{l}\text { PACKET } \\
\text { TYPE }\end{array}$ & $\underset{\text { DEP }}{\text { rOI }}$ & $\begin{array}{l}\text { LOCA } \\
\text { ENR }\end{array}$ & ${ }_{\mathrm{PU}}^{10 \mathrm{~N}}$ & PACKET USE \\
\hline A & 0.625 & & & $f^{28} . c^{28}$ RADIAL TRAVERSE \\
\hline B & & 0.625 & 1.250 & $7^{25} . f^{49}$ RADIAL TRAVERSE \\
\hline c & 0.625 & 1.875 & & $\begin{array}{l}\text { UNIT CELL MEASUREMENTS } \\
\text { NEXT TO ALL BUT FUEL PLATES }\end{array}$ \\
\hline D & 0.625 & 1.875 & 1.250 & $\begin{array}{l}\text { UNIT CELL MEASUREMENTS } \\
\text { NEXT TO FUEL PLATES }\end{array}$ \\
\hline
\end{tabular}

Fiq. IV-3. Aluminum Foil Holders (1-mil thick) Used for Irradiations with Enriched and Depleted Uranium and Plutonium Foils.

ANL Neg. No. 116-80-46 

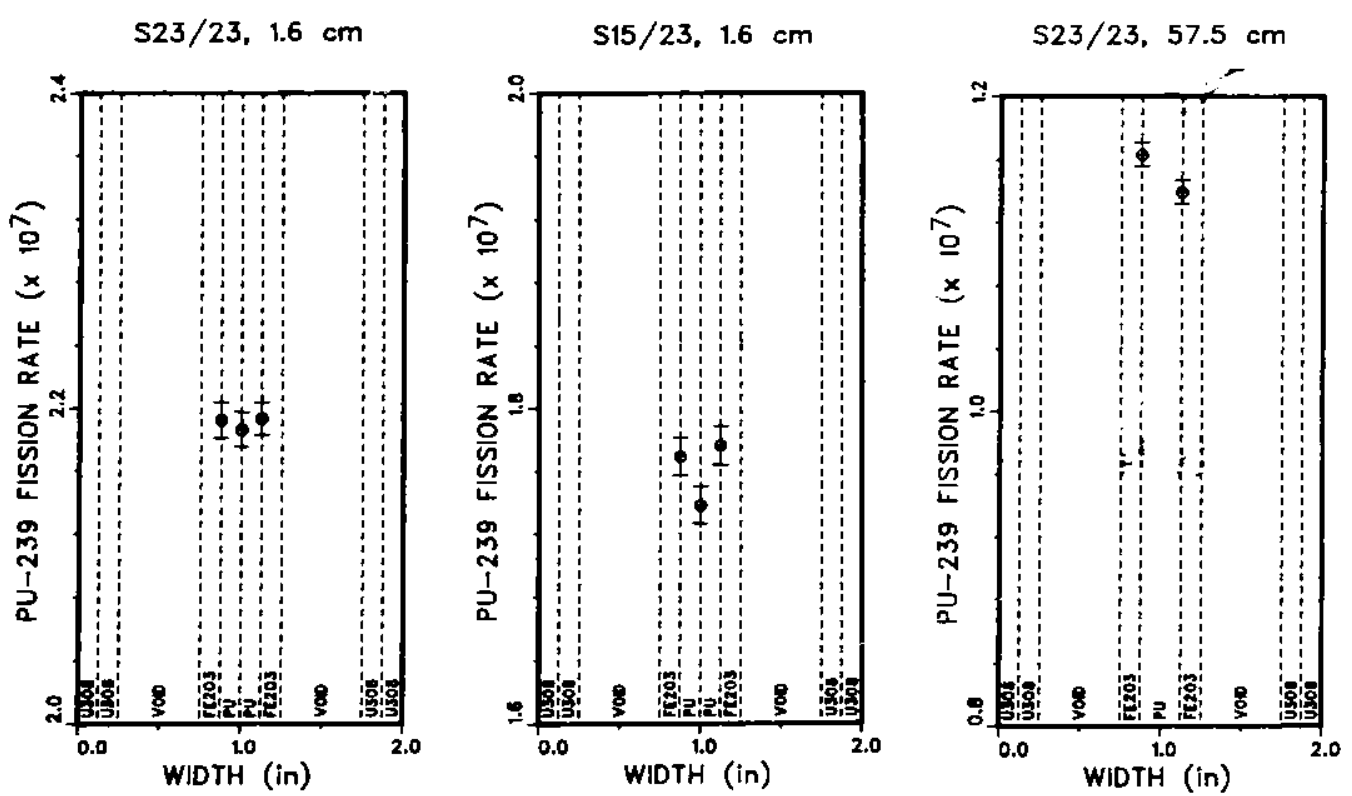

Fig. IV-4.

Intra-cell ${ }^{239} \mathrm{Pu}$ Fission Rates in Core Zone I:

$\mathrm{S}-23 / 23, \mathrm{Z}=1.6 \mathrm{~cm}$; $\mathrm{S}-15 / 23, \mathrm{Z}=1.6 \mathrm{~cm}$; $\mathrm{S}-23 / 23, Z=57.5 \mathrm{~cm}$. ANL Neg. No. 116-80-49

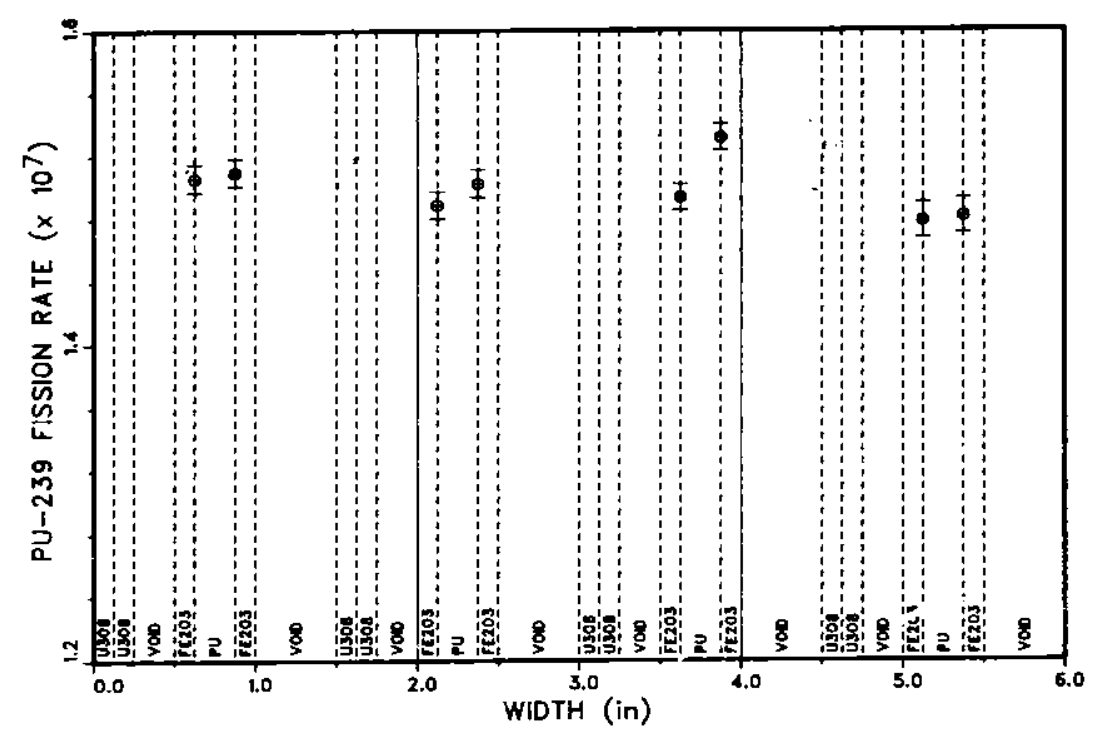

Fig. IV -5.

Intra-cell $239 \mathrm{Pu}$ Fission Rates in Core Zone II:

$\mathrm{S}-13 / 22-24, Z=1.6 \mathrm{~cm}$.

ANL Neg. No. 116-80-52 


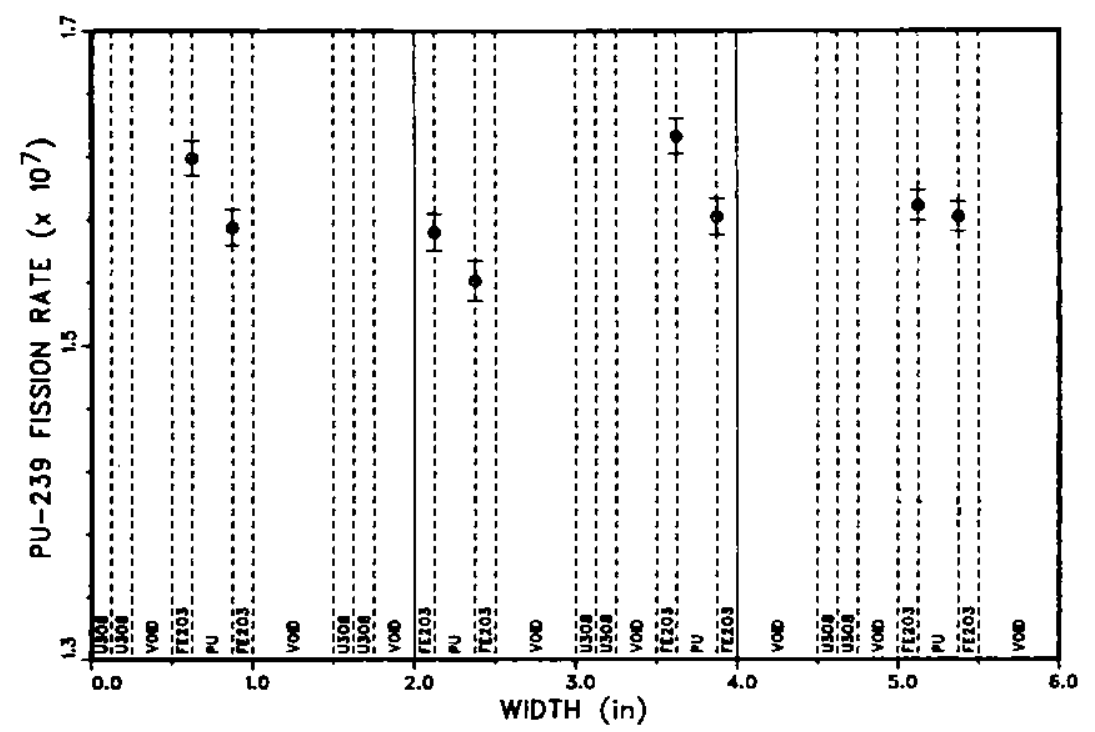

Fig. IV-6. Intra-cell ${ }^{239} \mathrm{Pu}$ Fission Rates in Core Zone II:

$\mathrm{S}-23 / 32-34, \mathrm{Z}=1.6 \mathrm{~cm}$.

ANL Neg. No. 116-80-7

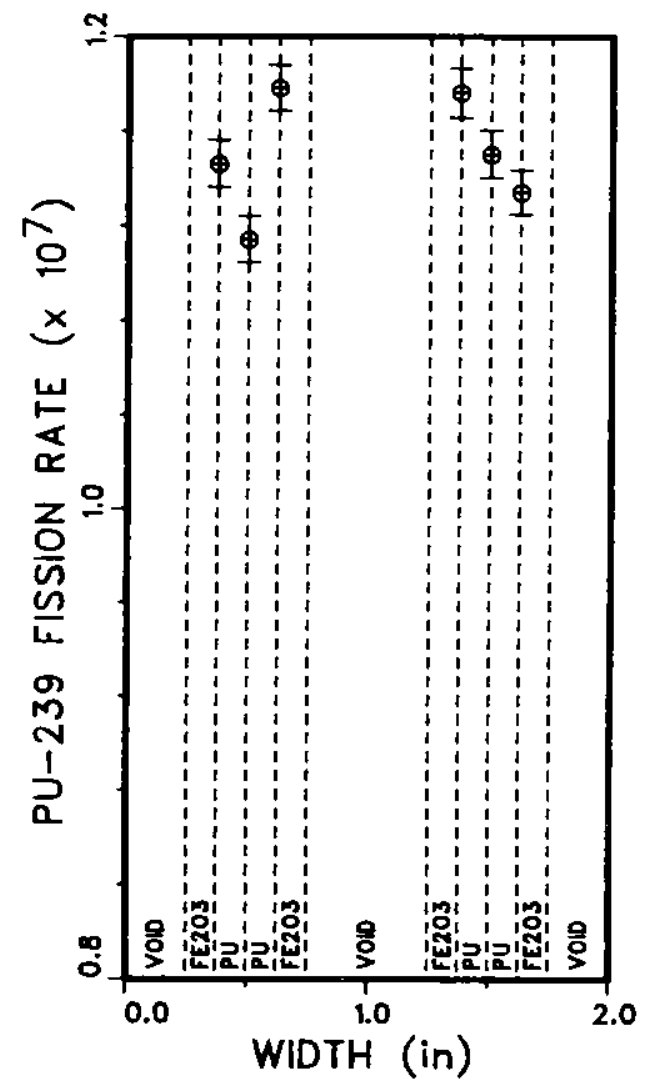

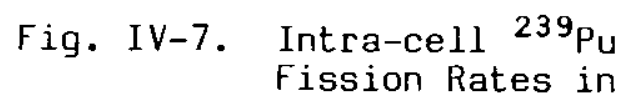
Fission Rates $\mathrm{S}-11 / 23$, $\mathrm{Z}=1.6 \mathrm{~cm}$. ANL Neg. No. 116-80-8 

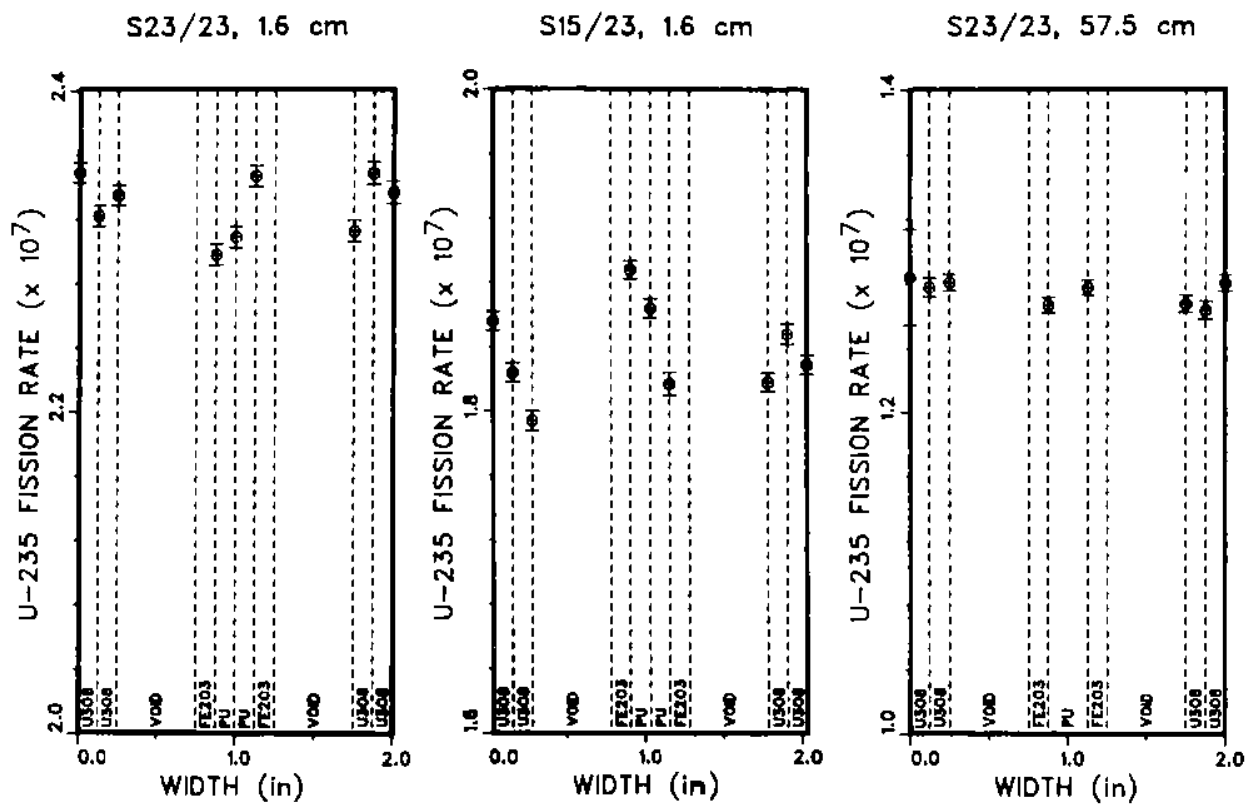

Fig. IV-8. Intra-cell $235 \mathrm{U}$ Fission Rates in Core Zone I: $\mathrm{S}-23 / 23, \mathrm{Z}=1.6 \mathrm{~cm} ; \mathrm{S}-15 / 23, \mathrm{Z}=1.6 \mathrm{~cm}$; $\mathrm{S}-23 / 23, \mathrm{Z}=57.5 \mathrm{~cm}$.

ANL Neg. No. 116-80-72

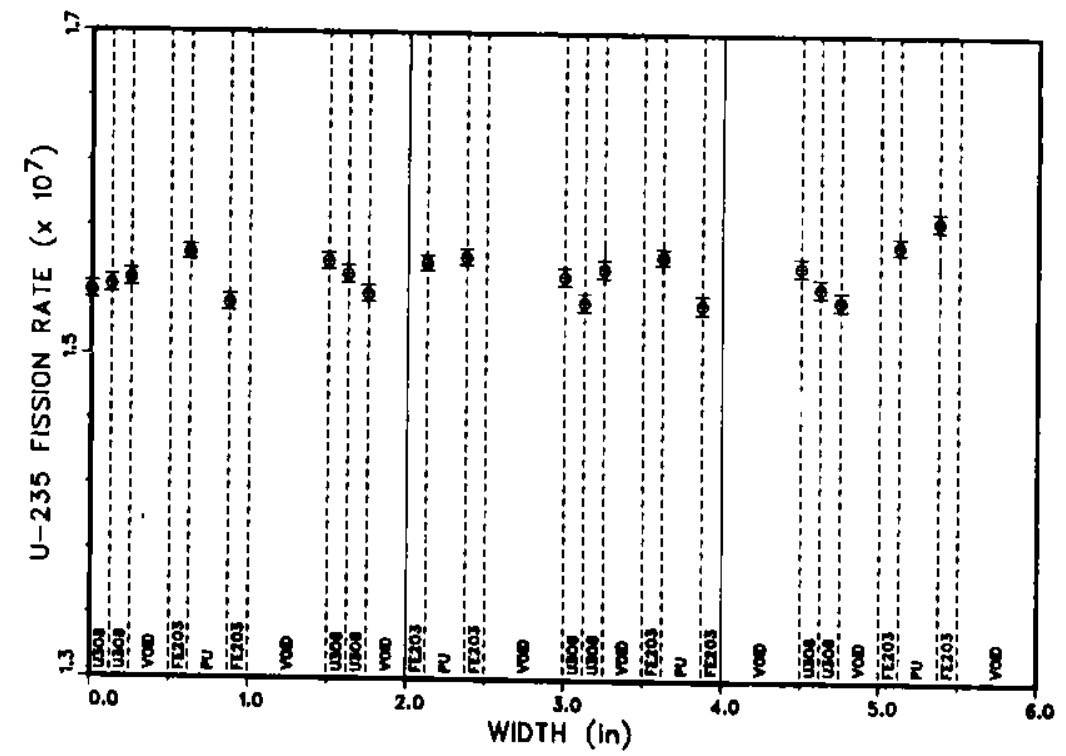

Fig. IV-9. Intra-cell ${ }^{235} \mathrm{U}$ Fission Rates in Core Zone II: $\mathrm{S}-13 / 22-24, Z=1.6 \mathrm{~cm}$. ANL Neg. No. 116-80-73 


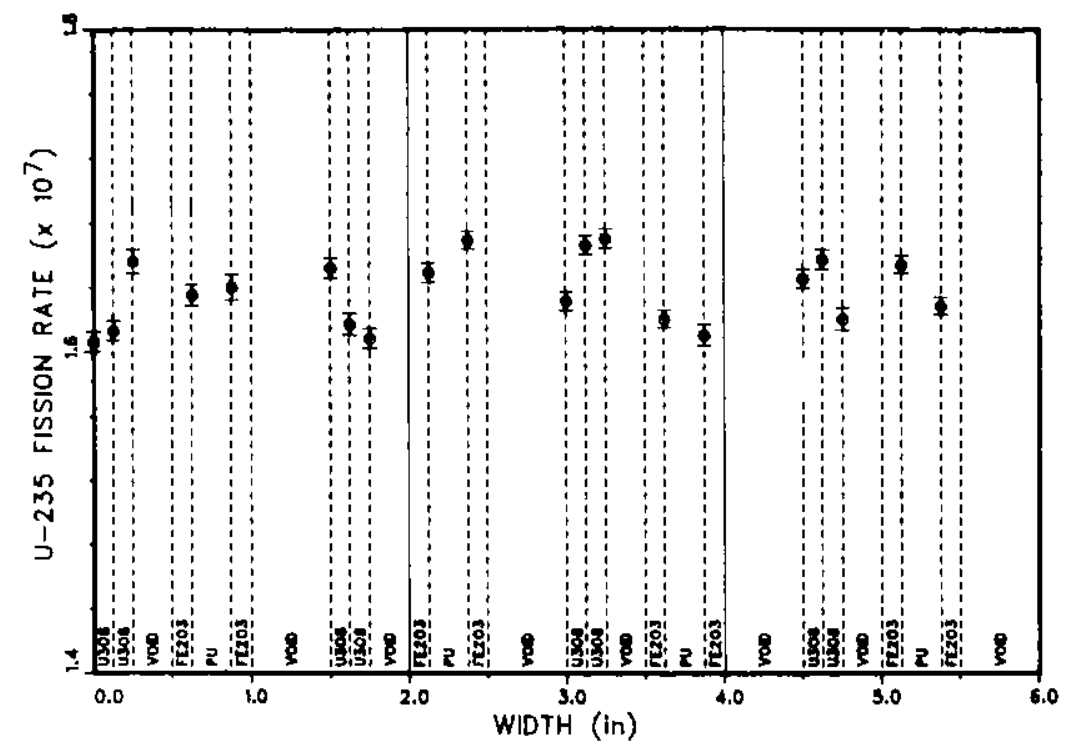

Fiq. IV-10.

Intra-cell $235 \mathrm{U}$ Fission

Rates in Core Zone II; $\mathrm{S}-23 / 32-34, \mathrm{Z}=1.6 \mathrm{~cm}$. ANL Neg. No. 116-80-74

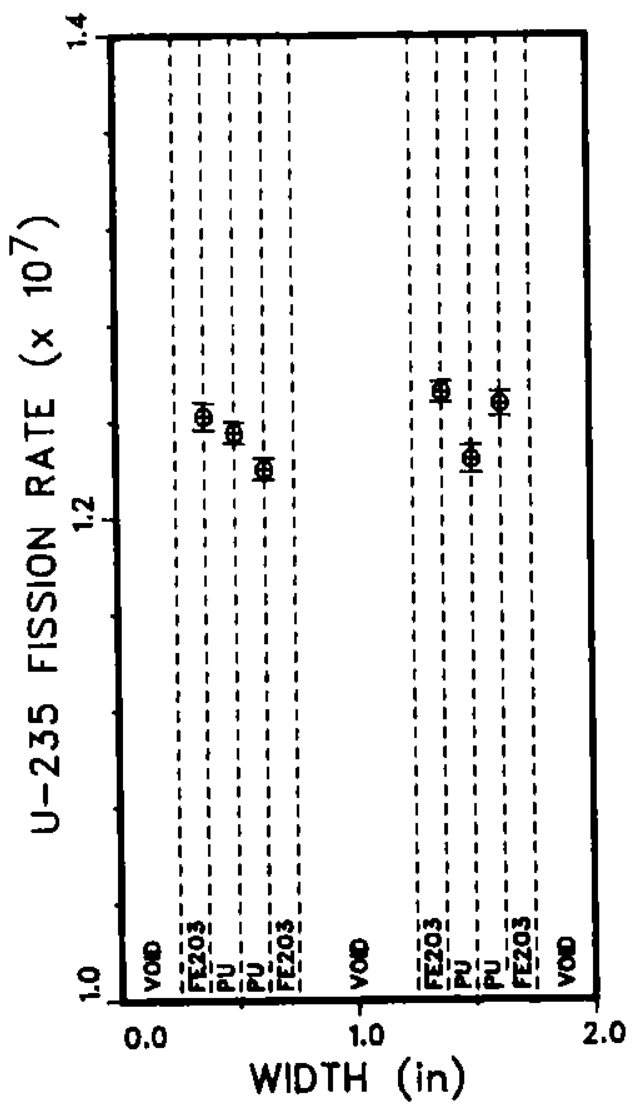

Fig. IV-11.

Intra-cell ${ }^{235} \mathrm{U}$ Fission Rates in Core Zone III: S-11/23, Z = $1.6 \mathrm{~cm}$. ANL Neg. No. 116-80-9 

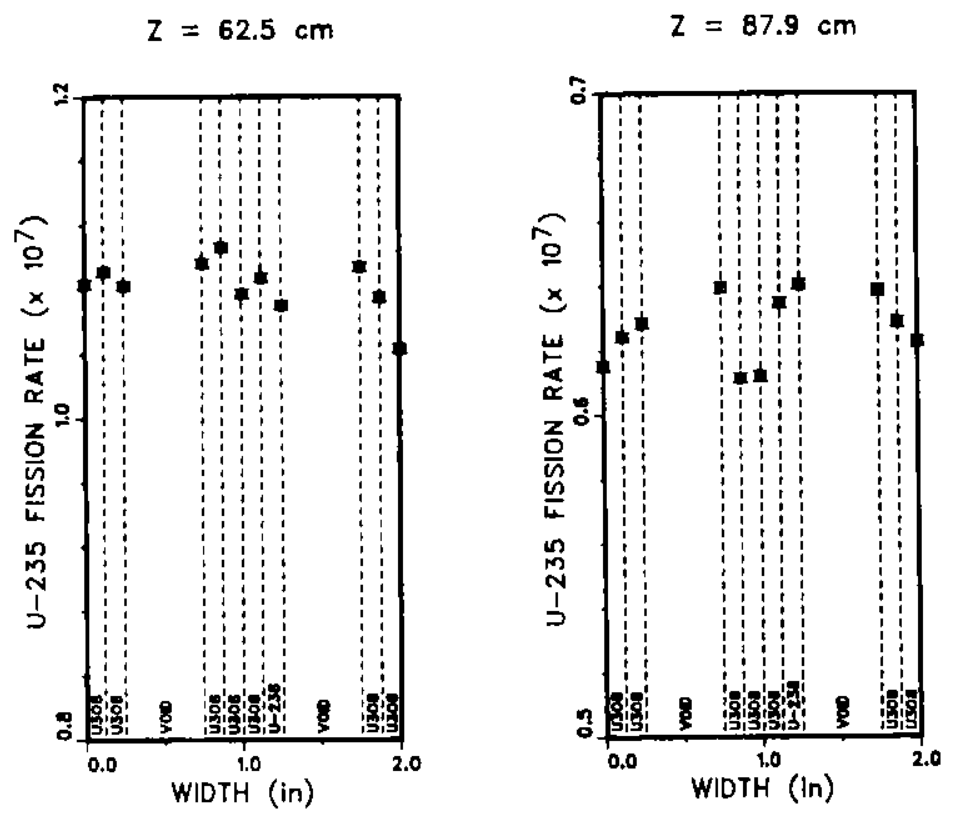

Fig. IV-12.

Intra-cell 235U Fission

Rates in the Axial Blanket

Region: S-23/23,

$Z=62.5 \mathrm{~cm} ; \mathrm{S}-23 / 23$,

$Z=87.9 \mathrm{~cm}$.

ANL Neg. No. 116-80-63
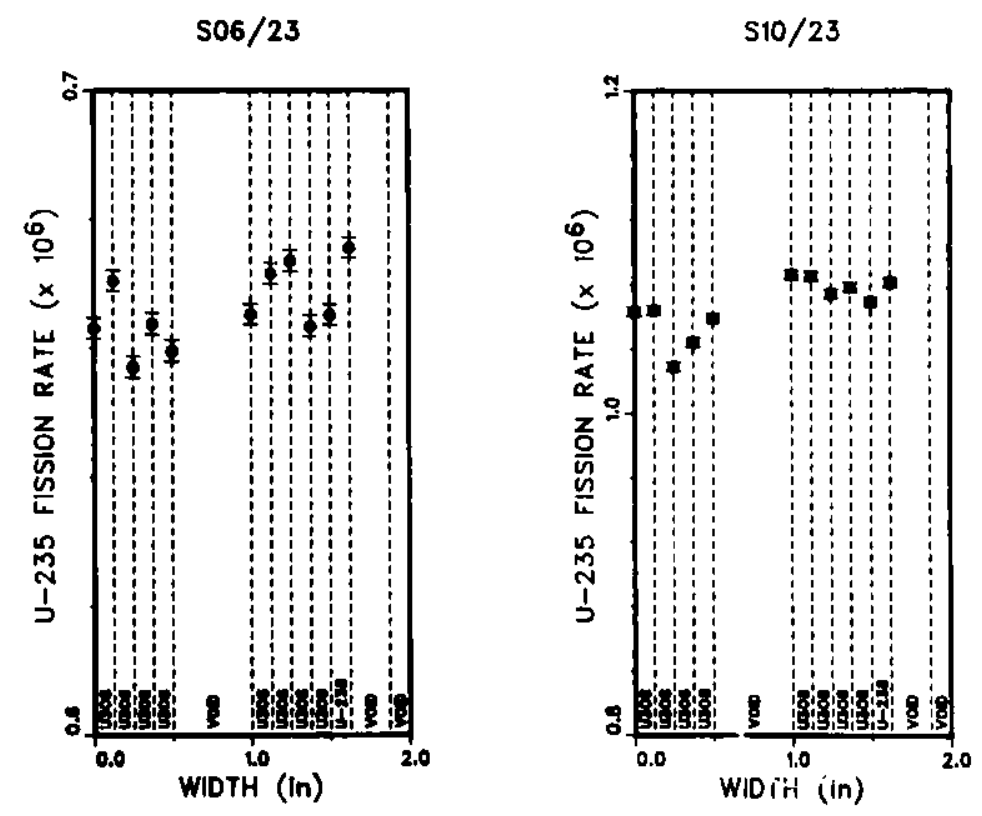

Fiq. IV-13.

Intra-cell 235U Fission

Rates in the Axial Blanket

Region: $\mathrm{S}-6 / 23, \mathrm{Z}=1.6 \mathrm{~cm}$;

S-10/23, $Z=1.6 \mathrm{~cm}$.

ANL Neg. No. 116-80-64 

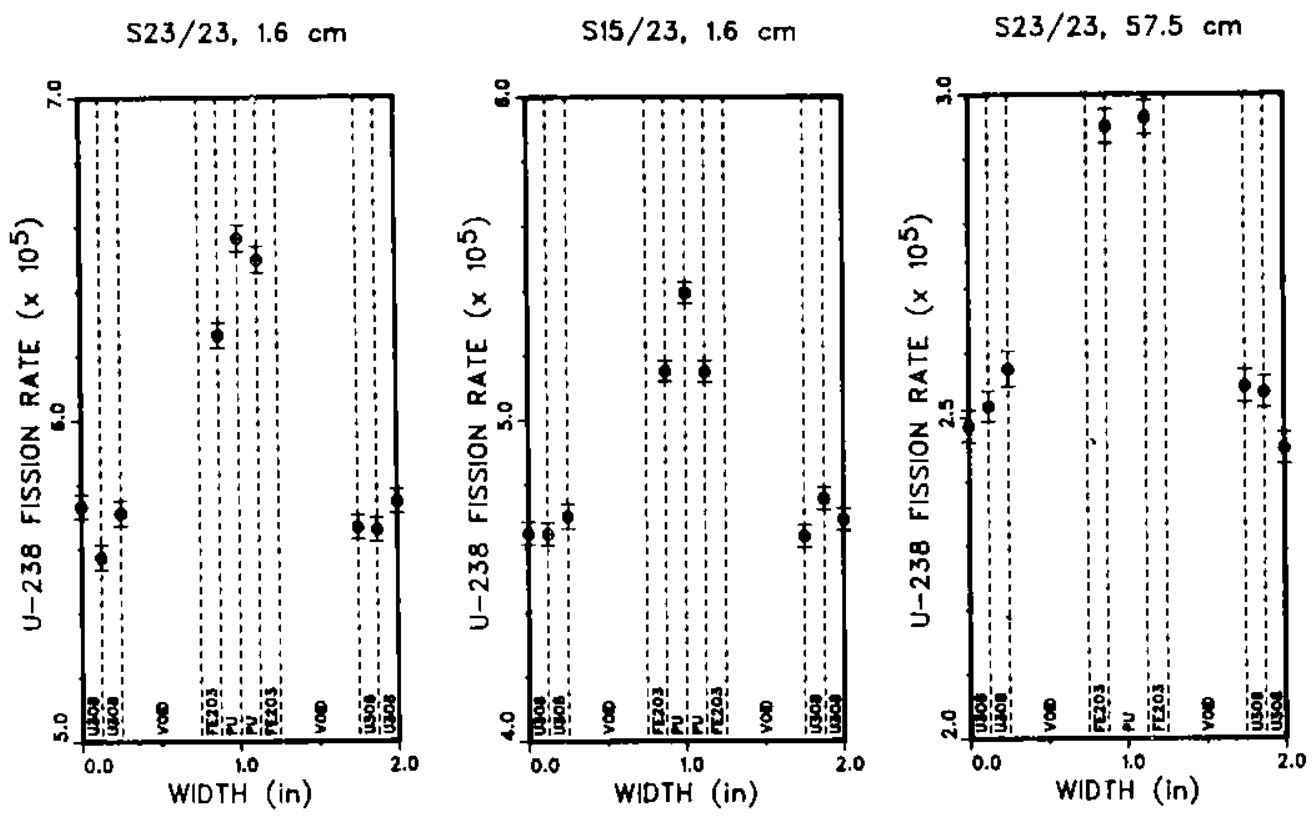
Fig. IV-14. Intra-cell ${ }^{238} \mathrm{U}$ Fission Rates in Core Zone I: $\mathrm{S}-23 / 23, Z=1.6 \mathrm{~cm}$; S-15/23, $Z=1.6 \mathrm{~cm}$; $5-23 / 23, Z=57.7 \mathrm{~cm}$. ANL Neg. No. 116-80-66

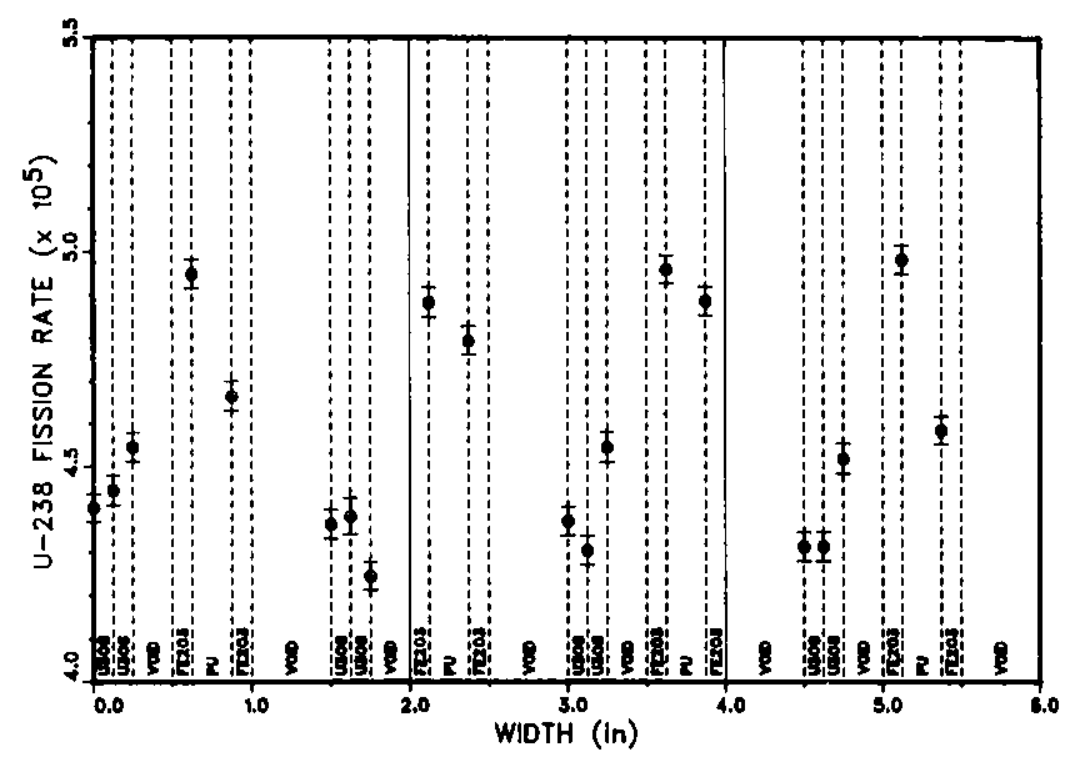

Fig. IV-15. Intra-cell ${ }^{238} \mathrm{U}$ Fission Rates in Core Zone II: S-13/22-24, $Z=1.6 \mathrm{~cm}$. ANL Neq. No. 116-80-65 


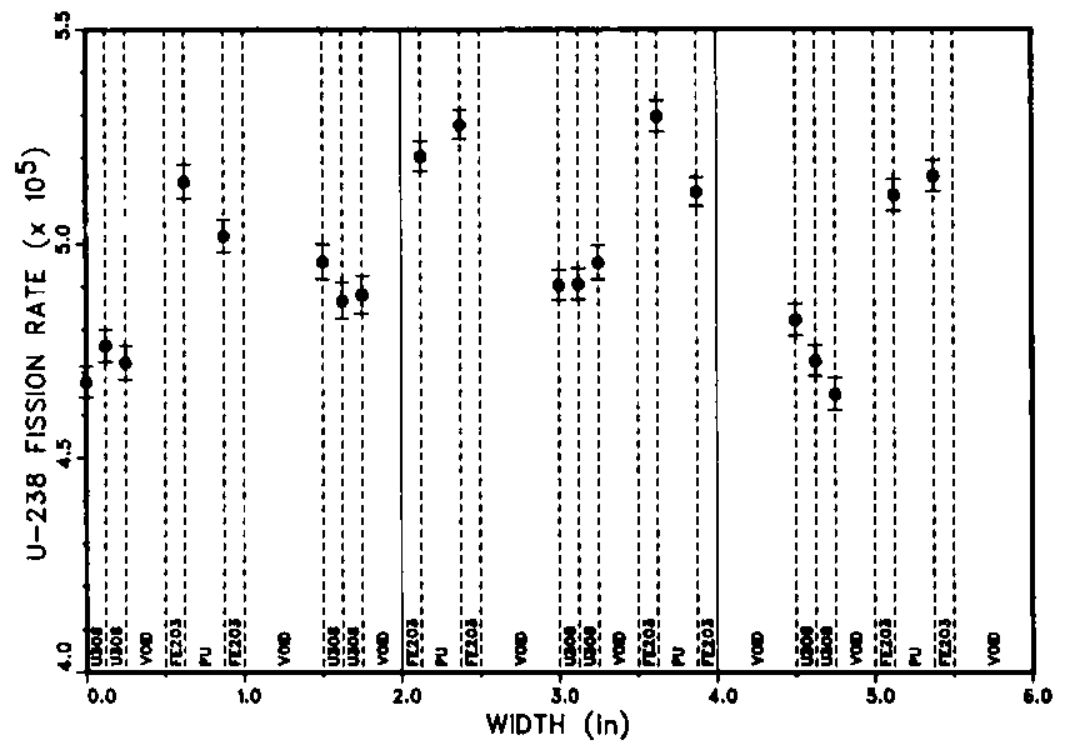

Fig. IV-16.

Intra-cell ${ }^{238} \mathrm{U}$ Fission

Rates in Core Zone II : $\mathrm{S}-23 / 32-34, Z=1.6 \mathrm{~cm}$. ANL Neg. No. 116-80-70

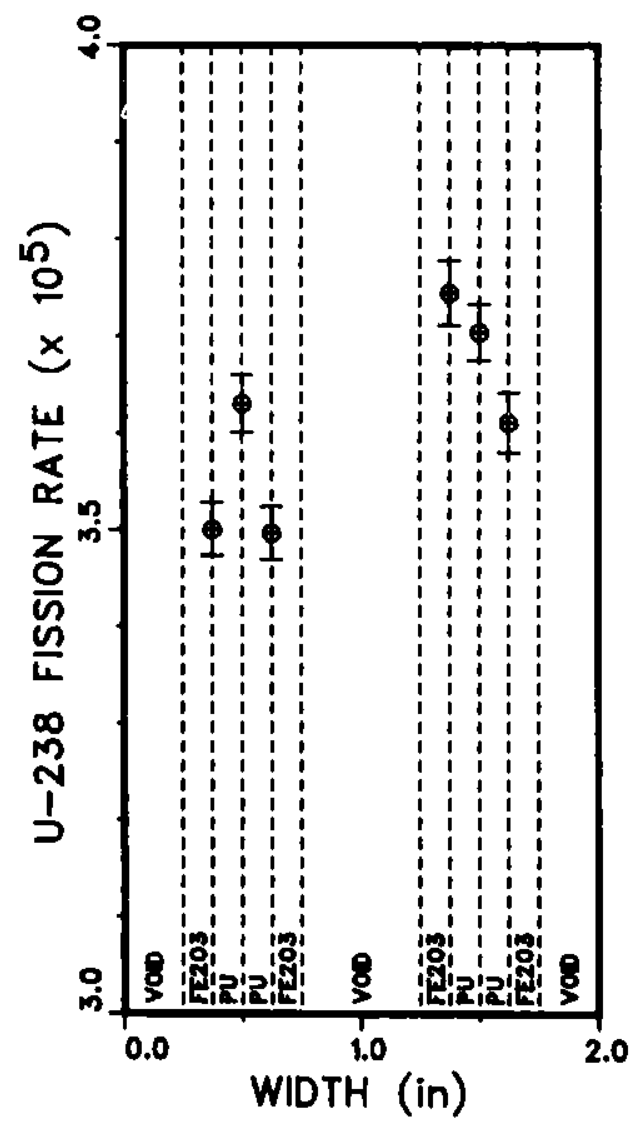

Fig. IV-17.

Intra cell ${ }^{238} \mathrm{U}$ Fission Rates in Core Zone III: S-11/73, $Z=1.6 \mathrm{~cm}$. ANL Neg. No. 116-80-26 

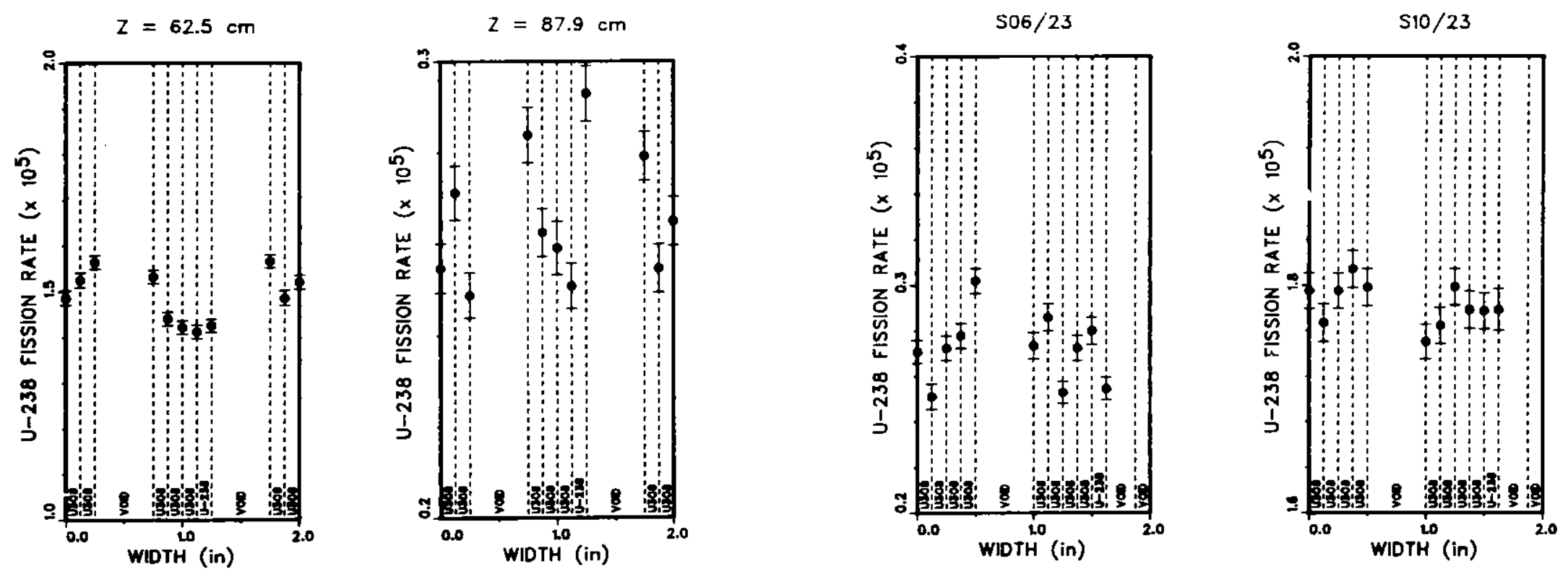

Fig. IV-18. Intra-cell $238 \mathrm{U}$ Fission Rates in the Axial Blanket Region:

$\mathrm{S}-23 / 23, z=62.5 \mathrm{~cm}$; $5-23 / 23, Z=87.9 \mathrm{~cm}$. ANL Neg. No. 116-80-69

Fig. IV-19. Intra-cell $238 \mathrm{U}$ Fission Rates in the Radial Blanket Reqion: $\mathrm{S}-6 / 23, z=1.6 \mathrm{~cm}$; $\mathrm{S}-10 / 23, Z=1.6 \mathrm{~cm}$. ANL Neg. No. 116-80-67 

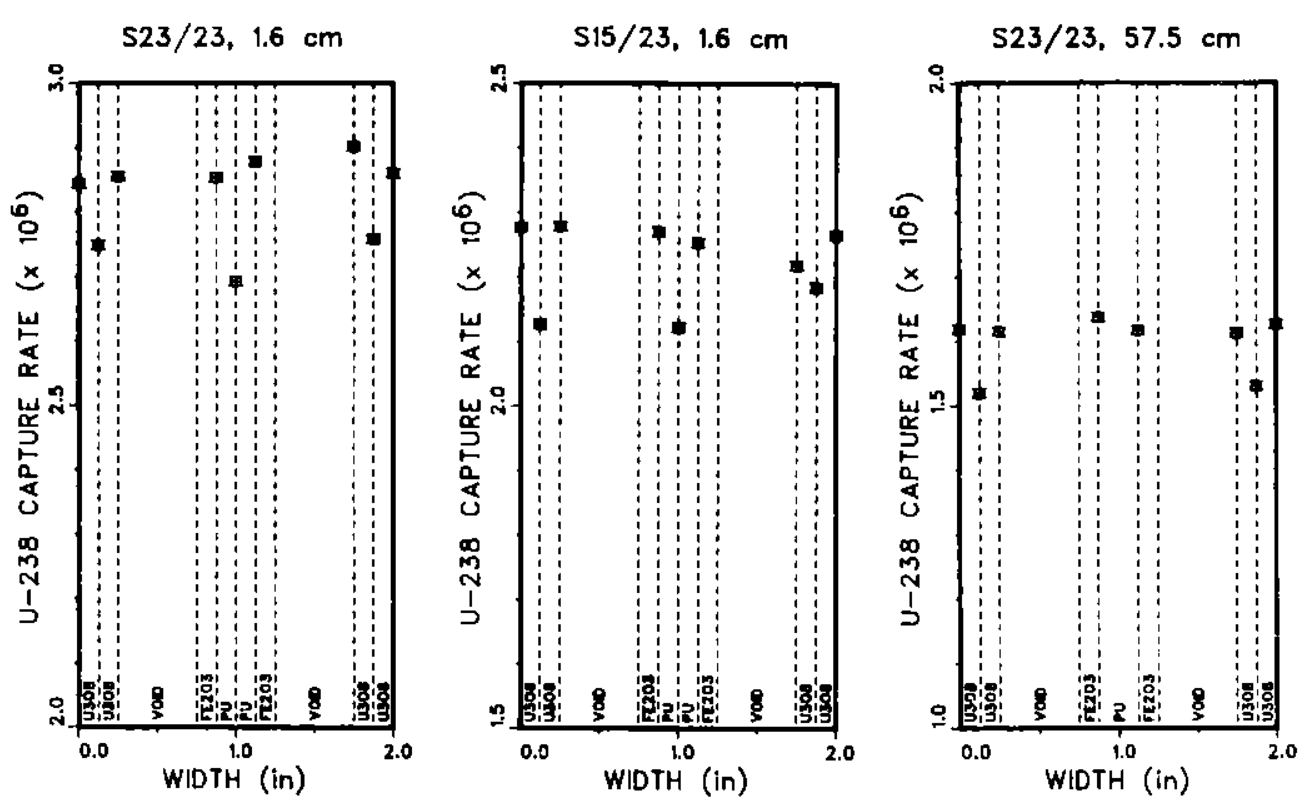

Fig. IV-20. Intra-cell $238 \mathrm{U}$ Capture Rates in Core Zone I:

$\mathrm{S}-23 / 23, \mathrm{Z}=1.6 \mathrm{~cm}$;

$\mathrm{S}-15 / 23, \mathrm{Z}=1.6 \mathrm{~cm}$;

$\mathrm{S}-23 / 23, Z=57.5 \mathrm{~cm}$.

ANL Neg. No. 116-80-68

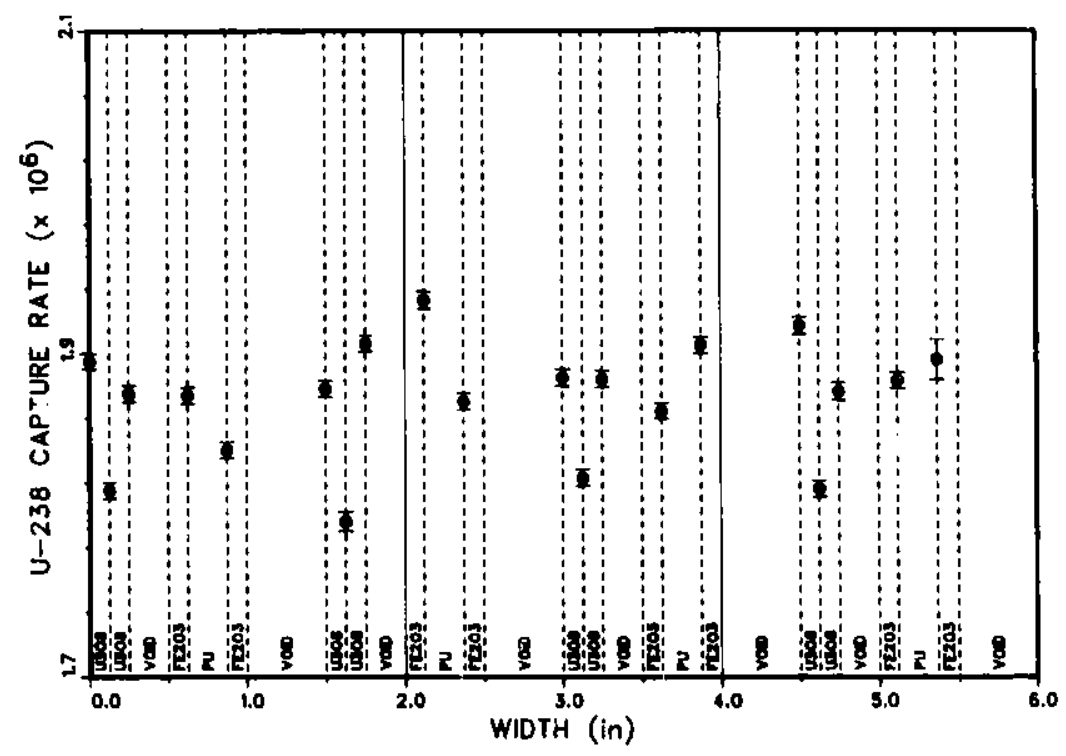

Fig. IV-21. Intra-cell 238U Capture Rates in Core Zone II :

$\mathrm{S}-13 / 22-24, \mathrm{Z}=1.6 \mathrm{~cm}$.

ANL Neg. No. 116-80-14 


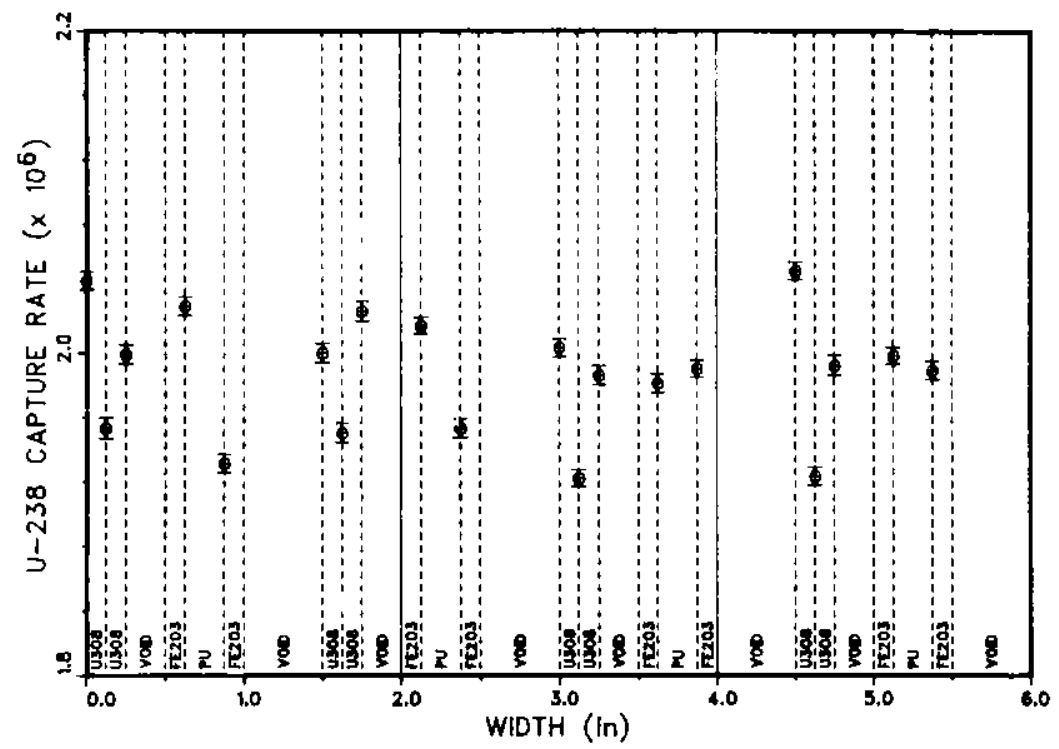

Fig. IV-22.

Intra-cell 238U Capture

Rates in Core Zone II: $\mathrm{S}-23 / 32-34, \mathrm{Z}=1.6 \mathrm{~cm}$.

ANL Neg. No. 116-80-59

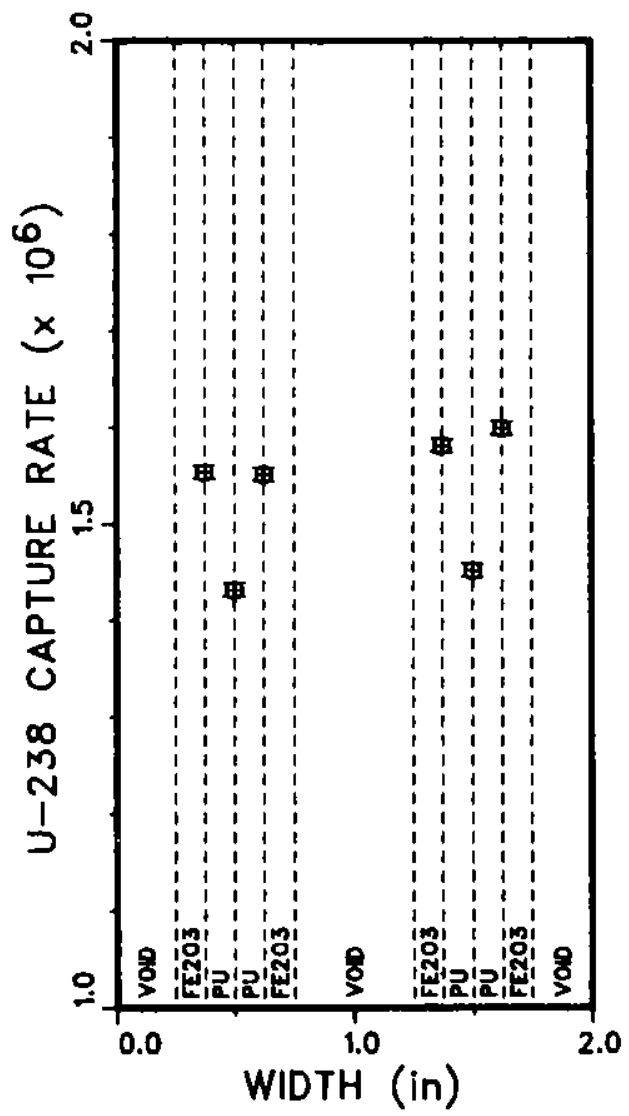

Fig. IV-23.

Intra-cell ${ }^{238} \mathrm{U}$ Capture Rates in Core Zone III: $\mathrm{S}-11 / 23, \mathrm{Z}=1.6 \mathrm{~cm}$. ANL Neg. No. 116-80-28 

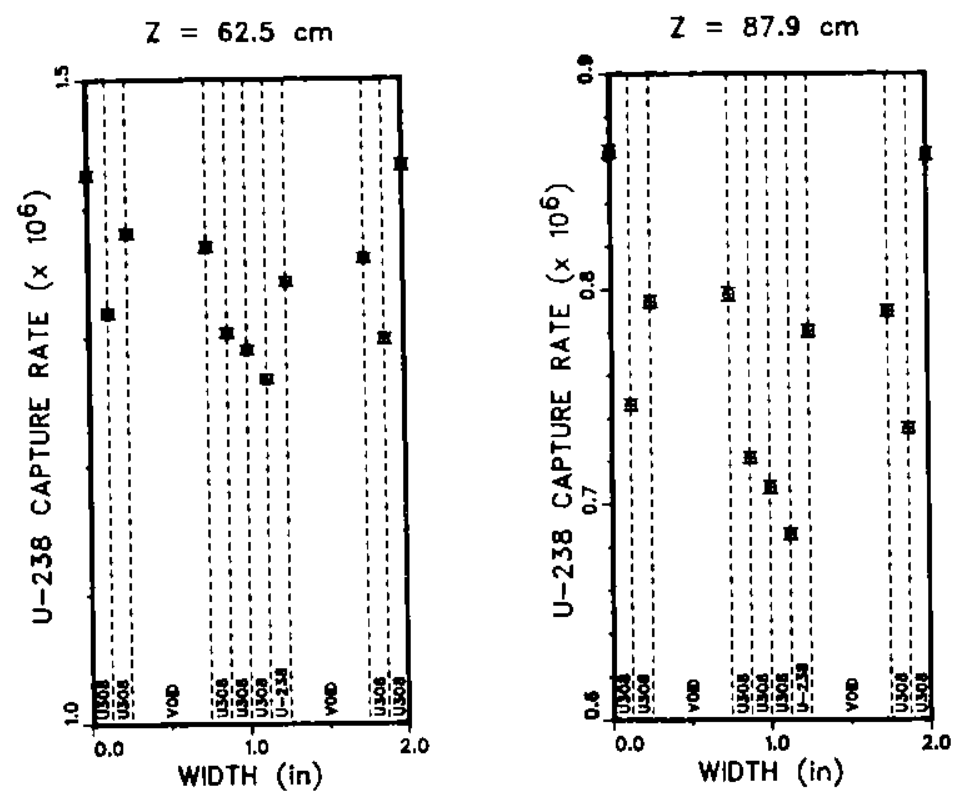

Fig. IV-24.

Intra-cell $238 \mathrm{U}$ Capture Rates in the Axial Blanket Region: S-23/23, $Z=62.5 \mathrm{~cm}: 5-23 / 23$, $Z=87.9 \mathrm{~cm}$.

ANL. Neg. No. 116-80-58
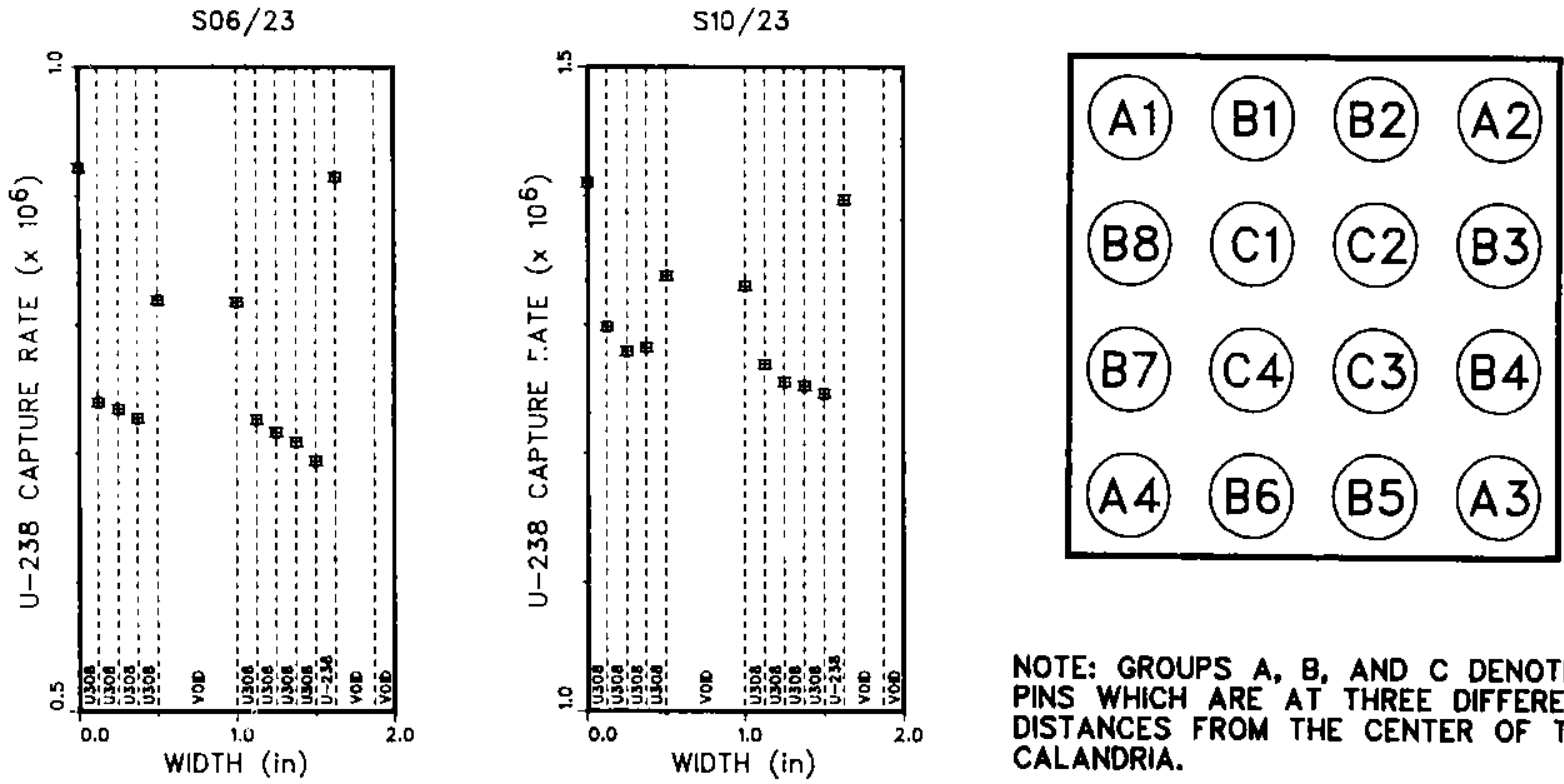

Fig. IV-25. Intra-cell $238_{\mathrm{U}}$ Capture Rates in the Radial Blanket Region: S-6/23, $Z=1.6 \mathrm{~cm} ; \mathrm{S}-10 / 23$, $Z=1.6 \mathrm{~cm}$.

ANL Neg. No. 116-80-15

Fig. IV-26. Sixteen Pin Array Within Each Calandria Included in the Pin Zone of the GCFR Phase III Assembly. ANL Neg. No. 116-80-27 


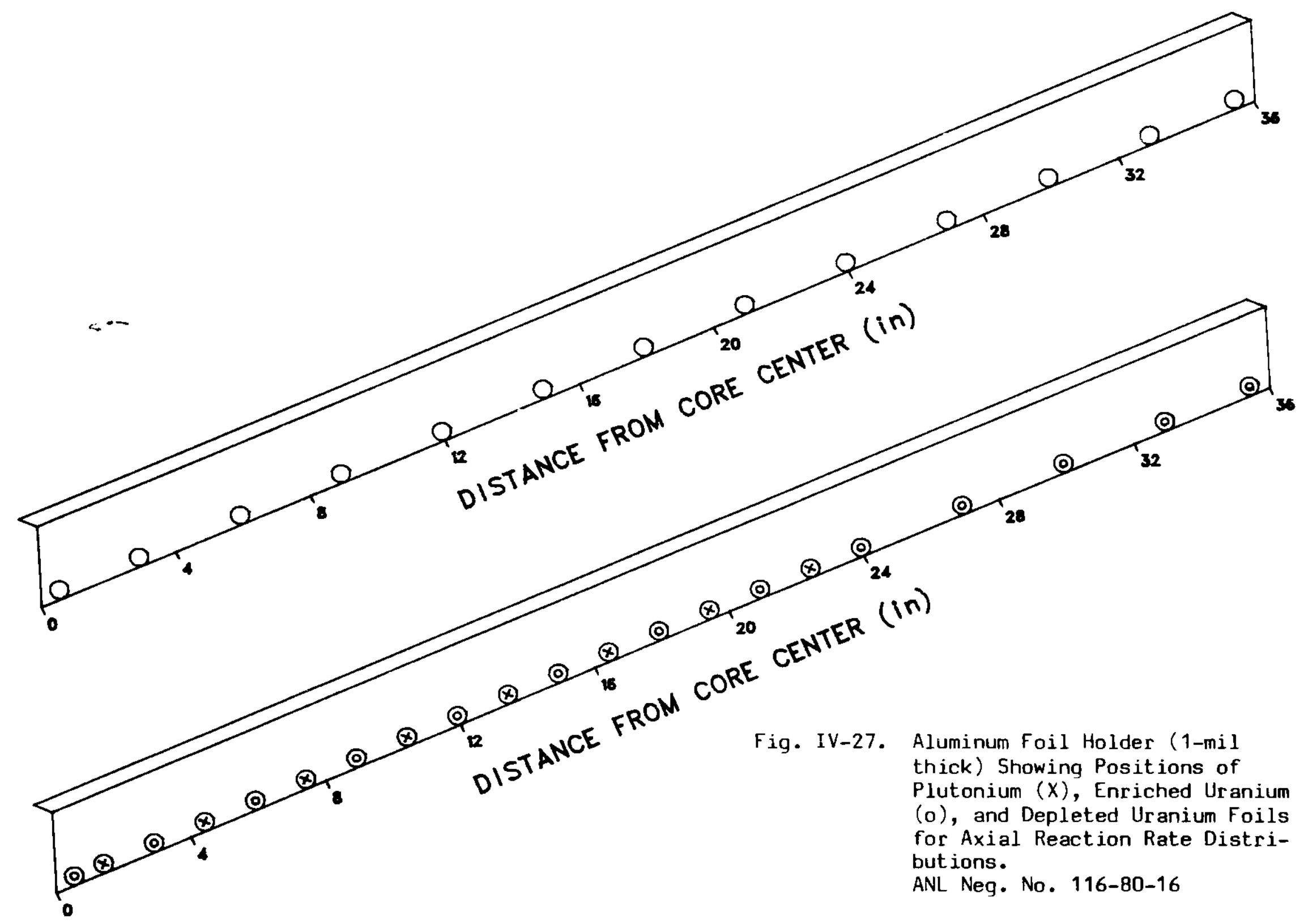



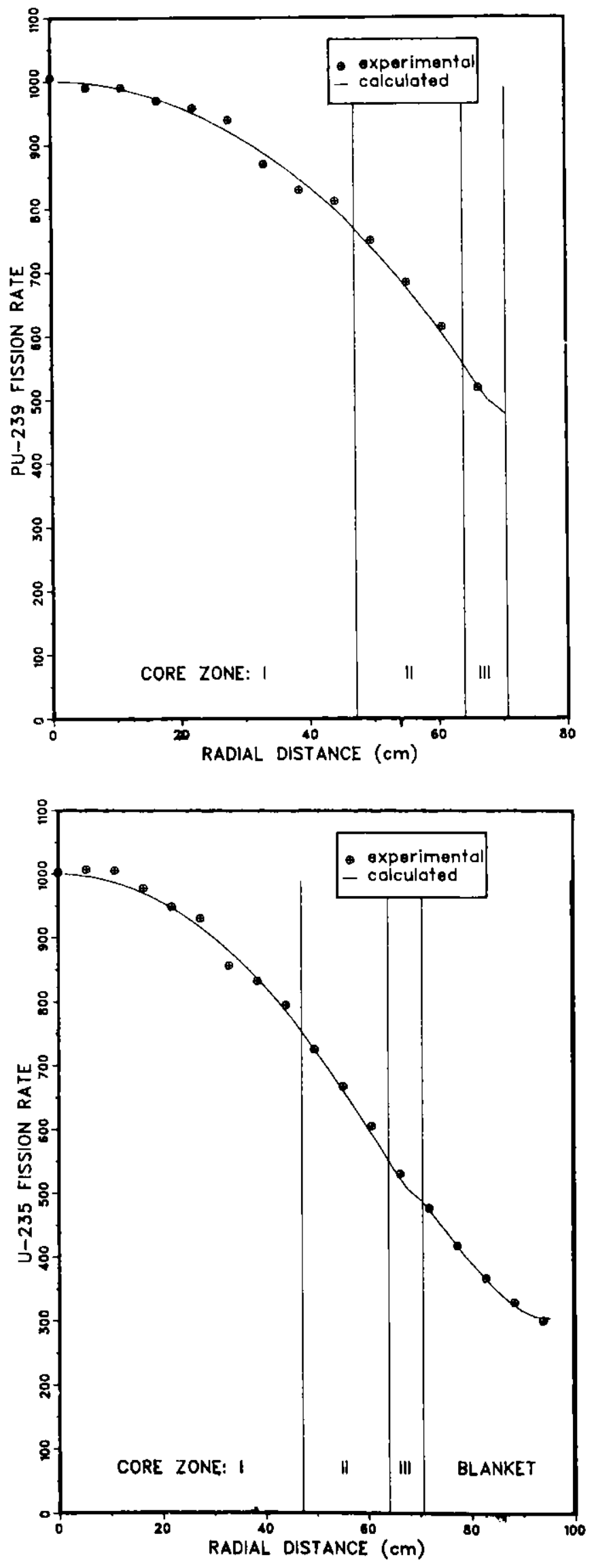

Fig. IV -28 .

Radial ${ }^{239} \mathrm{Pu}$ Fission Rate Distribution, Column 23.

ANL Neg. No. 116-80-17
Fig. IV-29.

Radial ${ }^{235} \mathrm{U}$ Fission Rate Distribution, Column 23.

ANL Neg. No. 116-80-44 


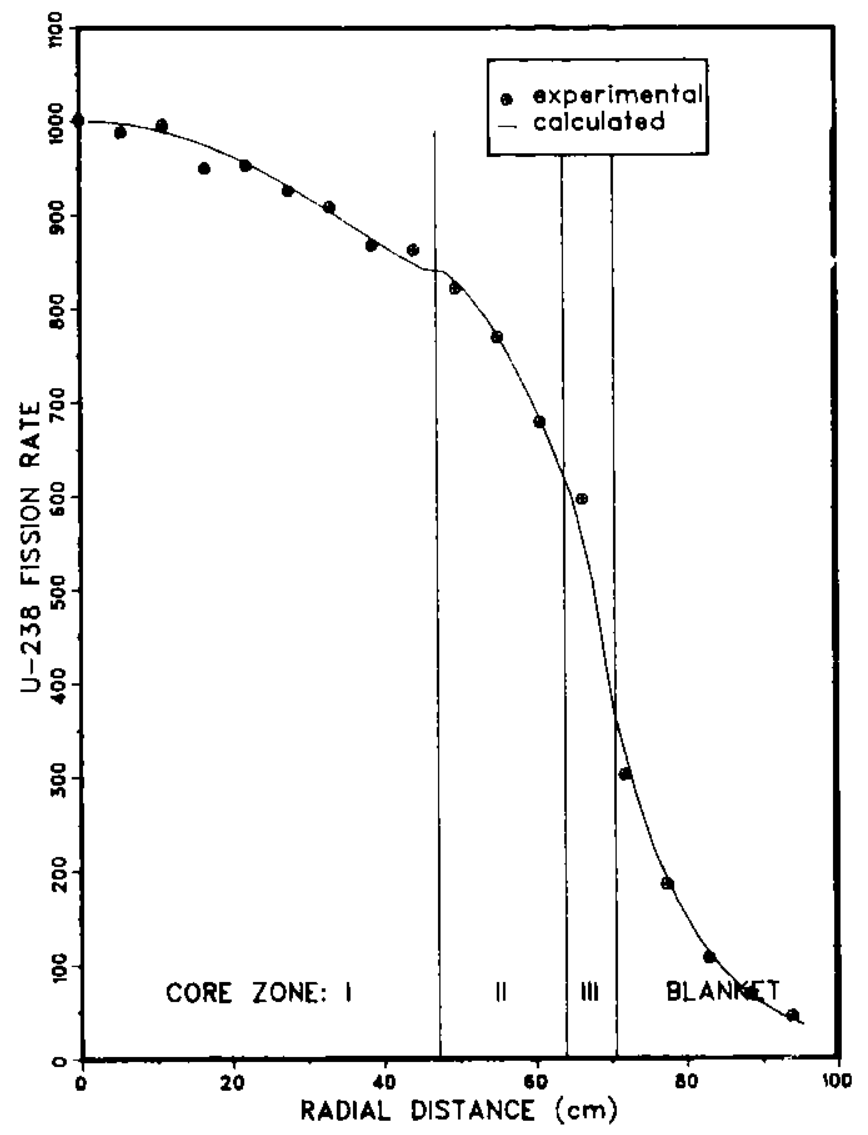

Fig. IV -30 .

Radial ${ }^{238} \mathrm{U}$ Fission Rate Distribution, Column 23.

ANL Neg. No. 116-80-45

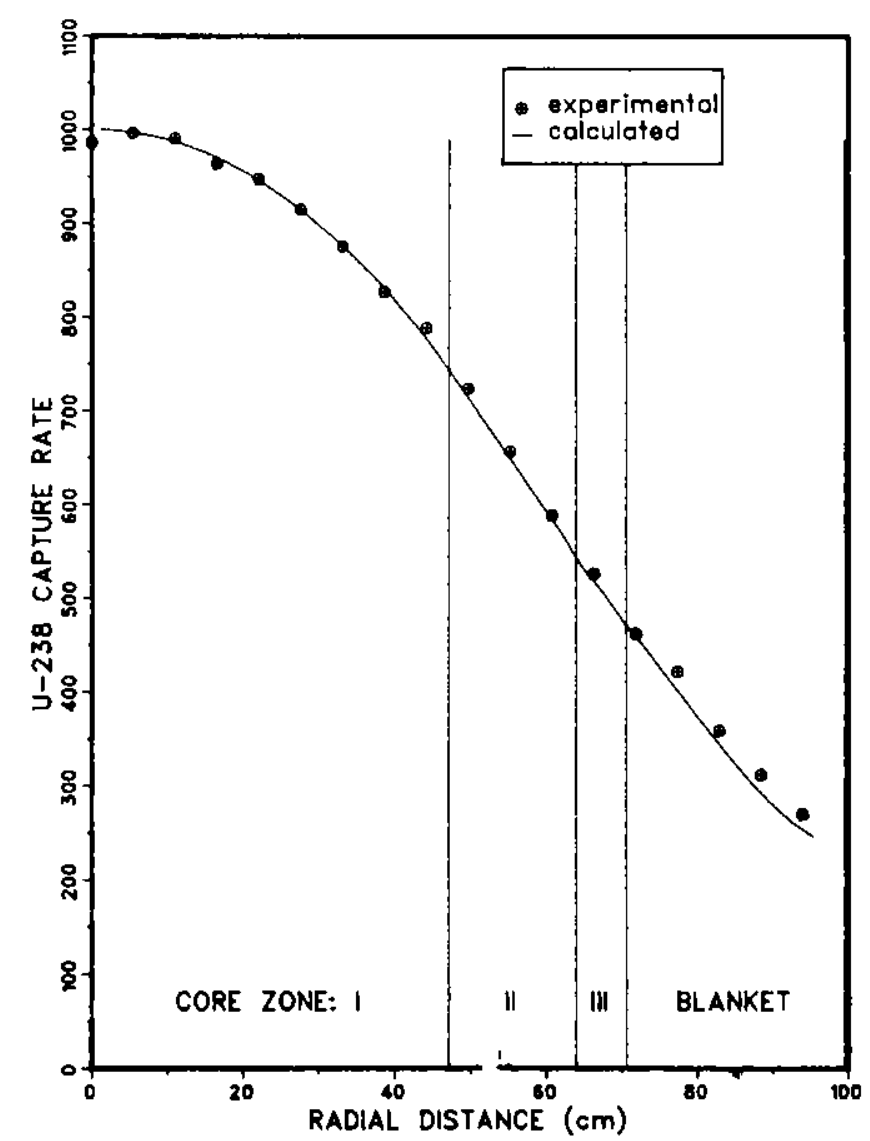

Fig. IV -31

Radial ${ }^{238} \mathrm{U}$ Capture Rate Distribution, Column 23.

ANL Neg. No. 116-80-25 

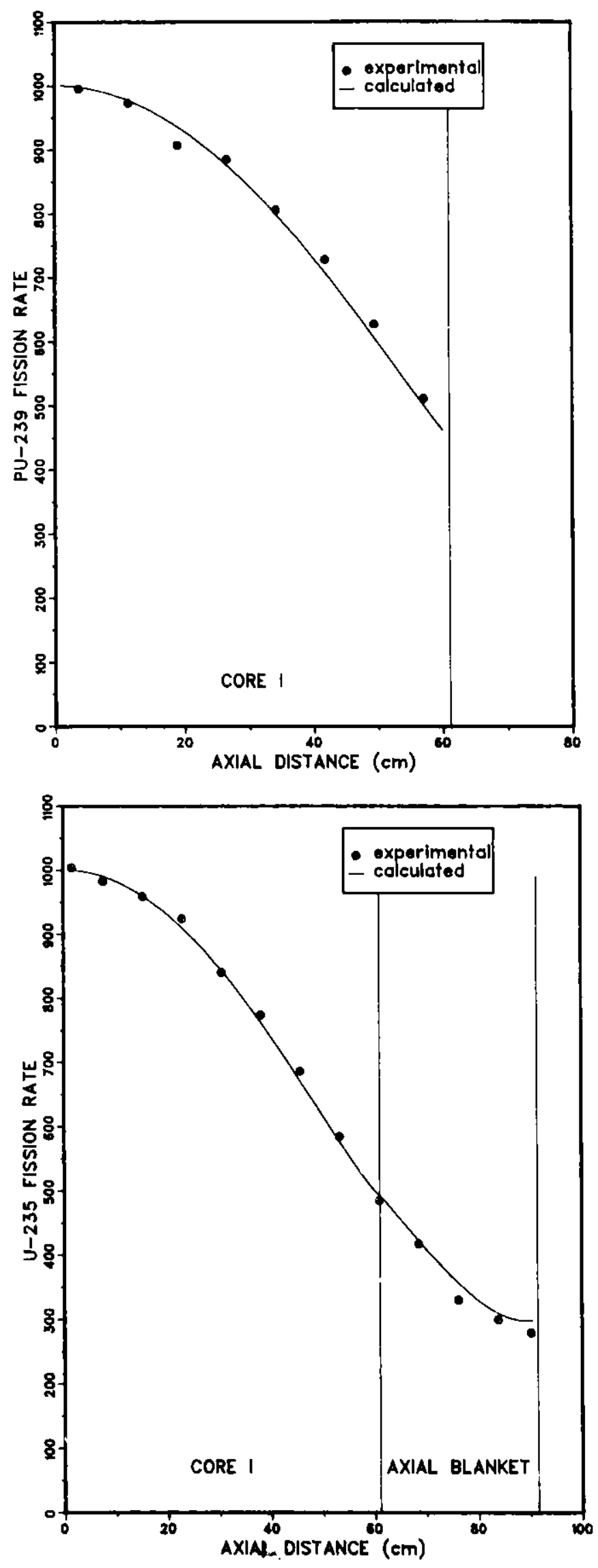

Fig. IV-32.

Axial ${ }^{239} \mathrm{Pu}$ Fission Rate Distribution.

ANL Neg. No. 116-80-2
Fig. IV-33.

Axial $235 \mathrm{U}$ Fission Rate Distribution.

ANL Neg. No. 116-80-39 


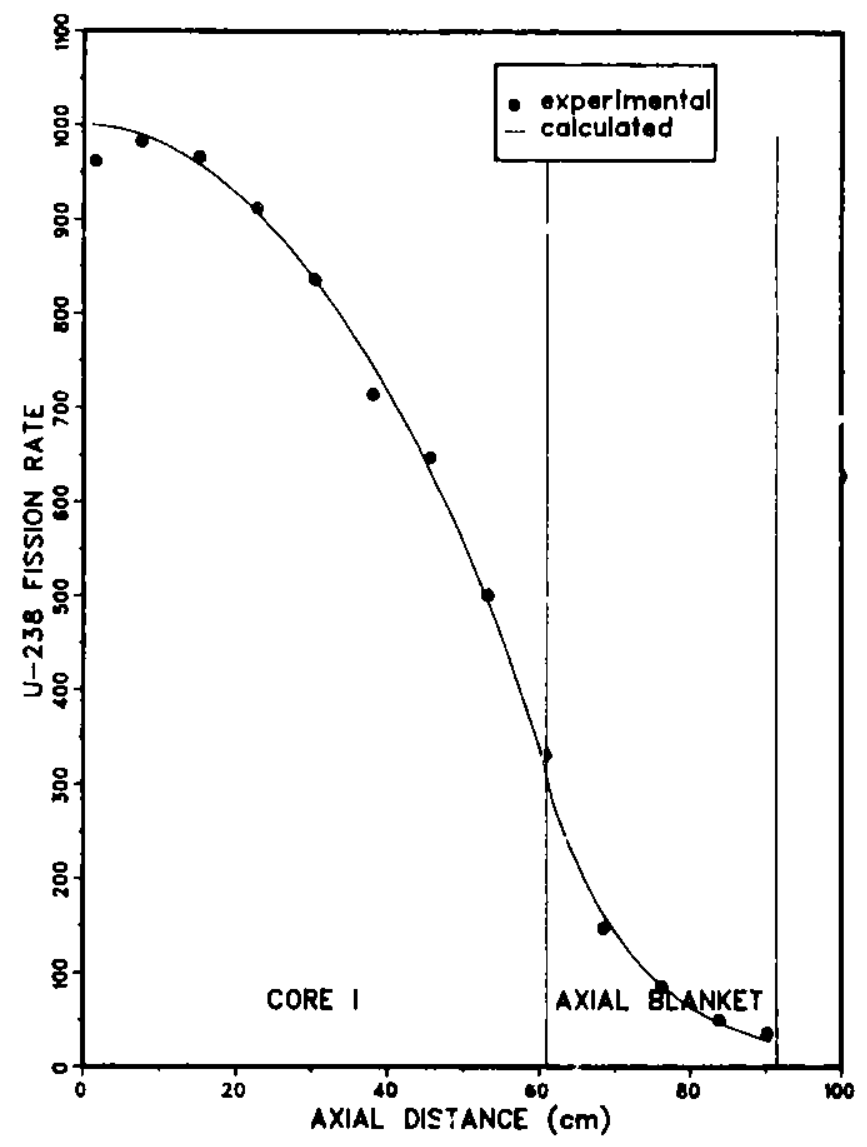

Fig. IV-34. Axial ${ }^{238} \mathrm{U}$ Fission Rate Distribution.

ANL Neg. No. 116-80-40

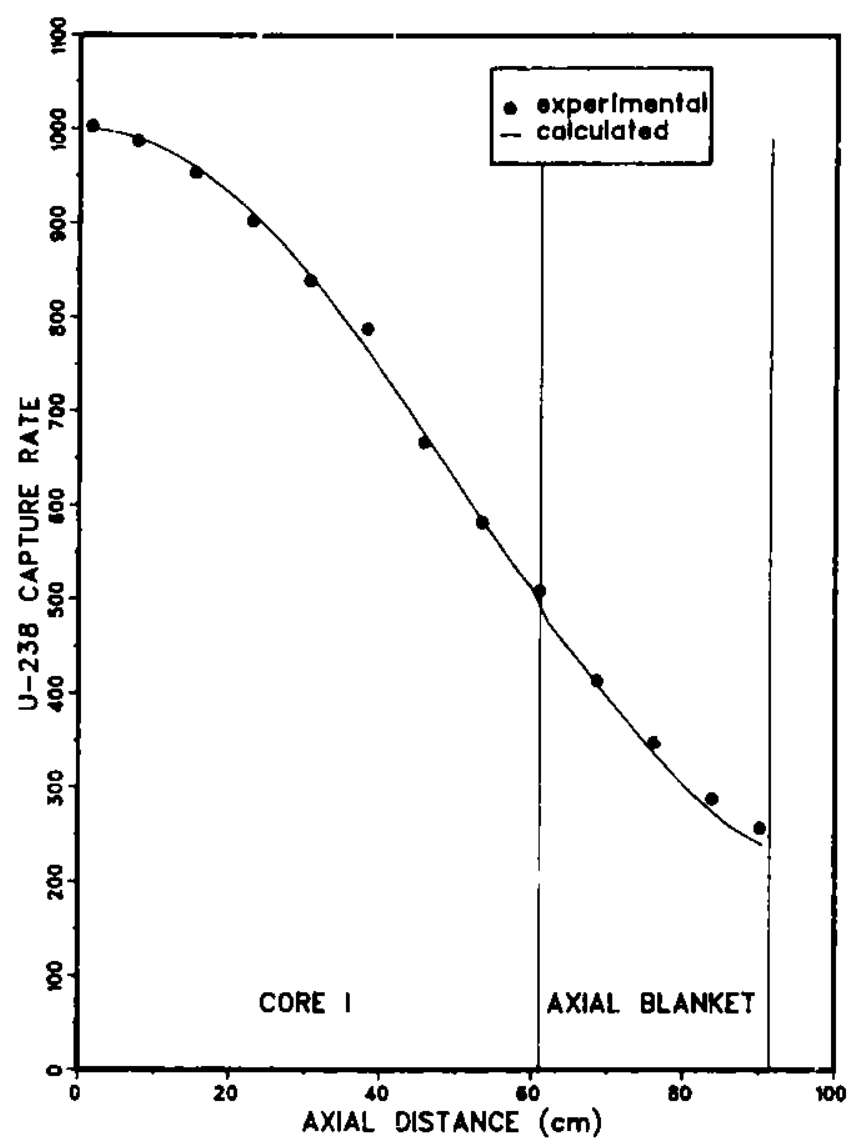

Fig. IV-35. Axial ${ }^{238}$ U Capture Rate Distribution. ANL Neq. No. 116-80-38

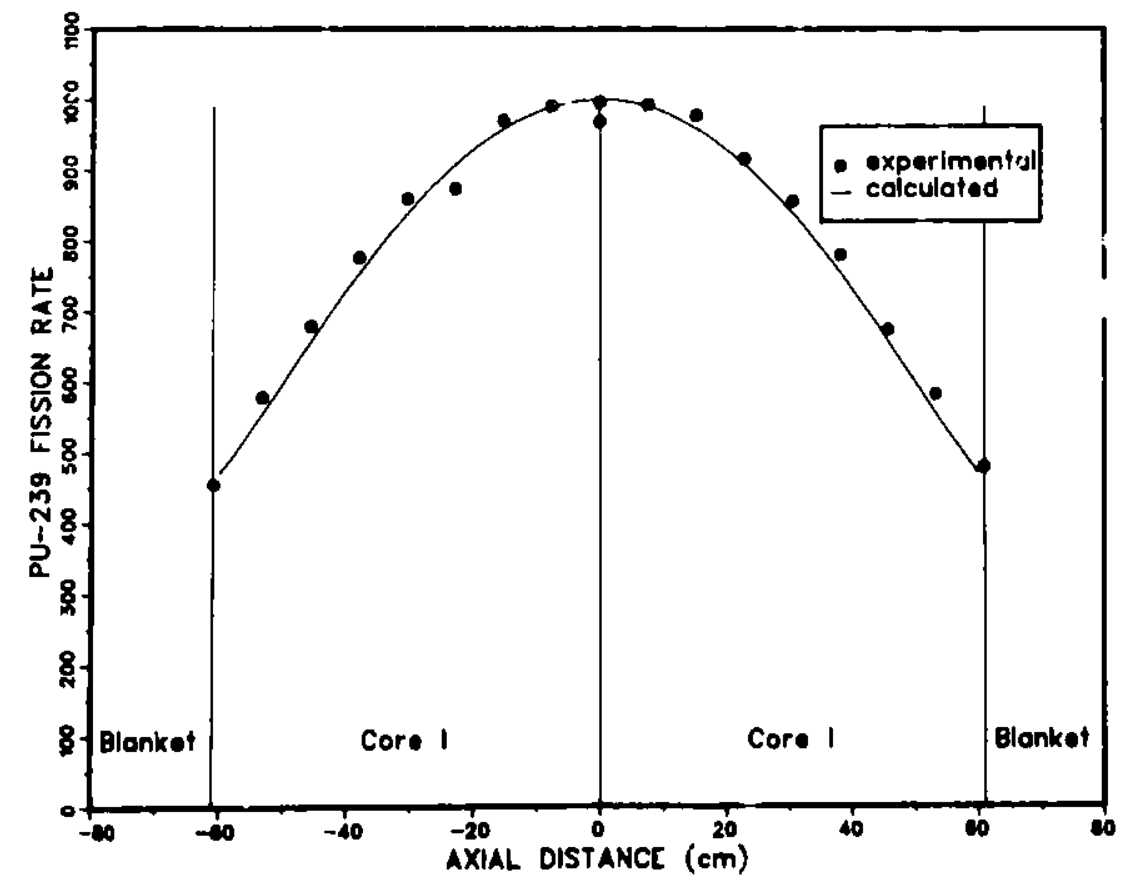

Fig. IV-36.

Axial 239pu Fission Rate Distribution in the Pin Zone.

ANL Neg. No. 116-80-37 
TABLE I-1. Unit Cell Averaged Atom Densities for GCFR Phase III Plate Compositions (1021) atoms/cm ${ }^{3}$ )

\begin{tabular}{|c|c|c|c|c|c|c|c|c|}
\hline & \multicolumn{3}{|c|}{ Core Region } & \multicolumn{3}{|c|}{ Axial Bianket Region } & \multirow[b]{2}{*}{$\begin{array}{l}\text { Radial } \\
\text { Blanket }\end{array}$} & \multirow[b]{2}{*}{ Reflector } \\
\hline & Zone I & Zone II $^{\mathbf{a}}$ & Zone III $^{b}$ & Zone I & Zone II $^{\mathrm{a}}$ & Zone III $^{\mathrm{b}}$ & & \\
\hline $\mathbf{F e}$ & 13.2544 & 15.3744 & 18.9341 & 8.3648 & 8.8520 & 9.0957 & 8.6832 & 55.3173 \\
\hline $\mathrm{Ni}$ & 1.2056 & 1.3240 & 1.4606 & 1.0667 & 1.1384 & 1.1743 & 1.1136 & 6.9735 \\
\hline $\mathrm{Cr}$ & 2.6337 & 2.8669 & 3.1381 & 2.3563 & 2.4963 & 2.5663 & 2.4478 & 15.6724 \\
\hline Mn & 0.2107 & 0.2291 & 0.2515 & 0.1870 & 0.1975 & 0.2027 & 0.1938 & 1.5646 \\
\hline 0 & 14.8674 & 13.8595 & 11.8173 & 15.6918 & 15.8164 & 15.7200 & 18.5944 & 1.9709 \\
\hline Mo & 0.2258 & 0.3022 & 0.4521 & -- & -- & $-\infty$ & -- & - \\
\hline $235_{U}$ & 0.0126 & 0.0122 & 0.0111 & 0.0175 & 0.0176 & 0.0175 & 0.0198 & -- \\
\hline $238_{\mathrm{U}}$ & 5.8098 & 5.5423 & 4.9782 & 8.1763 & 8.2170 & 8.1763 & 9.2582 & --- \\
\hline $238_{\mathrm{Pu}}$ & 0.0006 & 0.0007 & 0.0008 & - & - & - & - & -- \\
\hline $239 \mathrm{Pu}$ & 0.8842 & 1.1832 & 1.7718 & -- & -- & -- & --- & $-\infty$ \\
\hline $240 \mathrm{Pu}$ & 0.1171 & 0.1569 & 0.2351 & --- & -- & --- & -- & -- \\
\hline $241_{\mathrm{Pu}}{ }^{\mathrm{C}}$ & 0.0130 & 0.0163 & 0.0227 & - & --- & --- & -- & --- \\
\hline $242 \mathrm{Pu}$ & 0.0019 & 0.0024 & 0.0032 & --- & -- & -- & -- & -- \\
\hline $241_{\mathrm{Am}}^{\mathrm{C}}$ & 0.0052 & 0.0094 & 0.0178 & -- & -- & -- & -- & --- \\
\hline
\end{tabular}

${ }^{a}$ Three-drawer unit-cell averaged atom densities.

brawer-weighted averaged atom densities -- computed from unit-cell averaged atom densities and numbers of drawers per half for the three core drawer types in Zone III (Table I-2).

${ }^{c}$ Atom densities corrected for ${ }^{24} \mathrm{Pu}$ decay to $7 / 1 / 75$. 
TABLE 1-2. Number of Drawers Per Half, Fuel Plate Loading and Unit Cell Averaged Atom Densities for Each Type of Zone III Core Drawer

\begin{tabular}{|c|c|c|c|}
\hline & Type 1 & Type 2 & Ty pe 3 \\
\hline $\begin{array}{l}\text { Number of Drawers } \\
\text { per Half }\end{array}$ & 34 & 50 & 8 \\
\hline $\begin{array}{l}\text { Fuel Plate Loading } \\
\text { (from midplane to } \\
\text { axial blanket) }\end{array}$ & $\begin{array}{l}\text { DOW 8" } \\
\text { DOW 7" } \\
\text { DOW 5" } \\
\text { DOW 4" }\end{array}$ & $\begin{array}{r}\text { DOW } 7 " \\
\text { DOW } 5 " \\
\text { DOW 4" } \\
\text { DOW 4" } \\
\text { NUMEC 4" }\end{array}$ & $\begin{array}{ll}\text { NUMEC } & 6 " \\
\text { NUMEC } & 6 " \\
\text { NUMEC } & 6 " \\
\text { NUMEC } & 6 "\end{array}$ \\
\hline \multicolumn{4}{|l|}{$\begin{array}{l}\text { Unit-Ce } 11 \text { Ave raged } \\
\text { Atom Densities } \\
\left(10^{2} \text { atoms } / \mathrm{cm}^{3}\right)\end{array}$} \\
\hline $\begin{array}{c}\mathrm{Fe} \\
\mathrm{Ni} \\
\mathrm{Cr} \\
\mathrm{Mn} \\
0 \\
\mathrm{Mo} \\
235 \mathrm{U} \\
238 \mathrm{U} \\
238 \mathrm{Pu} \\
239 \mathrm{Pu} \\
240 \mathrm{Pu} \\
241 \mathrm{Pu} \\
242 \mathrm{Pu} \\
241 \mathrm{Am}^{\mathrm{a}}\end{array}$ & $\begin{array}{r}18.8930 \\
1.4546 \\
3.1262 \\
0.2505 \\
11.8149 \\
0.4558 \\
0.0112 \\
4.9999 \\
0.0007 \\
1.7836 \\
0.2369 \\
0.0221 \\
0.0031 \\
0.0195\end{array}$ & $\begin{array}{r}18.9727 \\
1.4662 \\
3.1493 \\
0.2524 \\
11.8187 \\
0.4496 \\
0.0111 \\
4.9562 \\
0.0008 \\
1.7643 \\
0.2341 \\
0.0226 \\
0.0032 \\
0.0179\end{array}$ & $\begin{array}{r}18.8678 \\
1.4510 \\
3.1189 \\
0.2498 \\
11.8158 \\
0.4518 \\
0.0112 \\
5.0236 \\
0.0012 \\
1.7684 \\
0.2343 \\
0.0260 \\
0.0038 \\
0.0104\end{array}$ \\
\hline
\end{tabular}

atom densities corrected for ${ }^{241} \mathrm{Pu}$ decay to $7 / 1 / 75$.

TABLE I-3. Number of Drawers per Half, Corresponding Equivalent Radif and Fissile-Plutonium Mass for Each Zone or Reglon

\begin{tabular}{|c|c|c|c|}
\hline $\begin{array}{r}\text { Zone/ } \\
\text { Region } \\
\end{array}$ & $\begin{array}{c}\text { Number of Drawers } \\
\text { per Half }\end{array}$ & $\begin{array}{l}\text { Equivalent } \\
\text { Radius }(\mathrm{cm})\end{array}$ & $\begin{array}{c}\text { Fissile Plutonium Mass } \\
\left(\mathrm{kg} 2{ }^{39} \mathrm{Pu}+241_{\mathrm{Pu}}\right)\end{array}$ \\
\hline $\begin{array}{l}\text { Zone I } \\
\text { Zone II } \\
\text { Zone III } \\
\text { Radial Blanket } \\
\text { Radial Reflector }\end{array}$ & $\begin{array}{r}229 \\
192 \\
92 \\
508 \\
332\end{array}$ & $\begin{array}{r}47.17 \\
63.95 \\
70.60 \\
99.59 \\
114.65\end{array}$ & $\begin{array}{c}303.7 \pm 0.1 \\
340.4 \pm 0.1 \\
244.0 \pm 0.1 \\
-\ldots \\
-\cdots\end{array}$ \\
\hline
\end{tabular}


TABLE I-4. Atom Densities for the Pin Zone and Zone I Plate Untt Cells

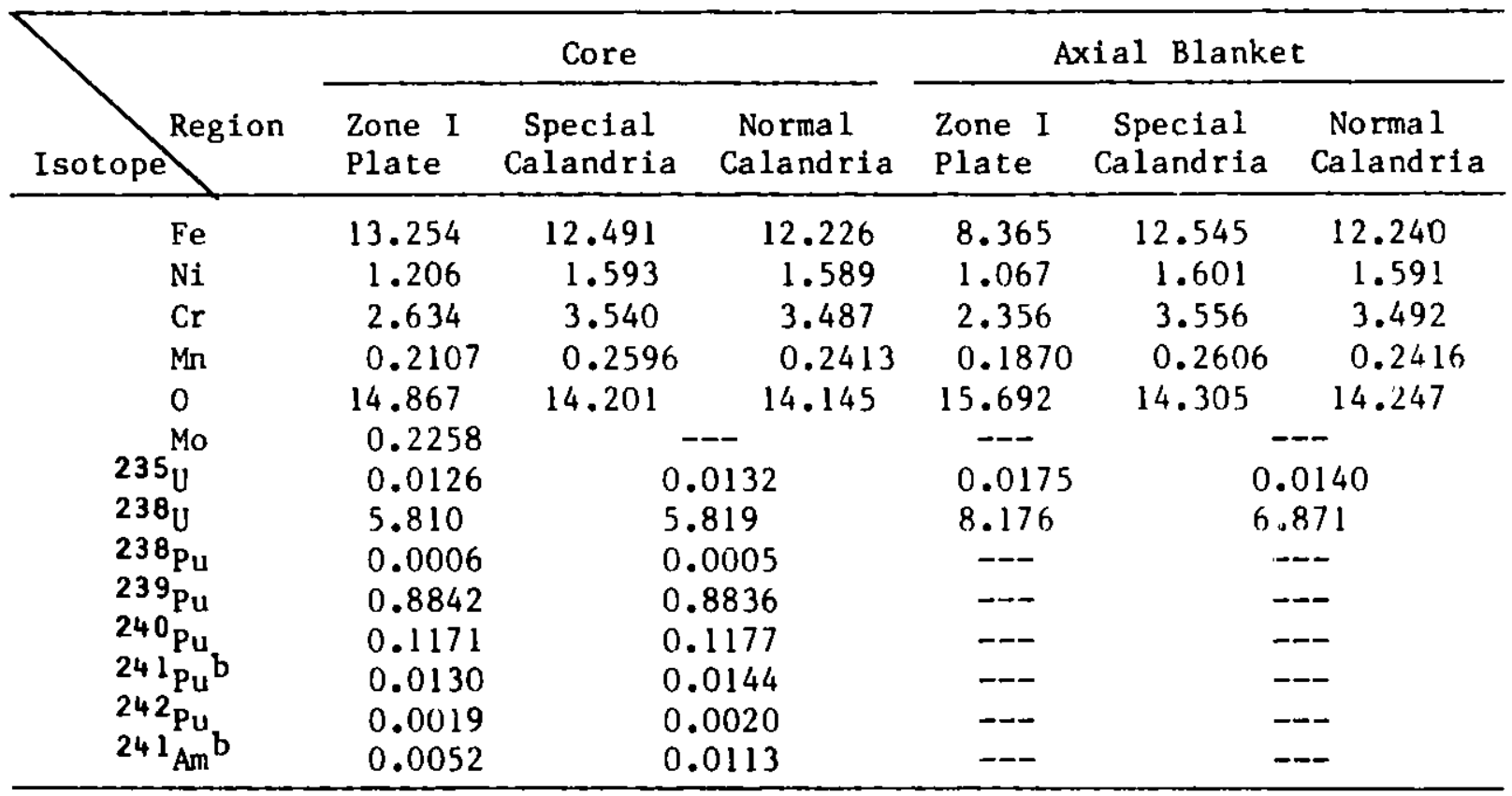

anits of $10^{21}$ atoms/cc.

$b_{\text {Atom densities corrected for }}{ }^{2}{ }^{4} \mathrm{Pu}$ decay to $7 / 1 / 75$.

TABLE I-5. Fuel Loadings for the GCFR Phase III Approach-to-Critical

\begin{tabular}{cccc}
\hline $\begin{array}{c}\text { Loading } \\
\text { Step }\end{array}$ & $\begin{array}{c}\text { ZPR-9 } \\
\text { Loading } \\
\text { Numbers }\end{array}$ & Date & $\begin{array}{c}\text { Fissile Plutonium Mass } \\
\left(\mathrm{kg} 239_{\left.\mathrm{Pu}+241_{\mathrm{Pu}}\right)}\right.\end{array}$ \\
\hline 1 & $1-13$ & $6 / 10 / 76$ & 479.3 \\
2 & $14-18$ & $6 / 16 / 76$ & 644.1 \\
3 & $19-22$ & $6 / 21 / 76$ & 723.8 \\
4 & 23,24 & $6 / 23 / 76$ & 792.6 \\
5 & 25 & $6 / 24 / 76$ & 856.2 \\
6 & 26 & $6 / 25 / 76$ & 888.1 \\
\hline
\end{tabular}

a The ralues of the fissile plutonium mass have been adjusted to reflect ${ }^{241} \mathrm{Pu}$ decay as of $7 / 1 / 76$. 
TABLE 1-6. Estimated Critical Mass of Fissile Plutonium, $M_{c}$ (kg), Using $1 / C$ vs. Mf Technique ${ }^{a}$

\begin{tabular}{cccccc}
\hline \multirow{2}{*}{$\begin{array}{c}\text { Charne } \\
\text { Number }\end{array}$} & Description & \multicolumn{4}{c}{ Loading Step } \\
\cline { 4 - 6 } 1 & 235 U FC, S23/23-24" & 707 & 853 & 871 & 884 \\
2 & 235 U FC, M23/23-24" & 708 & 854 & 873 & 884 \\
3 & SP-10, Movable Half & 797 & 827 & 859 & 884 \\
4 & SP-11, Stationa ry Half & 809 & 826 & 858 & 882 \\
5 & Reactor Channe1 No. 1 & 808 & 844 & 868 & 894 \\
6 & Feactor Channel No. 2 & 811 & 847 & 870 & 892 \\
7 & Reactor Channel No. 3 & 776 & 840 & - & - \\
8 & Reactor Channel No. 4 & 789 & 832 & 862 & 882 \\
9 & Reactor Channe1 No. 5 & 769 & 838 & 869 & 881 \\
10 & Reactor Channe1 No. 6 & 824 & 835 & 862 & 883 \\
\hline
\end{tabular}

${ }^{a}$ The data were accumulated with the assembly in the most reactive configuration.

TABLE I-7. Estimated reitical Mass of Fissile plutonium, $M_{c}(\mathrm{~kg})$, Using $:_{i} / C$ vs. $M_{f}$ Technique ${ }^{a}$

\begin{tabular}{|c|c|c|c|c|c|}
\hline \multirow{2}{*}{$\begin{array}{l}\text { Channel } \\
\text { Number }\end{array}$} & \multirow[b]{2}{*}{ Description } & \multicolumn{4}{|c|}{ Loading Step } \\
\hline & & No. 2 & No. 3 & No. 4 & No. 5 \\
\hline 1 & $235_{\mathrm{U}} \mathrm{FC}, \mathrm{S} 23 / 23-24^{\prime \prime}$ & 724 & 905 & 888 & 887 \\
\hline 2 & ${ }^{235} \mathrm{U} \mathrm{FC}, \mathrm{M} 23 / 23-24^{\prime \prime}$ & 725 & 907 & 891 & 887 \\
\hline 3 & SP-10, Movable Half & 878 & 862 & 872 & 887 \\
\hline 4 & SP-1 1 , Stationary Half & 883 & 860 & 872 & 885 \\
\hline 5 & Reactor Channel No. 1 & 874 & 890 & 884 & 899 \\
\hline 6 & Reactor Channel No. 2 & 881 & 894 & 888 & 897 \\
\hline 7 & Reactor Channel No. 3 & 854 & 883 & - & - \\
\hline 8 & Reactor Charinel No. 4 & 832 & 870 & 877 & 885 \\
\hline 9 & Reactor Channel No. 5 & 776 & 879 & 886 & 884 \\
\hline 10 & Reactor Channel No. 6 & 843 & 875 & 877 & 886 \\
\hline
\end{tabular}

The data were accumulated with the assembly in the nost reactive conf iguration. 
TABLE I-8. Sumary of the Reactivity Correctlons and the Corresponding Ad justments to the CCFR Phase II Seforence

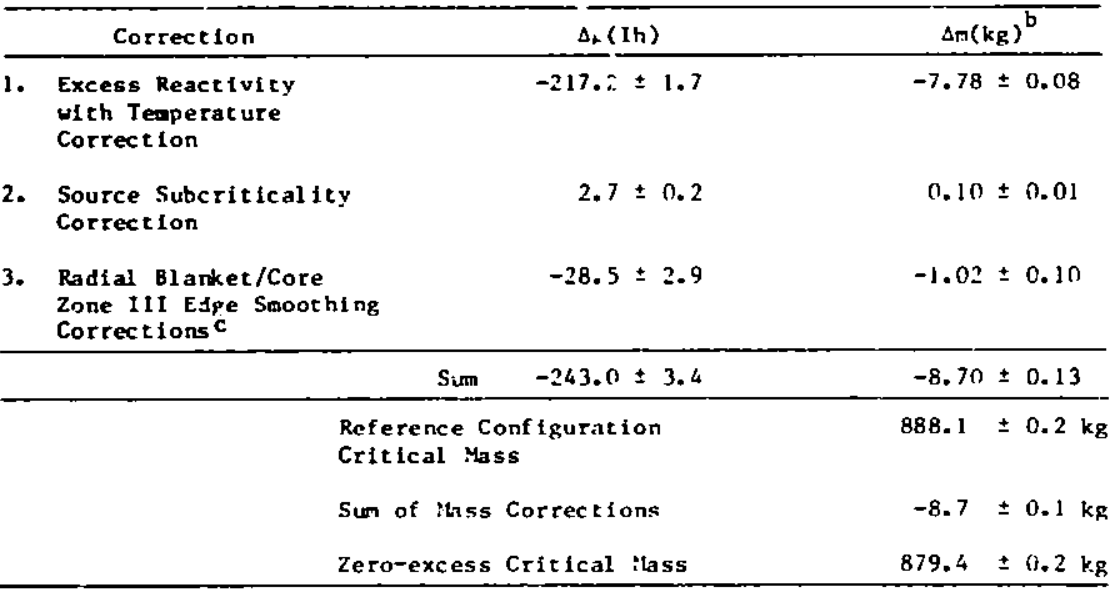

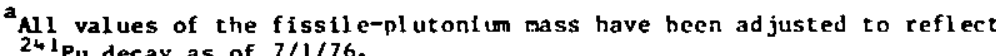
Pu decay as of $7 / 1 / 76$.

bTe $\Delta_{0}$ to $\Delta_{m}$ conversion is conputed using, the operationat value of the edge-f wel worth of $27.9 \pm 0.2 \mathrm{Ih} / \mathrm{kg}$.

c Similar corrections for the Zone I/Zone II and Zone II/7one $I$ II boundaries are not included, but are expected to be of comparabie magnitude.
TABLE I-9. Summary of ZPR-9 GC.R Phase II Operational Measurements

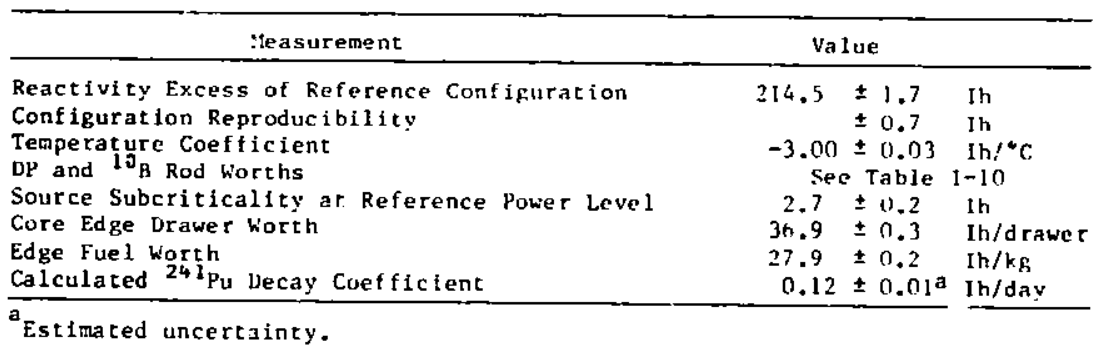

TABLE I-10. Locations and Measured Worths of the ZPR-9 Control Rods for the GCFR Phase III Assembly

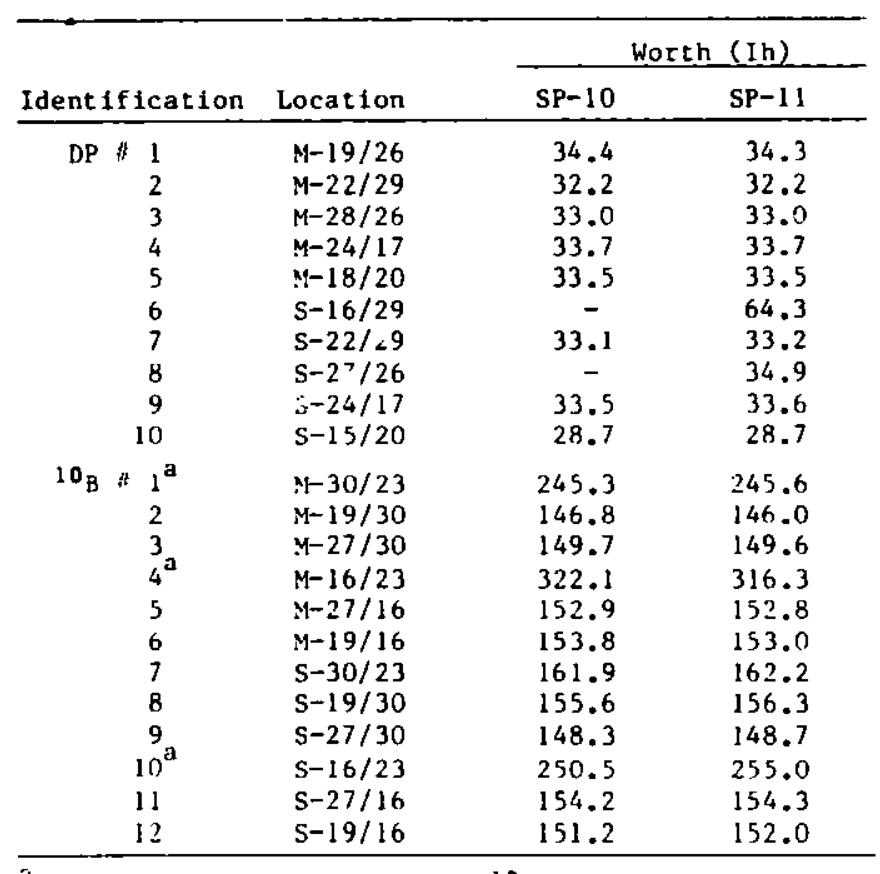

"Dual bladed assemblies with $10_{\mathrm{B}}$ blades in the drawers on both sides of the center drawer listed. 
TAbl.f, 1 I-1. Energy/Lethargy Group Structure for the 29-Group Calculations

\begin{tabular}{|c|c|c|}
\hline Group No. & Ipper Energy, ey & Lethargy \\
\hline 1 & $1.4191 \times 10^{\prime}$ & 0.00 \\
\hline 2 & $1.0000 \times 10^{7}$ & 0.35 \\
\hline 3 & $6.0653 \times 10^{6}$ & 0.85 \\
\hline 4 & $3.6788 \times 10^{6}$ & 1.35 \\
\hline 5 & $2.2313 \times 10^{6}$ & 1.85 \\
\hline 6 & $1.353 t:=10^{t}$ & 2.35 \\
\hline 7 & $3.2085 \times 10^{5}$ & 2.15 \\
\hline$x$ & $4.9787 \times 10^{5}$ & 3.35 \\
\hline 9 & $3.0197 \times 10^{5}$ & 3.85 \\
\hline 30 & $1.8316 \times 10^{5}$ & 4.35 \\
\hline 11 & $1.1109 \times 10^{5}$ & 4.85 \\
\hline 12 & $5.7379 \times 10^{4}$ & 5.35 \\
\hline 13 & $4.0868 \times 101^{4}$ & $j .85$ \\
\hline 14 & $2.4788 \times 10^{4}$ & 6.35 \\
\hline 15 & $1.5034 \times 10^{4}$ & 6.85 \\
\hline 16 & $9.1188 \times 10^{3}$ & 7.35 \\
\hline 17 & $5.5308 \times 10^{3}$ & 7.85 \\
\hline I & $3.3546 \times 10^{3}$ & 8.35 \\
\hline 19 & $2.0347 \times 10^{3}$ & 8.85 \\
\hline 211 & $1.2341 \times 10^{3}$ & 9.35 \\
\hline 21 & $7.4852 \times 10^{2}$ & 9.85 \\
\hline 22 & $4.5400 \times 10^{2}$ & 10.35 \\
\hline 23 & $2.7536 \times 10^{2}$ & 10.85 \\
\hline 24 & $1.0130 \times 10^{2}$ & 11.85 \\
\hline 25 & $3.7267 \times 101$ & 12.85 \\
\hline 26 & $1.3740 \times 10^{1}$ & 13.85 \\
\hline 27 & $5.0435 \times 10^{0}$ & 14.85 \\
\hline 28 & $1.8554 \times 10^{0}$ & 15.85 \\
\hline 29 & $4.1399 \times 10^{-1}$ & 17.35 \\
\hline
\end{tabular}

TAkLF. II-2. Benolst Anisotropic Diffusion Coefficient Multipliers, M , for the GCFR-III Pl ate lint Cells

\begin{tabular}{|c|c|c|c|c|c|c|c|}
\hline \multirow{2}{*}{$\begin{array}{l}\text { Group } \\
\text { Number }\end{array}$} & \multicolumn{3}{|c|}{ Core } & \multicolumn{3}{|c|}{ Axia1 Blanket } & \multirow{2}{*}{$\begin{array}{l}\text { Radial } \\
\text { Blanket }\end{array}$} \\
\hline & Zone I & Zorse II & Zone III & Zone I & Zone II & Zone III & \\
\hline $\begin{array}{l}1 \\
2\end{array}$ & $\begin{array}{l}1.0408 \\
1.0426\end{array}$ & $\begin{array}{l}1.0419 \\
1.0440\end{array}$ & $\begin{array}{l}1.0402 \\
1.0429\end{array}$ & $\begin{array}{l}1.0316 \\
1.0319\end{array}$ & $\begin{array}{l}1.0269 \\
1.0265\end{array}$ & $\begin{array}{l}1.0243 \\
1.0250\end{array}$ & $\begin{array}{l}1.0246 \\
1.0246\end{array}$ \\
\hline 3 & 1.0483 & 1.0502 & 1.0492 & 1.0353 & $\begin{array}{l}1.0265 \\
1.0298\end{array}$ & $\begin{array}{l}1.0250 \\
1.0276\end{array}$ & $\begin{array}{l}1.0246 \\
1.0276\end{array}$ \\
\hline 4 & 1.0514 & 1.0544 & 1.0531 & 1.0358 & 1.0301 & 1.0288 & 1.0285 \\
\hline 5 & 1.0644 & 1.0643 & 1.0628 & 1.0500 & 1.0428 & 1.0394 & 1.0398 \\
\hline 6 & 1.0931 & 1.0867 & 1.0856 & 1.0822 & 1.0739 & 1.0712 & 1.0738 \\
\hline 7 & 1.0830 & 1.0807 & 1.0803 & 1.0690 & 1.0606 & 1.0582 & 1.0591 \\
\hline 8 & 1.1360 & 1.1256 & 1.1222 & 1.1234 & 1.1114 & 1.1090 & 1.1122 \\
\hline 9 & 1.1229 & 1.1174 & 1.1158 & 1.1050 & 1.0922 & 1.0884 & 1.0902 \\
\hline 10 & 1.1323 & 1.1267 & 1.1 .279 & 1.1142 & 1.1006 & 1.0975 & 1.0986 \\
\hline 11 & 1.1380 & 1.1356 & 1.1360 & 1.1126 & 1.0971 & 1.0927 & 1.0928 \\
\hline 12 & 1.1453 & 1.1445 & 1.1452 & 1.1156 & 1.0991 & 1.0943 & 1.0943 \\
\hline 13 & 1.1493 & 1.1542 & 1.1509 & 1.1027 & 1.0856 & 1.0798 & 1.0775 \\
\hline 14 & 1.1472 & 1.1413 & 1.1466 & 1.1253 & 1.1094 & 1.1054 & 1.1044 \\
\hline 15 & 1.1438 & 1.1440 & 1.1430 & 1.1105 & 1.0929 & 1.0872 & 1.0857 \\
\hline 16 & 1.1606 & 1.1772 & 1.1648 & 1.1054 & 1.0905 & 1.0912 & 1.0834 \\
\hline 17 & 1.1496 & 1.1575 & 1.1519 & 1.1052 & 1.0878 & 1.0852 & 1.0797 \\
\hline 18 & 1.1553 & 1.1657 & 1.1596 & 1.1047 & 1.0983 & 1.0847 & 1.0794 \\
\hline 19 & 1.1668 & 1.1778 & 1.1738 & 1.1074 & 1.0906 & 1.0840 & 1.0809 \\
\hline 20 & 1.1740 & 1.1884 & 1.1836 & 1.1067 & 1.0902 & 1.0841 & 1.0803 \\
\hline 21 & 1.1779 & 1.1955 & 1.1896 & 1.1011 & 1.0842 & 1.0796 & 1.0758 \\
\hline 22 & 1.1714 & 1.1944 & 1.1796 & 1.1017 & 1.1006 & 1.0901 & 1.0824 \\
\hline 23 & 1.2094 & 1.2340 & 1.2313 & 1.1076 & 1.0894 & 1.0852 & 1.0808 \\
\hline 24 & 1.2693 & 1.3121 & 1.3223 & 1.1001 & 0.0826 & 1.0796 & 1.0752 \\
\hline 25 & 1.2616 & 1.2766 & 1.2953 & 1.1418 & 1.1164 & 1.1142 & 1.1099 \\
\hline 26 & 1.3501 & 1.3600 & 1.3901 & 1.1138 & 1.0932 & 1.0918 & 1.0868 \\
\hline 27 & 1.1847 & 1.2087 & 1.2025 & 1.1004 & 1.0830 & 1.0804 & 1.0758 \\
\hline 28 & 1.4931 & 1.5417 & 1.7753 & 1.0928 & 1.0773 & 1.0753 & 1.0704 \\
\hline 29 & 3.6353 & 4.2561 & 4.7431 & 1.0995 & 1.0835 & 1.0889 & 1.0808 \\
\hline
\end{tabular}


TABLE II-3. Benoist Anisotropic Diffusion Coefficient Mul : inliers, ML' for the GCFR-III Plate linit Cells

\begin{tabular}{|c|c|c|c|c|c|c|c|}
\hline \multirow{2}{*}{$\begin{array}{l}\text { Group } \\
\text { Number }\end{array}$} & \multicolumn{3}{|c|}{ Core } & \multicolumn{3}{|c|}{ Axial Blanket } & \multirow{2}{*}{$\begin{array}{l}\text { Rddial } \\
\text { Blanket }\end{array}$} \\
\hline & Zone I & Zone II & Zone III & Zone I & Zone II & Zone III & \\
\hline$\frac{1}{2}$ & 1.0010 & 1.0013 & & 1.0007 & 1.0007 & 1.0006 & 1.0007 \\
\hline 2 & 1.0011 & $\begin{array}{l}1.0015 \\
1.0020\end{array}$ & 1.0011 & 1.0008 & 1.0007 & 1.0006 & 1.0008 \\
\hline 3 & 1.0015 & 1.0020 & 1.0014 & 1.0010 & 1.0009 & 1.0008 & 1.0010 \\
\hline 4 & 1.0017 & 1.0023 & 1.0016 & 1.0011 & 1.0010 & 1.0009 & 1.0012 \\
\hline 5 & 1.0022 & 1.0028 & 1.0021 & 1.0017 & 1.0016 & 1.0013 & 1.0016 \\
\hline 6 & 1.0032 & 1.0034 & 1.0030 & 1.0030 & 1.0031 & 1.0029 & 1.0035 \\
\hline 7 & 1.0030 & 1.0036 & 1.0030 & 1.0025 & 1.0025 & 1.0022 & 1.0027 \\
\hline 8 & 1.0065 & 1.0066 & 1.0061 & 1.0063 & 1.0066 & 1.0064 & 1.0075 \\
\hline 9 & 1.0064 & 1.0071 & 1.0062 & 1.0056 & 1.0055 & 1.0049 & 1.0060 \\
\hline 10 & 1.0073 & 1.0082 & 1.0075 & 1.0063 & 1.0063 & 1.0058 & 1.0070 \\
\hline 11 & 1.0094 & 1.0110 & 1.0093 & 1.0074 & 1.0070 & 1.0062 & 1.0076 \\
\hline 12 & 1.0108 & 1.0130 & 1.0107 & 1.0082 & 1.0076 & 1.0068 & 1.0083 \\
\hline 13 & 1.0138 & 1.0175 & 1.0124 & 1.0096 & 1.0084 & 1.0072 & 1.0090 \\
\hline 14 & 1.0101 & 1.0111 & 1.0105 & 1.0085 & 1.0081 & 1.0076 & 1.0090 \\
\hline 15 & 1.0131 & 1.0159 & 1.0123 & 1.0097 & 1.0086 & 1.0075 & 1.0093 \\
\hline 16 & 1.0237 & 1.0342 & 1.0213 & 1.0184 & 1.0157 & 1.0177 & 1.0186 \\
\hline 17 & 1.0194 & 1.0256 & 1.0176 & 1.0148 & 1.0124 & 1.0125 & 1.0140 \\
\hline 18 & 1.0202 & 1.0274 & 1.0184 & 1.0147 & 1.0136 & 1.0125 & 1.0140 \\
\hline 19 & 1.0195 & 1.0263 & 1.0181 & 1.0118 & 1.0102 & 1.0091 & 1.0109 \\
\hline 20 & 1.0218 & 1.0300 & 1.0201 & 1.0125 & 1.0107 & 1.0098 & 1.0116 \\
\hline 21 & 1.0230 & 1.0321 & 1.0210 & 1.0120 & 1.0101 & 1.0094 & 1.0110 \\
\hline 22 & 1.0268 & 1.0400 & 1.0240 & 1.0191 & 1.0183 & 1.0187 & 1.0193 \\
\hline 23 & 1.0319 & 1.0441 & 1.0298 & 1.0136 & 1.0114 & 1.0109 & 1.0126 \\
\hline 24 & 1.0509 & 1.0683 & 1.0503 & 1.0126 & 1.0105 & i. 0102 & 1.0117 \\
\hline 25 & 1.0413 & 1.0531 & 1.0440 & 1.0179 & 1.0148 & 1.0147 & 1.0173 \\
\hline 26 & 1.0786 & 1.0838 & 1.0682 & 1.0140 & 1.0116 & 1.0118 & 1.0135 \\
\hline 27 & 1.0259 & 1.0374 & 1.0240 & 1.0128 & 1.0107 & 1.0106 & 1.0121 \\
\hline 28 & 1.1415 & 1.1551 & 1.1954 & 1.0124 & 1.0104 & 1.0105 & 1.0117 \\
\hline 29 & 2.4850 & 2.7449 & 2.7300 & 1.0163 & 1.0135 & 1.0168 & 1.0174 \\
\hline
\end{tabular}


TABLE II-4. Comparison of Benolst An1sotropic Ijffusion Loeridelent Multipliers for the (iCFR-Ill contral pin and liate tones

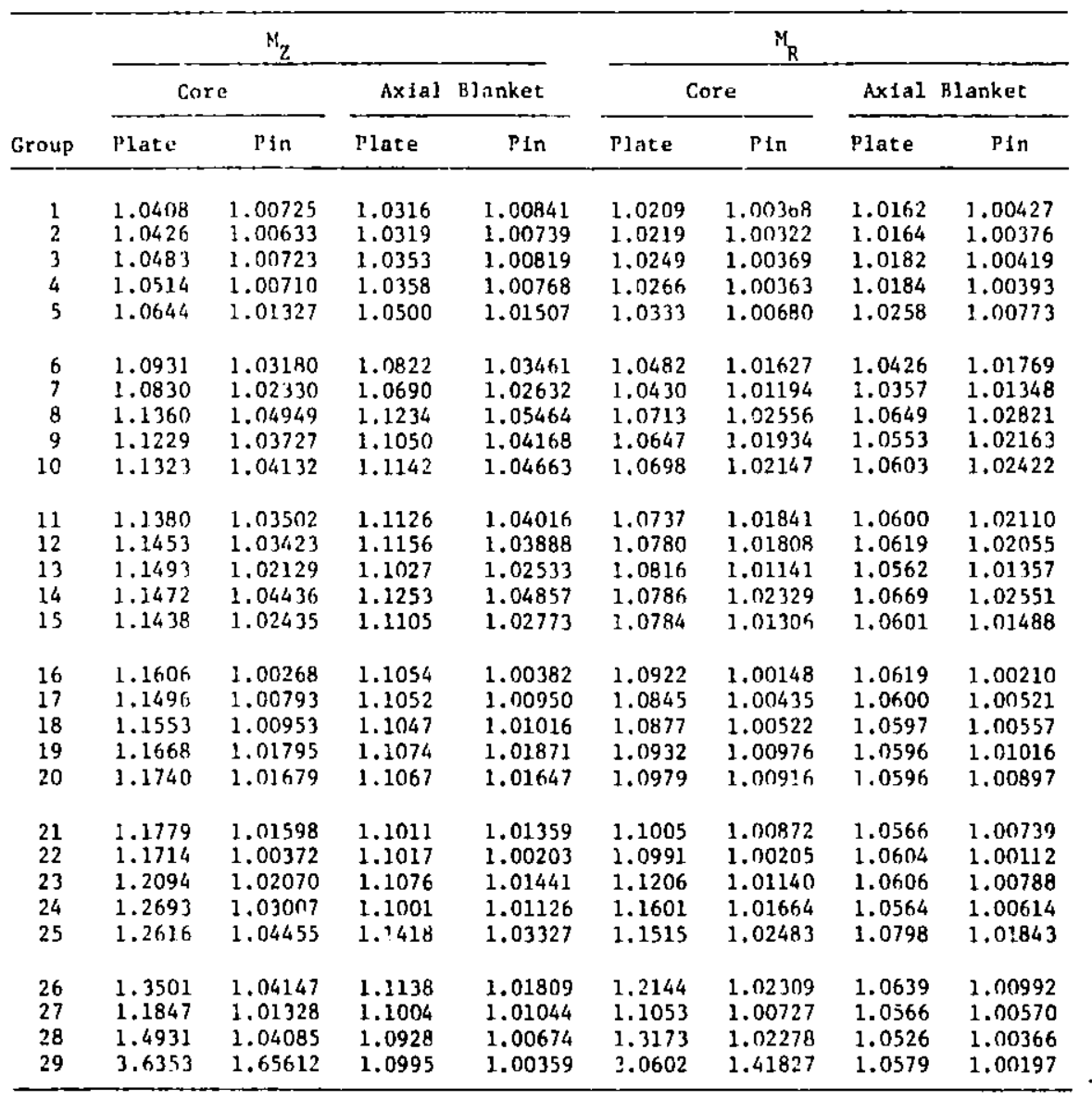

TABLE II-5. KInetIcB Iarameters for the GCFR Phase III Assembly

\begin{tabular}{|c|c|c|c|}
\hline & With otreaning & With axial streaming & W1 thout strean1 ng \\
\hline $\begin{array}{l}\text { Radfal D' } \\
\text { Axial D'S }\end{array}$ & $\begin{array}{l}\text { Benol st } \\
\text { Benol gt }\end{array}$ & $\begin{array}{l}\text { Isotroplc } \\
\text { Benoist }\end{array}$ & $\begin{array}{l}\text { Isotroplc } \\
\text { Isotrop Ic }\end{array}$ \\
\hline $\begin{array}{l}\text { Ef fect Ive Delayed Neutron } \\
\text { Fraction, Beff }\end{array}$ & $3.3743 \times 10^{-3}$ & $3.3701 \times 10^{-3}$ & $3.3623 \times 10^{-3}$ \\
\hline $\begin{array}{l}\text { Prompt Neutron Lifertine, } \\
\text { ip (Bec) }\end{array}$ & $4.1765 \times 10^{-1}$ & $4.191) 6 \times 10^{-1}$ & $4.1981 \times 10^{-1}$ \\
\hline $\begin{array}{l}\text { Neutron Generation Time, } \\
\qquad \text { (sec) }\end{array}$ & $4.2373 \times 10^{-1}$ & $4.2260 \times 10^{-1}$ & $4.2023 \times 10^{-7}$ \\
\hline $\begin{array}{l}\text { Inhourg per Percent } \\
\text { Reactivity, Ih/\%,k }\end{array}$ & $9.5683 \times 10^{2}$ & $9.5695 \times 10^{2}$ & $9.5753 \times 10^{2}$ \\
\hline $\begin{array}{l}\text { Inhoure per Dollar } \\
\text { Reactivity, Ih/s }\end{array}$ & $3.2286 \times 10^{2}$ & $3.2250 \times 10^{2}$ & $3.2195 \times 10^{2}$ \\
\hline $\begin{array}{l}\text { Normallzed Perturbacion } \\
\text { Denonlinator }\end{array}$ & $4.25,84 \times 10^{5}$ & $4.2250 \times 10^{5}$ & $4.1748 \times 10^{5}$ \\
\hline $\begin{array}{l}\text { Effect Ive Mulcipltcation } \\
\text { Factor, Keff }\end{array}$ & 0.9856 & 0.9916 & 0.9990 \\
\hline
\end{tabular}


TABLE. II-h. Delayed Nelit ron Fractions and Fffect tve Decay Constants for the CCFA Phase Ill Asaembly

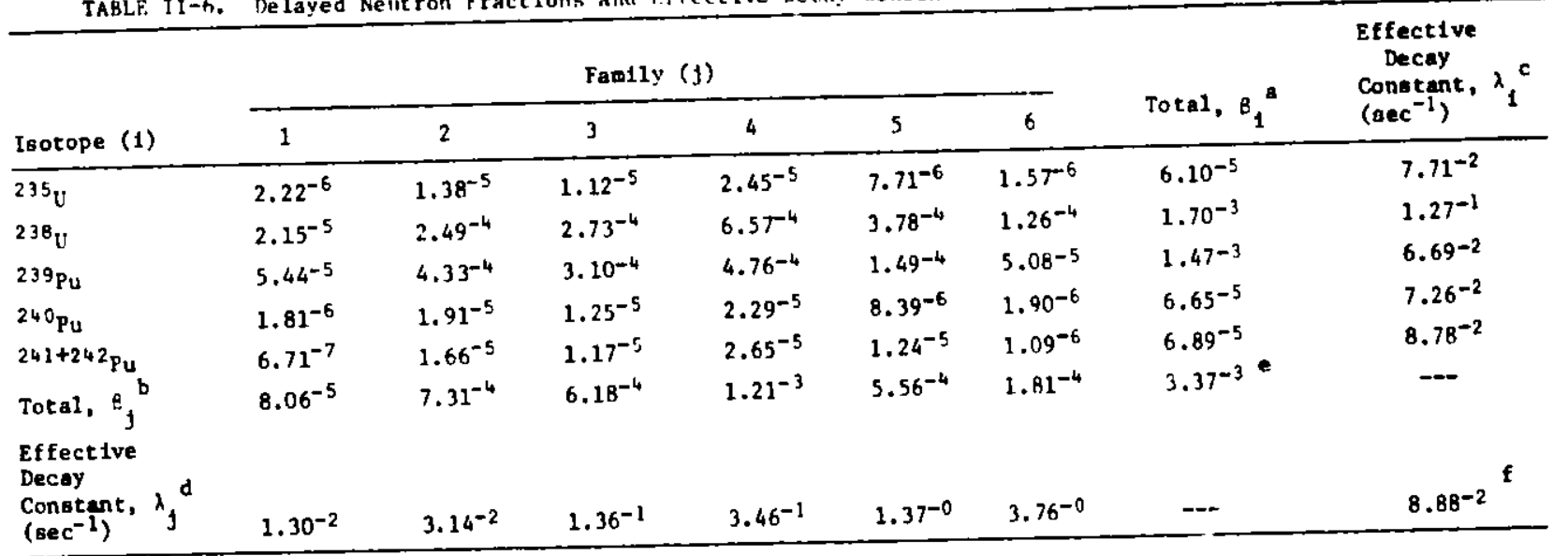

\footnotetext{
$a_{B_{1}}=\left\{B_{1 j}\right.$

$b_{j}=\sum_{1} \beta_{i j}$

$c \lambda_{i}=\beta_{i} / \sum_{j}\left(\beta_{1 j} / \lambda_{1 j}\right) ;$ see Table II-7 for $\lambda_{11}$.

$d_{\lambda_{f}}=\beta_{f} /\left[\left(\beta_{1 j} / \lambda_{1 j}\right)\right.$; see Table II-7 for $\lambda_{11}$.

e $B=\underset{1}{i B_{1}}=\underset{j}{\left[\beta_{f}\right.}$

$f_{\lambda}=\beta /\left[\sum\left(\beta_{1} / \lambda_{1}\right)=g /\left[j\left(\beta_{j} / \lambda_{j}\right)\right.\right.$.
}

TABLE 1I-7. Decay Constant $8, \lambda_{1 j}\left(\mathrm{sec}^{-1}\right)$

\begin{tabular}{lcccccc}
\hline Isotope (1) & 1 & 2 & 3 & 4 & 5 & 6 \\
\hline $235_{\mathrm{U}}$ & 0.01272 & 0.03174 & 0.116 & 0.311 & 1.40 & 3.87 \\
$238_{\mathrm{U}}$ & 0.01323 & 0.03212 & 0.139 & 0.359 & 1.41 & 4.03 \\
$239 \mathrm{Pu}$ & 0.01290 & 0.03110 & 0.134 & 0.332 & 1.26 & 3.21 \\
$240 \mathrm{Pu}$ & 0.01294 & 0.03131 & 0.135 & 0.333 & 1.36 & 4.03 \\
$241_{\mathrm{Pu}}{ }^{\mathrm{a}}$ & 0.01280 & 0.02990 & 0.124 & 0.352 & 1.61 & 3.47 \\
\hline
\end{tabular}

${ }^{241} \mathrm{Pu}$ data used for ${ }^{242} \mathrm{Pu}$. 
TABLE II-8. Summary of Calculated Eigenvalues and Kinetics Parameters for Plate and Pin Zone Reference Conf Igurations

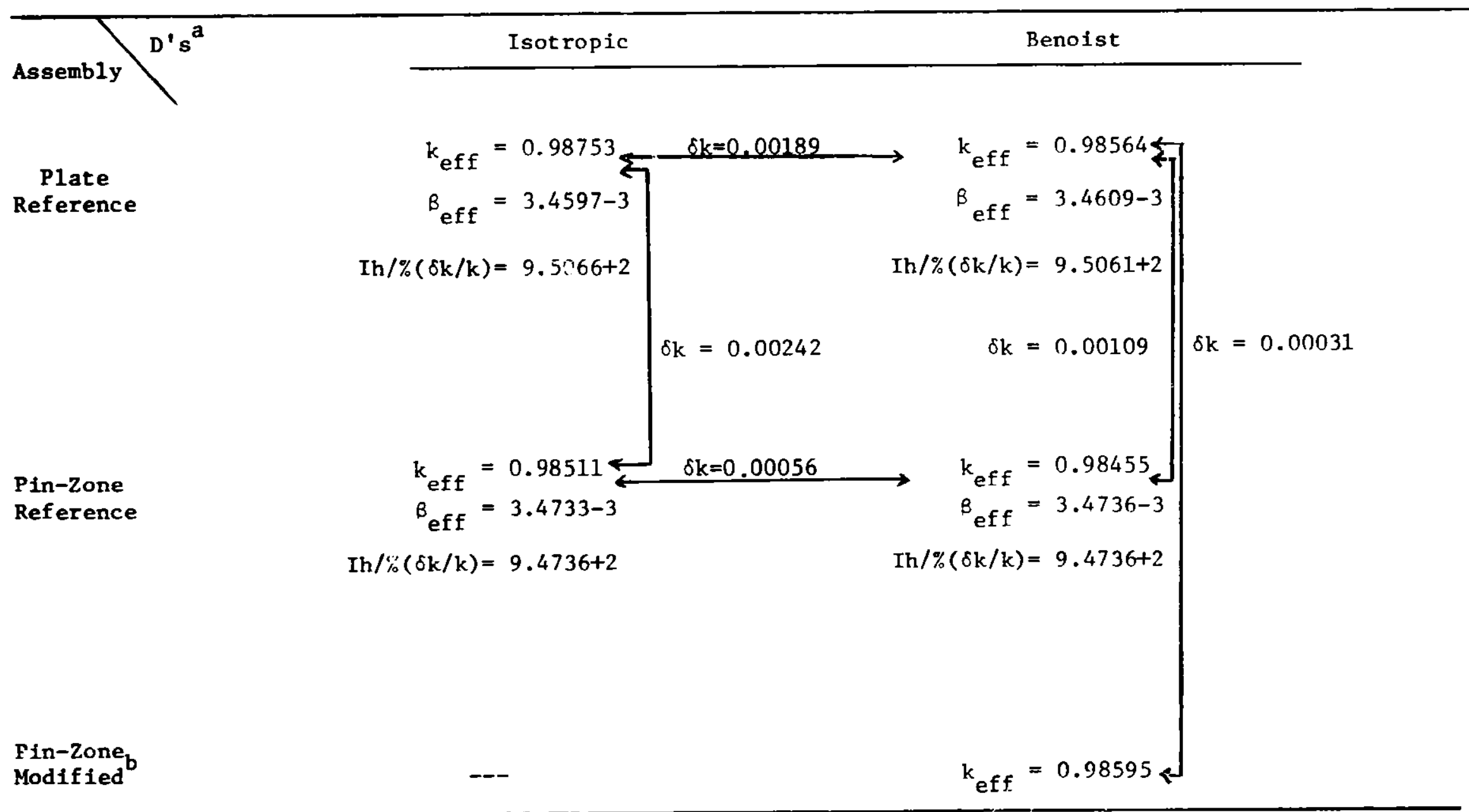

aiffusion coefficient type in 85 drawer central zone. Benoist diffusion coefficients in all other core and blanket regions.

${ }^{b}$ Calculational pin zone RZ model with Zone III/radial blanket boundary identical to that of plate reference $\mathrm{RZ}$ model. 
TABLE II-9. Worth of Pin Zone Replacing Plate Zone:

Experimental Determination.

\begin{tabular}{|c|c|c|c|}
\hline Step & State or Operation & Change in Fxcess & Excess (Ih) \\
\hline 1 & Plate Reference $8 / 18 / 76$ & --- & $+193.1 \pm 2.2$ \\
\hline 2 & Remove 4 edge drawers & $=\begin{aligned} &-4 *(36.94 \pm 0.28) \\
&-147.76 \pm 1.12\end{aligned}$ & \\
\hline 3 & Decay $241 \mathrm{Pu}$ for 9 days & $=\begin{aligned}-9 *(0.12 & \pm 0.01) \\
-1.08 & \pm 0.09\end{aligned}$ & \\
\hline 4 & $\begin{array}{l}\text { Pin Zone Reference } \\
\text { Configuration With } \\
\text { Plates in the Zone }\end{array}$ & --- & $+44.3 \pm 2.5$ \\
\hline 5 & Pin Zone Reference & --- & $+12.6 \pm 1.2$ \\
\hline \multirow[t]{2}{*}{6} & Replace Plates by Pins & $\begin{aligned} 12.6 & \pm 1.2 \\
-44.3 & \pm 2.5\end{aligned}$ & \\
\hline & & $-31.7 \pm 2.8$ & \\
\hline
\end{tabular}

TABLE II-10. Worth of Pin Zone Replacing Plate Zone:

Calculational Determination of Components and Total Worth

\begin{tabular}{|c|c|c|c|}
\hline Step & State or Operation & Clange ili Freses: & Excess \\
\hline 1 & Plate Reference & -- & $k_{1}=0.98564$ \\
\hline 2 & $\begin{array}{l}\text { Plate } \rightarrow \text { Pin Composition } \\
\text { (Composition Change) }\end{array}$ & $\begin{aligned}\left(k_{3}-k_{1}\right) & =+0.00166 \\
& =+157.80 \mathrm{Ih}\end{aligned}$ & \\
\hline 3 & $\begin{array}{l}\text { Plate } \rightarrow \text { Pin Cross Sections } \\
\text { (Heterogeneity Change) }\end{array}$ & $\begin{aligned}\left(k_{4}-k_{3}\right)= & -0.00264 \\
& -250.96 \mathrm{Ih}\end{aligned}$ & \\
\hline 4 & $\begin{array}{l}\text { Plate + Pin Diffusion Coef } \mathrm{f} \\
\text { (Streaming Change) }\end{array}$ & $\begin{aligned}\left(k_{6}-k_{4}\right) & =+0.00129 \\
& =+122.63 \mathrm{Ih}\end{aligned}$ & \\
\hline 5 & $\begin{array}{l}\text { Sum of Effects yields } \Delta p= \\
\text { P1n Zone in the Plate } \\
\text { Reference Outer Core } \\
\quad \text { Boundary }\end{array}$ & $\begin{array}{r}\left(k_{3}-k_{1}\right) \\
+\left(k_{4}-k_{3}\right) \\
+\left(k_{6}-k_{4}\right) \\
+29.47 \text { Ih }\end{array}$ & $k_{6}=0.98595$ \\
\hline \multirow{3}{*}{6} & $C-E$ & $\begin{array}{l}+29.47-(-31.66) \\
61.13 \mathrm{Ih} \\
0.0006 \Delta \mathrm{k}\end{array}$ & \\
\hline & Remove Edge Drawers & $\begin{aligned}\left(k_{7}-k_{6}\right) & =-0.0014 \\
& =-132.63 \mathrm{Ih}\end{aligned}$ & $k_{7}=0.98455$ \\
\hline & $C / E$ & $\begin{array}{l}132.63 / 147.76 \\
0.90\end{array}$ & \\
\hline
\end{tabular}


TABLE II-11. Calculated Components of the Pin-for-Plate Replacement worth

\begin{tabular}{|c|c|c|c|c|c|c|c|}
\hline \multirow[b]{2}{*}{$\begin{array}{l}\text { Calculation } \\
\text { Number }\end{array}$} & \multirow{2}{*}{\multicolumn{2}{|c|}{$\begin{array}{l}\text { Outer } \\
\text { Boundary }\end{array}$}} & \multicolumn{3}{|c|}{ Central Zone } & \multicolumn{2}{|c|}{ Result } \\
\hline & & & $\begin{array}{l}\text { Number } \\
\text { Densities }\end{array}$ & $\sigma^{\prime} s$ & $D^{\prime} s$ & $k$ & Ih $/ \% \Delta \mathrm{k}$ \\
\hline 1 & Plate & Reference & plare & plate & Benoist plate & 0.98564 & 950.61 \\
\hline 2 & $"$ & $"$ & plate & plate & Isotropic plate & 0.98763 & \\
\hline 3 & $"$ & $" 1$ & pin & plate & Benoist plate & 0.98730 & \\
\hline 4 & $"$ & $"$ & pin & pin & Benoist plate & $n .98466$ & \\
\hline 5 & $"$ & $"$ & plate & pin & Benoist plate & 0.98309 & \\
\hline 6 & $"$ & $"$ & pin & pin & Benoist pin & 0.98595 & \\
\hline 7 & Pin R & eference & pin & in & Benoist pin & 0.98455 & 947.36 \\
\hline 8 & $"$ & $"$ & pin & pin & Isotropic pin & 0.98511 & \\
\hline
\end{tabular}


TALLE III-1. Ractivity Jorth Sample Deacription

\begin{tabular}{|c|c|c|c|c|c|c|c|c|c|c|}
\hline \multirow{2}{*}{$\begin{array}{c}\text { Saple } \\
\text { ID }\end{array}$} & \multirow{2}{*}{$\begin{array}{c}\text { Mejor } \\
\text { Sample } \\
\text { Component }\end{array}$} & \multirow[b]{2}{*}{$\begin{array}{l}\text { Material } \\
\text { State }\end{array}$} & \multirow[b]{2}{*}{$\begin{array}{c}\text { Sanple } \\
\text { Geomet ry }\end{array}$} & \multicolumn{3}{|c|}{ Sample size, In. } & \multirow{2}{*}{$\begin{array}{c}\text { Sasple } \\
\text { Mand, } \\
\text { B }\end{array}$} & \multirow{2}{*}{$\begin{array}{c}\text { Sunple } \\
\text { Compoltion } \\
\text { or } \\
\text { Purity }\end{array}$} & \multirow{2}{*}{$\begin{array}{c}\text { Capsule } \\
\text { Mane, } \\
8\end{array}$} & \multirow[b]{2}{*}{$\begin{array}{c}\text { Capoule } \\
\text { Description }\end{array}$} \\
\hline & & & & 0.0 . & Leneth & Th1ckneos & & & & \\
\hline $\begin{array}{l}P U-25 \\
P U-27\end{array}$ & $\begin{array}{l}219 \mathrm{PU}-\Lambda \mathrm{L} \\
239 \mathrm{PU}-\Lambda \mathrm{L}\end{array}$ & $\begin{array}{l}\text { Metal } \\
\text { Metnl }\end{array}$ & $\begin{array}{l}\text { Cyl I nder } \\
\text { Cyl I nder }\end{array}$ & $\begin{array}{l}0.100 \\
0.200\end{array}$ & $\begin{array}{l}2.173 \\
2.173\end{array}$ & $=$ & $\begin{array}{r}4.480 \\
17.062\end{array}$ & $\begin{array}{l}\text { P239-8 } \\
\text { P239-8 }\end{array}$ & $\begin{array}{l}10.750 \\
11.207\end{array}$ & $\begin{array}{l}\text { II } \\
\text { II }\end{array}$ \\
\hline$m-10$ & $239 \mathrm{PU}-\mathrm{N}$ & Metal & Annul uo & 0.835 & 1.156 & 0.015 & 9.956 & P239-A & 13.458 & I \\
\hline$P U-2<0-2 D$ & $240 \mathrm{PuO}_{2}$ & Powder & Annul ue & $0.604 \mathrm{~b}$ & 1.600 & 0.205 & 45.135 & P240-A & 2B.B2I & IV \\
\hline$v-233-3$ & $233 \mathrm{v}$ & Metal & Strip & $0.830^{\circ}$ & 1.805 & 0.010 & 4.158 & U233-A & 16.513 & VI \\
\hline$A(B-21$ & $235 \mathrm{U}$ & Metal & Annul un & 0.835 & 1.688 & 0.015 & 15.778 & U235-A & 13.729 & I \\
\hline$u-3$ & $235_{v}$ & Metal & Cyl tnder & 0.200 & 2.173 & -- & 21.015 & $v 235-c$ & 11.112 & II \\
\hline-25 & $238_{U}$ & Metal & Annul us & 0.835 & 1.688 & 0.036 & 38.163 & $11238-\lambda$ & 13.691 & I \\
\hline $\begin{array}{l}3-7 \\
L I-5\end{array}$ & $\begin{array}{c}10_{B} \\
{ }_{6} L_{1}\end{array}$ & $\begin{array}{l}\text { Powder } \\
\text { Metal }\end{array}$ & Annul ue & $\begin{array}{l}0.400 \\
0.309\end{array}$ & $\begin{array}{l}2.173 \\
1.678\end{array}$ & 0.0094 & $\begin{array}{l}0.4968 \\
0.9736\end{array}$ & B10-A & 20.776 & VII \\
\hline$(H ?,+5)-1$ & POLYETHYLENE & Foant & Cyl 1 nder & 0.875 & 2.656 & -- & $\begin{array}{l}0.9736 \\
0.843\end{array}$ & $\begin{array}{l}\text { L.I6-A } \\
\text { CH2-A }\end{array}$ & 2.0468 & XI \\
\hline $\mathrm{CH} 2(\mathrm{~F})-6$ & POLYETHYLENE & Foam & Cyll inder & 0.975 & 2.00 & -- & 0.898 & CH2-A & $\overline{-}$ & Bare Sample \\
\hline POLY 1 & POLYETHYLENE. & Solld & Cyl 1 nder & 0.390 & 2.173 & --- & 4.024 & $(\mathrm{CH} 2 . \mathrm{CH} 2) \mathrm{N}$ & 10.567 & I1 \\
\hline H20-1А & $\mathrm{H}_{2} \mathrm{O}$ & Li quid & Cyl 1 nder & 0.440 & 1.710 & -- & 4.177 & 99.99997 & $6.64 B$ & XII \\
\hline $\mathrm{FE}-1$ & FE & Metal & Cyl Inder & 0.389 & 2.172 & -- & 33.277 & $99.99 x$ & 10.611 & II \\
\hline CR-3 & CR & Metal & Cyl inder & 0.375 & 2.173 & --- & 26.999 & 99.9962 & 10.644 & II \\
\hline $2 \mathrm{~N}-1$ & MS & Pouder & Cyl I nder & 0.399 & 2.173 & --- & 18.010 & 99.992 & 10.343 & Il \\
\hline $0-1$ & SST Dutary & --- & -- & 0.420 & 2.625 & 0.010 & --- & --- & 10.667 & 11 \\
\hline $58-19$ & SST DUNAY & --- & --- & --- & --- & --- & -- & --- & 13.807 & $\mathrm{I}$ \\
\hline TT-RAH- 6 & RABBIT CAN & -- & $m$ & --- & -- & -- & -- & -- & 57.670 & $x$ \\
\hline DUM-2D & INCONEL DUM. & -- & -- & --- & 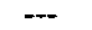 & --- & -- & --- & $2 A, 473$ & IV \\
\hline LI-DLIM & NLUM. DUMHY & --- & -- & 0.352 & 1.99 & 0.020 & $-\cdots$ & --- & 2.0545 & XI \\
\hline NSD- $56^{\circ}$ & NEUT. SOUKC.F. & Sol 1d & Potnt & --- & $\rightarrow$ & -- & 0.0000374 & C252-A & $\cdots$ & XIII \\
\hline
\end{tabular}

Capsule Description:

1- Mittertal: 304 SST.d

Size, Inches: 0.D., 0.865; length, 2.00; wall and end thickness, 0.015. Ends are recessed 0.094. iehes.

11- Material: 304 SST.

S1ze, inches: $0.4 ., 0.420$, lenkth, 2.625; wall thickness, 0.010 ; end thicknesses, 0.226.

IV- Miterlal: Inconell b00."

S1ze, Inches: 0.D. Outer cylinder, 0.670; 0.0., Inner cylinder, 0.195; wall thickness, outer cylinder, 0.033; wal1 thickneks,

taier cyltnder, 0.030 ; length, 2.00; end ihlcknesues, 0.090 and 0.110 , Capsule has 0.135 Inch dianeter axlal hole through center.

VI- Material: 304 SST.

isze, inchen: 0.0., 0.420; length, 2.625; wall thekness, 0.010; end thicknesses, 0.310.

VIl- Mhterlal: 304 SST.

Si2e, Inches: n.D., outer cylinder, 0.420; 0.0., Inner cylinder, 0.380; wall thickness, outer cyltinder, (9.0l0; wall thickniss, inner cylinder, 0.020 ; length, 2.625; end thicknesses, 0.392

X- Heterlal: Jus SST.

S1ze, Inches: 0.D., 0.938; length, 2.719; wall thickness, 0.031 for 2.00 inches of Inside length, 0.094 for the next 0.417

Inthes of Inside length, 0.253 for the last 0.219 incles of indide length; end thicknesees, 0.031 .

Xl- Miterlal: Aluminum.

S1ze, Inchex: 0.D, U.352; length, 1.99; wall and end thlckneov, 0.020, Ende are recesed 0.120 Inrhes.

XI1- Macerial: 304 SST.

S1ze, inches: 0.D., 0.470; length, 2. 0; wall and end thickneas, 0.015. Ende are receseed 0.094 incher.

xill- matertal: 304t. SST,

S1ze, Inches--capeule portlon: 0.0., 0.500; length, 1.525; wall ond bottom thlcknese, n. 1(110; top thlekness, 0.37s.

S1ze, Inched--thrended portion: $0.0 ., 0.250$; length, 0.462 . Overall length $1 \mathrm{~b} 1,987$ Inchen with the threated portian at ilie top ond of the capaule.

Stev Table $111-2$.

biancion is inmple vidth.

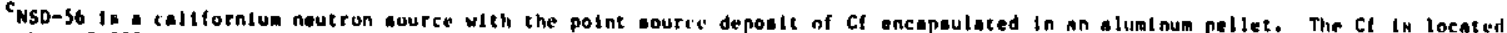
about 0.233 inchen from the botson of the capeule.

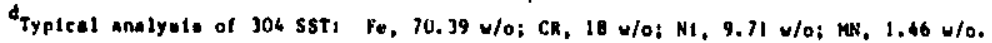

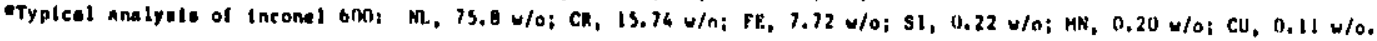


TABLE IIt-2. Reactivity Worth Sample Compostion

\begin{tabular}{|c|c|c|c|c|c|}
\hline $\begin{array}{c}\text { Sample } \\
\text { ID }\end{array}$ & $\begin{array}{c}\text { Composition } \\
\text { ID }\end{array}$ & $\begin{array}{l}\text { Sample } \\
\text { Materlal }\end{array}$ & $\begin{array}{l}\text { Sample } \\
\text { Mass, } \\
(\mathrm{s})\end{array}$ & $\begin{array}{c}\text { Meterial } \\
\text { Composttion, } \\
\text { w/o }\end{array}$ & $\begin{array}{c}\text { Isotoplc } \\
\text { Componition, } \\
\text { v/o }\end{array}$ \\
\hline MB- 10 & P239-A & PII-Al. & 9.956 & $\begin{array}{l}P U=97.985 \\
A L=1.208\end{array}$ & $\begin{array}{r}239 \\
240 \mathrm{PU}-98.932 \\
241 \mathrm{PU}-1.012 \\
242 \mathrm{PU}-0.053 \\
\mathrm{PU}-0.003\end{array}$ \\
\hline $\begin{array}{l}P U-25 \\
P U-27\end{array}$ & P239-B & $\mathrm{PU}-\mathrm{AL}$ & $\begin{array}{r}4.480 \\
17.062\end{array}$ & $\begin{array}{l}P U=98.26 \\
A L=0.95 \\
N I=1.00 \mathrm{a} \\
F E=0.17^{a} \\
C R=0.11^{a}\end{array}$ & $\begin{array}{l}239 \\
240 \mathrm{PU}-98.926 \\
241 \mathrm{PU}-1.023 \\
242 \mathrm{PU}-0.049 \\
\mathrm{PU}-0.002\end{array}$ \\
\hline$P U-240-2 D$ & $\mathrm{P} 240-\mathrm{A}$ & PUO? & 45.135 & $\begin{aligned} P U-86.10 \\
O-11.97 \\
H-0.035 \\
N-0.02\end{aligned}$ & $\begin{array}{l}239 P U-1.05 \\
240 P U=93.73 \\
241 \mathrm{PU}=0.57 \\
242 \mathrm{PU}=4.65\end{array}$ \\
\hline$y-233-1$ & U2.13-A & u & 4.158 & $\begin{array}{c}U=99.8 \\
0=0.31 \\
F E=0.15^{\mathrm{a}} \\
C R=0.02^{\mathrm{a}} \\
\mathrm{NA}-<0.01^{\mathrm{a}}\end{array}$ & $\begin{array}{l}233 u-99.47 \\
234 u=0.193 \\
233 u=0.071 \\
236 u=0.014 \\
238 v-0.266\end{array}$ \\
\hline MB-21 & U2 35-A & $\mathrm{u}$ & 15.778 & $L^{*}-100.0$ & $\begin{array}{l}234 v=0.665 \\
235 v=93.244 \\
236 u-0.316 \\
238 v=5.775\end{array}$ \\
\hline $\mathrm{U}-3$ & U2 $35-C$ & l & 21.015 & $u-100.0$ & $\begin{array}{lr}234 \mathrm{y} & 0.945 \\
235_{\mathrm{y}} & 93.192 \\
23 \epsilon_{\mathrm{U}} & 0.259 \\
238 & 5.604\end{array}$ \\
\hline$M B-25$ & U2 38-A & u & 38.163 & $U-100.0$ & $\begin{array}{r}235 v-0.233 \\
\angle 38 v-99.767\end{array}$ \\
\hline NSD $-56^{b}$ & $C 252-A$ & CF & 0.0000374 & $C F^{b}-$ & $\begin{array}{lr}{ }^{249} \mathrm{CF} & 1.40^{\mathrm{b}} \\
250 \mathrm{CF} & 7.73^{\mathrm{b}} \\
251 \mathrm{CF} & 2.17 \mathrm{~b} \\
252 \mathrm{CF} & 88.34^{\mathrm{b}} \\
25{ }^{3} \mathrm{CF} & 0.327^{\mathrm{b}} \\
254 \mathrm{CF} & 0.037^{\mathrm{b}}\end{array}$ \\
\hline$L 1-5$ & {$[.16-2$} & L. & 0.9736 & $\begin{array}{r}L C=99.870 \\
c=0.045\end{array}$ & $\begin{array}{r}99.208 \\
0.792\end{array}$ \\
\hline$B-7$ & $B 10-A$ & BORON & 0.4968 & $\begin{array}{r}B=94.50 \\
0=1.43 \\
C=0.96 \\
\text { SI }=0.26^{\circ} \\
H-0.09 \\
\text { AL }=0.05^{\circ}\end{array}$ & $\begin{array}{l}10 B-92.19 \\
11_{B}-7.81\end{array}$ \\
\hline $\begin{array}{l}\mathrm{CH} 2(8)-1 \\
\mathrm{CH} 2(8)-6\end{array}$ & $\mathrm{CH} 2-\mathrm{A}$ & POL.YETHYI.ENE & $\begin{array}{l}0.843 \\
0.898\end{array}$ & $\begin{array}{l}\text { CH2 }-99.8^{\mathrm{C}} \\
2 \mathrm{~N}=0.12^{\mathrm{a}} \\
\mathrm{CA}-0.10^{\circ}\end{array}$ & $\begin{array}{l}C=85.50^{c} \\
H=14.50^{c}\end{array}$ \\
\hline
\end{tabular}

Aactor of 2 uncertainty.

bNSD-56 is a epontaneous fimsion $\left({ }^{292} \mathrm{Cf}\right)$ neutron source. The only cosposition inforastion avallable to the itotoplc conposition of callfornitum--dace of analyala: $2 / 11 / 72$.

cThe actual rat to of carbon to hydrogen atome was deterained by analyais. 
TABLE III-3. Experimental Small Sanple Central Reactivity Worths in GCFR Phase III

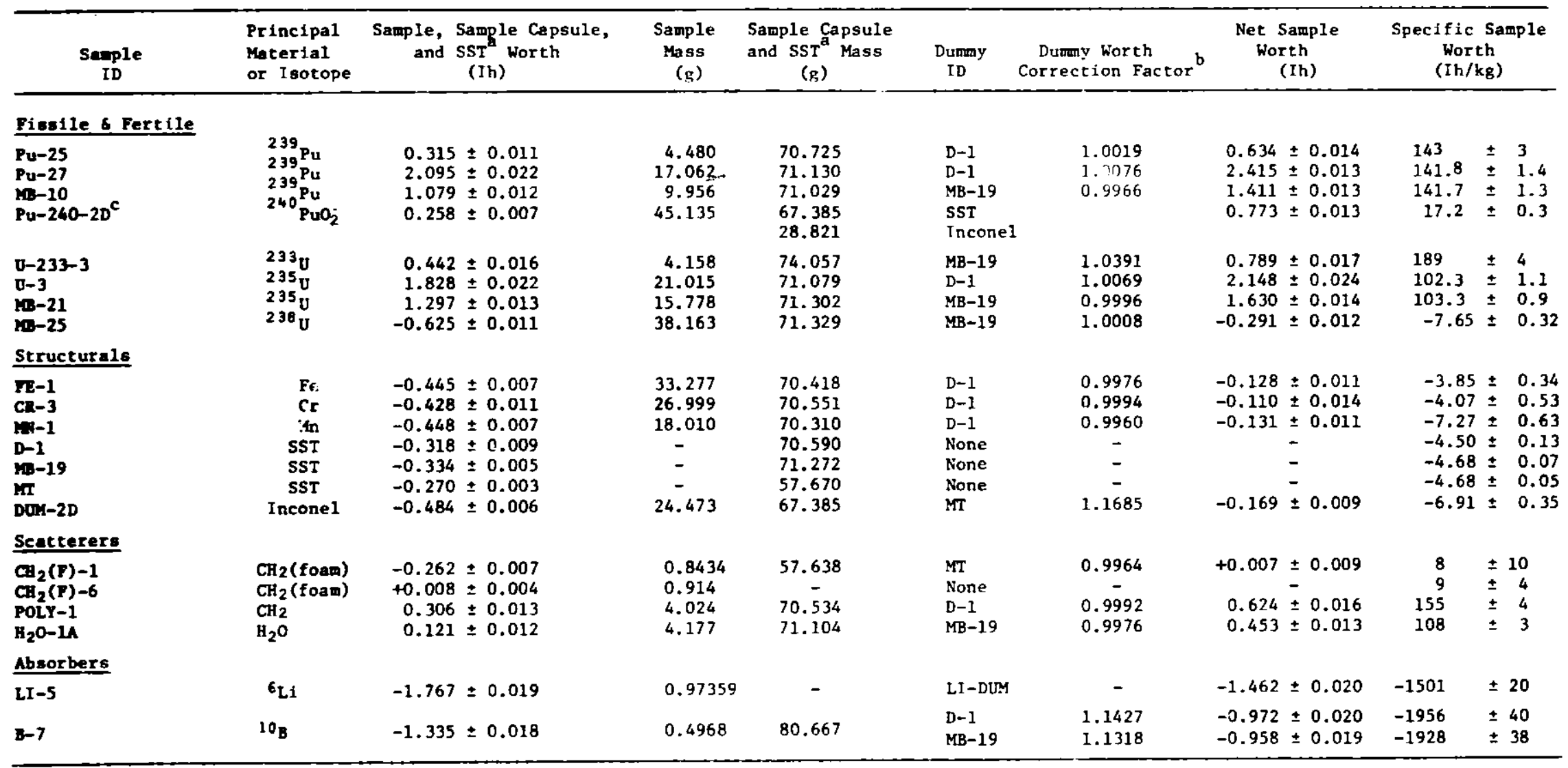

ast refers to the stainless steel capsule holders and stainless steel shims or spacers, if used.

bratio of sample capsule and SST mass to dummy capsule and SST mass.

Cung, DUI-2D + capsule hc lder, is composed of INCONEL and SST, respectively. 
TABLE III-4. Experimental Small Sample Radial Reactivity Worth Traverses in GCFR Phase III

\begin{tabular}{|c|c|c|c|c|c|c|c|c|c|c|c|c|c|}
\hline \multirow{2}{*}{$\frac{\text { Semple }}{\text { ID }}$} & \multirow{2}{*}{$\begin{array}{l}\text { Principal } \\
\text { Mterial } \\
\text { or Inotope } \\
239 \mathrm{Pu}\end{array}$} & \multicolumn{2}{|c|}{$\begin{array}{l}\text { Radial } \\
\text { Position } \\
(\mathrm{col}) \quad(\mathrm{cm})\end{array}$} & $\begin{array}{c}\text { Sample, Sample Capsule, } \\
\text { and SST Worth } \\
\text { (Ih) }\end{array}$ & \multirow{2}{*}{$\begin{array}{l}\begin{array}{c}\text { Sample } \\
\text { Mass } \\
(\mathrm{B})\end{array} \\
9.955\end{array}$} & \multirow{2}{*}{$\begin{array}{c}\begin{array}{c}\text { Sample Capsule and } \\
\text { SST Mass } \\
(\mathrm{g})\end{array} \\
71.029\end{array}$} & \multirow{2}{*}{$\frac{\begin{array}{c}\text { Dumny } \\
\text { ID }\end{array}}{\text { MB-19 }}$} & \multirow{2}{*}{$\begin{array}{l}\text { Dummy Worth } \\
\text { Ad justment Fact or }\end{array}$} & \multicolumn{2}{|c|}{$\begin{array}{l}\text { Net Sample } \\
\text { Worth } \\
\text { (Ih) }\end{array}$} & \multicolumn{3}{|c|}{$\begin{array}{c}\text { Specific Sample } \\
\text { Worth } \\
\text { (Ih/kg) }\end{array}$} \\
\hline & & $\begin{array}{l}23 \\
24 \\
26 \\
28 \\
30 \\
33 \\
35 \\
38\end{array}$ & $\begin{array}{r}0.00 \\
5.52 \\
16.57 \\
27.62 \\
38.67 \\
55.25 \\
66.29 \\
82.87\end{array}$ & $\begin{array}{l}1.079 \pm 0.012 \\
1.066 \pm 0.012 \\
1.016 \pm 0.012 \\
0.926 \pm 0.012 \\
0.824 \pm 0.009 \\
0.681 \pm 0.007 \\
0.562 \pm 0.011 \\
0.181 . \pm 0.008\end{array}$ & & & & & $\begin{array}{l}1.411 \\
1.382 \\
1.307 \\
1.169 \\
1.014 \\
0.652 \\
0.395 \\
0.137\end{array}$ & $\begin{array}{l} \pm 0.013 \\
\pm 0.016 \\
\pm 0.014 \\
\pm 0.013 \\
\pm 0.013 \\
\pm 0.009 \\
\pm 0.012 \\
\pm 0.009\end{array}$ & $\begin{array}{r}141.7 \\
138.8 \\
131.2 \\
117.4 \\
101.7 \\
65.5 \\
39.6 \\
13.8\end{array}$ & $\begin{array}{ll} \pm & 1 \\
\pm & 1 \\
\pm & 1 \\
\pm & 1 \\
\pm & 1 \\
\pm & 0 \\
\pm & 1 \\
\pm & 0\end{array}$ & $\begin{array}{l}1.3 \\
1.6 \\
1.4 \\
1.3 \\
1.3 \\
0.9 \\
1.2 \\
0.9\end{array}$ \\
\hline$n-21$ & $235 v$ & $\begin{array}{l}23 \\
24 \\
26 \\
29 \\
33 \\
35 \\
38\end{array}$ & $\begin{array}{r}0.00 \\
5.52 \\
16.57 \\
33.15 \\
55.25 \\
66.29 \\
82.87\end{array}$ & $\begin{array}{l}1.297 \pm 0.013 \\
1.275 \pm 0.014 \\
1.229 \pm 0.013 \\
1.054 \pm 0.017 \\
0.777 \pm 0.010 \\
0.651 \pm 0.007 \\
0.264 \pm 0.006\end{array}$ & 13.790 & 71.302 & $M B-19$ & 0.9996 & $\begin{array}{l}1.630 \\
1.592 \\
1.521 \\
1.281 \\
0.748 \\
0.483 \\
0.220\end{array}$ & $\begin{array}{l} \pm 0.014 \\
\pm 0.018 \\
\pm 0.015 \\
\pm 0.019 \\
\pm 0.011 \\
\pm 0.009 \\
\pm 0.008\end{array}$ & $\begin{array}{r}103.3 \\
100.9 \\
96.4 \\
81.2 \\
47.4 \\
30.6 \\
13.9\end{array}$ & $\begin{array}{l} \pm \\
\pm \\
\pm \\
\pm \\
\pm \\
\pm \\
\pm\end{array}$ & $\begin{array}{l}0.9 \\
1.1 \\
1.0 \\
1.2 \\
0.7 \\
0.6 \\
0.5\end{array}$ \\
\hline $\mathrm{mB}-25$ & $238 \mathrm{U}$ & $\begin{array}{l}23 \\
26 \\
29 \\
33 \\
35 \\
38\end{array}$ & $\begin{array}{r}0.00 \\
16.57 \\
33.15 \\
55.25 \\
66.29 \\
82.87\end{array}$ & $\begin{array}{l}-0.625 \pm 0.011 \\
-0.566 \pm 0.007 \\
-0.434 \pm 0.005 \\
-0.035 \pm 0.009 \\
+0.159 \pm 0.008 \\
+0.061 \pm 0.007\end{array}$ & 38.163 & 71.329 & $M B-19$ & 1.0008 & $\begin{array}{l}-0.291 \\
-0.274 \\
-0.207 \\
-0.064 \\
-0.009 \\
+0.017\end{array}$ & $\begin{array}{l} \pm 0.012 \\
\pm 0.011 \\
\pm 0.009 \\
\pm 0.010 \\
\pm 0.009 \\
\pm 0.009\end{array}$ & $\begin{array}{l}-7.65 \\
-7.17 \\
-5.42 \\
-1.68 \\
-0.24 \\
+0.45\end{array}$ & $\begin{array}{l} \pm 0 \\
\pm 0 \\
\pm 0 \\
\pm 0 \\
\pm \\
\pm \\
\pm\end{array}$ & $\begin{array}{l}0.32 \\
0.29 \\
0.25 \\
0.27 \\
0.25 \\
0.24\end{array}$ \\
\hline $10-19$ & SST & $\begin{array}{l}23 \\
24 \\
26 \\
28 \\
29 \\
30 \\
33 \\
35 \\
38\end{array}$ & $\begin{array}{r}0.00 \\
5.52 \\
16.57 \\
27.62 \\
33.15 \\
38.67 \\
55.25 \\
66.29 \\
82.87\end{array}$ & $\begin{array}{l}-0.334 \pm 0.005 \\
-0.317 \pm 0.011 \\
-0.292 \pm 0.008 \\
-0.244 \pm 0.006 \\
-0.227 \pm 0.007 \\
-0.191 \pm 0.008 \\
+0.029 \pm 0.005 \\
+0.168 \pm 0.005 \\
+0.044 \pm 0.005\end{array}$ & -- & 71.272 & None & -- & & $\begin{array}{l}-- \\
=- \\
=- \\
=- \\
=- \\
=\end{array}$ & $\begin{array}{l}-4.68 \\
-4.45 \\
-4.10 \\
-3.42 \\
-3.18 \\
-2.68 \\
+0.41 \\
+2.36 \\
+0.62\end{array}$ & $\begin{array}{ll} \pm & 0 \\
\pm & 0 \\
\pm & 0 \\
\pm & 0 \\
\pm & 0 \\
\pm & 0 \\
\pm & 0 \\
\pm & 0 \\
\pm & 0\end{array}$ & $\begin{array}{l}0.07 \\
0.15 \\
0.11 \\
0.08 \\
0.11 \\
0.13 \\
0.07 \\
0.07 \\
0.07\end{array}$ \\
\hline$B-7$ & B & $\begin{array}{l}23 \\
26 \\
29 \\
33 \\
35 \\
38\end{array}$ & $\begin{array}{r}0.00 \\
16.57 \\
33.15 \\
55.25 \\
66.29 \\
82.87\end{array}$ & $\begin{array}{l}-1.335 \pm 0.018 \\
-1.230 \pm 0.014 \\
-1.016 \pm 0.011 \\
-0.410 \pm 0.007 \\
-0.073 \pm 0.008 \\
+0.016 \pm 1.005\end{array}$ & 0.4968 & 80.667 & $M B-19$ & 1.1318 & $\begin{array}{l}-0.958 \\
-0.900 \\
-0.759 \\
-0.443 \\
-0.263 \\
-0.034\end{array}$ & $\begin{array}{l} \pm 0.019 \\
\pm 0.017 \\
\pm 0.014 \\
\pm 0.009 \\
\pm 0.010 \\
\pm 0.008\end{array}$ & $\begin{array}{r}-1928 \\
-1812 \\
-1528 \\
-892 \\
-529 \\
-68\end{array}$ & $\begin{array}{l} \pm 38 \\
\pm 34 \\
\pm 28 \\
\pm 18 \\
\pm 20 \\
\pm 16\end{array}$ & \\
\hline $\mathrm{CH}_{2}(\mathrm{~F})-6$ & $\mathrm{CH}_{2}($ foos $)$ & $\begin{array}{l}23 \\
26 \\
29 \\
33 \\
35 \\
38\end{array}$ & $\begin{array}{r}0.00 \\
16.57 \\
33.15 \\
55.25 \\
66.29 \\
82.87\end{array}$ & $\begin{array}{l}+0.008 \pm 0.704 \\
+0.008 \pm 0.003 \\
+0.013 \pm 0.002 \\
+0.077 \pm 0.005 \\
+0.030 \leq 0.004 \\
-0.043 \pm 0.003\end{array}$ & 0.9104 & --- & None & --- & & $\begin{array}{l}-- \\
-- \\
-- \\
-- \\
-\end{array}$ & $\begin{array}{r}9 \\
9 \\
14 \\
85 \\
33 \\
-53\end{array}$ & $\begin{array}{l} \pm \\
\pm \\
\pm \\
\pm \\
\pm \\
\pm \\
\pm\end{array}$ & $\begin{array}{l}4 \\
3 \\
2 \\
5 \\
4 \\
3\end{array}$ \\
\hline
\end{tabular}

ast refere to the stainless sceel capsul $<$ holders and stainless steel shimb or spacers, if used.

blatio of smple capsule and SST ass to dumm; capsule and SST mass. 
TABLE III-5. LI-5 $\left({ }^{6} \mathrm{Li}\right)$ ExperImental Small Sample Radial Reactivity Worth Traverse in GCFR Phase III

\begin{tabular}{|c|c|c|c|c|c|c|c|}
\hline \multicolumn{2}{|c|}{$\begin{array}{l}\text { Redial } \\
\text { Position } \\
\text { (col) (ca) }\end{array}$} & \multirow{2}{*}{$\begin{array}{l}\text { LI-5 Sanple, Al Sample } \\
\text { Capsule, and SST Worth } \\
\text { (Ih) }\end{array}$} & \multirow{2}{*}{$\begin{array}{l}\begin{array}{c}\text { Sample } \\
\text { Mass } \\
\left(b^{\prime}\right)\end{array} \\
0.97359\end{array}$} & \multirow{2}{*}{$\begin{array}{c}\begin{array}{c}\text { LI-DUM AI Sample } \\
\text { Capsula } \\
\text { and SST Worth } \\
\text { (Ih) }\end{array} \\
-0.306 \pm 0.006\end{array}$} & \multirow{2}{*}{$\begin{array}{l}\begin{array}{l}\text { Dummy Worth } \\
\text { Adjustment Factor }\end{array} \\
0.9971\end{array}$} & \multirow{2}{*}{$\frac{\begin{array}{c}\text { Net Sample } \\
\text { Worth } \\
\text { (Ih) }\end{array}}{-1.462 \pm 0.020}$} & \multirow{2}{*}{ 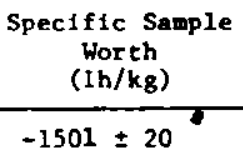 } \\
\hline 23 & 0.00 & & & & & & \\
\hline 24 & 5.52 & $-1.760 \pm 0.018$ & & $-0.310 \pm 0.003$ & & $-1.451 \pm 0.018$ & $-1491 \pm 19$ \\
\hline 26 & 16.57 & $-1.651 \div 0.017$ & & $-0.280 \pm 0.014$ & & $-1.372 \pm 0.022$ & $-1409 \pm 23$ \\
\hline 28 & 27.62 & $-1.495 \pm 0.015$ & & $-0.243 \pm 0.005$ & & $-1.253 \pm 0.016$ & $-1287 \pm 16$ \\
\hline 30 & 38.67 & $-1.238 \pm 0.013$ & & $-0.184 \pm 0.003$ & & $-1.055 \pm 0.013$ & $-1083 \pm 14$ \\
\hline 33 & 55.25 & $-0.629 \pm 0.007$ & & $+0.040 \pm 0.008$ & & $-0.669 \pm 0.011$ & $-693 \pm 11$ \\
\hline
\end{tabular}

Al capaule mes $2.0468 \mathrm{~g}$; SST shims and capsule holder mass $63.192 \mathrm{~g}$.

bl capaul e anss $2.0545 \mathrm{~g}$; SST shims and capsule hol der mass $63.374 \mathrm{~g}$.

TABLE III-6. ORNL-NSO-56 (252Cf) Experimental Small Sample Radial Reactivity Worth Traverse in GCFR Phase III

\begin{tabular}{|c|c|c|c|c|c|c|c|c|c|}
\hline \multirow[b]{2}{*}{$\underset{\text { ID }}{\text { Sample }}$} & \multirow{2}{*}{\multicolumn{2}{|c|}{$\begin{array}{l}\text { Radial } \\
\text { Position } \\
\begin{array}{cc}\text { (col) } & \text { (cm) }\end{array}\end{array}$}} & \multicolumn{5}{|c|}{ Sample Worth (Ih) } & \multirow[b]{2}{*}{$\begin{array}{l}\text { Slope }^{b} \\
(\text { Ih * Power) }\end{array}$} & \multirow[b]{2}{*}{$\begin{array}{l}\text { Relative } \\
\text { Worth }\end{array}$} \\
\hline & & & FAR Power Level: & $5.45 \times 10^{-6}$ & 1.00 & $\times 10^{-5}$ & $4.90 \times 10^{-5}$ & & \\
\hline \multirow[t]{7}{*}{ OPUL-KSD-56 } & 23 & -1.95 & & $2.951=0.030$ & 1.345 & \pm 0.014 & $-0.120 \pm 0.003$ & $1.8835 \times 10^{-5}$ & 1.00 \\
\hline & 24 & 3.58 & & $2.949 \pm 0.030$ & & - & $-0.111 \pm 0.003$ & $1.8764 \times 10^{-5}$ & 0.996 \\
\hline & 26 & 14.62 & & $2.913 \pm 0.029$ & & - & $-0.083 \pm 0.003$ & $1.8372 \times 10^{-j}$ & 0.975 \\
\hline & 28 & 25.67 & & $2.844 \pm 0.028$ & & - & $-0.033 \pm 0.002$ & $1.7642 \times 10^{-5}$ & 0.937 \\
\hline & 30 & 36.72 & & $2.695 \pm 0.0$ & & - & $+0.039 \pm 0.001$ & $1.6287 \times 10^{-5}$ & 0.865 \\
\hline & 33 & 53.30 & & $2.481 \div 0.025$ & & - & $+0.302 \pm 0.006$ & $1.3362 \times 10^{-5}$ & 0.709 \\
\hline & 35 & 64.35 & & $2.120 \pm 0.023$ & & - & $+0.447 \pm 0.006$ & $1.0259 \times 10^{-5}$ & 0.545 \\
\hline
\end{tabular}

Point ${ }^{252}$ Cf cource $-1.95 \mathrm{~cm}$ from center of each column.

blope of reactivity verous inverse pover level. 
TABLE III $\cdot 7$. Calcul ated and Experimental

Central Small Sample Reactivity Worths for GCFR Phase III

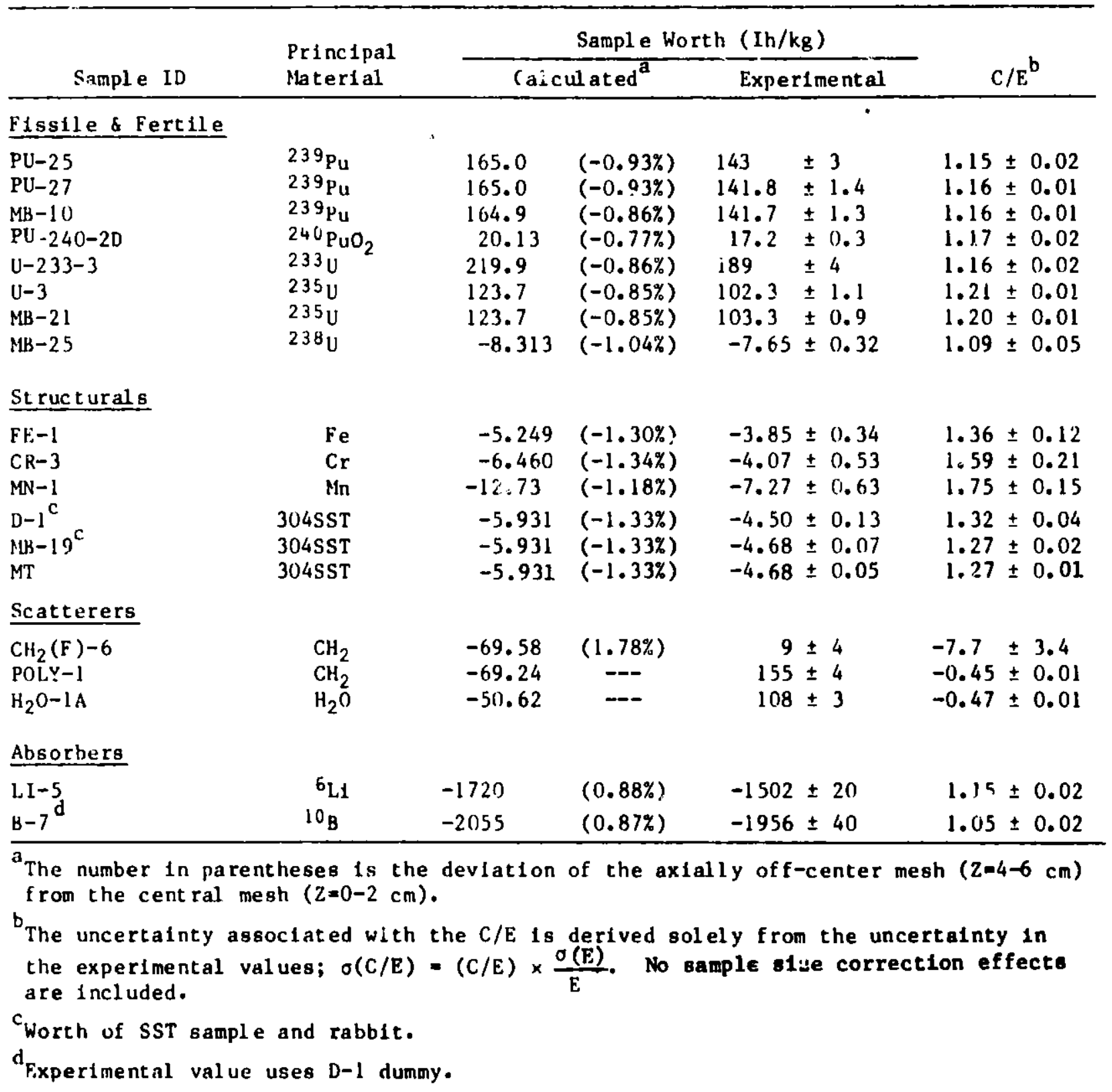


TABLE III-8. Calculated Central Isotopic Reactivity Worths

\begin{tabular}{|c|c|c|}
\hline $\begin{array}{l}\text { I sotope/ } \\
\text { Element }\end{array}$ & $\begin{array}{l}\text { Calculated } \\
\text { Worth }(\mathrm{Ih} / \mathrm{kg})\end{array}$ & $C / E^{a}$ \\
\hline $\mathrm{H}$ & -316.76 & - \\
\hline${ }^{3} \mathrm{He}$ & -9657.4 & - \\
\hline${ }^{4} \mathrm{He}$ & -154.57 & - \\
\hline${ }^{6} \mathrm{Li}$ & -1735.3 & $1.15 \pm 0.02$ \\
\hline${ }^{7} \mathrm{LI}$ & -41.070 & - \\
\hline${ }^{9} \mathrm{Be}$ & -49.040 & - \\
\hline $10_{\mathrm{B}}$ & -2281.9 & $1.05 \pm 0.02$ \\
\hline $11_{\mathrm{B}}$ & -31.190 & - \\
\hline${ }^{12} \mathrm{C}$ & -27.665 & - \\
\hline $14 \mathrm{~N}$ & -37.675 & - \\
\hline 160 & -17.086 & - \\
\hline${ }^{23} \mathrm{Na}$ & -9.7077 & - \\
\hline $27 \mathrm{Al}$ & -9.1911 & - \\
\hline Si & -8.7434 & - \\
\hline $\mathrm{Cr}$ & -6.4597 & $1.59 \pm 0.21$ \\
\hline $55_{M n}$ & -12.730 & $1.75 \pm 0.15$ \\
\hline $\mathrm{Fe}$ & -5.2485 & $1.36=0.12$ \\
\hline $\mathrm{Ni}$ & -8.8468 & - \\
\hline Mo & -17.385 & - \\
\hline $151 \mathrm{Eu}$ & -200.97 & - \\
\hline $153 \mathrm{Eu}$ & -127.76 & - \\
\hline $181 \mathrm{Ta}$ & -42.593 & - \\
\hline $232 \mathrm{Th}$ & -16.819 & - \\
\hline $23{ }^{3} \mathrm{U}$ & 221.16 & $1.16 \pm 0.02$ \\
\hline $234 \mathrm{U}$ & 3. $\$ 375$ & - \\
\hline $235_{U}$ & 133.22 & $1.20 \pm 0.01$ \\
\hline $236 \mathrm{U}$ & -14.559 & - \\
\hline $2.38 \mathrm{U}$ & -8.6430 & $1.09 \pm 0.05$ \\
\hline $238 \mathrm{Pu}$ & 102.29 & - \\
\hline $239 \mathrm{Pu}$ & 168.68 & $1.15 \pm 0.01$ \\
\hline $240 \mathrm{Pu}$ & 22.854 & $1.17 \pm 0.02$ \\
\hline $24 l_{\mathrm{Pu}}$ & 240.14 & - \\
\hline $242 \mathrm{Pu}$ & 18.081 & - \\
\hline $241 \mathrm{Am}$ & 2.7327 & - \\
\hline
\end{tabular}

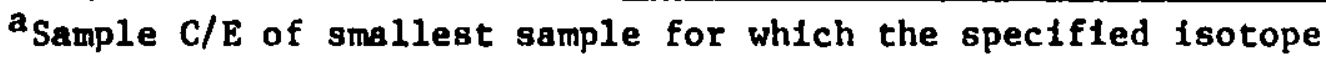
or element is the predominant component. 
TABLE III-9. Calculated and Experimental Radial Reactivity Worth Traverse Results for MB-10 (239P.1) and MB-21 (235U)

\begin{tabular}{|c|c|c|c|c|c|c|c|c|c|c|}
\hline & \multirow{2}{*}{\multicolumn{2}{|c|}{$\begin{array}{c}\text { Sample } \\
\text { Position } \\
\text { (COL) (CM) }\end{array}$}} & \multicolumn{4}{|c|}{$M B-10(239 \mathrm{Pu})$} & \multicolumn{4}{|c|}{$M B-21\left(23 S_{L}\right)$} \\
\hline & & & $\begin{array}{l}\text { Reactivity } \\
\text { Calculated }\end{array}$ & $\begin{array}{l}\text { Worth }(\mathrm{Ih} / \mathrm{kg}) \\
\text { Experimental }\end{array}$ & $C / E$ & $C-E$ & $\begin{array}{l}\text { Reactivity } \\
\text { Calculated }\end{array}$ & $\begin{array}{l}\text { Worth }(\mathrm{Ih} / \mathrm{Kg}) \\
\text { Experimental }\end{array}$ & $C / E$ & $C-E$ \\
\hline & 23 & 0.000 & 164.92 & $141.7 \pm 1.3$ & $1.16 \pm 0.01$ & $23.2 \pm 1.3$ & 123.70 & $103.3 \pm 0.9$ & $1.20 \pm 0.01$ & $20.4 \pm 0.9$ \\
\hline & 24 & 5.524 & 163.88 & $138.8 \pm 1.6$ & $1.18 \pm 0.01$ & $25.1 \pm 1.6$ & 122.89 & $100.9 \pm 1.1$ & $1.22 \pm 0.01$ & $22.0 \pm 1.1$ \\
\hline & 25 & 11.049 & 160.75 & --- & --- & --- & 120.49 & -- & --- & --- \\
\hline CRE & 26 & 16.573 & 155.62 & $131.2 \pm 1.4$ & $1.19 \pm 0.01$ & $24.4 \pm 1.4$ & 116.52 & $96.4 \pm 1.0$ & $1.21 \pm 0.01$ & $20.1 \pm 1.0$ \\
\hline ZONE & 27 & 22.098 & 148.56 & $-\infty$ & --- & --- & 111.07 & --- & --- & --- \\
\hline \multirow[t]{4}{*}{$\mathrm{I}$} & 28 & 27.622 & 139.71 & $117.4 \pm 1.3$ & $1.19 \pm 0.01$ & $22.3 \pm 1.3$ & 104.21 & -- & --- & -- \\
\hline & 29 & 33.147 & 129.29 & -- & -- & -- & 96.11 & $81.2 \pm 1.2$ & $1.18 \pm 0.02$ & $14.9 \pm 1.2$ \\
\hline & 30 & 38.671 & 117.49 & $101.7 \pm 1.3$ & $1.16 \pm 0.01$ & $15.8 \pm 1.3$ & 86.92 & --- & --- & -- \\
\hline & 31 & 44.196 & 104.56 & -- & --- & -- & 76.80 & --- & -- & --- \\
\hline (2) & 32 & 49.720 & 90.48 & - & --- & -- & 65.85 & $-\infty$ & -- & --- \\
\hline$I I^{a}(3)$ & 33 & 55.245 & 75.17 & $65.5 \pm 0.9$ & $1.15 \pm 0.02$ & $9.7 \pm 0.9$ & 54.59 & $47.4 \pm 0.7$ & $1.15 \pm 0.02$ & $7.2 \pm 0.7$ \\
\hline (1) & 34 & 60.769 & 59.51 & -- & --- & --- & 43.57 & --- & --- & -- \\
\hline \multirow[t]{2}{*}{$\therefore$ II } & 35 & 66.294 & 44.45 & $39.6 \pm 1.2$ & $1.12 \pm 0.03$ & $4.8 \pm 1.2$ & 33.53 & $30.6 \pm 0.6$ & $1.10 \pm 0.02$ & $2.9 \pm 0.6$ \\
\hline & 36 & 71.818 & 31.58 & --- & -- & --- & 25.54 & --- & --- & --- \\
\hline RADIAL. & 37 & 77.343 & 21.59 & --- & -- & +- & 18.51 & --- & --- & --- \\
\hline \multirow[t]{3}{*}{ BLAMKET } & 38 & 82.867 & 14.60 & $13.8 \pm 0.9$ & $1.06 \pm 0.07$ & $0.8 \pm 0.9$ & 13.02 & $13.9 \pm 0.5$ & $0.93 \pm 0.03$ & $-0.9 \pm 0.5$ \\
\hline & 39 & 88.392 & 9.96 & --- & -- & --- & 9.07 & --- & --- & -- \\
\hline & 40 & 93.916 & 7.19 & -- & --- & --- & 6.54 & --- & --- & -- \\
\hline
\end{tabular}

a The numbers in parentheses indicate the drawer type of the three drawer unit cell zone II loading. 
TABLE III-10. Calculated and Experimental Radial Reactivity Worth Traverse Results for MB-25 (238U) and MB-19 (SST-304)

\begin{tabular}{|c|c|c|c|c|c|c|c|c|c|c|}
\hline & \multirow{2}{*}{\multicolumn{2}{|c|}{$\begin{array}{l}\text { Sample } \\
\text { Position }\end{array}$}} & \multicolumn{4}{|c|}{$M B-25\left({ }^{238} U\right)$} & \multicolumn{4}{|c|}{$M B-19(S S T-304)$} \\
\hline & & & $\begin{array}{l}\text { Reactivity } \\
\text { Calculated }\end{array}$ & $\begin{array}{l}\text { Worth ( } \mathrm{Ih} / \mathrm{kg} \text { ) } \\
\text { Experimental }\end{array}$ & $\mathrm{C} / \mathrm{E}$ & $\mathrm{C}-\mathrm{E}$ & $\begin{array}{l}\text { Reactivity } \\
\text { Calculated } \\
\end{array}$ & $\begin{array}{r}\text { Worth }(\mathrm{Ih} / \mathrm{Kg}) \\
\text { Experimental }\end{array}$ & $\mathrm{C} / \mathrm{E}$ & $\mathrm{C}-\mathrm{E}$ \\
\hline & 23 & 0.000 & -8.313 & $-7.65 \pm 0.32$ & $1.09 \pm 0.04$ & $-0.66 \pm 0.32$ & -5.930 & $-4.68 \pm 0.07$ & $1.27 \pm 0.02$ & $-1.25 \pm 0.07$ \\
\hline & 24 & 5.524 & -8.252 & $\ldots$ & $-\cdots$ & --- & -5.883 & $-4.45 \pm 0.15$ & $1.32 \pm 0.05$ & $-1.44 \pm 0.15$ \\
\hline & 25 & 11.049 & -8.071 & -- & ..-- & --- & -5.742 & --- & -- & -- \\
\hline CORE & 26 & 16.573 & -7.772 & $-7.17 \pm 0.29$ & $1.08 \pm 0.04$ & $-0.60 \pm 0.29$ & -5.510 & $-4.10 \pm 0.11$ & $1.34 \pm 0.04$ & $-1.41 \pm 0.11$ \\
\hline ZONE & 27 & 22.098 & -7.360 & -- & --- & --- & -5.192 & -- & --- & -- \\
\hline \multirow[t]{4}{*}{ I } & 28 & 27.622 & -6.841 & -- & $\cdots$ & -- & -4.796 & $-3.42 \pm 0.08$ & $1.40 \pm 0.03$ & $-1.37 \pm 0.08$ \\
\hline & 29 & 33.147 & -6.232 & $-5.42 \pm 0.25$ & $1.15 \pm 0.05$ & $-0.81 \pm 0.25$ & -4.330 & $-3.18 \pm 0.11$ & $1.36 \pm 0.04$ & $-1.15 \pm 0.11$ \\
\hline & 30 & 38.671 & -5.543 & 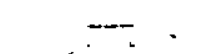 & -- & --- & -3.812 & $-2.68 \pm 0.13$ & $1.42 \pm 0.06$ & $-1.13 \pm 0.13$ \\
\hline & 31 & 44.196 & -4.789 & $--\div$ & --- & -- & -3.263 & --- & -- & --- \\
\hline (2) & 32 & 49.720 & -3.894 & --- & -- & --- & -2.474 & -- & --- & --- \\
\hline $11^{a}(3)$ & 33 & 55.245 & -2.833 & $-1.68 \pm 0.27$ & $1.69 \pm 0.26$ & $-1.16 \pm 0.27$ & -1.408 & $0.41 \pm 0.07$ & $-3.46 \pm 0.60$ & $-1.81 \pm 0.07$ \\
\hline (1) & 34 & 60.769 & -1.822 & -- & -- & $-\cdots$ & -0.350 & -- & -- & $\cdots$ \\
\hline \multirow[t]{2}{*}{ III } & 35 & 66.294 & -0.720 & $-0.24 \pm 0.25$ & $3.05 \pm 3.05$ & $-0.48 \pm 0.25$ & 1.024 & $2.36 \pm 0.07$ & $0.43 \pm 0.01$ & $-1.33 \pm 0.07$ \\
\hline & 36 & 71.818 & -0.004 & -- & --- & --- & 1.543 & --- & --- & -- \\
\hline RADIAL & 37 & 77.343 & -0.018 & -- & -- & --- & 0.958 & -- & --- & $-\cdots$ \\
\hline \multirow[t]{3}{*}{ BLANKET } & 38 & 82.867 & -0.019 & $0.45 \pm 0.24$ & $-0.04 \pm 0.02$ & $-0.46 \pm 0.24$ & 0.537 & $0.62 \pm 0.07$ & $0.87 \pm 0.10$ & $-0.08 \pm 0.07$ \\
\hline & 39 & $88.3 \subseteq 2$ & -0.020 & --- & --- & -- & 0.278 & -- & -- & $\rightarrow$ \\
\hline & 40 & 93.916 & -0.024 & --- & -- & --- & 0.131 & --- & --- & $\rightarrow$ \\
\hline
\end{tabular}

${ }^{a}$ The numbers in parentheses indicate the drawer type of the three drawer unit cell zone Il loading. 
TABLE III-11. Calculated and Experimental Radial Reactivity worth Traverse Results for B-7 (10B) and LI-5 (6LI)

\begin{tabular}{|c|c|c|c|c|c|c|c|c|c|c|}
\hline & \multirow{2}{*}{\multicolumn{2}{|c|}{$\begin{array}{l}\text { Sample } \\
\text { Position }\end{array}$}} & \multicolumn{4}{|c|}{$B-7\left(10_{B}\right)$} & \multicolumn{4}{|c|}{$L I-5\left({ }^{6} \mathrm{Li}\right)$} \\
\hline & & & $\begin{array}{l}\text { Reactivity } \\
\text { Calculated }\end{array}$ & $\begin{array}{l}\text { y Worth ( } \mathrm{Ih} / \mathrm{Kg}) \\
\text { d Experimental }\end{array}$ & $C / E$ & $C-E$ & \multicolumn{2}{|c|}{$\begin{array}{l}\text { Reactivity Worth ( } \mathrm{Ih} / \mathrm{Kg} \text { ) } \\
\text { Calculated Experimental }\end{array}$} & $C / E$ & $C-E$ \\
\hline & 23 & 0.000 & -2054.7 & $-1928 . \pm 38$ & $1.07 \pm 0.02$ & $-126 . \pm 38$ & -1719.8 & $-1501 . \pm 21$ & $1.15 \pm 0.02$ & $-219 . \pm 21$ \\
\hline & 24 & 5.524 & -2041.0 & --- & --- & -- & -1708.8 & $-1491 . \pm 18$ & $1.15 \pm 0.01$ & $-218 . \pm 18$ \\
\hline & 25 & 11.049 & -2000.1 & --- & --- & -- & -1676.2 & --- & -- & -- \\
\hline CORE & 26 & 16.573 & -1932.8 & $-1812 \pm 34$ & $1.07 \pm 0.02$ & $-121 . \pm 34$ & -1622.3 & $-1409 . \pm 23$ & $1.15 \pm 0.02$ & $-213 . \pm 23$ \\
\hline ZONE & 27 & 22.098 & -1840.2 & $\cdots$ & --- & --- & -1548.5 & -- & --- & -- \\
\hline \multirow[t]{4}{*}{ I } & 28 & 27.622 & -1723.9 & $\ldots$ & -- & -- & -1456.1 & $-1287 \pm 16$ & $1.13 \pm 0.01$ & $-169 \pm 16$ \\
\hline & 29 & 33.147 & -1588.7 & $-1528 . \pm 28$ & $1.04 \pm 0.02$ & $-61 . \pm 28$ & -1347.4 & -- & -- & --- \\
\hline & 30 & 38.671 & -1437.2 & - & -- & -- & -1224.6 & $-1083 \pm 13$ & $1.13 \pm 0.01$ & $-142 \pm 13$ \\
\hline & 31 & 44.196 & -1272.9 & --- & -- & -- & -1090.4 & -- & -- & $\cdots$ \\
\hline (2) & 32 & 49.720 & -1093.7 & -- & -- & --- & -942.1 & -- & --- & -- \\
\hline $\mathrm{II}^{\mathrm{a}}(3)$ & 33 & 55.245 & -900.0 & $-892 . \pm 18$ & $1.01 \pm 0.02$ & $-8 . \pm 18$ & -775.1 & $-693 . \pm 11$ & $1.12 \pm 0.02$ & $-82 . \pm 11$ \\
\hline (1) & 34 & 60.769 & -707.8 & --- & -- & --- & -603.0 & --- & --- & --- \\
\hline \multirow[t]{2}{*}{ III } & 35 & 66.294 & -524.3 & $-529 . \pm 20$ & $0.99 \pm 0.04$ & 5. \pm 20 . & -432.8 & --- & --- & -- \\
\hline & 36 & 71.818 & -351.1 & -- & -- & --- & $-2 /: .3$ & -- & -- & -- \\
\hline RADLAL. & 37 & 77.343 & -216.0 & --- & -- & --- & -161.8 & $\cdots$ & -- & -- \\
\hline \multirow[t]{3}{*}{ BLANKET } & 38 & 82.867 & -128.3 & $-68 . \pm 16$ & $1.87 \pm 0.44$ & $-60 . \pm 16$ & -92.0 & -- & -- & -- \\
\hline & 39 & 88.392 & -76.4 & -- & --- & -- & -52.1 & --- & --- & -- \\
\hline & 40 & 93.916 & -48.8 & $-\infty$ & --- & -- & -30.8 & --- & --- & --- \\
\hline
\end{tabular}

The numbers in parentheses indicate the drawer type of the three drawer unit cell zone II loading. 
TABLE IIt-12. Calculated and Experimental Radial Reactivity Worth Traverse Results for $\mathrm{CH}_{2}$ (F)-6 (CH2-Foam)

\begin{tabular}{|c|c|c|c|c|c|c|}
\hline & \multirow{2}{*}{\multicolumn{2}{|c|}{$\begin{array}{c}\text { Sample } \\
\text { Position } \\
\text { (COL) (CM) }\end{array}$}} & \multicolumn{4}{|c|}{$\mathrm{CH}_{2}(\mathrm{~F})-6\left(\mathrm{CH}_{2}\right)$} \\
\hline & & & $\begin{array}{l}\text { Reactivity } \\
\text { Calculated }\end{array}$ & $\begin{array}{r}\text { Worth }(\mathrm{Ih} / \mathrm{Kg}) \\
\text { Experimental }\end{array}$ & $\mathrm{C} / \mathrm{E}$ & $C-E$ \\
\hline & 23 & 0.000 & -69.58 & $8.8 \pm 4.4$ & $-7.92 \pm 3.96$ & $-78.4 \pm 4.4$ \\
\hline & 24 & 5.524 & -69.61 & -- & -- & -- \\
\hline & 25 & 11.049 & -69.65 & --- & $-\cdots$ & --- \\
\hline CORE & 26 & 16.573 & -69.53 & $8.8 \pm 3.3$ & $-7.91 \pm 2.97$ & $-78.3 \pm 3.3$ \\
\hline ZONE & 27 & 22.098 & -68.92 & -- & --- & -- \\
\hline \multirow[t]{4}{*}{$\mathbf{I}$} & 28 & 27.622 & -67.01 & $\cdots$ & --- & -- \\
\hline & 29 & 33.147 & -61.74 & $14.3 \pm 2.2$ & $-4.32 \pm 0.67$ & $-76.0 \pm 2.2$ \\
\hline & 30 & 38.671 & -50.79 & -- & --- & --- \\
\hline & 31 & 44.196 & -30.00 & -- & $-\infty$ & -- \\
\hline \multirow{3}{*}{$\begin{aligned} & I I^{a}(2) \\
&(1) \\
&(1)\end{aligned}$} & 32 & 49.720 & 2.09 & -- & --- & --- \\
\hline & 33 & 55.245 & 17.24 & $84.6 \pm 5.5$ & $0.20 \pm 0.01$ & $-67.3 \pm 5.5$ \\
\hline & 34 & 60.769 & 21.45 & -- & -- & -- \\
\hline \multirow[t]{2}{*}{ III } & 35 & 66.294 & 3.70 & $33.0 \pm 4.4$ & $0.11 \pm 0.01$ & $-29.3 \pm 4.4$ \\
\hline & 16 & 71.818 & $-65 \cdot 34$ & -- & --- & --- \\
\hline \multirow{4}{*}{$\begin{array}{l}\text { RADIAL } \\
\text { BLANKET }\end{array}$} & 37 & 77.343 & -73.51 & $\cdots$ & -- & -- \\
\hline & 38 & 82.867 & -57.79 & $-52.7 \pm 3.3$ & $1.10 \pm 0.07$ & $-5.1 \pm 3.3$ \\
\hline & 39 & 88.392 & -37.86 & -- & --- & $\cdots$ \\
\hline & 40 & 93.916 & -21.87 & --- & --- & --- \\
\hline
\end{tabular}

${ }^{a}$ The numbers in parentheses indicate the drawer type of the three drawer unit cell zone II loading. 
TABLE III-13. Comparison of GCFR Phase I and Phase III Central Worth C/E's

\begin{tabular}{|c|c|c|c|c|c|c|c|}
\hline \multirow[b]{2}{*}{ Sample I.D. } & \multirow[b]{2}{*}{ Isotope } & \multicolumn{2}{|c|}{$\mathrm{C} / \mathrm{E}^{\mathrm{a}}$} & \multicolumn{2}{|c|}{$2{ }^{39} \mathrm{Pu}$ Normalized $\mathrm{C} / \mathrm{E}^{\mathrm{b}}$} & \multicolumn{2}{|c|}{ PD Adjusted $C / E^{C}$} \\
\hline & & $I$ & III & I & III & $I$ & III \\
\hline MB-10 & $239 \mathrm{Pu}$ & 1.27 & 1.16 & - & - & 0.95 & 1.00 \\
\hline$P U-240-2 D$ & $240 \mathrm{PuO}_{2}$ & 1.36 & 1.17 & 1.07 & 1.01 & 1.02 & 1.01 \\
\hline$U-233-3$ & $23^{3} U$ & 1.27 & 1.16 & 1.00 & 1.00 & 0.95 & 1.00 \\
\hline$M B-21$ & $235 U$ & 1.32 & 1.20 & 1.04 & 1.03 & 0.99 & 1.03 \\
\hline $\mathrm{MB}-\dot{25}$ & $23^{8} \mathrm{U}$ & 1.12 & 1.09 & 0.88 & 0.94 & 0.84 & 0.94 \\
\hline$B-7$ & $10_{B}$ & 1.12 & 1.05 & 0.88 & 0.90 & 0.84 & 0.90 \\
\hline MB-19 & SST & 1.66 & 1.27 & 1.31 & 1.09 & 1.25 & 1.09 \\
\hline
\end{tabular}

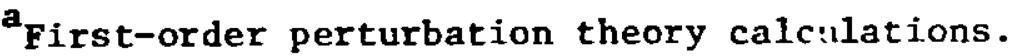

bample C/E divided by ${ }^{239} \mathrm{Pu}$ sample $\mathrm{C} / \mathrm{E}$.

Cample C/E multiplied by perturbation denominator $\mathrm{C} / \mathrm{E}$. 
TABLE IV-1. Mass and Composition of Fission Counter Sources

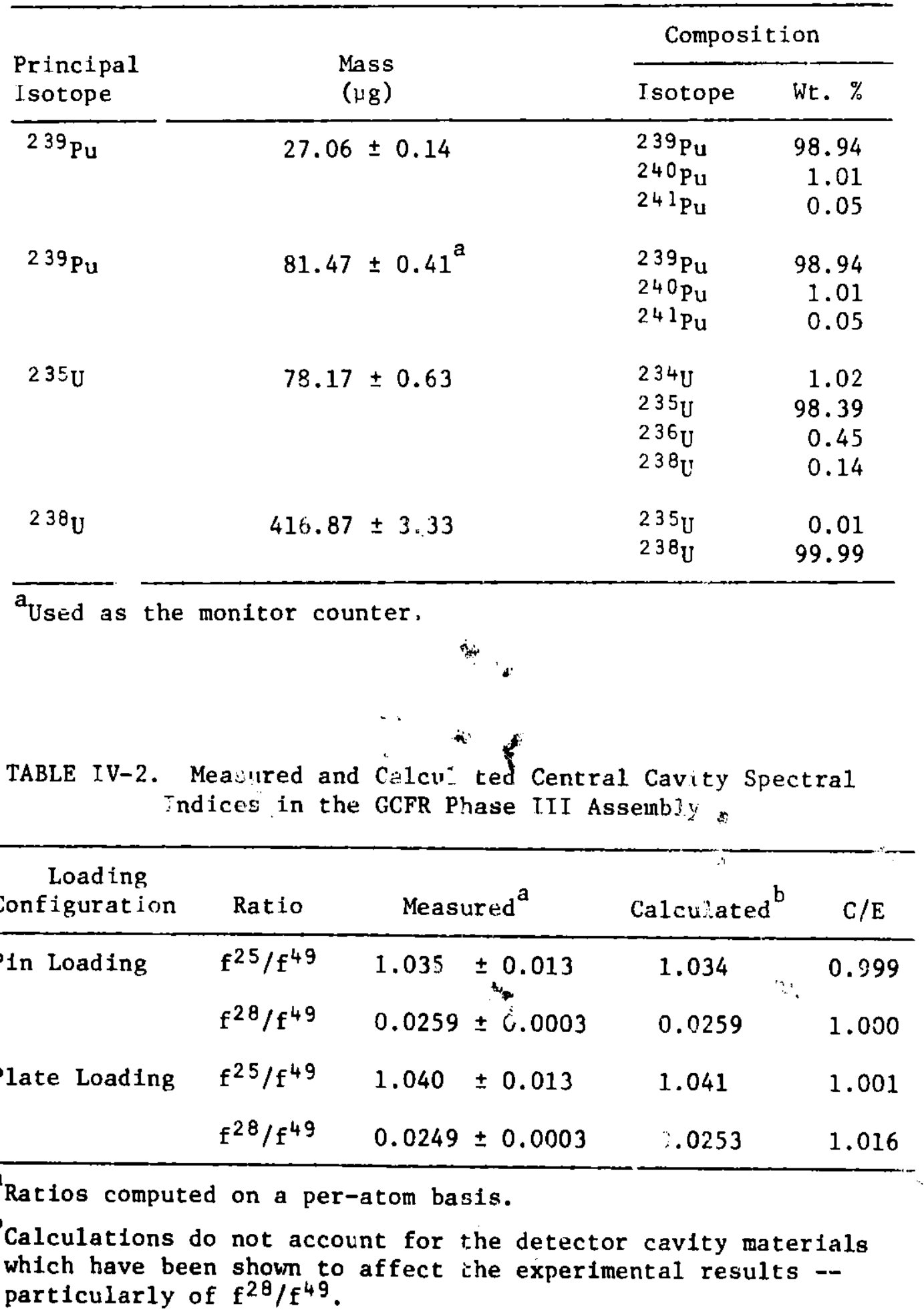


TABLE IV-3. Gamma-ray Peaks Analyzed to Determine Fission and Capture Rates in Foils

\begin{tabular}{lccccc}
\hline $\begin{array}{l}\text { keaction } \\
\text { Rate }\end{array}$ & $\begin{array}{l}\gamma \text {-ray } \\
\text { Energy } \\
(\mathrm{keV})\end{array}$ & Isotope & $\begin{array}{c}\gamma \text {-ray } \\
\text { Intensity }\end{array}$ & $\begin{array}{c}\text { Half-Life } \\
(\mathrm{hr})\end{array}$ & $\begin{array}{c}\text { Detection } \\
\text { Effjciency }\end{array}$ \\
\hline $\begin{array}{l}235 \mathrm{U}(\mathrm{n}, \mathrm{f}) \\
238 \mathrm{U}(\mathrm{n}, \mathrm{f})\end{array}$ & 529.9 & $133^{\mathrm{I}}$ & 0.891 & 21.0 & 0.038 \\
$239 \mathrm{Pu}(\mathrm{n}, \mathrm{f})$ & 657.9 & $97 \mathrm{Nb}$ & 0.983 & 17.0 & 0.030 \\
& 667.7 & $132 \mathrm{I}$ & 1.0 & 80.0 & 0.029 \\
\hline $238 \mathrm{U}(\mathrm{n}, \mathrm{\gamma})$ & 277.6 & $23{ }^{2} \mathrm{~Np}$ & 0.141 & 17.0 & 0.026 \\
\hline
\end{tabular}

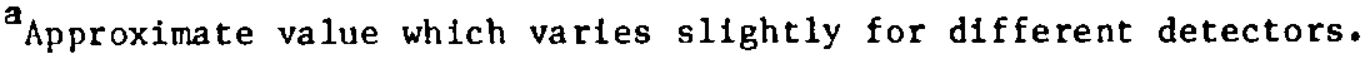

TABLE IV-4. Description of Activation Foils Used for Plate Measurements

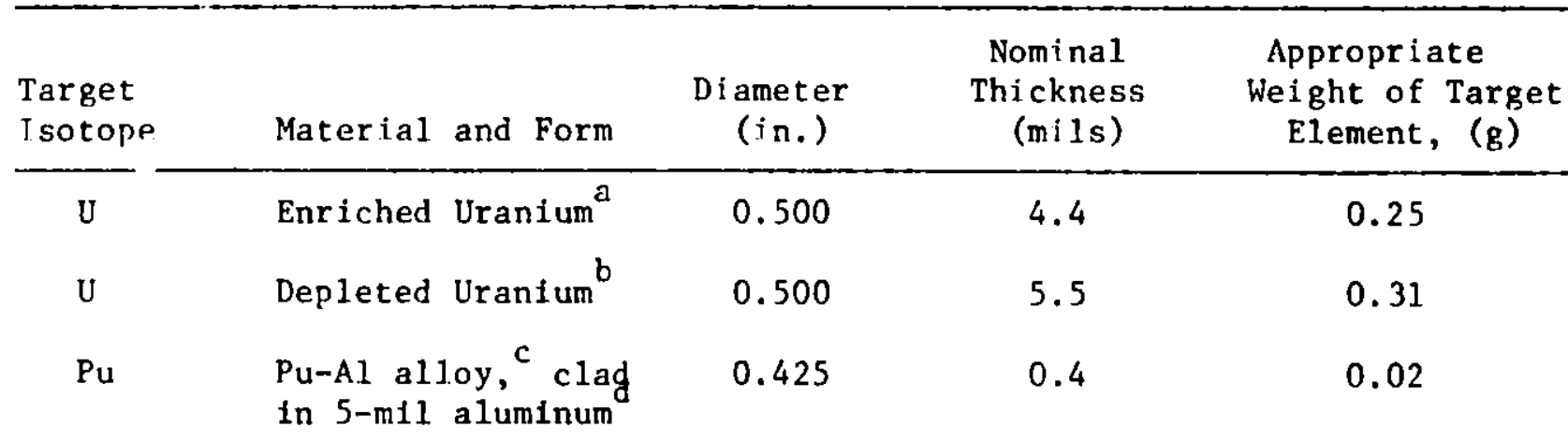

\begin{tabular}{rrr}
\hline Isotopic composition of enriched uranium folls: & $234 \mathrm{U}:$ & $1.03 \mathrm{wt} \%$ \\
$235 \mathrm{U}:$ & 93.07 \\
$236 \mathrm{U}:$ & 0.27 \\
$238 \mathrm{U:}$ & 5.63
\end{tabular}

${ }^{b}$ Isotopic composition of depleted urantum foils: ${ }^{235} \mathrm{U}: \quad 0.215$

$236 \mathrm{U}: \quad 0.005$

$238 \mathrm{U:} \quad 99.78$

cIsotopic composition of the plutonium foll

$\begin{array}{ll}239 \mathrm{Pu}: & 94.98 \\ 240 \mathrm{Pu}: & 4.7 \\ 241 \mathrm{Pu}: & 0.303 \\ 242 \mathrm{Pu}: & 0.019\end{array}$

Aluminum cladding is $0.5-1 n$. diameter and 5 mils thick. 
TABLE IV-5. In-Ceil Reaction Rates, Core Zone I

\begin{tabular}{|c|c|c|c|c|c|c|}
\hline Drawer & Position & Interface & $\begin{array}{c}\mathrm{f}^{49} \\
\left(\times 10^{7}\right)\end{array}$ & $\left(\begin{array}{c}\mathrm{f}^{25} \\
\left.\times \quad 10^{7}\right)\end{array}\right.$ & $\left(\begin{array}{c}f^{28} \\
\left(\times 10^{5}\right)\end{array}\right.$ & $\left(\begin{array}{c}c^{28} \\
\left.\times 10^{6}\right)\end{array}\right.$ \\
\hline $\begin{array}{c}523 / 23 \\
0-2^{\prime \prime}\end{array}$ & $\begin{array}{l}0.0 \\
0.125 \\
0.25 \\
0.875 \\
1.0 \\
1.125 \\
1.75 \\
1.875 \\
2.0\end{array}$ & $\begin{array}{l}\text { DR-UO } \\
\text { UO-UO } \\
\text { UO-V } \\
\text { FE-PU } \\
\text { PU-PU } \\
\text { PU-FE } \\
\text { V-UO } \\
\text { UO-UO } \\
\text { UO-DR }\end{array}$ & $\begin{array}{l}2.192 \\
2.186 \\
2.193\end{array}$ & $\begin{array}{l}2.348 \\
2.321 \\
2.334 \\
2.297 \\
2.308 \\
2.346 \\
2.312 \\
2.348 \\
2.336\end{array}$ & $\begin{array}{l}5.732 \\
5.573 \\
5.711 \\
6.264 \\
6.563 \\
6.497 \\
5.666 \\
5.658 \\
5.746\end{array}$ & $\begin{array}{l}2.844 \\
2.748 \\
2.855 \\
2.853 \\
2.692 \\
2.878 \\
2.901 \\
2.758 \\
2.860\end{array}$ \\
\hline $\begin{array}{l}S 15 / 23 \\
0-2^{\prime \prime}\end{array}$ & $\begin{array}{l}0.0 \\
0.125 \\
0.25 \\
0.875 \\
1.0 \\
1.125 \\
1.75 \\
1.875 \\
2.0\end{array}$ & $\begin{array}{l}\text { DR-UO } \\
\text { UO-UO } \\
\text { UO-V } \\
\text { FE-PU } \\
\text { PU-PU } \\
\text { PU-FE } \\
\text { V-UO } \\
\text { UO-UO } \\
\text { UO-DR }\end{array}$ & $\begin{array}{l}1.769 \\
1.738 \\
1.776\end{array}$ & $\begin{array}{l}1.856 \\
1.824 \\
1.794 \\
1.888 \\
1.864 \\
1.817 \\
1.818 \\
1.848 \\
1.829\end{array}$ & $\begin{array}{l}4.647 \\
4.645 \\
4.700 \\
5.151 \\
5.393 \\
5.149 \\
4.636 \\
4.753 \\
4.688\end{array}$ & $\begin{array}{l}2.277 \\
2.126 \\
2.278 \\
2.270 \\
2.121 \\
2.253 \\
2.218 \\
2.184 \\
2.265\end{array}$ \\
\hline $\begin{array}{l}\mathrm{S} 23 / 23 \\
22-24^{\prime \prime}\end{array}$ & $\begin{array}{l}0.0 \\
0.125 \\
0.25 \\
0.875 \\
1.125 \\
1.75 \\
1.875 \\
2.0\end{array}$ & $\begin{array}{l}\text { DR-UO } \\
\text { UO-UO } \\
\text { UO-V } \\
\text { FE-PU } \\
\text { PU-FE } \\
\text { V-UO } \\
\text { UO-UO } \\
\text { UO-DR }\end{array}$ & $\begin{array}{l}1.163 \\
1.139\end{array}$ & $\begin{array}{l}1.283 \\
1.277 \\
1.280 \\
1.266 \\
1.277 \\
1.267 \\
1.263 \\
1.280\end{array}$ & $\begin{array}{l}2.486 \\
2.517 \\
2.575 \\
2.950 \\
2.964 \\
2.547 \\
2.538 \\
2.451\end{array}$ & $\begin{array}{l}1.618 \\
1.519 \\
1.615 \\
1.637 \\
1.616 \\
1.612 \\
1.530 \\
1.626\end{array}$ \\
\hline
\end{tabular}

a Mapping foll locations.

${ }^{b}$ U = depleted uranfum oxide; $D U=$ depleted uranium; $V=$ vold can;

$\mathrm{PU}$ = plutonium fuel; $\mathrm{FE}=$ iron oxide; $\mathrm{DR}=\mathrm{drawer}$ side. 
TABLE IV-6. In-Ce11 Reaction Rates, Core Zone II, Row 13

\begin{tabular}{|c|c|c|c|c|c|c|}
\hline Drawer & $\operatorname{Pos} 1$ tion(1n.) & Interface ${ }^{b}$ & $\begin{array}{c}f^{49} \\
\left(\times 10^{7}\right)\end{array}$ & $\begin{array}{c}f^{25} \\
\left(\times 10^{7}\right)\end{array}$ & $\begin{array}{c}f^{28} \\
\left(\times \quad 10^{5}\right)\end{array}$ & $\left(\begin{array}{c}c^{2 B} \\
\left.\times 10^{6}\right)\end{array}\right.$ \\
\hline $\begin{array}{c}\mathrm{S} 13 / 22 \\
0-2^{\prime \prime}\end{array}$ & $\begin{array}{l}0.0 \\
0.125 \\
0.25 \\
0.625 \\
0.875 \\
1.5 \\
1.625 \\
1.75\end{array}$ & $\begin{array}{l}\text { DR-UO } \\
\text { UO-UO } \\
\text { UO-V } \\
\text { FE-PU } \\
\text { PU-FE } \\
\text { V-UO } \\
\text { UO-UO } \\
\text { UO-V }\end{array}$ & $\begin{array}{l}1.506 \\
1.510\end{array}$ & $\begin{array}{l}1.539 \\
1.543 \\
1.547 \\
1.563 \\
1.532 \\
1.558 \\
1.550 \\
1.538\end{array}$ & $\begin{array}{l}4.404 \\
4.445 \\
4.546 \\
4.948 \\
4.664 \\
4.366 \\
4.385 \\
4.246\end{array}$ & $\begin{array}{l}1.895 \\
1.815 \\
1.875 \\
1.874 \\
1.840 \\
1.878 \\
1.796 \\
1.906\end{array}$ \\
\hline $\begin{array}{c}513 / 23 \\
0-2^{\prime \prime}\end{array}$ & $\begin{array}{l}2.125 \\
2.357 \\
3.000 \\
3.125 \\
3.250 \\
3.625^{a} \\
3.875\end{array}$ & $\begin{array}{l}\text { FE-PU } \\
\text { PU-FE } \\
\text { V-UO } \\
\text { UO-UO } \\
\text { UO-V } \\
\text { FE-PU } \\
\text { PU-FE }\end{array}$ & $\begin{array}{l}1.89 \\
1.503\end{array}$ & $\begin{array}{l}1.557 \\
1.561 \\
1.549 \\
1.533 \\
1.554 \\
1.562 \\
1.532\end{array}$ & $\begin{array}{l}4.882 \\
4.793 \\
4.374 \\
4.306 \\
4.546 \\
4.960 \\
4.886\end{array}$ & $\begin{array}{l}1.933 \\
1.870 \\
1.885 \\
1.823 \\
1.884 \\
1.864 \\
1.905\end{array}$ \\
\hline $\begin{array}{c}S 13 / 24 \\
0-2^{\prime \prime}\end{array}$ & $\begin{array}{l}4.500 \\
4.625 \\
4.750 \\
5.125 \\
5.375\end{array}$ & $\begin{array}{l}\text { V-UO } \\
\text { UO-UO } \\
\text { UO-V } \\
\text { FE-PU } \\
\text { PU-FE }\end{array}$ & $\begin{array}{l}1.479 \\
1.482\end{array}$ & $\begin{array}{l}1.556 \\
1.543 \\
1.535 \\
1.570 \\
1.585\end{array}$ & $\begin{array}{l}4.315 \\
4.315 \\
4.520 \\
4.983 \\
4.585\end{array}$ & $\begin{array}{l}1.917 \\
1.816 \\
1.876 \\
1.883 \\
1.896\end{array}$ \\
\hline
\end{tabular}

a Mapping foll location.

${ }^{b}$ U = depleted uranium oxlde; FE = Iron oxide; $V=$ vold can; $P U$ = plutonium fuel; $\mathrm{DU}=$ depleted uranfum; $\mathrm{DR}=$ drawer side.

TABLE IV-7. In-Cell Reaction Rates, Core Zone II, Row 23 with Radial Corrections

\begin{tabular}{|c|c|c|c|c|c|c|}
\hline Drawer & Positton(1n.) & Interface ${ }^{b}$ & $\begin{array}{c}f^{49} \\
\left(\times 10^{\prime}\right)\end{array}$ & $\left(\begin{array}{c}f^{25} \\
\left.\times \quad 10^{7}\right)\end{array}\right.$ & $\begin{array}{l}\mathrm{f}^{28} \\
\left(\times 10^{5}\right)\end{array}$ & $\left(\times^{c^{28}} 10^{6}\right)$ \\
\hline $\begin{array}{c}523 / 32 \\
0-2^{*}\end{array}$ & $\begin{array}{l}0.125 \\
0.375 \\
1.0 \\
1.125 \\
1.250 \\
1.625^{a} \\
1.875\end{array}$ & $\begin{array}{l}\text { FE-PU } \\
P U-F E \\
V-U O \\
U O-U O \\
U O-V \\
F E-P U \\
P U-F E\end{array}$ & $\begin{array}{l}1.619 \\
1.575 \\
1.572 \\
1.541\end{array}$ & $\begin{array}{l}1.649 \\
1.669 \\
1.631 \\
1.666 \\
1.670 \\
1.620 \\
1.610\end{array}$ & $\begin{array}{l}5.203 \\
5.277 \\
4.903 \\
4.906 \\
4.956 \\
5.296 \\
5.120\end{array}$ & $\begin{array}{l}2.017 \\
1.953 \\
2.003 \\
1.922 \\
1.986 \\
1.981 \\
1.990\end{array}$ \\
\hline $\begin{array}{c}523 / 33 \\
0-2^{*}\end{array}$ & $\begin{array}{l}2.500 \\
2.625 \\
2.75 \\
3.125 \\
3.375\end{array}$ & $\begin{array}{l}V-U O \\
\text { UO-UO } \\
U O-V \\
\text { FE-PU } \\
P U-F E\end{array}$ & $\begin{array}{l}1.633 \\
1.582\end{array}$ & $\begin{array}{l}1.645 \\
1.657 \\
1.620 \\
1.654 \\
1.628\end{array}$ & $\begin{array}{l}4.822 \\
4.726 \\
4.649 \\
5.1112 \\
5.157\end{array}$ & $\begin{array}{l}2.051 \\
1.923 \\
1.992 \\
1.998 \\
1.989\end{array}$ \\
\hline $\begin{array}{c}\$ 23 / 34 \\
0-2 "\end{array}$ & $\begin{array}{l}4.000 \\
4.125 \\
4.250 \\
4.625 \\
4.875 \\
5.500 \\
5.625 \\
5.750\end{array}$ & $\begin{array}{l}\text { DR-UO } \\
\text { UO-UO } \\
U U-V \\
F E-P U \\
P U-F E \\
V-U O \\
\text { UO-UO } \\
\text { UO-V }\end{array}$ & $\begin{array}{l}1.589 \\
1.582\end{array}$ & $\begin{array}{l}1.606 \\
1.613 \\
1.656 \\
1.635 \\
1.640 \\
1.652 \\
1.617 \\
1.608\end{array}$ & $\begin{array}{l}4.677 \\
4.762 \\
4.722 \\
5.144 \\
5.017 \\
4.958 \\
4.867 \\
4.881\end{array}$ & $\begin{array}{l}2.045 \\
1.953 \\
1.999 \\
2.029 \\
1.931 \\
2.000 \\
1.950 \\
2.026\end{array}$ \\
\hline
\end{tabular}

Mapplng foll location; all values radially corrected to this position.

buo - depleted uranlum oxide; FE - Iron oxide; V - vold can; PU - plutonlum fuel; DU - depleted uranlum; OR - drawer side. 
TABLE IV-8. In-Ce11 Reaction Rates, Core Zone III

\begin{tabular}{|c|c|c|c|c|c|c|}
\hline Drawer & Position & Interface & $\begin{array}{c}f^{49} \\
\left(\times \quad 10^{7}\right)\end{array}$ & $\begin{array}{c}\mathrm{f}^{25} \\
\left(\times 10^{7}\right)\end{array}$ & $\begin{array}{c}f^{28} \\
\left(\times 10^{5}\right)\end{array}$ & $\begin{array}{c}c^{28} \\
\left(\times 10^{6}\right)\end{array}$ \\
\hline & 0.375 & FE-PU & 1.146 & 1.242 & 3.500 & 1.553 \\
\hline \multirow[t]{2}{*}{$S 11 / 23$} & 0.500 & PU-PU & 1.114 & 1.235 & 3.630 & 1.431 \\
\hline & 0.625 & PU-FE & 1.178 & 1.220 & 3.496 & 1.551 \\
\hline \multirow[t]{3}{*}{$0-2^{\prime \prime}$} & $1.375^{\mathrm{a}}$ & FE-PU & 1.176 & 1.252 & 3.744 & 1.581 \\
\hline & 1.500 & PU-PU & 1.150 & 1.224 & 3.703 & 1.451 \\
\hline & 1.625 & PU-FE & 1.134 & 1.247 & 3.610 & 1.599 \\
\hline
\end{tabular}

Mapping foil location.

${ }^{b} \mathrm{FE}=$ iron oxide, $\mathrm{PU}=$ plutonium fuej.

TABLE IV-9. In-Cell Reaction Rates, Axlal Blanket Region

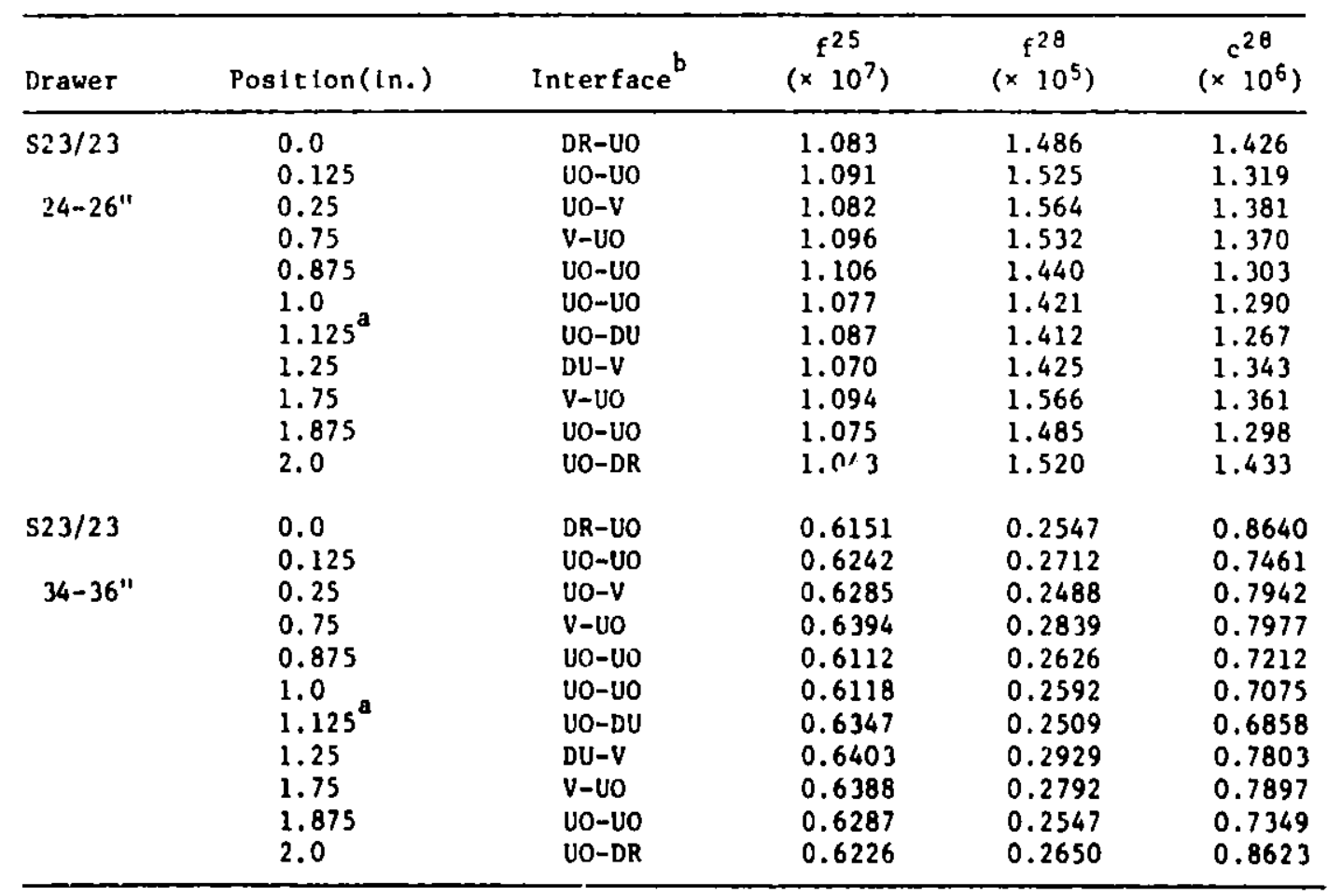

\footnotetext{
Mapping foil locations.

bu - depleted urantum oxide; DU - depleted uranfum; V = vold can; DR = drawer side.
} 
TABLE IV-10. In-Cell Reaction Rates, Radial Blanket Region

\begin{tabular}{|c|c|c|c|c|c|}
\hline Drawer & Posttion(1n.) & Interface ${ }^{b}$ & $\begin{array}{c}f^{25} \\
\left(\times \quad 10^{6}\right)\end{array}$ & $\begin{array}{c}f^{28} \\
\left(\times 10^{5}\right)\end{array}$ & $\begin{array}{c}c^{28} \\
\left(\times 10^{6}\right)\end{array}$ \\
\hline $510 / 23$ & $\begin{array}{l}0.0 \\
0.125\end{array}$ & $\begin{array}{l}\text { DR-UO } \\
\text { UO-UO }\end{array}$ & $\begin{array}{l}1.063 \\
1.064\end{array}$ & $\begin{array}{l}1.795 \\
1.767\end{array}$ & $\begin{array}{l}1.410 \\
1.298\end{array}$ \\
\hline $0-2^{\prime \prime}$ & $\begin{array}{l}0.25 \\
0.375 \\
0.50 \\
1.00 \\
1.125 \\
1.25 \\
1.375 \\
1.50 \\
1.625\end{array}$ & $\begin{array}{l}\text { UO-UO } \\
\text { UO-UO } \\
\text { UO-V } \\
\text { V-UO } \\
\text { UO-UO } \\
\text { UO-UO } \\
\text { UO-UO } \\
\text { UO-DU } \\
\text { DU-V }\end{array}$ & $\begin{array}{l}1.029 \\
1.044 \\
1.059 \\
1.086 \\
1.085 \\
1.074 \\
1.078 \\
1.069 \\
1.081\end{array}$ & $\begin{array}{l}1.795 \\
1.814 \\
1.798 \\
1.750 \\
1.764 \\
1.798 \\
1.778 \\
1.777 \\
1.778\end{array}$ & $\begin{array}{l}1.279 \\
1.282 \\
1.338 \\
1.330 \\
1.269 \\
1.255 \\
1.252 \\
1.246 \\
1.397\end{array}$ \\
\hline $\begin{array}{c}506 / 23 \\
0-2^{\prime \prime}\end{array}$ & $\begin{array}{l}0.0 \\
0.125 \\
0.25 \\
0.375 \\
0.50 \\
1.00 \\
1.125 \\
1.25 \\
1.375 \\
1.50 \\
1.625\end{array}$ & $\begin{array}{l}\text { DR-UO } \\
\text { UO-UO } \\
\text { UO-UO } \\
\text { UO-UO } \\
\text { UO-V } \\
\text { V-UO } \\
\text { UO-UO } \\
\text { UO-UO } \\
\text { UO-UO } \\
\text { UO-DU } \\
\text { DU-V }\end{array}$ & $\begin{array}{l}0.6630 \\
0.6704 \\
0.6570 \\
0.6637 \\
0.6595 \\
0.6652 \\
0.6715 \\
0.6735 \\
0.6633 \\
0.6651 \\
1.6755\end{array}$ & $\begin{array}{l}0.2708 \\
0.2511 \\
0.2724 \\
0.2778 \\
0.3019 \\
0.2734 \\
0.2859 \\
0.2529 \\
0.2725 \\
0.2800 \\
0.2545\end{array}$ & $\begin{array}{l}0.9217 \\
0.7392 \\
0.7340 \\
0.7270 \\
0.8189 \\
0.8176 \\
0.7260 \\
0.7158 \\
0.7085 \\
0.6938 \\
0.9150\end{array}$ \\
\hline
\end{tabular}

Mapping foil locations.

${ }^{b}$ o = depleted uranium oxide; $D U=$ depleted uranium; $V=$ vold can;

DR = drawer side.

TABLE IV-11. Cell-Average-to-Mapping-Foll Rutios

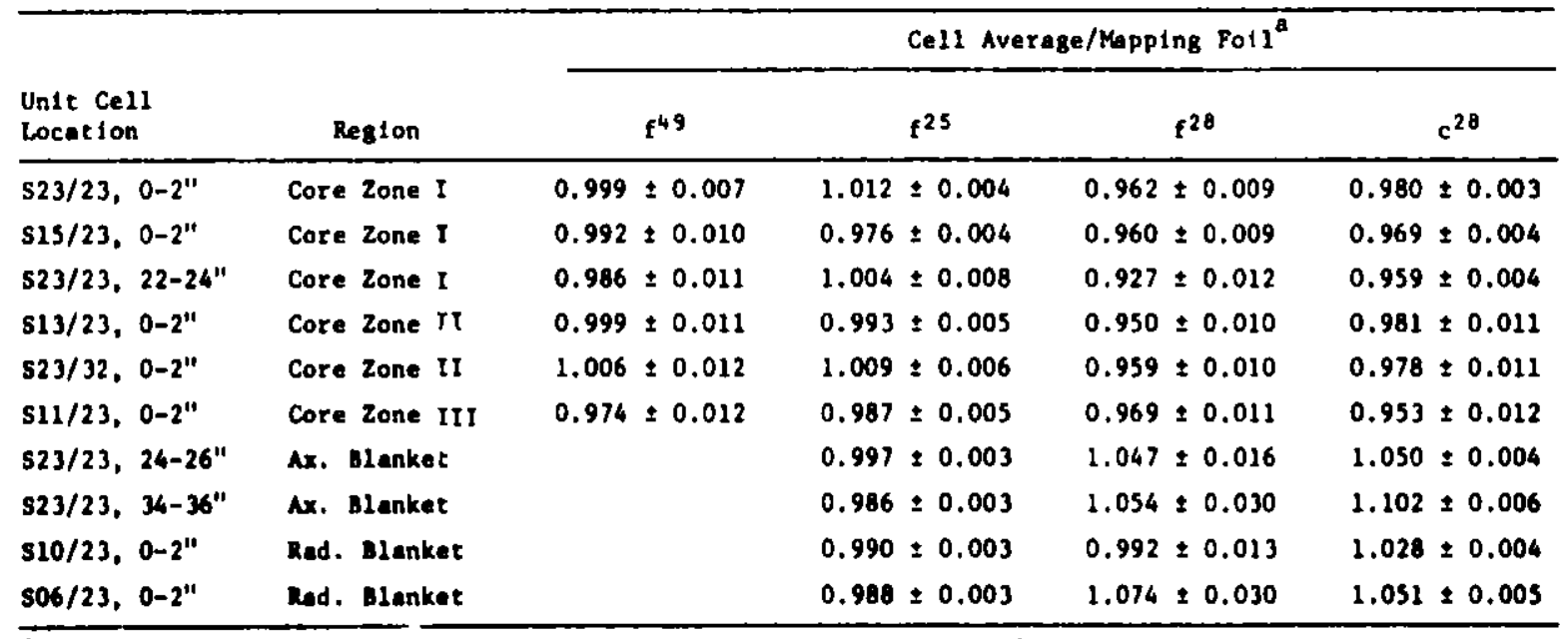

tho etafnlece steel correctione applied to mpplng foll deta for $c^{20}$. 
TABLE IV-12. Heasured and Calculated Cell-Averaged Per-Atom Reaction Rate Ratios in the GCFR Phase III Assembly

\begin{tabular}{|c|c|c|c|c|c|c|c|c|c|c|c|c|c|}
\hline \multirow[b]{2}{*}{ Lecation } & \multirow{2}{*}{\multicolumn{3}{|c|}{ Region }} & \multirow{2}{*}{$\begin{array}{r}R_{,} z \\
(\mathrm{cn})\end{array}$} & \multicolumn{3}{|c|}{$f^{25} / f^{49}$} & \multicolumn{3}{|l|}{$f^{28} / f^{49}$} & \multicolumn{3}{|c|}{$c^{2 \theta} / f^{49}$} \\
\hline & & & & & Measured & Calculated & $C / E$ & Measured & Colculated & $C / E$ & Measured & Calculated & $\mathrm{C} / \mathrm{E}$ \\
\hline $523 / 23$ & Core & zone & $\mathbf{I}$ & $0.0,1.6$ & $1.044 \pm 0.016$ & 1.038 & 0.994 & $0.02740 \pm 0.00044$ & 0.02640 & 0.963 & $0.1272 \pm 0.0017$ & 0.1434 & 1.127 \\
\hline $515 / 23$ & core & Zone & I & $44.2,1.6$ & $1.032 \pm 0.017$ & 1.021 & 0.989 & $0.02806 \pm 0.00047$ & 0.02803 & 0.999 & $0.1248 \pm 0.0017$ & 0.1394 & 1.117 \\
\hline $523 / 23$ & Core & Zone & $\mathbf{I}$ & $0.0,55.9$ & $1.090 \div 0.017$ & 1.092 & 1.002 & $0.02375 \pm 0.00040$ & 0.02253 & 0.949 & $0.1363 \pm 0.0021$ & 0.1533 & 1.125 \\
\hline $513 / 22-24$ & Core & Zone & II & $55.2,1.6$ & $1.021 \pm 0.018$ & 1.016 & 0.995 & $0.03140 \pm 0.00057$ & 0.03012 & 0.959 & $0.1219 \pm 0.0020$ & 0.1378 & 1.130 \\
\hline $523 / 32-34$ & Core & Zone & II & $51.3,1.6$ & $1.017 \pm 0.018$ & 1.013 & 0.996 & $0.03200 \pm 0.00059$ & 0.03021 & 0.944 & $0.1221 \pm 0.0020$ & 0.1372 & 1.124 \\
\hline \multirow[t]{3}{*}{$\mathbf{s 1 1 / 2 3}$} & Core & 2one & III & $66.3,1.6$ & $1.060 \div 0.018$ & 1.043 & 0.984 & $0.03153 \pm 0.00056$ & 0.02804 & 0.889 & $0.1309 \pm 0.0022$ & 0.1426 & 1.089 \\
\hline & & & & & & & & \multicolumn{3}{|l|}{$f^{2 \theta} / f^{25}$} & \multicolumn{3}{|c|}{$c^{28 / f^{49}}$} \\
\hline & & & & & & & & Neasured & Calculated & $C / E$ & Measured & Calculated & $\mathrm{C} / \mathrm{E}$ \\
\hline $523 / 23$ & Axtal & Blenke & & 0.0 .62 .7 & & & & $0.01382 \div 0.00025$ & 0.01460 & 1.057 & $0.1243 \pm 0.0016$ & 0.1356 & 1.091 \\
\hline $523 / 23$ & Axtal & Blanke & & $0.0,86.4$ & & & & $0.00428 \pm 0.00011$ & 0.00328 & 0.766 & $0.1223 \pm 0.0017$ & 0.1185 & 0.969 \\
\hline $510 / 23$ & Ped1el & Blank & & $71.8,1.6$ & & & & $0.01698 \pm 0.00030$ & 0.01743 & 1.026 & $0.1228 \pm 0.0016$ & 0.1335 & 1.087 \\
\hline $506 / 23$ & Radial & Dlank & & 93.9, & & & & $0.00413 \pm 0.00010$ & 0.00342 & 0.827 & $0.1145 \pm 0.0016$ & 0.1148 & 1.003 \\
\hline
\end{tabular}

TABLE IV-13. Description of Activation Po11. for Pin Zone Measurements

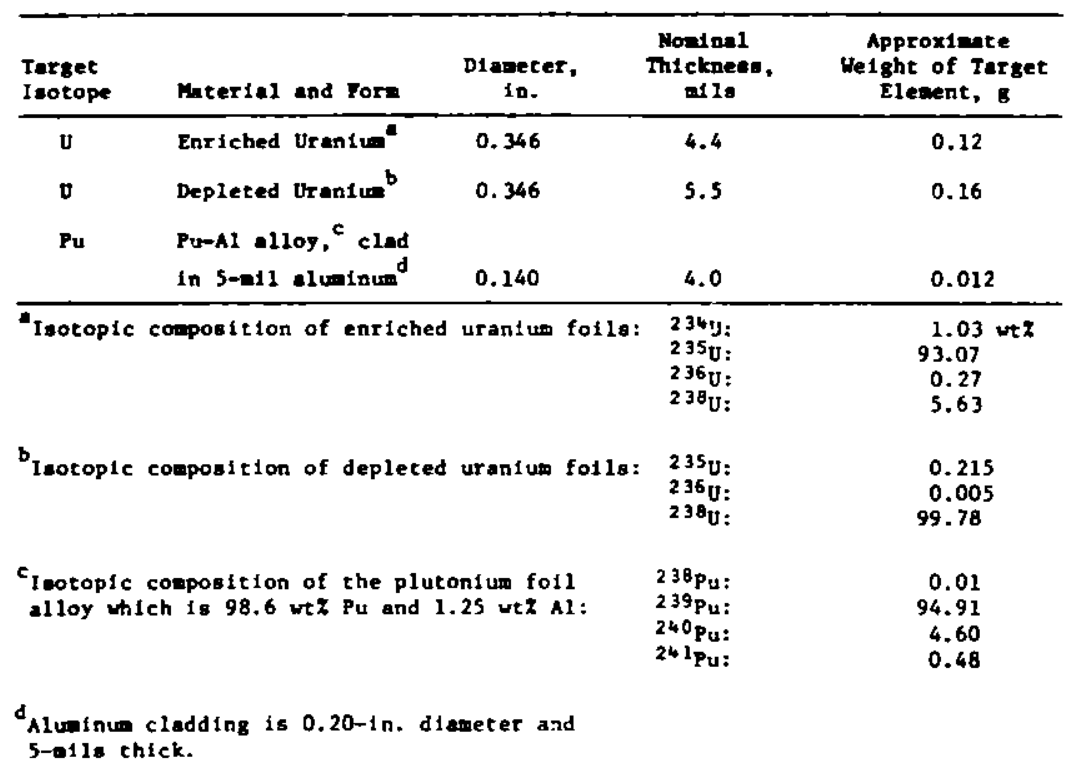


TABLE IV-14. GCFR Phase III Pin Zone Intra-Cell Reaction Rates

\begin{tabular}{|c|c|c|c|c|c|c|}
\hline Region & $\begin{array}{c}\text { Axial } \\
\text { Distance } \\
\text { (cm) }\end{array}$ & $\begin{array}{c}\text { Cell } \\
\text { Location }\end{array}$ & $\begin{array}{c}f^{49} \\
\left(\times 10^{6}\right)\end{array}$ & $\begin{array}{c}\mathrm{f}^{25} \\
\left(\times 10^{6}\right)\end{array}$ & $\begin{array}{c}f^{28} \\
\left(\times \quad 10^{5}\right)\end{array}$ & $\left(x^{c^{28}} 10^{5}\right)$ \\
\hline Core & 7.62 & Al & $7.166 \pm 0.050$ & - & -- & -- \\
\hline Zone I & & A2 & - & $-\infty$ & $1.979 \pm 0.020$ & $9.166 \pm 0.095$ \\
\hline \multirow[t]{6}{*}{$\$ 23 / 23$} & & A3 & -- & $7.646 \pm 0.083$ & -- & -- \\
\hline & & B6 & $7.169 \pm 0.050$ & -- & -- & --- \\
\hline & & B8 & -- & -- & $2 . r 02 \pm 0.020$ & $9.005 \pm 0.095$ \\
\hline & & $\mathrm{Cl}$ & -- & $7.680 \pm 0.084$ & -- & --- \\
\hline & & $\mathrm{C} 2$ & $7.042 \pm 0.049$ & -- & $\cdots$ & -- \\
\hline & & C3 & -- & -- & $2.018 \pm 0.020$ & $8.980 \pm 0.094$ \\
\hline Axial & 68.58 & $\mathbf{A l}$ & & --- & $0.327 \pm 0.004$ & $4.082 \pm 0.044$ \\
\hline Blanket & & A2 & & $3.474 \pm 0.038$ & --- & -- \\
\hline \multirow[t]{5}{*}{$523 / 23$} & & & & & & \\
\hline & & B6 & & --- & $0.334 \pm 0.004$ & $4.058 \pm 0.043$ \\
\hline & & B8 & & $3.489 \pm 0.038$ & -- & --- \\
\hline & & c2 & & -- & $0.331=0.004$ & $3.960 \pm 0.042$ \\
\hline & & $\mathrm{C3}$ & & $3.458 \pm 0.038$ & - & --- \\
\hline
\end{tabular}

Locations refer to Fig. IV-26.

TABLE IV-15. Cell-Averaged Reaction Race Ratios in the
GCFR Phise III Plate- and PIn-Loaded Aasembl ies

\begin{tabular}{|c|c|c|c|c|c|c|c|c|}
\hline \multirow{3}{*}{$\frac{20 t i 0^{\circ}}{25 / 60}$} & \multirow{3}{*}{$\begin{array}{l}\text { Aesions } \\
\text { Core }\end{array}$} & \multirow{3}{*}{$\frac{\begin{array}{c}z(e-\infty)^{c} \\
(p / n / p l e t e)\end{array}}{7.6 / 1.6}$} & \multicolumn{3}{|c|}{ P1n Loaded Zone } & \multicolumn{3}{|c|}{ Plecte Loeded Zose } \\
\hline & & & Meouured & \multirow{2}{*}{$\begin{array}{l}\text { Calculated } \\
1.034\end{array}$} & \multirow{2}{*}{$\frac{C / E}{0.979=0.013}$} & Meanured & \multirow{2}{*}{$\frac{\text { Calculated }}{1.038}$} & \multirow{2}{*}{$\frac{C / E}{0.994=0.015}$} \\
\hline & & & $=0.014$ & & & $=0.016$ & & \\
\hline$f^{2 * / f^{69}}$ & core & $7.6 / 1.6$ & $0.02791=0.00034$ & 0.02627 & $0.941=0.012$ & $0.02740=0.00046$ & 0.02640 & $0.963=0.015$ \\
\hline$e^{20 / e^{*+1}}$ & core & $7.6 / 1.6$ & $0.1267=0.0016$ & 0.1445 & $1.141=0.014$ & $0.1272=0.0017$ & 0.1634 & $1.127=0.015$ \\
\hline $20 / 8^{25}$ & Ariel Bunket & $68.6 / 62.7$ & $0.00966=0.00016$ & 0.00956 & $0.989=0.016$ & $0.01382=0.00025$ & 0.01460 & $1.057=0.019$ \\
\hline$c^{20 / \ell^{25}}$ & Ax1ed Mtapket & $68.6 / 62.7$ & $0.1176=0.0018$ & 0.1380 & $1.173=0.01 \mathrm{~A}$ & $0.1243=0.0016$ & 0.1356 & $1.091 \pm 0.014$ \\
\hline
\end{tabular}

Gat 100 are siver on I per-etan beass.

all menurmate me mo tn S-23/23.

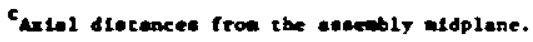


TABLE IV-16. Normalized Experimental Radial Reaction Rate Distributions in the GCFR Phase III

Plate-Loaded Assembly

\begin{tabular}{lrrrrr}
\hline $\begin{array}{c}\text { Row/ } \\
\text { Column }\end{array}$ & $\begin{array}{c}\text { Radius } \\
(\mathrm{cm})\end{array}$ & $\mathrm{f}^{49}$ & \multicolumn{1}{c}{$\mathrm{f}^{25}$} & $\mathbf{f}^{28}$ & $\mathrm{c}^{28}$ \\
\hline $\mathrm{S} 23 / 23$ & 0.00 & 1005.2 & 1002.9 & 1001.7 & 986.3 \\
$\mathrm{~S} 22 / 23$ & 5.52 & 989.5 & 1007.5 & 987.7 & 996.2 \\
$\mathrm{~S} 21 / 23$ & 11.05 & 990.1 & 1005.7 & 995.7 & 990.2 \\
$\mathrm{~S} 20 / 23$ & 16.57 & 968.8 & 978.0 & 949.3 & 963.1 \\
$\mathrm{~S} 19 / 23$ & 22.10 & 957.6 & 949.0 & 952.3 & 946.8 \\
$\mathrm{~S} 18 / 23$ & 27.62 & 938.8 & 930.3 & 925.2 & 914.3 \\
$\mathrm{~S} 17 / 23$ & 33.15 & 869.4 & 857.0 & 908.1 & 875.0 \\
$\mathrm{~S} 16 / 23$ & 38.67 & 828.6 & 833.0 & 867.2 & 826.5 \\
$\mathrm{~S} 15 / 23$ & 44.20 & 811.2 & 794.9 & 861.9 & 788.0 \\
$\mathrm{~S} 14 / 23$ & 49.72 & 749.8 & 725.8 & 821.2 & 724.0 \\
$\mathrm{~S} 13 / 23$ & 55.25 & 683.9 & 667.8 & 769.5 & 657.0 \\
$\mathrm{~S} 12 / 23$ & 60.77 & 614.2 & 605.2 & 679.2 & 588.5 \\
$\mathrm{~S} 11 / 23$ & 66.29 & 518.6 & 530.6 & 596.9 & 526.3 \\
$\mathrm{~S} 10 / 23$ & 71.82 & & 476.8 & 303.0 & 462.4 \\
$\mathrm{~S} 9 / 23$ & 77.34 & & 417.8 & 186.5 & 421.5 \\
$\mathrm{~S} 8 / 23$ & 82.87 & & 367.0 & 107.7 & 358.8 \\
$\mathrm{~S} 7 / 23$ & 88.39 & & 329.4 & 69.44 & 311.8 \\
$\mathrm{~S} 6 / 23$ & 93.92 & & 300.5 & 45.21 & 269.7 \\
\hline
\end{tabular}

TABLE IV-17. Normalized Experimental Axial Reaction Rate Uistributions in the GCFR Phase III

Plate-Loaded Assembly

\begin{tabular}{|c|c|c|c|c|}
\hline $\begin{array}{c}\text { Axtal } \\
\text { Distance } \\
\text { (cm) }\end{array}$ & $f^{49}$ & $\mathrm{f}^{25}$ & $f^{2 \theta}$ & $c^{28}$ \\
\hline $\begin{array}{r}1.59 \\
3.81 \\
7.62 \\
11.43 \\
15.24 \\
19.05 \\
22.86 \\
26.67 \\
30.48 \\
34.29 \\
38.10 \\
41.91 \\
45.72 \\
49.53 \\
53.34 \\
57.15 \\
60.96 \\
68.58 \\
76.20 \\
83.82 \\
90.17\end{array}$ & $\begin{array}{l}995.0 \\
972.4 \\
907.1 \\
884.9 \\
805.6 \\
728.5 \\
627.2 \\
511.6\end{array}$ & $\begin{array}{l}958.2 \\
923.8 \\
840.1 \\
774.0 \\
686.5 \\
584.2 \\
484.3 \\
417.4 \\
330.4 \\
299.2 \\
279.0\end{array}$ & $\begin{array}{c}966.3 \\
911.9 \\
836.4 \\
714.3 \\
647.2 \\
501.0 \\
331.2 \\
148.1 \\
85.66 \\
50.61 \\
35.90\end{array}$ & $\begin{array}{l}953.4 \\
901.8 \\
838.6 \\
787.8 \\
666.8 \\
582.0 \\
509.0 \\
413.6 \\
347.7 \\
287.9 \\
257.1\end{array}$ \\
\hline
\end{tabular}


TABLE IV-18. Notanlized Calculated Radial Reaction Rate Distributions in the GCFR Phase III Plate-Loaded Asseably

\begin{tabular}{|c|c|c|c|c|}
\hline $\begin{array}{c}\text { Radius } \\
\text { (cE) }\end{array}$ & $f^{49}$ & $f^{25}$ & $f^{2 \theta}$ & $c^{28}$ \\
\hline 1.38 & 1000.0 & 1000.0 & 1000.0 & 1000.0 \\
\hline 4.14 & 998.4 & 998.4 & 998.5 & 998.3 \\
\hline 6.91 & 995.3 & 995.0 & 995.6 & 994.9 \\
\hline 9.67 & 990.5 & 990.1 & 991.3 & 989.8 \\
\hline 12.43 & 984.2 & 983.4 & 985.6 & 983.0 \\
\hline 15.19 & 976.3 & 975.1 & 978.4 & 974.4 \\
\hline 17.96 & 966.8 & 905.1 & 970.0 & 964.1 \\
\hline 20.72 & 955.8 & 953.5 & 960.2 & 952.0 \\
\hline 23.48 & 943.1 & 940.1 & 949.3 & 938.2 \\
\hline 26.24 & 928.8 & 924.8 & 937.2 & 922.3 \\
\hline 29.00 & 913.0 & 908.1 & 924.2 & 905.0 \\
\hline 31.77 & 895.7 & 889.7 & 910.4 & 885.8 \\
\hline 34.53 & 876.8 & 869.6 & 896.2 & 864.8 \\
\hline 37.29 & 856.4 & 847.7 & 881.6 & 842.0 \\
\hline 40.05 & 834.4 & 824. I & 867.3 & 817.4 \\
\hline 42.82 & 810.9 & 798.7 & 853.6 & 790.7 \\
\hline 45.58 & 785.8 & 771.5 & $3 / 41.4$ & 762.0 \\
\hline 48.34 & 754.1 & 740.3 & 838.7 & 729.5 \\
\hline 51.10 & 724.1 & 709.0 & 318.0 & 697.3 \\
\hline 53.86 & 691.8 & 676.7 & 788.4 & 664.8 \\
\hline 56.63 & 657.3 & 643.5 & 751.0 & 632.1 \\
\hline 59.39 & 621.0 & 609.5 & 706.5 & 599.3 \\
\hline 62.15 & 583.2 & 575.2 & 655.3 & 566.6 \\
\hline 64.91 & 540.4 & 538.0 & 600.2 & 531.1 \\
\hline 67.68 & 500.0 & 506.6 & 507.0 & 503.3 \\
\hline 70.44 & & 487.7 & 368.2 & 471.5 \\
\hline 73.20 & & 459.4 & 283.0 & 444.4 \\
\hline 75.96 & & 430.8 & 217.6 & 415.6 \\
\hline 78.72 & & 403.0 & 167.3 & 386.2 \\
\hline 81.49 & & 377.2 & 128.4 & 357.8 \\
\hline 84.25 & & 353.3 & 99.05 & 330.0 \\
\hline$B 7.01$ & & 332.6 & 76.58 & 304.1 \\
\hline 89.77 & & 316.4 & 59.34 & 280.9 \\
\hline 92.54 & & 306.2 & 46.12 & 261.2 \\
\hline 95.30 & & 304.1 & 35.94 & 246.3 \\
\hline
\end{tabular}

TABLE IV-19. Norma11zed Calculated Axial Reaction Rate Dlatributiong in the GCFR Phase III Plate-Loaded Assembly

\begin{tabular}{|c|c|c|c|c|}
\hline $\begin{array}{c}\text { Axial } \\
\text { Distance } \\
\text { (cm) }\end{array}$ & $f^{49}$ & $f^{25}$ & $f^{28}$ & $c^{28}$ \\
\hline 1.00 & 1000.0 & 1000.0 & 1000.0 & 1000.0 \\
\hline 3.00 & 998.6 & 998.6 & 998.6 & 998.6 \\
\hline 5.00 & 995.7 & 995.7 & 995.6 & 995.8 \\
\hline 7.00 & 991.4 & 991.5 & 991.3 & 991.5 \\
\hline 9.00 & 985.6 & 985.8 & 985.5 & 985.9 \\
\hline 11.00 & 973.5 & 978.8 & 978.3 & 978.9 \\
\hline 13.00 & 909.9 & 970.4 & 969.7 & 970.6 \\
\hline $\begin{array}{l}15.00 \\
17.00\end{array}$ & $\begin{array}{l}960.0 \\
948.7\end{array}$ & $\begin{array}{l}960.6 \\
949.5\end{array}$ & $\begin{array}{l}959.6 \\
948.2\end{array}$ & $\begin{array}{l}960.8 \\
949.8\end{array}$ \\
\hline 19.06 & 936.1 & 937.2 & 935.3 & 937.5 \\
\hline 21.00 & 922.1 & 923.5 & 921.1 & 924.0 \\
\hline 23.00 & 906.9 & 908.6 & 905.5 & 909.2 \\
\hline 25.00 & 890.4 & 892.5 & 888.5 & 893.3 \\
\hline 27.00 & 872.7 & 875.3 & 870.2 & 876.3 \\
\hline 29.00 & 853.9 & 857.0 & 850.6 & 858.2 \\
\hline 31.00 & 833.9 & 837.6 & 829.6 & 839.1 \\
\hline 33.00 & 812.8 & 817.3 & 807.2 & 819.1 \\
\hline 35.00 & 790.7 & 796.0 & 783.6 & 798.2 \\
\hline 37.00 & 767.7 & 773.9 & 758.5 & 776.6 \\
\hline 39.00 & 743.7 & 751.1 & 732.1 & 754.3 \\
\hline 41.05 & 718.4 & 727.3 & 703.5 & 731.0 \\
\hline 43.16 & 691.4 & 702.0 & 672.5 & 706.3 \\
\hline 45.26 & 663.8 & 676.1 & 639.6 & 681.2 \\
\hline 47.36 & 635.4 & 650.0 & 604.9 & 655.8 \\
\hline 49.47 & 606.6 & 623.5 & 568.1 & 630.3 \\
\hline 51.57 & 577.5 & 597.3 & 528.9 & 604.9 \\
\hline 53.68 & 548.2 & 571.4 & 487.0 & 579.9 \\
\hline 55.78 & 519.1 & 546.2 & 442.1 & 555.6 \\
\hline 57.88 & 490.3 & 522.2 & 393.6 & 532.3 \\
\hline 59.99 & 462.2 & 499.8 & 340.8 & 510.4 \\
\hline 62.04 & & 484.0 & 277.2 & 475.6 \\
\hline 64.04 & & 464.8 & 235.0 & 455.6 \\
\hline 66.04 & & 445.6 & 199.4 & 435.3 \\
\hline 68.04 & & 426.5 & 169.2 & 415.0 \\
\hline 70.04 & & 407.9 & 143.6 & 394.8 \\
\hline 72.06 & & 390.3 & 121.3 & 375.1 \\
\hline 74.11 & & 372.8 & 102.7 & 355.3 \\
\hline 76.16 & & 356.4 & 87.09 & 336.2 \\
\hline 78.21 & & 341.4 & 73.88 & 318.0 \\
\hline 80.26 & & 327.9 & 62.74 & 301.0 \\
\hline 82.30 & & 316.4 & 53.33 & 285.2 \\
\hline $8 \div .25$ & & 307.1 & 45.38 & 270.8 \\
\hline 86.40 & & 300.6 & 38.65 & 258.2 \\
\hline 88.45 & & 297.5 & 32.94 & 247.6 \\
\hline 90.50 & & 298.4 & 28.09 & 239.4 \\
\hline
\end{tabular}


TABLE IV-20. Experimenta1 239Pu Axial Fission Rate Distributions in the GCFR Phase III Plate and Pin Loadings

\begin{tabular}{|c|c|c|}
\hline \multirow{2}{*}{$\begin{array}{c}\text { Axial Distance } \\
(\mathrm{cm})\end{array}$} & \multicolumn{2}{|c|}{${ }^{239} \mathrm{Pu}$ Fission Rate } \\
\hline & Pin Zone & Plate Loading \\
\hline $\begin{array}{r}60.96 \\
57.15 \\
53.34 \\
49.53 \\
45.72 \\
41.91 \\
38.10 \\
34.29 \\
30.48 \\
26.67 \\
22.86 \\
19.05 \\
15.24 \\
11.43 \\
7.62 \\
3.81 \\
0.00 \\
-0.00 \\
-7.62 \\
-15.24 \\
-7.2 .86 \\
-30.48 \\
-38.10 \\
-45.72 \\
-53.34 \\
-60.96\end{array}$ & $\begin{array}{l}479.3 \\
582.4 \\
674.2 \\
780.0 \\
855.4 \\
916.6 \\
\\
977.6 \\
\\
993.2 \\
968.8 \\
996.5 \\
990.7 \\
970.4 \\
873.8 \\
859.1 \\
775.6 \\
678.4 \\
578.0 \\
454.7\end{array}$ & $\begin{array}{l}511.6 \\
627.2 \\
728.5 \\
805.6 \\
884.9 \\
907.1 \\
972.4 \\
995.0\end{array}$ \\
\hline
\end{tabular}

TABLE IV-21. Calculated 239 Pu Axial Fission Rate Distribution in the GCFR Phase III Pin Zone

\begin{tabular}{|c|c|c|c|}
\hline $\begin{array}{c}\text { Axial Distance } \\
\text { (cm) }\end{array}$ & $239^{9} \mathrm{Pu}$ & Fission & Rate \\
\hline 1.00 & & 1000.00 & \\
\hline 3.00 & & 998.55 & \\
\hline 5.00 & & 995.65 & \\
\hline 7.00 & & 991.32 & \\
\hline 9.00 & & 985.55 & \\
\hline 11.00 & & 978.36 & \\
\hline 13.00 & & 969.76 & \\
\hline 15.00 & & 959.78 & \\
\hline 17.00 & & $948.4 ?$ & \\
\hline 19.00 & & 935.72 & \\
\hline 21.00 & & 921.70 & \\
\hline 23.00 & & 889.83 & \\
\hline 25.00 & & 889.83 & \\
\hline 27.00 & & 872.05 & \\
\hline 29.00 & & 853.10 & \\
\hline 31.00 & & 833.03 & \\
\hline 33.00 & & 811.89 & \\
\hline 35.00 & & 789.74 & \\
\hline 37.00 & & 766.64 & \\
\hline 39.00 & & 742.69 & \\
\hline 41.05 & & 717.49 & \\
\hline 43.16 & & 690.65 & \\
\hline 45.26 & & 663.12 & \\
\hline 47.36 & & 635.06 & \\
\hline 49.47 & & 606.67 & \\
\hline 51.57 & & 578.18 & \\
\hline 53.68 & & 549.90 & \\
\hline 55.78 & & 522.23 & \\
\hline 57.88 & & 495.72 & \\
\hline 59.99 & & 471.19 & \\
\hline
\end{tabular}


TABLE V-1. Centra1 Cavity Fission Rate Ratios in the GCFR Phase III Assembly

\begin{tabular}{lccc}
\hline Ratio & Measured $(\mathrm{E})^{\mathrm{a}}$ & Calculated $(\mathrm{C})^{\mathrm{a}}$ & $\mathrm{C} / \mathrm{E}$ \\
\hline $2{ }^{3} \mathrm{f} /{ }^{49} \mathrm{f}$ & $1.521 \pm 0.025$ & 1.518 & $0.997 \pm 0.016^{\mathrm{b}}$ \\
$25 \mathrm{f} / 49_{\mathrm{f}}$ & $1.040 \pm 0.013$ & 1.041 & $1.001 \pm 0.013$ \\
$28 \mathrm{f} / 49 \mathrm{f}$ & $0.0249 \pm 0.0003$ & 0.0253 & $1.016 \pm 0.012^{4}$ \\
${ }^{40} \mathrm{f} / 49_{\mathrm{f}}$ & $0.2204 \pm 0.0017$ & 0.2251 & $1.0214 \pm 0.0081^{\mathrm{b}}$ \\
\hline
\end{tabular}

${ }_{\text {Ratios on a per-atom basis. }}$

$b_{\text {These }} \mathrm{C} / \mathrm{E}$ values are taken from the GCFR Phase II measurements (Ref。2). The corresponding "measured" values were obtained by dividing the $\mathrm{C} / \mathrm{E}$ ratio into the calculated value. No direct measurements of ${ }^{23} \mathrm{f} /{ }^{49} \mathrm{f}$ and ${ }^{40} \mathrm{f} /{ }^{49} \mathrm{f}$ were made in the GCFR Phase III assembly.

TABLE V-2. Absolute Reaction Rate Measurements in the GCFR Phase III Assembly

\begin{tabular}{|c|c|c|c|c|c|c|}
\hline Matrix & $\begin{array}{l}\text { Position } \\
\text { (cm) }\end{array}$ & $\begin{array}{l}\mathrm{R}_{0} / \mathrm{R} \text { for } \\
{ }^{6} \mathrm{~L} 1(\mathrm{n}, \alpha)\end{array}$ & $10^{9} \stackrel{\mathrm{R}_{\alpha}}{\text { eve }}$ & $\begin{array}{l}\left({ }^{6} L i\right) \\
\text { ents/sec-g }\end{array}$ & $\begin{array}{c}R_{0} / R \text { for } \\
23{ }^{9} \mathrm{Pu}(n, f)\end{array}$ & $\begin{array}{c}{ }^{R} f_{0}\left({ }^{239} \mathrm{Pu}\right) \\
10^{7} \text { events } / \text { sec- } 8\end{array}$ \\
\hline$S 23 / 23$ & 0.000 & 1.0586 & 1.509 & $\pm 0.012^{a}$ & 1.0010 & $6.212 \pm 0.054$ \\
\hline$S 23 / 24$ & 5.524 & 1.0586 & 1.498 & \pm 0.012 & 1.0010 & $6.187 \pm 0.054$ \\
\hline$s 23 / 26$ & 16.574 & 1.0586 & 1.464 & \pm 0.012 & 1.0010 & $6.014 \pm 0.052$ \\
\hline $\mathrm{S} 23 / 28$ & 27.622 & 1.0585 & 1.397 & \pm 0.012 & 1.0011 & $5.739 \pm 0.050$ \\
\hline$S 23 / 30$ & 38.672 & 1.0583 & 1.289 & \pm 0.011 & 1.0012 & $5.334 \pm 0.046$ \\
\hline$S 23 / 32$ & 49.720 & 1.0582 & 1.1051 & \pm 0.0091 & 1.0014 & $4.654 \pm 0.041$ \\
\hline$s 23 / 33$ & 55.245 & 1.0582 & 1.0008 & $\pm 0.0083^{a}$ & 1.0015 & $4.220 \pm 0.037$ \\
\hline$s 23 / 34$ & 60.770 & 1.0588 & 0.8949 & \pm 0.0074 & 1.0014 & $3.787 \pm 0.033$ \\
\hline$\$ 23 / 35$ & 66.294 & & & & 1.0005 & $3.399 \pm 0.030$ \\
\hline
\end{tabular}

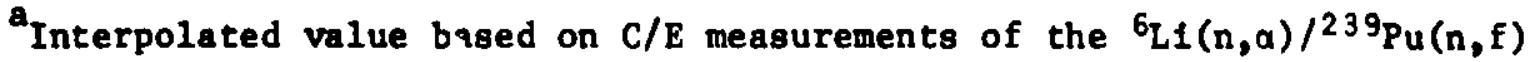
reaction rata rat 10 . See Table $V-13$. 
TABLE V-3. Description of the GCFR Phase III Reactivity Samples

\begin{tabular}{|c|c|c|c|c|c|c|c|c|c|}
\hline \multirow{2}{*}{$\begin{array}{l}\text { Sample } \\
\text { Ident }\end{array}$} & \multirow[b]{2}{*}{ Geometry } & \multicolumn{3}{|c|}{ Dimension, In. } & \multirow{2}{*}{$\begin{array}{c}\text { Sample } \\
\text { Mass } \\
(\mathrm{g}) \\
\end{array}$} & \multirow{2}{*}{$\begin{array}{c}\text { Capsule } \\
\text { Mass } \\
\text { (g) }\end{array}$} & \multirow{2}{*}{$\begin{array}{l}\text { Capsule } \\
\text { Material }\end{array}$} & \multirow{2}{*}{$\begin{array}{c}\text { Composition } \\
\text { Ident }^{\text {a }}\end{array}$} & \multirow{2}{*}{$\begin{array}{l}\text { Principal } \\
\text { Isotope }\end{array}$} \\
\hline & & Length & 0.D. & Wa11 & & & & & \\
\hline$L i-5$ & Cyl inder & 1.678 & 0.309 & - & 0.9736 & 2.0468 & $\mathrm{Al}$ & LI6-A & ${ }^{6} \mathrm{LI}$ \\
\hline $\mathrm{U}-233-3$ & Strip & 1.805 & 0.830 & 0.010 & 4.1576 & 16.5131 & ss & U2 33-A & $233 \mathrm{U}$ \\
\hline$U-3$ & Cylinder & 2.173 & 0.200 & - & 21.0147 & 11.1122 & ss & $\mathrm{U} 235-\mathrm{C}$ & $235 \mathrm{U}$ \\
\hline MB-2l & Annul us & 1.688 & 0.835 & 0.015 & 15.7780 & 13.7293 & ss & $\mathrm{U} 235-\mathrm{A}$ & ${ }^{235} \mathrm{U}$ \\
\hline$M B-25$ & Annul us & 1.688 & 0.835 & 0.036 & 38.1631 & 13.6910 & ss & U238-A & ${ }^{238} \mathrm{U}$ \\
\hline $\mathrm{Pu}-25$ & Cyl inder & 2.173 & 0.100 & - & 4.4799 & 10.7579 & ss & P239-B & $23{ }^{9} \mathrm{Pu}$ \\
\hline $\mathrm{Pu}-27$ & Cyl inder & 2.173 & 0.200 & - & 17.0618 & 11.2068 & ss & P239-B & ${ }^{239} \mathrm{Pu}$ \\
\hline$M B-10$ & Annul us & 1.156 & 0.835 & 0.015 & 9.956 & 13.458 & ss & P239-A & ${ }^{239} \mathrm{Pu}$ \\
\hline $\mathrm{Pu}-240-2 \mathrm{D}$ & Annul us & 1.800 & 0.604 & 0.205 & 45.135 & 28.821 & Inconel & P240-A & $240 \mathrm{Pu}$ \\
\hline
\end{tabular}

See Table V-4. 
TABLE V-4. Composition (w/o) of Reactivity Samples

\begin{tabular}{|c|c|c|c|c|c|c|c|c|}
\hline Composition I.D.: & LI6-A & U233-A & $\mathrm{U} 235-\mathrm{C}$ & U235-A & U238-A & P239-B & P239-A & P240-A \\
\hline & $L I-5$ & $U-233-3$ & $\mathrm{u}-3$ & $M B-21$ & $M B-25$ & $P_{u}-25,27$ & $\mathrm{MB}-10$ & $\mathrm{Pu}-240-2 \mathrm{D}$ \\
\hline \multicolumn{9}{|l|}{ Major Elements } \\
\hline $\begin{array}{l}\text { Li } \\
C\end{array}$ & $\begin{array}{r}99.870 \\
0.045\end{array}$ & & & & & & & \\
\hline c & & & & & & & & 11.97 \\
\hline Al & & & & & & 9.95 & 1.208 & \\
\hline $\mathrm{y}$ & & 99.8 & $\sim 100.0$ & $\sim 100.0$ & $\sim 100.0$ & & & \\
\hline $\mathbf{P u}$ & & & & & & 98.26 & 97.985 & 86.10 \\
\hline \multicolumn{9}{|c|}{ Isotopic Composition } \\
\hline $\begin{array}{l}{ }^{6} \mathrm{Li} \\
{ }^{7} \mathrm{Li}\end{array}$ & $\begin{array}{r}98.21 \\
0.79\end{array}$ & & & & & & & \\
\hline $233 \mathrm{U}$ & & 99.47 & & & & & & \\
\hline $234 \mathrm{U}$ & & 0.183 & 0.9452 & 0.6651 & & & & \\
\hline $235_{\mathrm{U}}$ & & 0.071 & 93.1920 & 93.2438 & 0.2328 & & & \\
\hline $236_{U}$ & & 0.014 & 0.2585 & 0.3162 & & & & \\
\hline $238_{\mathrm{U}}$ & & 0.266 & 5.6043 & 5.7750 & 99.7672 & & & \\
\hline $239 \mathrm{Pu}$ & & & & & & 98.926 & 98.932 & 1.05 \\
\hline $240 \mathrm{Pu}$ & & & & & & 1.023 & 1.012 & 93.73 \\
\hline $241 \mathrm{Pu}$ & & & & & & 0.049 & 0.053 & 0.57 \\
\hline $242 \mathrm{Pu}$ & & & & & & 0.002 & 0.003 & 4.65 \\
\hline
\end{tabular}


TABLE V-5. Small Sample Reactivity Measurements in the GCFR Phase III Assembly

\begin{tabular}{|c|c|c|c|c|c|c|c|c|c|c|}
\hline \multirow{3}{*}{$\frac{\text { Sartple }}{L I-5}$} & \multirow{2}{*}{$\begin{array}{c}\begin{array}{c}\text { Matrix } \\
\text { Location }\end{array} \\
\$ 23 / 23\end{array}$} & \multirow{2}{*}{$\begin{array}{c}\begin{array}{c}\text { Radial } \\
\text { Position } \\
\text { (cm) }\end{array} \\
0.000\end{array}$} & \multirow{2}{*}{$\begin{array}{c}\begin{array}{c}\text { Principal } \\
\text { Isotope } \\
1\end{array} \\
{ }^{6} \mathrm{Li}\end{array}$} & \multicolumn{2}{|c|}{$\begin{array}{c}\rho(E) \\
(I h / k g)\end{array}$} & \multirow{2}{*}{$\frac{\rho_{0} / \rho}{1.06552}$} & \multirow{2}{*}{$\frac{t_{\rho_{0} / \rho_{0}}}{1.00911}$} & \multicolumn{3}{|c|}{$\begin{array}{l}{ }_{\rho_{0}}(E) \\
(I h / k g)\end{array}$} \\
\hline & & & & -1500.77 & \pm 6.13 & & & -1613.66 & \pm & 6.59 \\
\hline & $\mathrm{S} 23 / 24$ & 5.524 & $"$ & -1490.77 & \pm 1.59 & 1.06551 & 1.00911 & -1602.90 & \pm & 1.71 \\
\hline$\bullet$ & $\$ 23 / 26$ & 16.574 & 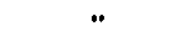 & -1409.02 & \pm 9.18 & 1.06545 & 1.00911 & -1514.92 & \pm & 9.87 \\
\hline$"$ & $\mathrm{~S} 23 / 28$ & 27.622 & $"$ & -1286.68 & \pm 3.63 & 1.06647 & 1.00911 & -1384.71 & \pm & 3.90 \\
\hline$"$ & $\mathrm{~s} 23 / 30$ & 38.672 & $"$ & -1083.14 & \pm 3.15 & 1.06624 & 1.00912 & -1165.42 & \pm & 3.39 \\
\hline • & $523 / 23$ & 55.245 & $"$ & -692.66 & \pm 5.22 & 1.06774 & 1.00918 & -746.37 & \pm & 5.63 \\
\hline $\mathrm{U}-233-3$ & $523 / 23$ & 0.000 & $233 \mathrm{U}$ & 189.46 & \pm 2.00 & 1.00467 & 1.00701 & 191.68 & \pm & 2.03 \\
\hline $\mathrm{U}-3$ & $523 / 23$ & 0.000 & $235 \mathrm{U}$ & $102 \cdot 34$ & \pm 0.30 & 1.01926 & 1.07759 & 112.41 & \pm & 0.33 \\
\hline$M B-21$ & $\$ 23 / 23$ & 0.000 & 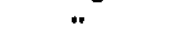 & 103.30 & \pm 0.21 & 1.01536 & 1.07724 & 112.99 & \pm & 0.23 \\
\hline$\infty$ & $\mathrm{S} 23 / 24$ & 5.524 & $"$ & 100.92 & \pm 0.46 & 1.01535 & 1.07723 & 110.39 & \pm & 0.50 \\
\hline$"$ & $s 23 / 26$ & 16.574 & $\ddot{m}$ & 96.44 & \pm 0.25 & 1.01522 & 1.07719 & 105.46 & \pm & 0.28 \\
\hline$M-25$ & $523 / 23$ & 0.000 & $238 \mathrm{U}$ & -7.651 & \pm 0.164 & 1.00601 & 1.03783 & -7.988 & \pm & 0.171 \\
\hline * & $\mathrm{s} 23 / 23$ & 16.574 & 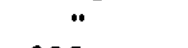 & -7.167 & \pm 0.114 & I. 00591 & 1.03809 & -7.484 & \pm & 0.119 \\
\hline$P u-25$ & $\mathrm{~S} 23 / 23$ & 0.000 & ${ }^{239} \mathrm{Pu}$ & 143.10 & \pm 1.33 & 0.99544 & 1.02719 & 146.32 & \pm & 1.36 \\
\hline $\mathbf{P u}-27$ & $523 / 23$ & 0.000 & " & 141.76 & \pm 0.37 & 0.97762 & 1.02719 & 142.36 & \pm & 0.37 \\
\hline$M B-10$ & $523 / 23$ & 0.000 & $"$ & 141.66 & $\therefore 0.41$ & 1.00122 & 1.03012 & 146.11 & \pm & 0.43 \\
\hline 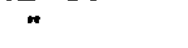 & S23/24 & 5.524 & $"$ & 138.52 & \pm 0.71 & 1.00121 & 1.03012 & 143.17 & \pm & 0.73 \\
\hline • & $523 / 26$ & 16.574 & " & $13 i .22$ & \pm 0.53 & 1.00112 & 1.03009 & 135.32 & \pm & 0.55 \\
\hline 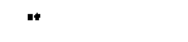 & $523 / 28$ & 27.622 & 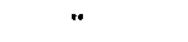 & 117.42 & \pm 0.56 & 1.00088 & 1.03003 & 121.06 & \pm & 0.58 \\
\hline$"$ & $\mathrm{~S} 23 / 30$ & 38.672 & $"$ & 101.73 & \pm 0.86 & 1.00030 & 1.02991 & 104.80 & \pm & 0.88 \\
\hline$\bullet$ & $2 ? 3 / 33$ & 55.245 & $"$ & 65.50 & \pm 0.32 & 1.00684 & 1.02930 & 67.88 & \pm & 0.33 \\
\hline " & $5 2 3 \longdiv { 3 5 }$ & 66.294 & " & 39.61 & \pm 0.63 & 1.01976 & 1.02819 & 41.53 & \pm & 0.66 \\
\hline$P u-240-2 D$ & $\mathrm{~S} 23 / 23$ & 0.000 & $240 \mathrm{Pu}$ & 17.17 & \pm 0.11 & 1.00259 & 1.1 .5448 & 19.87 & \pm & 0.12 \\
\hline
\end{tabular}

NOTE: The uncertainties in this table are statistical uncertaintes only. They do rot include uncertainties

$(\sim 1 \%)$ in the autorod calibration nor in the sample size correction factor, $\rho_{0} / 0$, and thus are not

identical to those listed ir. the tables of Section III. 
TABLE V-6. Apparent Worth of ${ }^{252} \mathrm{Cf}$ Spontaneous Fission Neutrons in the GCFR Phase III Assembly

\begin{tabular}{|c|c|c|c|c|c|c|c|}
\hline Sample & $\begin{array}{l}\text { Matrix } \\
\text { Location }\end{array}$ & $\begin{array}{l}\text { Radial } \\
\text { Position, } \\
\left(\mathrm{cm}^{2}\right)\end{array}$ & $\begin{array}{c}P^{\prime}(E)_{b} \\
(I h)\end{array}$ & póp & $\begin{array}{l}p_{0}^{-}(\mathrm{E}) \\
(\mathrm{Ih})\end{array}$ & $\begin{array}{l}\mathrm{s}(7 / 21 / 76)^{\mathrm{c}} \\
(\mathrm{n} / \mathrm{sec})\end{array}$ & $\bar{\phi}_{f_{0}}(C f) \times 10^{-5}$ \\
\hline ORNL-NSD-56 & $S 23 / 23$ & -1.948 & $0.11673 \pm 0.00035$ & 1.01815 & $0.11885 \pm 0.00036$ & $\begin{array}{l}(9.335 \\
\pm 0.061) 10^{7}\end{array}$ & 2.2387 \\
\hline$"$ & $523 / 24$ & 3.576 & $0.11636 \pm 0.00035$ & 1.01815 & $0.11848 \pm 0.00036$ & $"$ & 2.2382 \\
\hline " & $\mathrm{S} 23 / 26$ & 14.625 & $0.11395 \pm 0.00034$ & 1.01815 & $0.11602 \pm 0.00035$ & $"$ & 2.1924 \\
\hline$"$ & $S 23 / 28$ & 25.674 & $0.10942 \pm 0.000 ? 3$ & 1.01814 & $0.11141 \pm 0.00033$ & $"$ & 2.0913 \\
\hline$"$ & $\mathrm{~s} 23 / 30$ & 36.723 & $0.10105 \pm 0.00030$ & 1.01813 & $0.10288 \pm 0.00031$ & $"$ & 1.9349 \\
\hline$"$ & $\mathrm{~S} 23 / 33$ & 53.297 & $0.08275 \pm 0.00025$ & 1.02148 & $0.08453 \pm 0.00025$ & $"$ & 1.5887 \\
\hline$"$ & $523 / 35$ & 64.346 & $0.06349 \pm 0.00019$ & 1.02769 & $0.06524 \pm 0.00020$ & $"$ & 1.2271 \\
\hline
\end{tabular}

Measurements were made with the point scurce displaced $1.948 \mathrm{~cm}$ from the center of the matrix position in the negative $X$ direction.

$b_{p}-(E)$ has been evaluated at the power level used for the ${ }^{6} \mathrm{Li}$ and ${ }^{239} \mathrm{Pu}$ reaction rates $\mathrm{E}^{\mathrm{i}} \mathrm{iven}$ in Table $\mathrm{V}-2$. Errors are statistical only.

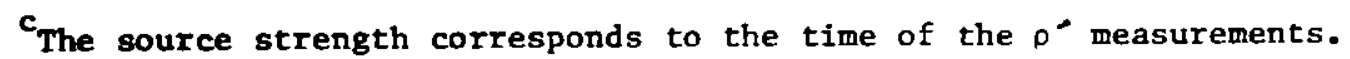


TABLE V-7. Calculated Quantities (ENDF/B-IV) for the GCFR Phase III Assembly

\begin{tabular}{|c|c|c|c|c|c|c|c|c|c|}
\hline Isotope & $\begin{array}{c}\text { Matrix } \\
\text { Location }\end{array}$ & $\begin{array}{l}\text { Radial } \\
\text { Position } \\
\text { (cm) }\end{array}$ & $\bar{\phi} \underset{\mathbf{f}}{\star} \times 10^{-5}$ & $\bar{\phi}_{a}^{*} \times 10^{-5}$ & $(1+\bar{\alpha})$ & $\bar{v}$ & RCF & $F C F \times 10^{4}$ & ACF \\
\hline 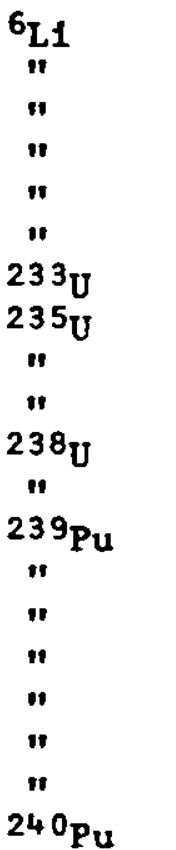 & $\begin{array}{l}\mathrm{s} 23 / 23 \\
\mathrm{~s} 23 / 24 \\
\mathrm{~s} 23 / 26 \\
\mathrm{~s} 23 / 28 \\
\mathrm{~s} 23 / 30 \\
\mathrm{~s} 23 / 33 \\
\mathrm{~s} 23 / 23 \\
\mathrm{~s} 23 / 23 \\
\mathrm{~s} 23 / 24 \\
\mathrm{~s} 23 / 26 \\
\mathrm{~s} 23 / 23 \\
\mathrm{~s} 23 / 26 \\
\mathrm{~s} 23 / 23 \\
\mathrm{~s} 23 / 24 \\
\mathrm{~s} 23 / 26 \\
\mathrm{~s} 23 / 28 \\
\mathrm{~s} 23 / 30 \\
\mathrm{~s} 23 / 33 \\
\mathrm{~s} 23 / 35 \\
\mathrm{~s} 23 / 23\end{array}$ & $\begin{array}{r}0.000 \\
5.524 \\
16.574 \\
27.622 \\
38.672 \\
55.245 \\
0.000 \\
0.000 \\
5.524 \\
16.574 \\
0.000 \\
16.574 \\
0.000 \\
5.524 \\
16.574 \\
27.622 \\
38.672 \\
55.245 \\
66.294 \\
0.000\end{array}$ & $\begin{array}{l}2.2058 \\
2.2093 \\
2.2041 \\
2.1493 \\
2.2139 \\
2.1537 \\
2.2247 \\
2.2195 \\
2.1642 \\
2.0540 \\
1.8900 \\
1.5244 \\
1.1481 \\
2.2185\end{array}$ & $\begin{array}{l}1.7650 \\
1.7611 \\
1.7191 \\
1.6362 \\
1.5159 \\
1.2490 \\
1.7730 \\
1.7671 \\
1.7631 \\
1.7210 \\
1.7940 \\
1.7475 \\
1.8081 \\
1.8040 \\
1.7608 \\
1.6756 \\
1.5525 \\
1.2806 \\
0.9465 \\
1.8942\end{array}$ & $\begin{array}{l}1.0934 \\
1.2838 \\
1.2838 \\
1.2833 \\
6.8134 \\
6.7830 \\
1.2551 \\
1.2550 \\
1.2540 \\
1.2513 \\
1.2465 \\
1.2338 \\
1.2478 \\
2.1777\end{array}$ & $\begin{array}{l}2.4835 \\
2.4506 \\
2.4506 \\
2.4507 \\
2.7718 \\
2.7717 \\
2.9373 \\
2.9373 \\
2.9375 \\
2.9380 \\
2.9395 \\
2.9447 \\
2.9411 \\
3.0725\end{array}$ & $\begin{array}{l}0.9642 \\
0.9642 \\
0.9646 \\
0.9654 \\
0.9672 \\
0.9774 \\
1.0090 \\
1.0147 \\
1.0146 \\
1.0143 \\
0.6807 \\
0.6838 \\
1.0108 \\
1.0107 \\
1.0105 \\
1.0099 \\
1.0088 \\
1.0015 \\
0.9796 \\
1.0858\end{array}$ & $\begin{array}{c}-4.0866 \\
-5.2649 \\
-5.2671 \\
-5.2871 \\
-475.50 \\
-475.56 \\
-2.3373 \\
-2.3381 \\
-2.3442 \\
-2.3640 \\
-2.4217 \\
-2.6940 \\
-2.5760 \\
-4.9619\end{array}$ & $\begin{array}{l}1.00043 \\
1.00043 \\
1.00043 \\
1.00043 \\
1.00045 \\
1.00050\end{array}$ \\
\hline
\end{tabular}

NOTE: The quantities in this table are defined by Eqs. $v-1$ to $v-4$ and refer to an infinitely dilute sample. 


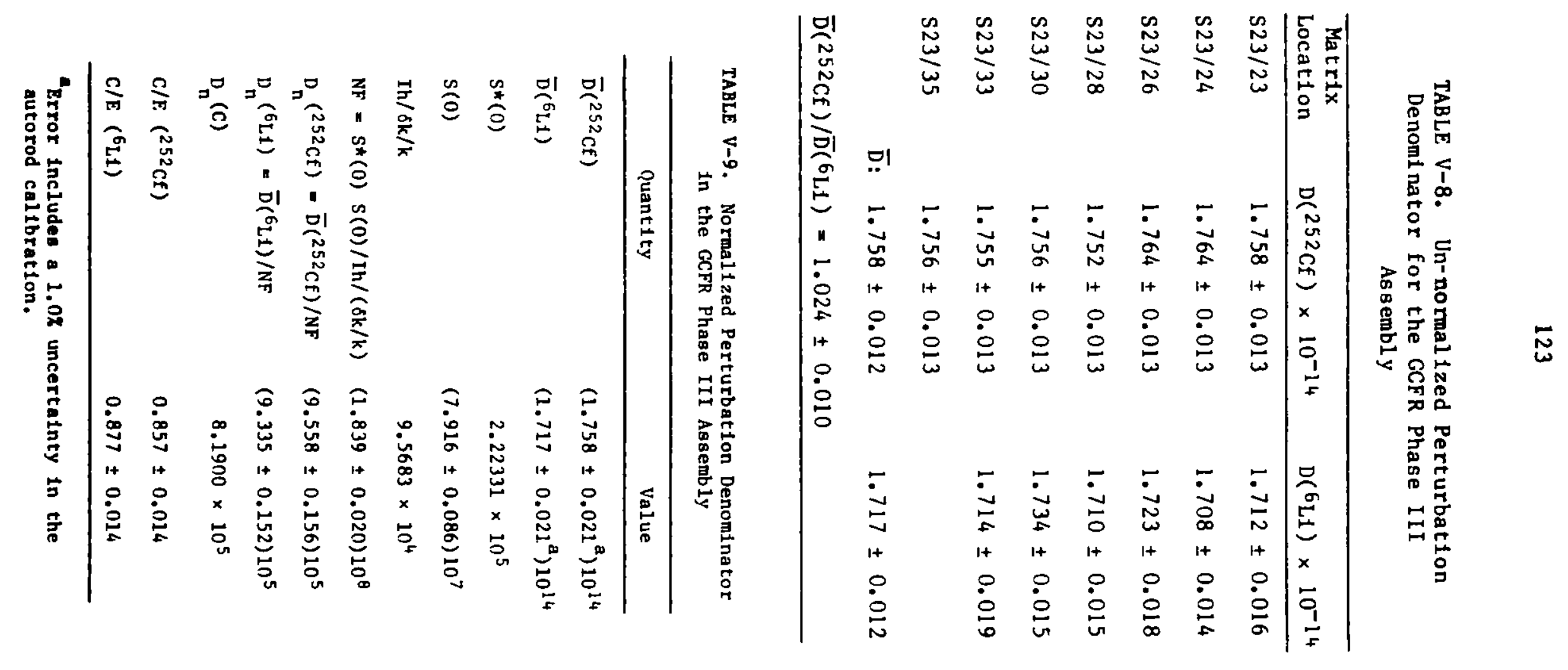


TABLE V-10. Th1n Sample $(1+\bar{a})$ Values 1n the GCFR Phase III Assembly

\begin{tabular}{|c|c|c|c|c|c|c|}
\hline $\begin{array}{l}\text { Reactivity } \\
\text { Sample }\end{array}$ & Isotope & $\begin{array}{l}\text { Matrix } \\
\text { Location }\end{array}$ & $\begin{array}{l}\text { Radial } \\
\text { Position } \\
\text { (cm) }\end{array}$ & $\begin{array}{c}(1+\bar{\alpha}) \\
\text { Calculated (c) }\end{array}$ & $\begin{array}{l}(1+\bar{\alpha}) \\
\text { Measured (E) }\end{array}$ & $C / E$ \\
\hline $\mathrm{U}-233-3$ & $233 \mathrm{U}$ & $\mathrm{s} 23 / 23$ & 0.000 & 1.093 & $1.086 \pm 0.051$ & $1.007 \pm 0.047$ \\
\hline $\mathrm{U}-3$ & $235 U$ & $523 / 23$ & 0.000 & 1.284 & $1.306 \pm 0.037$ & $0.983 \pm 0.028$ \\
\hline$M B-21$ & $"$ & " & 0.000 & 1.284 & $1.297 \pm 0.037$ & $0.990 \pm 0.028$ \\
\hline 1 & $"$ & $S 23 / 24$ & 5.524 & 1.284 & $1.326 \pm 0.038$ & $0.968 \pm 0.027$ \\
\hline$"$ & $" 1$ & $523 / 26$ & 16.574 & 1.283 & $1.312 \pm 0.037$ & $0.978 \pm 0.028$ \\
\hline MB-25 & ${ }^{238} \mathrm{U}$ & $523 / 23$ & 0.000 & 6.813 & $6.737 \pm 0.107$ & $1.011 \pm 0.016$ \\
\hline i1 & $"$ & $S 23 / 26$ & 16.574 & 6.783 & $6.727 \pm 0.096$ & $1.008 \pm 0.014$ \\
\hline Pu-27 & $239^{9 u}$ & $523 / 23$ & 0.000 & 1.255 & $1.330 \pm 0.038$ & $0.943 \pm 0.027$ \\
\hline Pu-25 & $"$ & "1 & 0.000 & 1.255 & $1.269 \pm 0.044$ & $0.987 \pm 0.034$ \\
\hline MB-10 & $"$ & $"$ & 0.000 & 1.255 & $1.272 \pm 0.039$ & $0.986 \pm 0.030$ \\
\hline$"$ & $"$ & $523 / 24$ & 5.524 & 1.255 & $1.304 \pm 0.040$ & $0.963 \pm 0.029$ \\
\hline$"$ & $"$ & $523 / 26$ & 16.574 & 1.254 & $1.309 \pm 0.039$ & $0.958 \pm 0.029$ \\
\hline$"$ & $"$ & $523 / 28$ & 27.622 & 1.251 & $1.335 \pm 0.039$ & $0.937 \pm 0.028$ \\
\hline " & $"$ & $s 23 / 30$ & 38.672 & 1.246 & $1.303 \pm 0.042$ & $0.957 \pm 0.031$ \\
\hline$"$ & $"$ & $523 / 33$ & 55.245 & 1.234 & $1.264 \pm 0.038$ & $0.976 \pm 0.030$ \\
\hline$n$ & $"$ & $\mathrm{~s} 23 / 35$ & 66.294 & 1.248 & $1.313 \pm 0.051$ & $0.950 \pm 0.037$ \\
\hline$P U-240-2 D$ & $240 \mathrm{Pu}$ & $523 / 23$ & 0.000 & 2.178 & $2.080 \pm 0.078$ & $1.047 \pm 0.039$ \\
\hline
\end{tabular}


TABLE V-11. Errors in $(1+\bar{\alpha})$ from Uncertainties in the Measured Quantities at the Central Location of the GCFR Phase III Assembly

\begin{tabular}{|c|c|c|c|c|c|c|c|}
\hline Isotope & $\begin{array}{r}(1 ; \bar{\alpha}) \\
\text { Measured }\end{array}$ & $\delta \overline{\mathbb{D}}\left({ }^{6} \mathrm{~L} \mathbf{i}\right)$ & $\delta \bar{D}\left({ }^{252} C F\right)$ & $\delta \rho$ & $\delta R_{f}$ & $\delta \bar{v}$ & $\begin{array}{l}\text { Total } \\
\text { Error }(1 \sigma)\end{array}$ \\
\hline${ }^{233} \mathrm{U}$ & $1.086 \pm 0.051$ & 0.0078 & 0.0200 & 0.0204 & 0.0359 & 0.0211 & 0.0511 \\
\hline${ }^{235} \mathrm{U}$ & $1.297 \pm 0.037$ & 0.0093 & 0.0198 & 0.0035 & 0.0258 & 0.0150 & 0.0372 \\
\hline$\angle 38 \mathrm{U}$ & $6.737 \pm 0.107$ & 0.0477 & 0.0221 & 0.0716 & 0.0496 & 0.0334 & 0.1071 \\
\hline${ }^{23}{ }^{9} \mathrm{Pu}$ & $1.272 \pm 0.039$ & 0.0091 & 0.0234 & 0.0066 & 0.0196 & 0.0212 & 0.0388 \\
\hline $240 \mathrm{Pu}$ & $2.080 \pm 0.078$ & 0.0148 & 0.0233 & 0.0088 & 0.0167 & 0.0703 & 0.0778 \\
\hline
\end{tabular}

TABLE V-12. Error Sensitivities in $(1+\bar{\alpha})$ Measurements at the Central Location of the GCFR Phase III Assembly

\begin{tabular}{|c|c|c|c|c|c|}
\hline \multirow[t]{2}{*}{ A $1.0 \%$ Increase In: } & \multicolumn{5}{|c|}{ Causes This Percent Increase in $(1+\bar{\alpha})$} \\
\hline & $233 \mathrm{U}$ & ${ }^{23}{ }^{5} \mathrm{U}$ & ${ }^{238} \mathrm{U}$ & $239^{9 u}$ & $240 \mathrm{Pu}$ \\
\hline $\bar{D}\left({ }^{G} L I\right) / \bar{\phi}_{a}^{\star}$ & 1.000 & 1.000 & 0.993 & 1.000 & 1.000 \\
\hline $\bar{\nu} \phi_{\mathrm{f}} \overline{\mathrm{D}}\left({ }^{252} \mathrm{Cf}\right)$ & 2.779 & 2.306 & 0.496 & 2.774 & 1.689 \\
\hline$\rho R C F / R_{f}$ & -1.780 & -1.306 & 0.497 & -1.774 & -0.689 \\
\hline$D\left({ }^{6} L 1\right)=-\frac{R_{a}(L 1) \bar{\phi}_{a}^{\star}(L i)}{\rho(L 1) R C F(L 1)}$ & 1.000 & 1.000 & 0.993 & 1.000 & 1.000 \\
\hline$D\left({ }^{252} C f\right)=\frac{S(C f) \bar{\phi}_{f}^{*}(C f)}{\rho^{\prime}(C f)}$ & -2.779 & -2.306 & -0.496 & -2.774 & -1.689 \\
\hline
\end{tabular}


TABLE V-13. Some C/E Ratios for the GCFR Phase III Assembly

\begin{tabular}{|c|c|c|c|c|c|c|c|}
\hline $\begin{array}{l}\text { Matrix } \\
\text { Location }\end{array}$ & $\begin{array}{l}\text { Core } \\
\text { Zone }\end{array}$ & $\mathrm{R}_{\alpha_{0}}(\mathrm{Li}-6) / \mathrm{R}_{\mathrm{f}_{0}}(\mathrm{Pu}-239)$ & $\begin{array}{l}\text { Pu Reactivity } \\
\text { Sample }\end{array}$ & $\rho_{0}(\mathrm{Li}-6) / \rho_{0}(\mathrm{Pu}-239)$ & $\frac{\rho_{0}^{\prime}(\mathrm{Cf})}{{ }^{49 \rho_{0}}}$ & & $\frac{{ }^{49} R_{f_{0}}}{S(C f)}$ \\
\hline $\begin{array}{l}S 23 / 23 \\
S 23 / 23 \\
S 23 / 23 \\
S 23 / 24 \\
S 23 / 26 \\
S 23 / 28 \\
S 23 / 30\end{array}$ & $\begin{array}{l}I \\
I \\
I \\
I \\
I \\
I \\
I\end{array}$ & $\begin{array}{l}1.004 \pm 0.012 \\
0.998 \pm 0.012 \\
0.996 \pm 0.012 \\
0.999 \pm 0.012\end{array}$ & $\begin{array}{l}\mathrm{Pu}-27 \\
\mathrm{Pu}-25 \\
\mathrm{MB}-10 \\
\mathrm{MB}-10 \\
\mathrm{MB}-10 \\
\mathrm{MB}-10 \\
\mathrm{ME}-10\end{array}$ & $\begin{array}{l}0.9302 \pm 0.0045^{a} \\
0.9561 \pm 0.0097 \\
0.9547 \pm 0.0048 \\
0.9418 \pm 0.0049 \\
0.9416 \pm 0.0072 \\
0.9213 \pm 0.0051^{a} \\
0.9479 \pm 0.0084\end{array}$ & $\begin{array}{l}0.955 \\
0.982 \\
0.980 \\
0.969 \\
0.967 \\
0.948 \\
0.961\end{array}$ & $\begin{array}{l} \pm \\
\pm \\
\pm \\
\pm \\
\pm \\
\pm \\
\pm\end{array}$ & $\begin{array}{l}0.011^{a} \\
0.014 \\
0.011 \\
0.012 \\
0.012 \\
0.012^{a} \\
0.014\end{array}$ \\
\hline $\begin{array}{l}\mathrm{s} 23 / 32 \\
\mathrm{~s} 23 / 33 \\
\mathrm{~s} 23 / 34\end{array}$ & $\begin{array}{l}\text { II } \\
\text { II } \\
\text { II }\end{array}$ & $\begin{array}{l}1.000 \pm 0.012 \\
1.006 \pm 0.012\end{array}$ & $\mathrm{MB}-10$ & $0.9497 \pm 0.0085$ & 0.972 & \pm & 0.012 \\
\hline$\overline{\mathrm{C} / \mathrm{E}}:$ & & $1.000 \pm 0.012$ & & $0.9486 \pm 0.0062$ & 0.972 & & 0.012 \\
\hline$\overline{C / E}$ (GCFR Phase & II): & $0.986 \pm 0.013$ & & $0.9145 \pm 0.0043$ & 0.993 & \pm & 0.014 \\
\hline
\end{tabular}

ata point omitted in the evaluation of $\overline{C / E}$. 
TABLE V-14. Central Point Conversion Ratio Measurement in the GCFR Phase III Assembly

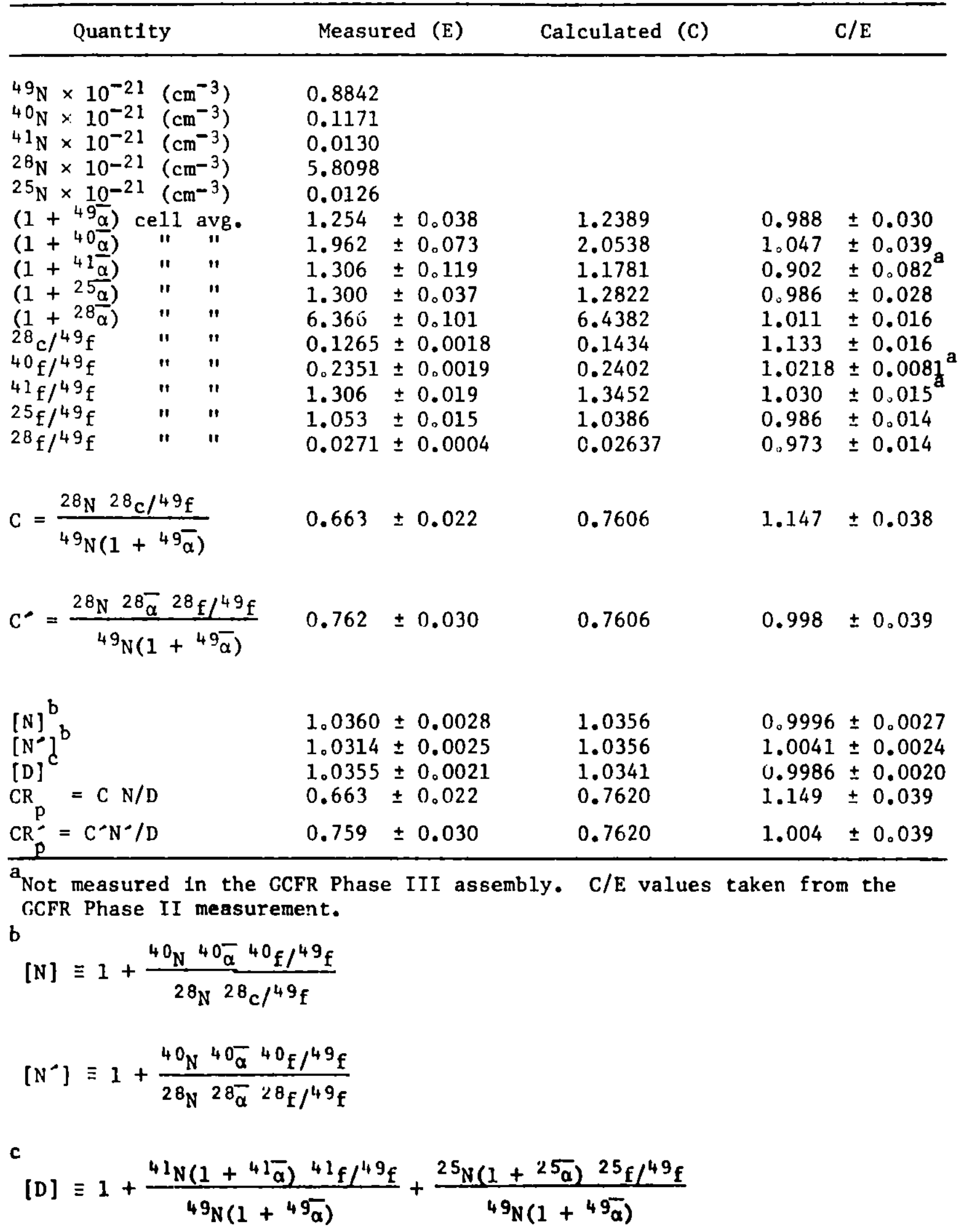


TABLE VI-1. Worth of Steam Zone Relative to Steam-free Reference

\begin{tabular}{|c|c|c|c|c|c|}
\hline \multirow[b]{2}{*}{$\begin{array}{c}\text { Axial } \\
\text { of } \\
\end{array}$} & \multirow[b]{2}{*}{$\begin{array}{l}\text { Half-Height } \\
\text { Steam Zone }\end{array}$} & \multicolumn{2}{|c|}{ Plate Environment } & \multicolumn{2}{|c|}{ P1n Envi ronment } \\
\hline & & $\begin{array}{l}\text { Mass of } \\
\mathrm{CH}_{2}(\mathrm{~g}) \\
\end{array}$ & $\begin{array}{c}\text { Worth of Steam Zone } \\
\text { (Ih) }\end{array}$ & $\begin{array}{l}\text { Mass of } \\
\mathrm{CH}_{2}(\mathrm{~g})\end{array}$ & $\begin{array}{c}\text { Worth of Steam Zone } \\
\text { (Ih) }\end{array}$ \\
\hline & 12 in. & 632 & $69.8 \pm 1.9$ & 687 & $107.5 \pm 2.7$ \\
\hline & $24 \mathrm{in.}$ & 1265 & $109.3 \pm 2.2$ & 1378 & $176.8 \pm 2.3$ \\
\hline & $36 \mathrm{in.}$ & 1901 & $84.4 \pm 2.0$ & 2075 & $146.4 \pm 2.2$ \\
\hline
\end{tabular}

TABLE VI-2. Steam Worth for Each 12-in. Axial Increnent of the Steam Zone

\begin{tabular}{lccc}
\hline Steam Loading & $\begin{array}{c}\text { P1ate Environment } \\
(\text { Ih/kg) }\end{array}$ & $\begin{array}{c}\text { Pin Environment } \\
(\text { Ih/kg })\end{array}$ & Pin/P1ate \\
\hline $0-12$ in. Axial Loading & $110 \pm 3$ & $156 \pm 4$ & 1.42 \\
12 in. - 24 in. Axial Loading & $62 \pm 4$ & $100 \pm 5$ & 1.60 \\
24 in. - 36 in. Axial Loading & $-39 \pm 4$ & $-44 \pm 5$ & 1.11 \\
$\begin{array}{l}\text { Total Wortr, } 0-36 \text { in. Axial } \\
\text { Loading }\end{array}$ & $44 \pm 1$ & $71 \pm 1$ & 1.59 \\
\hline
\end{tabular}


Distribution for ANL-79-35

Interna1:

W. E. Massey

J. A. Kyger

R. Avery

L. Burris

D. W. Cissel

S. A. Davis

B. R. T. Frost

E. V. Krivanec

R. J. Teunis

C. E. Till

R. S. Zeno

S. Carpenter
M. Abdou

M. Lineberry

A. B. Smith

E. F. Bennett

A. Travel11

D. Wade (10)

J. Morman (20)

R. Bucher

G. Dilorio

I. Olson

R. Pond

W. Robinson
R. Mc Knight

R. Schaefer

S. Yarlagadda

S. Bhat tacharyya

R. Le11

J. Liaw

D. M. Smith

J. Ulrich

A. B. Krisciunas ANL Contract File ANL Libraries (5)

TIS Files (6)

\section{Extemal:}

DOE-TIC, for distribution per UC-77 (166)

Manager, Chicago Operations and Regional office, DOE Chief, Office of Patent Counsel, DOE-CORO

Director, Technology Management, DOE-CORO

Director, DOE-RRT (2)

Chief, GCFR Branch, DOE-RRT (2)

President, Argonne Universities Association

Applied Physics Division Review Committee:

P. W. Dickson, Jr., Westinghouse Electric Corp.

R. L. Hellens, Combustion Engineering, Inc.

K. D. Lathrop, Los Alamos Scientific Laboratory

W. B. Loewenstein, Electric Power Research Inst.

R. F. Redmond, Ohio State U.

R. Sher, Stanford U.

D. B. Wehmeyer, Detroit Edison Co. 